\title{
Natural Gas Transmission and Distribution Model of the National Energy Modeling System
}

\section{Volume I}

January 1998

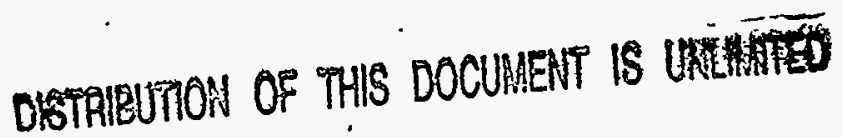
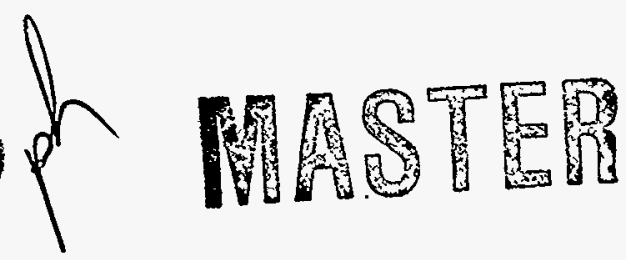

\section{Prepared by:}

Oil and Gas Analysis Branch

Energy Supply and Conversion Division

Office of Integrated Analysis and Forecasting

Energy Information Administration 


\section{DISCLAIMER}

This report was prepared as an account of work sponsored by an agency of the United States Government. Neither the United States Government nor any agency thereof, nor any of their employees, makes any warranty, express or implied, or assumes any legal liability or responsibility for the accuracy, completeness, or usefulness of any information, apparatus, product, or process disclosed, or represents that its use would not infringe privately owned rights. Reference herein to any specific commercial product, process, or service by trade name, trademark, manufacturer, or otherwise does not necessarily constitute or imply its endorsement, recommendation, or favoring by the United States Government or any agency thereof. The views and opinions of authors expressed herein do not necessarily state or reflect those of the United States Government or any agency thereof. 


\section{DISCLAIMER}

Portions of this document may be illegible electronic image products. Images are produced from the best available original document. 


\section{Contents}

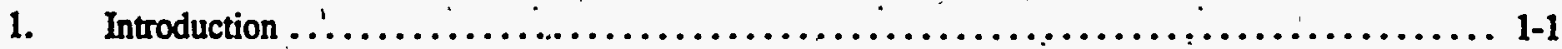

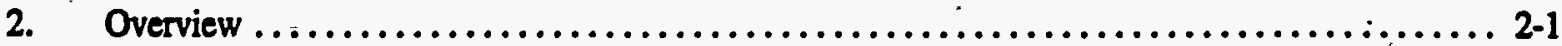

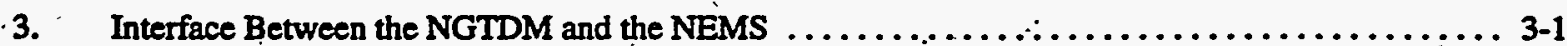
-

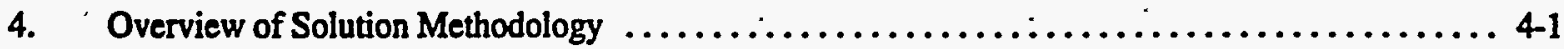

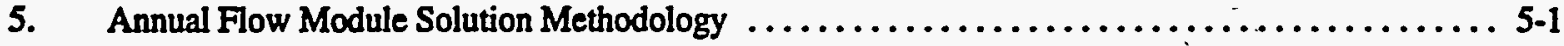

6. Distributor Tariff Module Solution Methodology $\ldots \ldots \ldots \ldots \ldots \ldots \ldots \ldots \ldots \ldots \ldots \ldots \ldots, \ldots \ldots$

7. Capacity Expansion Module Solution Methodology $\ldots \ldots \ldots \ldots \ldots \ldots \ldots \ldots \ldots \ldots \ldots \ldots \ldots$

8. Pipeline Tariff Module Solution Methodology $\ldots \ldots \ldots \ldots \ldots \ldots \ldots \ldots \ldots \ldots \ldots \ldots \ldots \ldots .1$

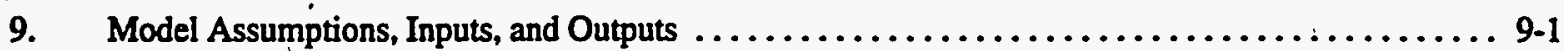

\section{Appendices}

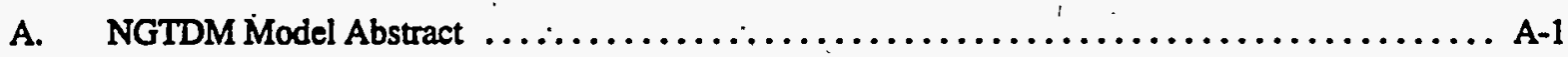

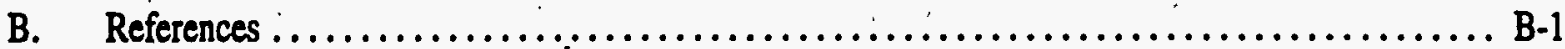

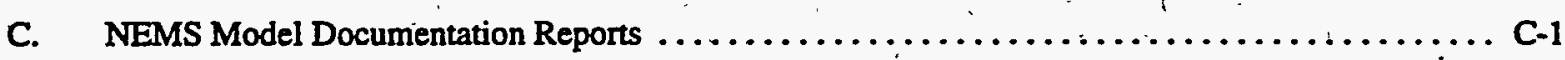

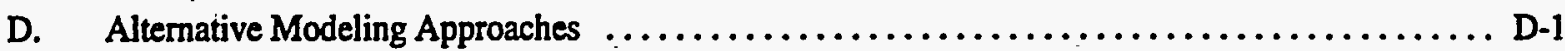

E. Model Input Variables Mapped to Input Data Files $\ldots \ldots \ldots \ldots \ldots \ldots \ldots \ldots \ldots \ldots \ldots \ldots \ldots \ldots \ldots \ldots \ldots$

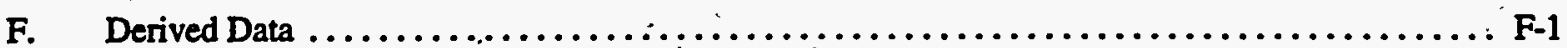

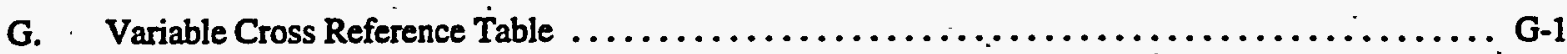

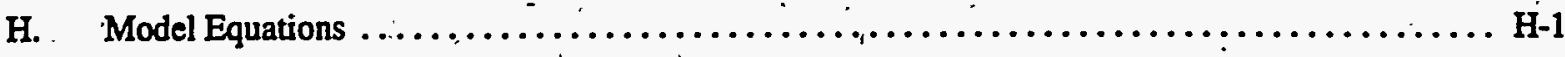




\section{Figures}

1-1 Schematic of the National Energy Modeling System $\ldots \ldots \ldots \ldots \ldots \ldots \ldots \ldots \ldots \ldots \ldots \ldots . \ldots \ldots$

-2-1 Natural Gas Transmission and Distribution Model (NGTDM) Regions . . . . . . . . . . . . . . . . . 2-2

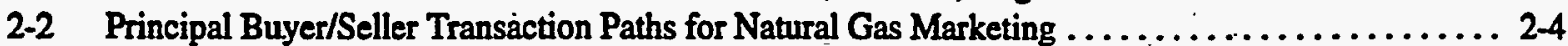

3-1 Primary Data Flows Between Oil and Gas Models of NEMS $\ldots \ldots \ldots \ldots \ldots \ldots \ldots \ldots \ldots \ldots \ldots, \ldots \ldots \ldots$

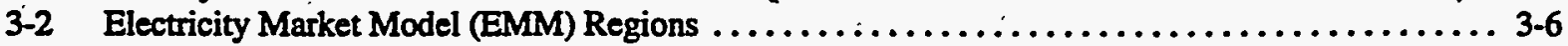

3-3 Natural Gas Transmission and Distribution Model/Electricity Market

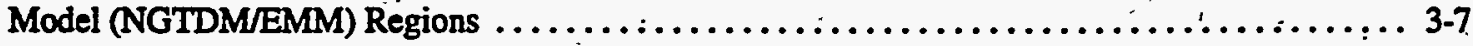

3-4 . Example NGTDM Electric Utility Demand Curve, Competitive With Residual

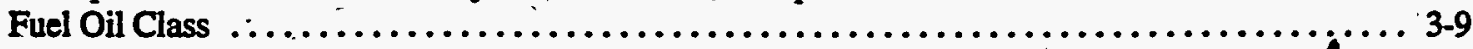

3-5 Oil and Gas Supply Model (OGSM) Regions ........................... 3-11

3-6 Natural Gas Transmission and Distribution ModelOil and Gas Supply

Model (NGTDM/OGSM) Regions . .................................... . $3-15$

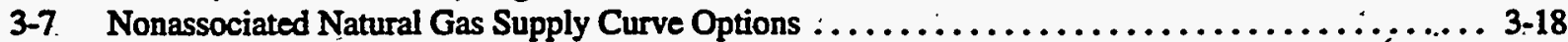

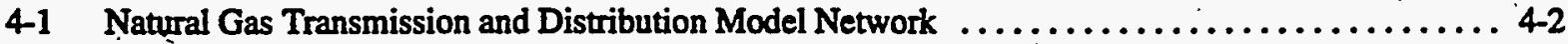

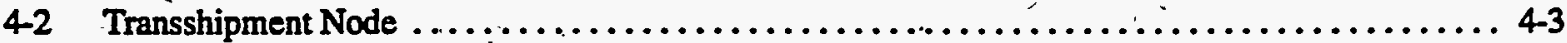

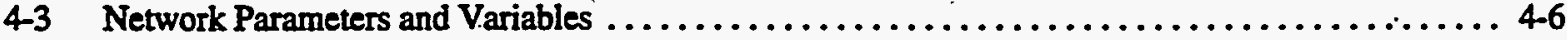

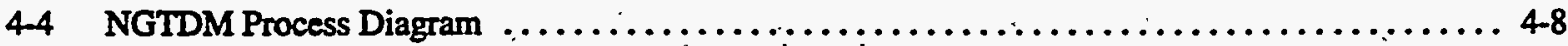

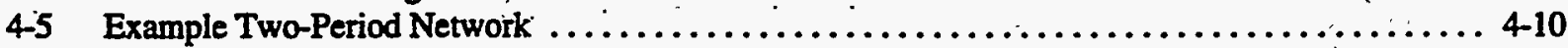

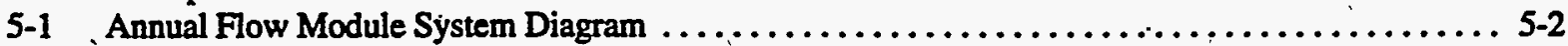

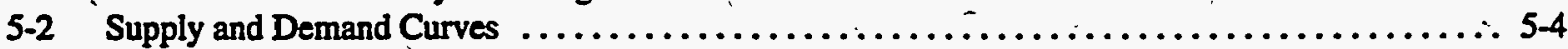

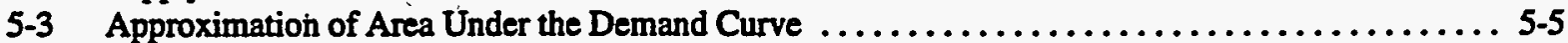

6-1 Tariff and Benchmark Components of Regional Markups $\ldots \ldots \ldots \ldots \ldots \ldots \ldots \ldots \ldots \ldots \ldots, 6,5$

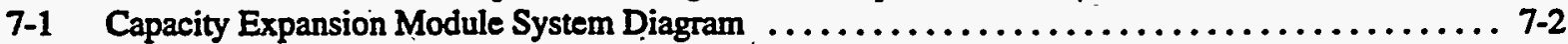

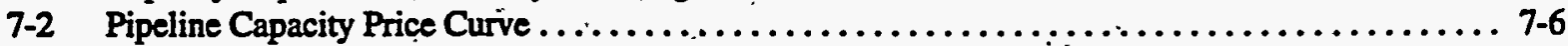

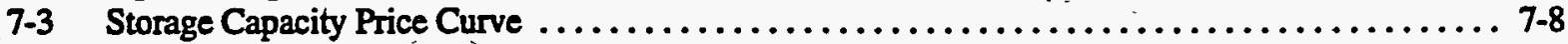

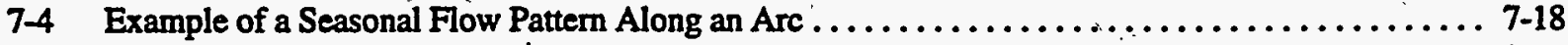

8-1 . Pipeline Tariff Module Systern Diagram ................................. 8-3

8-2 Processing Transportation Service Costs in the Ratemaking Process $\ldots \ldots \ldots \ldots \ldots \ldots \ldots \ldots \ldots .4$

8-3 Example of Apportioning Pipeline Costs to Network Arcs $\ldots \ldots \ldots \ldots \ldots \ldots \ldots \ldots \ldots \ldots \ldots$ 8-14

\section{Tables}

4-1 - Demand and Supply Types at Each Transshipment Node in the Network $\ldots \ldots \ldots \ldots \ldots \ldots \ldots$. 4.5

8-1 Illustration of Fixed and Variable Cost Classification $\ldots \ldots \ldots \ldots \ldots \ldots \ldots \ldots \ldots \ldots \ldots \ldots \ldots, 8,9$

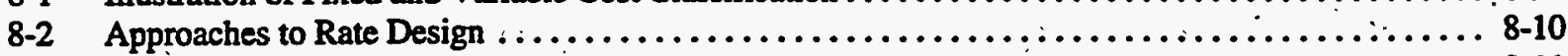

8-3a Illustration of Allocation of Fixed Costs to Rate Components $\ldots \ldots \ldots \ldots \ldots \ldots \ldots \ldots \ldots \ldots, 8-11$

8-3b Illustration of Allocation of Variable Costs to Rate Components $\ldots \ldots \ldots \ldots \ldots \ldots \ldots \ldots \ldots \ldots, 8-12$

8-4 Approach to Projection of Rate Base and Capital Costs $\ldots \ldots \ldots \ldots \ldots \ldots \ldots \ldots \ldots \ldots \ldots \ldots .8 .30$

8-5 Approach to Projection of Revenue Requirements: Capital-Related Costs and Taxes ......... 8-38

8-6 Approach to Projection of Revenue Credits and Normal Operating Expenses $\ldots \ldots \ldots \ldots \ldots \ldots .8$. 8 . 


\section{Introduction}

The Natural Gas Transmission and Distribution Model (NGTDM) is the component of the National Energy Modeling System (NEMS) that is used to represent the domestic natural gas transmission and distribution system. NEMS was developed in the Office of Integrated Analysis and Forecasting of the Energy Information Administration (EIA). NEMS is the third in a series of computer-based, midterm energy modeling systems used since 1974 by the EIA and its. predecessor, the Federal Energy Administration, to analyze domestic energy-economy markets and develop projections. From 1982 through 1993, the Intermediate Future Forecasting System (IFFS) was used by the EIA for its analyses, and the Gas Analysis Modeling System (GAMS) was used within IFFS to represent natural gas markets. Prior to 1982, the Midterm Energy Forecasting System (MEFS), also referred to às the Project Independence Evaluation System (PIES), was employed.

NEMS was developed to enhance and update EIA's modeling capability by internally incorporating models of energy markets that had previously been analyzed off-line. In addition, greater structural detail in NEMS permits the analysis of a broader range of energy issues. The time horizon of NEMS is the midterm period (i.e., through 2020 ). ${ }^{1}$ In order to represent the regional differences in energy markets, the component models of NEMS function at regional levels . appropriate for the markets represented, with subsequent aggregation/disaggregation to the Census Division level for reporting purposes.

The projections in NEMS are developed using a market-based approach ${ }^{2}$ to energy analysis, as had the earlier models. For each fuel and consuming sector, NEMS balances energy supply and demand, accounting for the economic competition between the various fuels and sources. NEMS is organized and implemented as a modular system. ${ }^{3}$ The NEMS models represent each of the fuel supply markets, conversion sectors, and end-use consumption sectors of the energy system. NEMS also includes macroeconomic and international models. The primary flows of information between each of these models are the delivered prices of energy to the end user and the quantities consumed by product, Census Division, and end-use sector. The delivered prices of fuel encompass all the activities necessary to produce (or import), and transport fuels to the end user. The information flows also include other data such as economic activity, domestic production activity, and international petroleum supply availability.

An integrating routine of NEMS controls the execution of each of the component models. The modular design provides the capability to execute models' individually, thus allowing independent analysis with, as well as development of, individual models. This modularity allows the use of the methodology and level of detail most appropriate for each energy sector. NEMS solves by iteratively calling each model in sequence until the delivered prices and quantities of each fuel in each region have converged within tolerance both within individual models and between the various models, thus achieving an economic equilibrium of supply and demand in the consuming sectors. Model solutions are reported annually through the midterm horizon. A schematic of the NEMS is provided in Figure 1-1; while a list of the associated model documentation reports is in Appendix C.

The NGTDM is the model within the NEMS that represents the transmission, distribution, and pricing of natural gas. The model also includes representations of the end-use demand for natural gas, the production of domestic natural gas, and the availability of natural gas traded on the international market based on information received from other NEMS models. The NGTDM determines the flow of natural gas in an aggregate, domestic pipeline network, connecting domestic and foreign supply regions with 12 demand regions. The methodology employed allows the analysis of impacts of regional capacity constraints in the interstate natural gas pipeline network and the identification of primary pipeline capacity expansion requirements. There is an explicit representation of core and noncore markets for natural gas transmission and distribution services, and the key components of pipeline tariffs are represented in a pricing algorithm. Natural gas pricing and flow patterns are derived by obtaining a market equilibrium across the three main elements of

'For the Annual Energy Outlook 1998 the NEMS was executed for each year from 1990 through 2020.

${ }^{2}$ The central theme of a market-based approach is that supply and demand imbalances will eventually be rectified through an adjustment in prices that eliminates excess supply or demand.

"The NEMS is composed of 13 models and a system integration routine. These components are frequently referred to as "modules" in other NEMS related publications; however, in this publication they will all be referred to as "models." Footnotes will be added when the formal name is different from the referenced name. The components of the NGTDM will be referred to as "modules." 
Figure 1-1. Schematic of the National Energy Modeling System
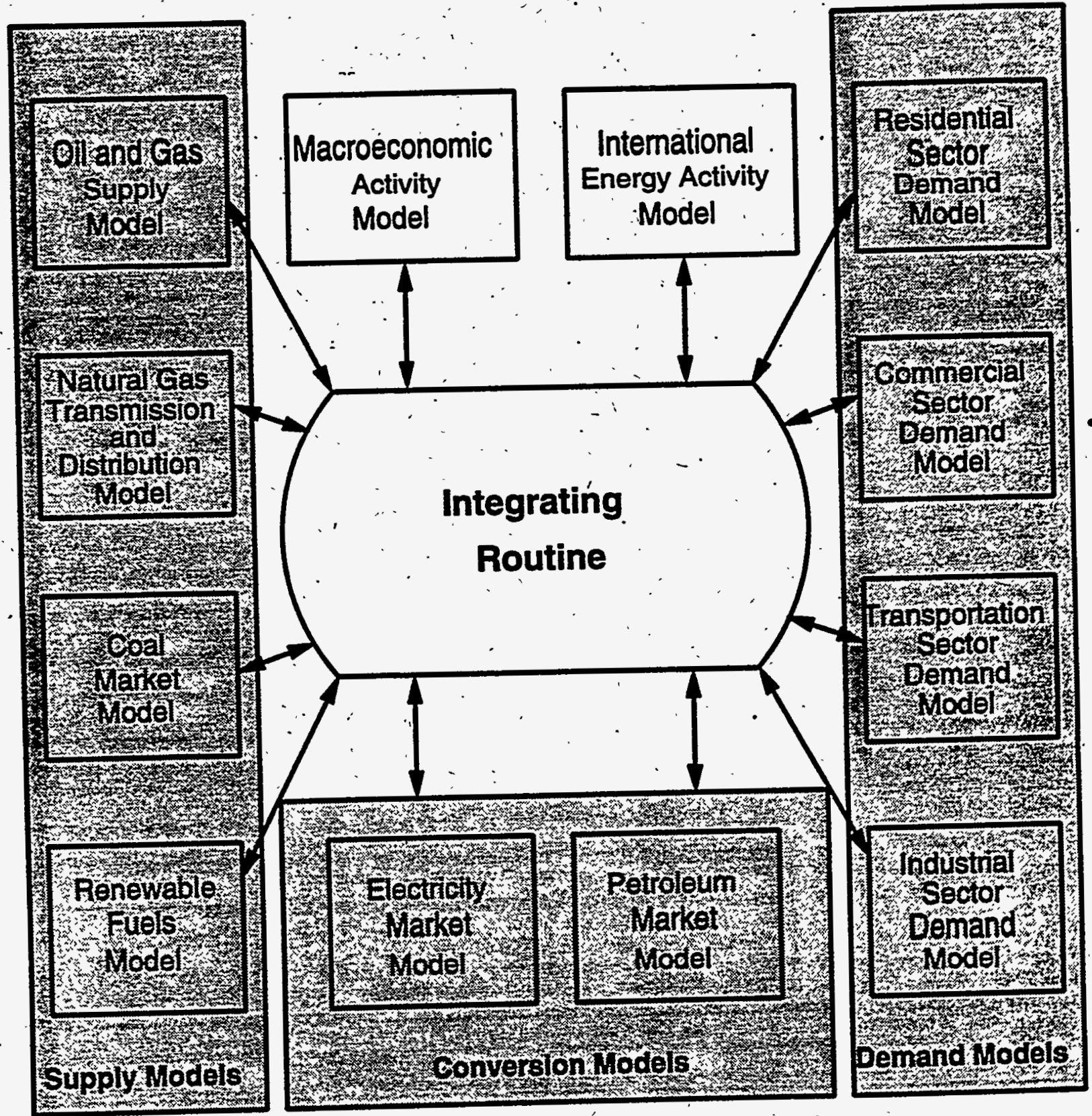


\section{Overview}

The purpose of this chapter is to provide a brief overview of the Natural Gas Transmission and Distribution Model (NGTDM) and its capabilities. The NGTDM is the component of the National Energy Modeling System (NEMS) that represents the mid-term natural gas market. The NGTDM models the natural gas transmission and distribution network in the Lower 48 States that links the suppliers (including importers) and consumers of natural gas, thus determining the regional market clearing natural gas end-use and supply (including border) prices. The demand regions modeled are the 12 NGTDM regions (Figure 2-1). These regions are based on the 9 Census.Divisions, with Census Division 5 split into South Atlantic and Florida, Census Division 8 split into Mountain and Arizona/New Mexico, Census Division 9 split into California and Pacific, and Alaska and Hawaii handled independently. Forecasts are reported annually through 2010 for natural gas end-use prices in the residential, commercial, industrial, electric generation, and transportation sectors.

The model structure consists of four major components. The Annual Flow Module (AFM) is the integrating module of the NGTDM. It simulates the natural gas price determination process by bringing together all major economic and technological factors that influence regional natural gas trade in the United States. The Capacity Expansion Module (CEM) forecasts the development of new natural gas pipeline and storage facilities and sets maximum annual utilization rates based on a seasonal analysis of supply capabilities and demand requirements. The Pipeline Tariff Module (PTM) represents the development of firm/interruptible tariffs for transportation and storage services provided by interstate pipeline companies.. The Distributor Tariff Module (DTM) represents the development of markups for distribution services provided by local distribution companies and for transmission services provided by intrastate pipeline companies. The modeling techniques employed are linear programs for the AFM and the CEM, an accounting algorithm for the PTM, and a largely empirical process based on historical data for the DTM.

The NGTDM provides a number of key modeling capabilities that were not available in its predecessor model, the Gas Analysis Modeling System (GAMS). These capabilities give the NGTDM the ability to:

- Represent interregional flows of gas ànd pipeline capacity constraints

- Represent regional supplies

- Represent different types of transmission service (firm and interruptible)

- Determine the amount and the location of additional pipeline and storage facilities on a regional basis

- Capture the economic tradeoffs between pipeline capacity additions and increases in regional storage capability

- Provide a peak/off-peak, or seasonal analysis capability in the area of capacity expansion

- Distinguish customers by category (core and noncore) in end-use sectors.

These capabilities will be described in greater detail in the subsequent chapters of this report which describe the individual modules of the NGTDM.

\section{Model Objectives}

The purpose of the NGTDM is to derive natural gas end-use and wellhead prices and flow patterns for movements of natural gas through the regional interstate network. The prices and flow patterns are derived by obtaining a markét equilibrium across the three main elements. of the natural gas market: the supply element, the demand element, and the transmission and distribution network that links them. The domestic supply, imports, and demand representations are provided as inputs to the NGTDM from other National Energy Modeling System (NEMS) modules. The representations 

of the key features of the transmission and distribution network, which include interregional network capacities and transmission and distribution service pricing, are the focus of the various components of the NGTDM.

The need to model these specific characteristics of the natural gas industry stems from the structural changes that have taken place in the industry over the last 15 years. These changes include complete deregulation of the wellhead market, the unbundling of pipeline services, and the introduction of competitive forces related to pipeline expansion decisions, and transmission and distribution service pricing. Some of these changes have already had a large effect on the market, while other changes have recently been initiated and have yet to provide a significant impact on the prices and availability of services. Two key factors support the need to include an explicit representation of the transmission and distribution of natural gas within NEMS. The first is the substantial decline in wellhead prices which results in the acquisition cost of the commodity itself generally being less than half of the end-use price. The second is the ongoing evolution of the market. This ongoing evolution also supports the need for significant flexibility in how prices for transmission and distribution services are represented in the NGTDM and how the interregional flows respond to prices over time. Because of this, the NGTDM provides, in addition to mid-term forecasts of end-use prices, forecasts of prices for, availability of, expansion of, and utilization of interstate natural gas pipeline services:

Prior to model development, a working paper was compiled by the EIA to establish the specific requirements for the overall NEMS, as well as for each of the component modules. ${ }^{5}$ Requirements pertaining specifically to the NGTDM were based on: (1) analyses performed with EIA's IFFS/GÄMS forecasting system, (2) limitations of GAMS, (3) the regulatory reform agenda of the Federal Energy Regulatory Commission (FERC), and (4) Department of Energy (DOE) policy initiatives as outlined in the National Energy Strategy. ${ }^{6}$ These requirements, along with recommendations from a Model Quality Audit of the GAMS by the Office of Statistical Standards, ${ }^{7}$ yielded a list of design guidelines for the NGTDM that support a broad array of desired analyses. Based on these guidelines, the NGTDM needed to:

- Represent pipeline capacity limitations exiting the major producing regions and entering the major market areas

- Employ a solution procedure based on an interregional trade equilibrium model that attempts to minimize simultaneously the global costs of supply and transportation subject to gas supplies available in each region, regional demand requirements, and pipeline capacity constraints

- Incorporate a transmission/storage capacity expansion/planning module that would recognize on-going, and planned/announced capacity expansion projects, as well as other capacity expansion needs throughout the forecast period

- Have the ability to endogenously determine market based rates for pipeline transportation services

- Have the ability to partition the natural gas market to apply either market based or cost based rates to specific segments of end-use sectors or to the market as a whole

- Employ a śhort-run supply curve that includes a direct representation of marginal sources of supply

- Represent Canadian and Mexican pipeline gas trade and liquefied natural gas trade

During the development of the model methodology, a study was made of existing models and modeling techniques that might be used to meet the above requirements. Based on this study and the reports mentioned previously, it-was. determined that no model currently in existence could satisfy the NEMS requirements, and thus a new model was needed. The results of the study are presented in Appendix D. Documients that were referenced in support of the model development effort are listed in Appendix B. The following sections provide brief overviews of the four components of the NGTDM.

\footnotetext{
'Energy Information Administration, Office of Integrated Analysis and Forecasting, "Requirements for a National Energy Modeling System," December 12, 1991.

${ }^{6}$ National Energy Strategy, First Edition, 1991/1992 (Washington, DC, February 1991).

${ }^{7}$ Carpenter, Paul R., Review of the Gas Analysis Modeling System (Boston, MA: Incentives Research, Inc., August 1991).
} 


\section{Annual Flow Module}

The Natural Gas Annual Flow Module (AFM) is the main integrating module of the NGTDM. One of its major functions is to simulate the natural gas price determination process. The AFM brings together all major economic and technological factors that influence regional natural gas trade in the United States. The economic considerations include the demand for and the supply of natural gas, competition from substitute fuels and conservation options, and competition from imported natural gas.

The AFM integrates all components of the NGTDM (the AFM itself, the Capacity Expansion Module, the Pipeline Tariff Module and the Distributor Tariff Module). Through this integration process, the AFM derives average annual natural gas prices (wellhead, city gate, and end-use) that reflect an interregional trade market equilibrium among competing gas supplies, end-use sector consumption and transportation routes. End-use prices are derived for both core and noncore markets. Within NEMS the classification of customers as core versus noncore is predetermined.

The historical evolution of the price determination process simulated by the AFM is depicted schematically in Figure 2-2. Until recently, the marketing chain was very straightforward, with end-users and local distribution companies contracting with pipeline companies, and the pipeline companies in turn contracting with producers. Prices typically reflected average costs of providing service plus some regulator-specified rate of return. Although this approach is still used as a basis for setting pipeline tariffs, more pricing flexibility is being introduced, particularly in the interstate pipeline industry and more recently by local distributors. Pipeline companies are also offering a range of services under competitive and market-based pricing arrangements. Additionally, new players-for example marketers of spot gas and

Figure 2-2. Principal Buyer/Seller Transaction Paths for Natural Gas Marketing

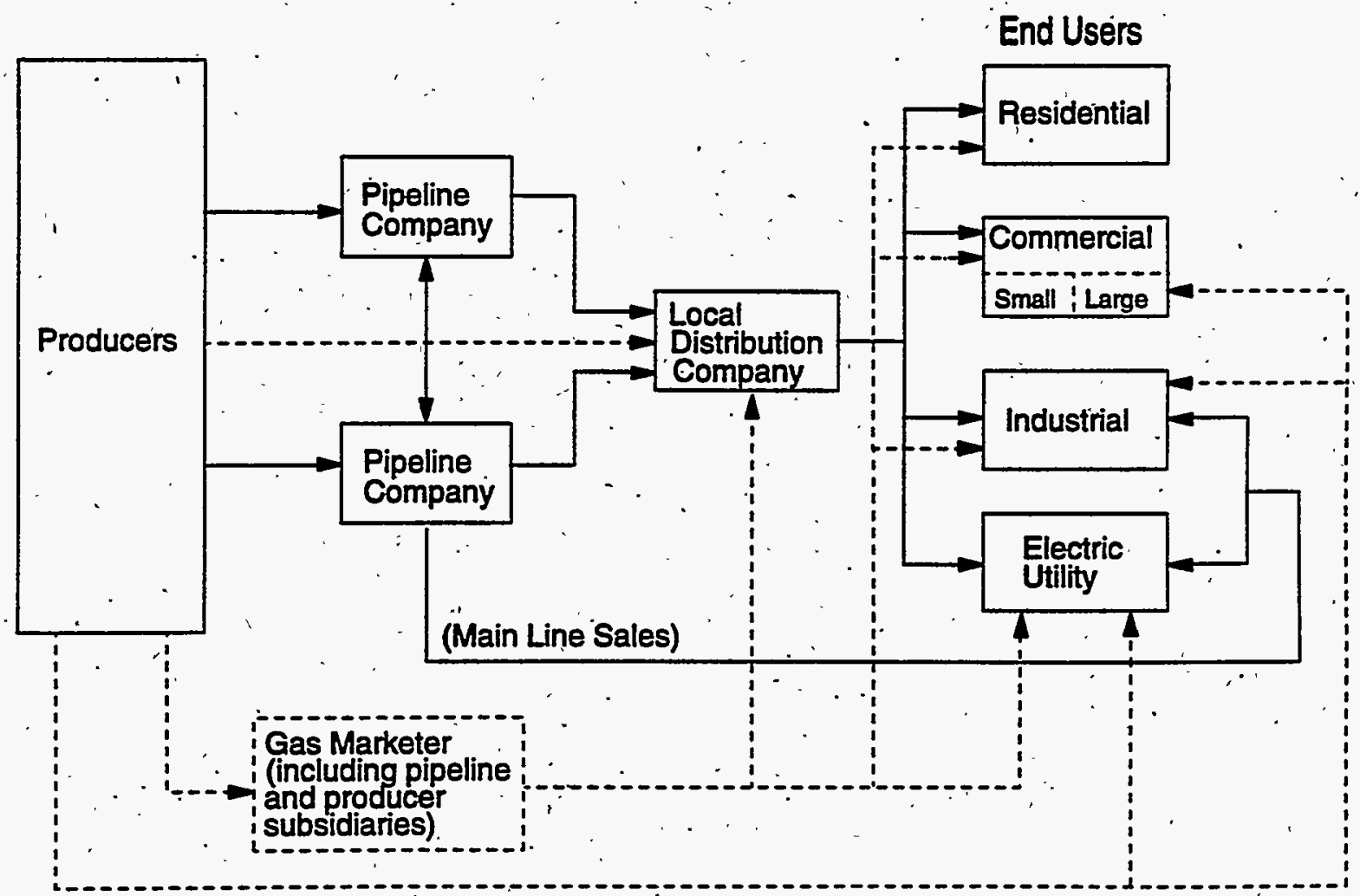


brokers for pipeline capacity -have entered the market, creating new links connecting suppliers with end-users. The marketing links will become increasingly complex in the future.

The level of competition for pipeline services (generally a function of the number of pipelines having access to a customer and the amount of capacity available) is currently driving the prices for interruptible transmission service and is beginning to have an effect on firm service prices. Currently, there are significant differences across regions in pipeline capacity utilization. ${ }^{8}$ These regional differences are evolving as new pipeline capacity has been and is being constructed to relieve the capacity constraints in the Northeast and on the West Coast, to expand markets in the Midwest, and to move more gas out of Canada and the Gulf of Mexico. As capacity changes take place, prices of services should adjust accordingly to reflect new market conditions.

Federal and State initiatives are reducing barriers to market entry and are encouraging the development of more competitive markets for pipeline and distribution services. Potential mechanisms used to make the transmission sector more competitive include the widespread capacity releasing programs, market-based rates, and the formation of market centers with deregulated upstream pipeline services. Some combination of these mechanisms will probably be used in the future. As the outcome is unknown at this point, the AFM is not designed to model any specific type of program. It is instead designed to simulate the overall impact of the movement towards market based pricing of transmission services.

The regional supply detail in the AFM, in conjunction with the AFM representation of pipeline capacity, supports analysis of regional shifts in supply and demand patterns. Regional differences in marginal sources of supply are also captured. Finally, the AFM addresses: transmission fuel consumption and losses; the impact of the Canadian and Mexican natural gas markets on the U.S. gas market; and capacity rationing (accomplished via the pricing of services).

\section{Capacity Expansion Module}

The primary purpose of the Capacity Expansion Module (CEM) is to simulate the decision-making process for expanding pipeline and/or storage capacity in the U.S. gas market. In simulating gas pipeline capacity expansion, the CEM: (1) determines the amount of pipeline and storage capacity to be added between or within regions in the NGTDM, and (2) establishes effective (or practical) maximum annual utilization rates for each of the interregional pipeline routes represented in the Annual Flow Module. Maximum utilization rates (or load factors) on pipeline routes are established to capture the impact of variations in seasonal demand on the maximum amount of gas which can practically flow between regions within a year. Pipeline and storage capacity additions are used in the Annual Flow Module (in combination with the maximum load factors) to set limits on annual interregional flows and to set working gas storage levels. These capacity additions are also used in the Pipeline Tariff Module when determining future storage rates and interregional pipeline tariffs.

The CEM was designed to address the guidelines that support a broad array of desired analyses and policy questions to be answered, such as:

- What impact will the increased demand for natural gas attributable to greater market penetration of new. end-use gas technologies have on the utilization of the U.S. pipeline grid and requirements for new capacity? In what regions is capacity likely to be added?

- What might be the impact of a proactive natural gas policy on the utilization of pipeline capacity and the need for pipeline expansion?

- How will unbundling and the increasingly market-oriented pricing of gas supply and transmission services affect the differences between delivered prices for residential/commercial and industrial and electric generators sector gas users?

\footnotetext{
Energy Information Administration, Capacity and Service on the Interstate Natural Gas Pipeline System, 1990: Regional Profiles
} and Aralyses, DOEELA-0551 (Washington, DC, May 1992). 
Regulation affecting the demand for gas and the supply of gas, such as emissions controls and tax credits, are modeled within the demand models of NEMS and the Oil and Gas Supply Model, respectively. The Pipeline Tariff Module and the Distributor Tariff Module provide tariffs to the CEM. Therefore, regulations affecting the setting of rates are specified within these two tariff modules, and are subsequently incorporated within the CEM. When the NGTDM is used to analyze the impact of new regulations which will increase or decrease expansion costs, these adjustments will be. incorporated within the Pipeline Tariff Module, where the interstate tariffs associated with expanded pipeline or storage capacity are calculated (e.g., incremental versus rolled-in rates for new capácity). Within the CEM, parameters can be set to capture the impact of changes in lead times associated with the regulatory approval process for pipeline and storage expansion.

The design of the CEM is consistent with the NEMS requirements for modeling natural gas pipeline capacity and capacity expansion: "The model will respond to external decisions (assumptions) about throughput capacity for natural gas facilities including the expansion of facilities (interstate pipelines, storage and import facilities), and maintenance and replacement of facilities, as well as the associated costs. The output reports will contain capacity requirements and utilization rates distinguished by region. ${ }^{\text {"9 }}$

\section{Pipeline Tariff Module}

The primary purpose of the Pipeline Tariff Module (PTM) is to compute tariffs for transportation and storage services provided by interstate pipeline companies. These tariffs are used within the Annual Flow Module to derive supply and end-use prices and within the Capacity Expansion Module to derive capacity additions. The tariffs are computed for individual pipeline companies, then aggregated to the major gas pipeline corridors or ares (in the United States) specified in the NGTDM network, as described in Chapter 4. An accounting system is used to track costs and compute rates under various rate design and regulatory scenarios. Tariffs are computed for both firm and interruptible transportation and storage services. Transportation tariffs are computed for interregional arcs defiried by the NGTDM network. These network tariffs represent an aggregation of the tariffs for individual pipeline companies supplying the network arc. Storage tariffs are defined at regional NGTDM network nodes, and, likewise, represent an aggregation of individual company storage tariffs. Note that these services are unbundled and do not include the price of gas, except for the cushion gas used to maintain minimum gas pressure. Furthermore, the module cannot address competition for pipeline or storage services along an aggregate are or within an aggregate region, respectively,

Since the tariffs determined by the PTM represent an aggregation of individual pipeline companies, the PTM is not designed to address the issue of analyzing competition within a regional pipeline corridor. It should also be noted that the PTM deals only with the interstate market, and thus does not capture the impacts of State-specific regulations for intrastate pipelines. Intrastate transportation charges are accounted for within the Distributor Tariff Module.

Pipeline tariffs for transportation and storage services represent a significant portion of the price of gas to industrial and electric generator end-users, in particular. Consumers of natural gas are grouped generally into two categories: (1) those who need firm or guaranteed service because gas is their only fuel option or because they are willing to pay for security of supply, and (2) those who do not need guaranteed service because they can either periodically terminate operations or use fuels other than natural gas. The first group of customers (core customers) are assumed to purchase firm transportation services, while the latter group (noncore customers) are assumed to purchase interruptible services or released capacity. Pipeline companies guarantee to their core customers that they will provide peak day service up to the maximum capacity specified under their contracts even though these customers may not actually request transport of gas on any given day. In return for this service guarantee, these customers pay monthly reservation fees (or demand charges). These reservation fees are paid in addition to charges for transportation service based on the quantity of gas actually transported (usage fees or commodity charges). The PTM transportation and storage rates to core customers are based on the average cost-of-service provided by the pipeline to all of its comparably situated core customers.

The actual reservation and usage fees (tariffs) that pipelines are allowed to charge are largely regulated by the Federal Energy Regulatory Cómmission (FERC). FERC's ratemaking traditionally allows (but does not necessarily guarantee) a pipeline company to recover its costs, including what the regulators consider a fair trate of return on capital. A

${ }^{9}$ Energy Information Administration, Requirements, pp. 12-13. 
fundamental decision in cost-based rate design is the apportionment of costs among customer classes. How costs are apportioned determines the extent of differences in the rates charged to different classes of customers and for different types of service. For example, the more fixed costs that are included in usage fees, the more noncore customers share in paying pipeline costs. However, transferring a larger share of fixed costs to reservation fees leads to core customers bearing a larger share of system costs. The PTM is designed to provide flexibility in allocating fixed and variable costs to core and noncore customers so that various policy initiatives may be examined. In addition, the PTM contains a revenue crediting mechanism to capture the gross effects of revenue crediting for pipeline-provided interruptible services. Should revenues from interruptible customers exceed costs allocated to them; a portion of the excess revenues is credited back to firm customers and the remainder is left for pipeline profits. In an effort to capture the alternate rate policy recently issued by FERC, a mechanism has been implemented in the PTM that lowers (raises) fixed costs to core customers on a pipline as the utilization rate falls (rises).

Since requirements of noncore customers generally are not taken into account in determining the peak-day delivery requirements of pipeline systems, the availability of capacity to serve these customers during peak consumption periods can be limited, and interruptions can occur. FERC sets maximum and minimum rates a pipeline is allowed to charge for interruptible service, unless a competitive market can be demionstrated; thus, pipeline companies are allowed to offer discounts from the maximum usage fee at their discretion provided they do not unduly discriminate among customers. Since rates may be discounted to the variable cost of moving gas, and the major portion of the pipeline costs are fixed costs, the pipelines have considerable discretion in setting rates. Additionally, various rate making policy options currently under discussion by FERC may allow peak-season rates to rise substantially above the 100-percent load factor. rate (also known as the full cost-of-service rate). In capacity-constrained markets, transportation rates based on marginal costs will be significantly above the full cost of service rates.

In the PTM, fixed and variable cost allocation provides flexibility in modeling a pipeline company's response to recent FERC regulatory decisions to unbundle pipeline sales and transportation services, and to encourage market-based responses to competition. The cost allocation is specified at the pipeline company-level. After individual company revenue requirements are determined, they are aggregated across companies to the arc-level specified by the NGTDM network. The PTM estimates maximum and minimum interruptible transportation service rates which are used to determine interruptible service arc-level tariffs charged to noncore customers. The maximum rate computed by the PTM is the full cost-of-service rate (currently the 100-percent load factor rate). The minimum rate is the variable cost of transporting gas. The actual rate charged noncore customers is a function of market conditions. The lower bound is set between the regulated maximum and minimum rates as a function of pipeline capacity utilization. In noncapacity constrained markets, the lower bound becomes the effective rate. The effective rate charged in the Annual Flow Module in capacity-constrained markets is based on marginal costs and, on occasion, exceeds the maximum rate computed by the PTM.

Theoretically, the PTM could compute either incremental or rolled-in (average) rates for new capacity, thus allowing a more comprehensive analysis of the results of supply and demand shifts on capacities and flow patterns, as well as a more representative analysis of the pricing of natural gas transportation and distribution services. ${ }^{10}$

\section{Distributor Tariff Module}

The primary purpose of the Distributor Tariff Module (DTM) is to determine the components of end-use prices that are regulated by State and local authorities. These consist of (1) distributor markups charged by local distribution companies for the distribution of natural gas from the city gate to the end user and (2) markups charged by intrastate pipeline companies for intrastate transportation services. Intrastate pipeline tariffs are specified exogenously to the model and are currently set to zero. However, these tariffs are accounted for in the model indirectly. End-use distribution service is distinguished within the DTM by sector and service type.

${ }^{10}$ Throughout the report, reference will be made to the current formulation of the NGIDM where incremental rates will be used as a market test for capacity expansion, and where the AFM will use rolled-in rates in solving for flows and prices in the firm market and market-based rates for the internuptible market. However, the capability exists within the PTM.to compute different types of rates allowing it, and thus the NGTDM, to respond to different rate design and regulatory scenarios. 
Distribution markups represent a significant portion of the price of gas to customers. These customers include the residential, commercial, industrial, electric generators, and transportation (compressed natural gas vehicles) sectors. Each sector has different distribution service requirements. For example, the core customers in the model (residential, transportation, commercial and some industrial and electric generator customers) require guaranteed on-demand (firm) service because natural gas is their only fuel option. In contrast, large portions of the industrial and electric generator sectors may not rely solely on guaranteed service because they can either periodically terminate operations or switch to other fuels. These customers are referred to as noncore. They can elect to receive some gas supplies through a lower priority (and lower cost) interruptible transportation service. During periods of peak demand, services to these sectors can be interrupted in order to meet the natural gas requirements of core customers. In addition, these customers may select to bypass the local distribution company pipelines and hook up directly to interstate or intrastate pipelines.

The actual rates that local distribution companies and intrastate carriers are allowed to charge are regulated by State authorities. State ratemaking traditionally allows (but does not necessarily guarantee) local distribution companies and intrastate carriers to recover their costs, including what the regulators consider a fair return on capital. These rates are derived from the cost of providing service to the end-use customer. The State authority determines which expenses can be passed through to customers and establishes an allowed rate of return. These measures provide the basis for distinguishing rate differences among customer classes and type of service by allocating costs to these classes and services based on a rate design. The DTM does not directly account for the separate cost components in deriving a revenue requirement for distribution services, but approximates the change in the total revenue requirement from year to year. In addition, the unbundling of distribution services (sales versus delivery, and sometimes local storage) is making considerable inroads.

The DTM represents distribution tariffs to the core customers (excluding the transportation and electric generator sectors) by estimating annual changes to total distribution costs, and subsequently the related tariffs, starting from a base year. Base year values for total costs and distributor tariffs are established using historical data. The annual change in total cost is dependent on an assumed increase in operational efficiencies, as well as the annual change in natural gas consumption and in national average capital and employment costs. The revenue requirements from core customers are adjusted due to an assumed contribution of revenues from noncore customers. The allocation of these revenue requirements to individual sectors is primarily dependent on the relative annual change in consumption across sectors. User-specified parameters allow adjustment of the markups to account for shifts due to regulatory policy. Many of these modeling choices are the result of data limitations."

Distributor markups to the noncore customers are set at historical levels and are held constant. A user-specified option is available for allowing these rates to decline (or increase) steadily throughout the forecast. Distributor markups to core electric generators are initially set at historical levels, then allowed to change in response to annual changes in consumption levels within the sector. The natural gas vehicle (NGV) sector markups are calculated separately for fleet and personal vehicles. Markups for fleet vehicles are set and held constant at historical levels with taxes added (although a user-specified decline rate is allowed). Markups for personal vehicles are set at the industrial sector core price, plus taxes, plus an assumed distribution cost. This price is capped at the gasoline equivalent price, as long as minimum costs are covered.'

Since the markups determined by the DTM represent an aggregation of individual local distribution companies and intrastate pipeline companies, this module is not designed to address the issue of analyzing competition for distribution services within a region. It should also be noted that the DTM deals only with issues at an aggregate regional level, and thus does not capture the impacts of State-specific regulations on intrastate tariffs and by-pass issues. Finally, the procedures used by the DTM to estimate markups are limited by the types and availability of data.

${ }^{11}$ EIA data surveys currently do not collect the cost components required to derive revenue requirements and cost-of-service for local distribution companies and intrastate carriers; nor are these data collected by other public or private sources. These cost components can be compiled from rate filings to Public Utility Commissions; however, an extensive data collection effort is beyond the scope of NEMS at this time. This data collection may be considered for a future development effort. 


\section{Interface Between the NEMS and the NGTDM}

This chapter presents the general role that the Natural Gas Transmission and Distribution Model (NGTDM) plays in the NEMS. First a general description of the NEMS is provided, along with an overview of the NGTDM. Second, the data passed to the NGTDM from other NEMS models will be described along with the methodology used within the NGTDM to transform these prior to their use in the model. The natural gas demand representation provided to the NGTDM from the Electricity Market Model (EMM) and from the end-use demand models of NEMS is described, followed by a section on the natural gas supply interface. Finally, the information that is passed to other NEMS models from the NGTDM will be described.

\section{A Brief Overview of NEMS and the NGTDM}

The NEMS represents all of the major fuel markets-crude oil and petroleum products, natural gas, coal, electricity, and imported energy - and iteratively solves for an annual supply/demand balance for each of the 9 Census Divisions, accounting for the price responsiveness in both energy production and end-use demand, and for the interfuel substitution possibilities. NEMS solves for an equilibrium in each forecast year by iteratively operating a series of fuel supply and demand models to compute the end-use prices and consumption of the fuels represented. ${ }^{12}$ The end-use demand models-for the residential, commercial, industrial, and transportation sectors-are. detailed representations of the important factors driving energy consumption in each of these sectors. Using the delivered prices of each fuel, computed by the supply modules, the demand models evaluate the consumption of each fuel, taking into consideration the interfuel substitution possibilities, the existing stock of fuel and fuel conversion burning equipment, and the level of economic activity. Conversely, the fuel conversion and supply models determine the end-use prices needed in order to supply the amount of fuel demanded by the customers; as determined by the demand models. Each supply module considers the factors relevant to that particular fuel, for example: the resource base for oil and gas, the transportation costs for coal, or the refinery configurations for petroleum products. Electric generators and refineries are both suppliers and consumers of energy:

Within the NEMS system, the NGTDM provides the interface between the Oil and Gas Supply Model (OGSM) and the demand models in NEMS, including the EMM. The NGTDM determines the price and flow of dry natural gas supplied internationally from the contiguous U.S. border ${ }^{13}$ or domestically from the wellhead (and indirectly from natural gas processing plants) to the domestic end-user. ${ }^{14}$ In so doing, the NGTDM models the markets for the transmission (pipeline companies) and distribution (local distribution companies) of natural gas in the contiguous United States. The primary data flows between the NGTDM and the other oil and gas models in NEMS, the Petroleum Market Model (PMM) and the OGSM, are depicted in Figure 3-1.

Functionally, each of the demand models in NEMS provides the level of natural gas that would be consumed at the burnertip by the represented sector at a given end-use price; and the OGSM provides the level of natural gas which would be produced (or imported) at the wellhead (or border crossing) for a given supply price. The NGTDM uses this information to build "short-term" supply or demand curves which are used to approximate a giver model's response to prices within a limited range. ${ }^{13}$ Given these short-term demand and supply curves, the NGTDM model solves for the end-use, wellhead, and border prices that represent a natural gas market equilibrium, while accounting for the cost and market for transmission and distribution services (including its physical and regulatory constraints). These solution ${ }^{\circ}$ prices, and associated production levels, are in turn passed to the OGSM and the demand models, including the EMM, as primary input variables. In addition to the basic calculations performed within these models, the parameters which

\footnotetext{
${ }^{12}$ A more detailed description of the NEMS system, including the convergence algorithm used, can be found in "National Energy Modeling System Integrating Module Documentation Report." DOE/EIA-M057, May 1995.

${ }^{13}$ Because of the distinct separation in the natural gas market between Alaska, Hawaii, and the contiguous United States, natural gas consumption in, and the associated supplies from, Alaska and Hawaii are modeled separately. from the contiguous United States within the NGTDM.

"Natural gas exports are also represented within the model.

${ }^{15}$ Special parameters are provided by OGSM for the construction of supply curves for domestic nonassociated natural gas production (some of which are no longer being used) and by EMM for the construction of demand curves for natural gas consumed by electric generators that can use residual fuel oil as an alternate.
} 
Figure 3-1. Primary Data Flows Between Oil and Gas Models of NEMS

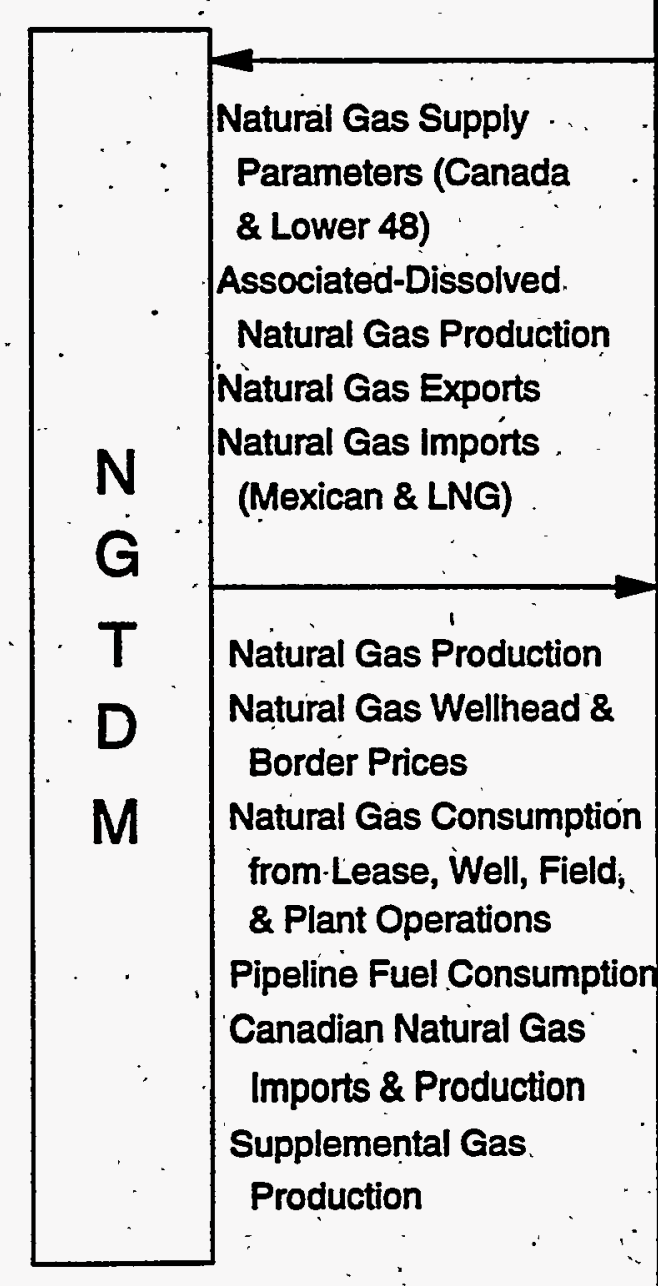

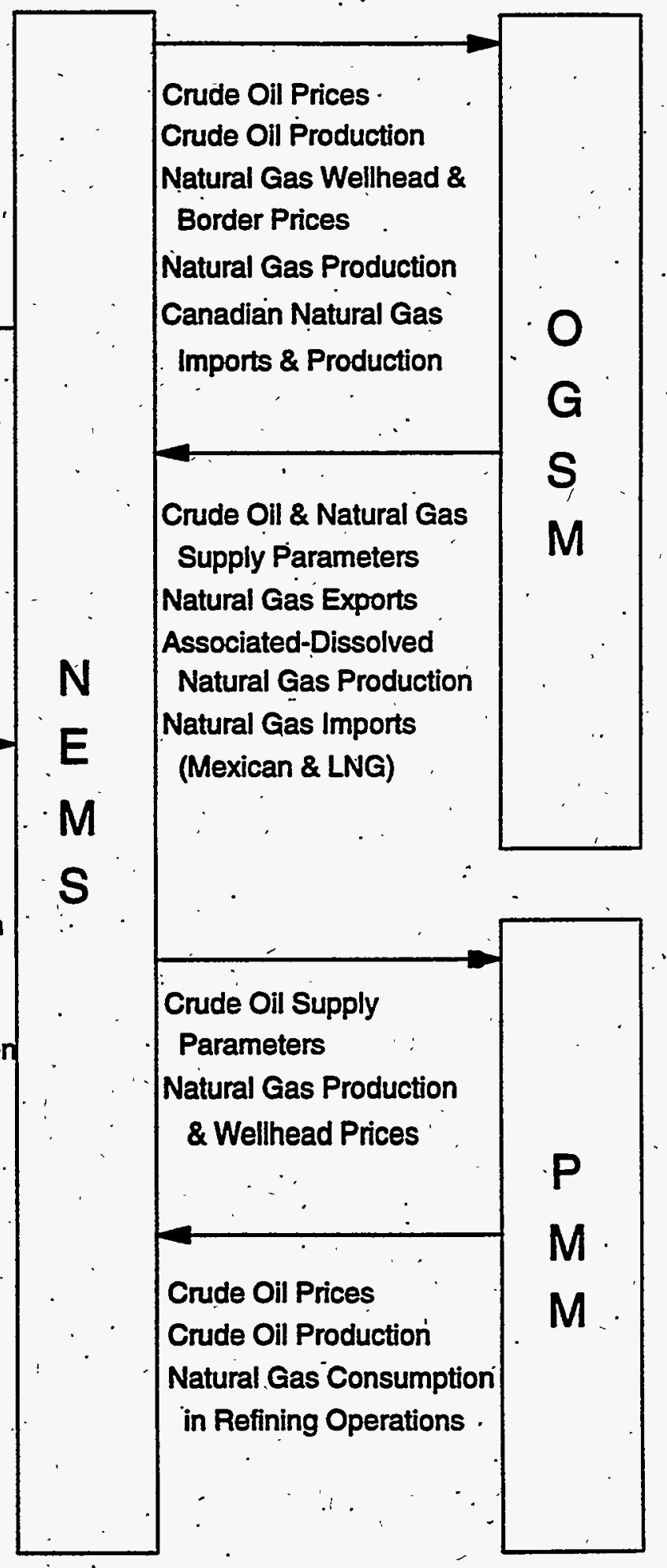


define the natural gas supply or demand curves used in the NGTDM are updated (as appropriate) to reflect the prices most recently provided by the NGTDM.

The NGTDM model is composed of four primary components or modules: the Annual Flow Module, the Capacity Expansion Module, the Pipeline Tariff Module, and the Distributor Tariff Module. The Annual Flow Module is the central module of the NGTDM, since it is used to derive flows and prices of natural gas in conjunction with an annual natural gas market equilibrium. Conceptually the Annual Flow Module is a simplified representation of the natural gas transmission and distribution system, structured as a network composed of nodes and arcs. The other three primary components serve as:satellite modules to the Annual Flow Module, providing parameters which define some of the characteristics of these nodes and arcs. Other parameters for defining the natural gas market (such as supply and demand curves) are derived based on information passed from other NEMS models. The Capacity Expansion Module provides the Annual Flow Module with regional underground storage activity ${ }^{16}$ and maximum annual flow limits along each of the arcs in the network. The Pipeline and Distributor Tariff Modules set the tariffs to be charged along each of the interregional, intraregional, intrastate, and distribution ares. Data are also passed back to these satellite modules from the Annual Flow Module and between the satellite modules themselves.

The NGTDM is called once for each iteration of NEMS, but all modules are not run for every call. The Pipeline Tariff Module and the Capacity Expansion Module are executed once for each forecast year, on the first iteration of each year and the last iteration of each year, respectively. The Annual Flow Module and the Distributor Tariff Module are executed once every NEMS iteration. The calling sequence of and the interaction among the NGTDM modules is as follows for each year of execution of NEMS:

- First Itération:

The Pipeline Tariff Module determines tariffs for interregional and interstate pipeline company transportation and storage services, using a cost based simulation, and establishes tariff curves for pipeline and storage expansion.

- Each Iteration:

The Distributor Tariff Module sets markups for intrastate transmission and for distribution services based on historical data and assimed parameters. Next, the Annual Flow Module incorporates tariffs from the Pipeline Tariff Module and markups from the Distributor Tariff Module into a linear program that solves for interregional flows based on supply availability, demand requirements, and pipeline capacity constraints. The linear program determines a market equilibrium solution by maximizing consumer and producer surpluses, while minimizing supply and transportation costs, thus determining natural gas end-use and supply prices and domestic production. Pipeline capacity constraints for the first year (or years) of execution are determined from historical data. Subsequent year's constraints are taken from the previous year's Capacity Expansion Module results.

- Last Iteration:

The Capacity Expansion Module employs the pipeline and storage expansion curves calculated in the Pipeline Tariff Module, the tariffs from the Distributor Tariff Module, and expected future supply availability and consumption levels from other models in the NEMS. The Capacity Expansion Module represents two natural gas market seasons within a linear program structure to determine pipeline and storage capacity expansion (beyond planned additions) for a future year, by minimizing the pipeline and storage expansion costs required to meet the expected consumption levels of natural gas. The resulting pipeline capacity build requirements and seasonal flow patterns are used to establish effective limits on the annual load along pipelines, for use in the Annual Flow Module. In addition, annual net storage withdrawals for the firm and interruptible service networks are set based on resulting peak/offpeak flows to and from storage in the Capacity Expansion Module.

\footnotetext{
${ }^{16}$ The CEM determines annual net storage withdrawals by firm and interruptible service types. The sum of these two values by region in the forecast period, beyond the years covered in the Short-Term Energy Outlook, equals zero.
} 
The primary outputs from the NGTDM, which are used as input in other NEMS models, result from establishing a natural gas market equilibrium solution:" end-use prices, wellhead and border crossing prices, nonassociated natural gas production, and Canadian import levels. In addition, the model provides a forecast of lease and plant fuel consumption, pipeline fuel use, as well as pipeline and distributor tariffs, pipeline and storage capacity expansion, and interregional natural gas flows.

\section{Natural Gas Demand Representation}

Natural gas which is produced within the United States is consumed in lease and plant operations, delivered to consumers, exported internationally, and consumed as pipeline fuel. The consumption of gas as lease, plant, and pipeline fuel is determined within the NGTDM. Gas used in well, field, and lease operations and in natural gas processing plants is set equal to an exogenously specified percentage (Appendix E.,PCTLSE_SUPL) of dry gas production. ${ }^{17}$ Pipeline fuel use depends on the amount and distance of gas transported and distributed in each region, as described in Chapter 5. The level of natural gas exports are currently determined exogenously to NEMS and passed to the NGTDM from the OGSM model. Exports are distinguished by six Canadian and three Mexican border crossing points, as well as for exports of liquefied natural gas to Japan from Alaska. The representation of gas delivered to consumers is described below.

\section{Classification of Natural Gas Consumers}

Natural gas that is delivered to consumers is represented within the NEMS at the Census Division level and by five primary end-use sectors: residential, commercial, industrial, transportation, and electric generation. ${ }^{18}$ These demands are further distinguished by customer class (core or-noncore), reflecting the type of natural gas transmission and distribution service that is predominately purchased. The "core" customers require guaranteed service, particularly during peak days/periods during the year. The "noncore" customers require a lower quality of transmission services and therefore, consume gas under a less certain and/or less continuous basis. In the NGTDM, the core customers are assumed to purchase firm transmission services and the noncore customers are assumed to purchase interruptible transmission services or released capacity.

Currently in NEMS, all customers in the transportation, residential, and commercial sectors are classified as core. ${ }^{19}$ Within the industrial sector the noncore segment includes the industrial boiler market and refineries. The noncore segment of the electric generation sector is further separated into two subclasses, depending on the alternative fuel a plant would burn should natural gas be unavailable or relatively uneconomic. The subclass of noncore electric generation plants that has the option of burning distillate fuel in lieu of natural gas is referred to as "competitive-with-distillate." The second subclass of noncore plants can burn either natural gas or residual fuel oil and is therefore referred to as "competitive-with-residual fuel." The electric generating units defining each of the three customer classes modeled are as follows: (1) core-gas steam units or gas combined cycle units, (2) competitive-with-distillate-dual-fired turbine units or gas turbine units, (3) competitive-with-residual fuel-dual-fired steam plants (consuming both natural gas and residual fuel oil): Within the NGTDM, natural gas is exported to Mexico under firm transmission service and to Canada under interruptible transmission service.

For any given NEMS iteration within a forecast year, the individual demand models in NEMS determine the level of natural gas consumption for each region and customer class at the end-use price for the same region, class, and sector, as calculated by the NGTDM in the previous NEMS iteration. Within the NGTDM, each of these consumption levels (and its associated price) is used in conjunction with an assumed price elasticity as a basis for building a short-term

\footnotetext{
${ }^{17}$ The factors used in calculating regional lease and plant fuel consumption are initially based on historical averages and held constant throughout the forecast period. However; in the historical years (and, if chosen, the first two forecast years as presented in the latest available Short-Term Energy Oullook (STEO), DOE/EIA-0202), these factors are scaled so the resulting national lease and plant fuel consumption will match the annual published value (Appendix E, QLPIN, STQLPIN). The scaled values for the last historical year are used throughout the forecast period. The adjustment attributable to benchmarking to STEO (if selected as an option) is phased out by the year STPHAS_YR. A similar adjustment is performed on the factors used in calculating pipeline fuel consumption.

"Natural gas bumed in the transportation sector is defined as compressed natural gas that is bumed in natural gas vehicles; and the electric generation sector includes all electric power generators except cogenerators.

${ }^{19}$ The NEMS is structurally able to classify a segment of these sectors as noncore, but currently sets the noncore consumption for the residential, commercial, and transportation sectors at zero.
} 
demand curve. [The price elasticities are set to zero if fixed consumption levels are to be used.] These curves are used within the NGTDM to minimize the required number of NEMS iterations by approximating the demand response to a different price. In so doing, the price where the implied market equilibrium would be realized can be approximated. Each of these market equilibrium prices is passed to the appropriate demand model during the next NEMS iteration to determine the consumption level that the model would actually forecast at this price. The NGTDM disaggregates the Census division regional consumption levels into the regional representation that the NGTDM requires. The demand curve representation and the regional mapping for the electric generation sector differ from the other NEMS sectors as described in the following sections.

\section{Regional Representations of Demand}

Natural gas consumption levels by all nonelectric ${ }^{20}$ sectors are provided by the NEMS demand models for the 9 Census divisions, the primary integrating regions represented in the NEMS. Alaska and Hawaii are included within the Pacific Census Division. The EMM represents the electricity generation process for 13 electricity supply regions-the 9 North American Electric Reliability Council (NERC) Regions and 4 selected NERC Subregions (Figure 3-2). Electricity generation in Alaska and Hawaii is handled separately. Within the EMM, the electric generators' consumption of natural gas is disaggregated into subregions which can be aggregated into Census Divisions or into the regions used in the NGTDM.

With the few following exceptions, the regional detail provided at a Census division level is adequate to build a simple network representative of the contiguous U.S. natural gas pipeline system. First, Alaska and Hawaii are not connected to the rest of the Nation by pipeline and are therefore treated separately from the contiguous. Pacific Division in the NGTDM. Second, Florida receives its gas from a distinctly different route than the rest of the South Atlantic Division and is therefore isolated. A similar statement applies to Arizona and New Mexico relative to the Mountain Division. Finally, Califormia is split off from the contiguous Pacific Division because of its relative size coupled with its unique energy related regulations. The resulting 12 primary regions represented in the Annual Flow Module are referred to as the "NGTDM Regions" (as shown in Figure 2-1).

The regions which are represented in the EMM do not always align with State borders and generally do not share common borders with the Census divisions or NGTDM regions (Figure 3-2). Therefore, demand in the electric generation sector is represented in the NGTDM at the regions (NGTDM/EMM) resulting from the combination of the NGTDM regions overlapped with the EMM regions, translated to the nearest State border (Figure 3-3). For example, - the South Atlantic NGTDM region (number 5) includes three NGTDM/EMM regions (part of EMM regions 1, 3, and 9). Within the EMM, the disaggregation into subregions is based on the relative geographic location (and natural gasfired generation capacity) of the current and proposed electricity generation plants within each region.

The consumption levels for each of the nonelectric sectors are disaggregated from the 9 Census divisions to the 12 NGTDM regions by applying historically based shares. which are held constant throughout the forecast (Appendix E, NG_CENSHR). For the Pacific Division, natural gas consumption estimates for Alaska are first subtracted to establish a consumption level for just the contiguous Pacific Division before the historical share is applied. The consumption of gas in Hawaii was considered to be negligible. Within the NGTDM, a relatively simple module (described later) was included for approximating the consumption of natural gas by each nonelectric sector in Alaska. These estimates, combined with the consumption levels provided by the EMM for consumption by electric generators in Alaska, are also used in the calculation of the production of natural gas in Alaska.

\section{Natural Gas Demand Curves for Nonelectric Sectors}

While the primary analysis of energy demand takes place in the NEMS demand models, the NGTDM itself directly incorporates limited price responsive demiand curves to speed the overall convergence of NEMS and to.improve the quality of the results obtained when the NGTDM is run as a stand-alone model. The NGTDM may also be executed to determine end-use prices for fixed consumption levels (represented by setting the price elasticity of demand in the

\footnotetext{
${ }^{20}$ The "nonelectric" sectors refer to sectors that do not produce electricity using natural gas (i.e., the residential, commercial, industrial, and transportation demand sectors.)
} 


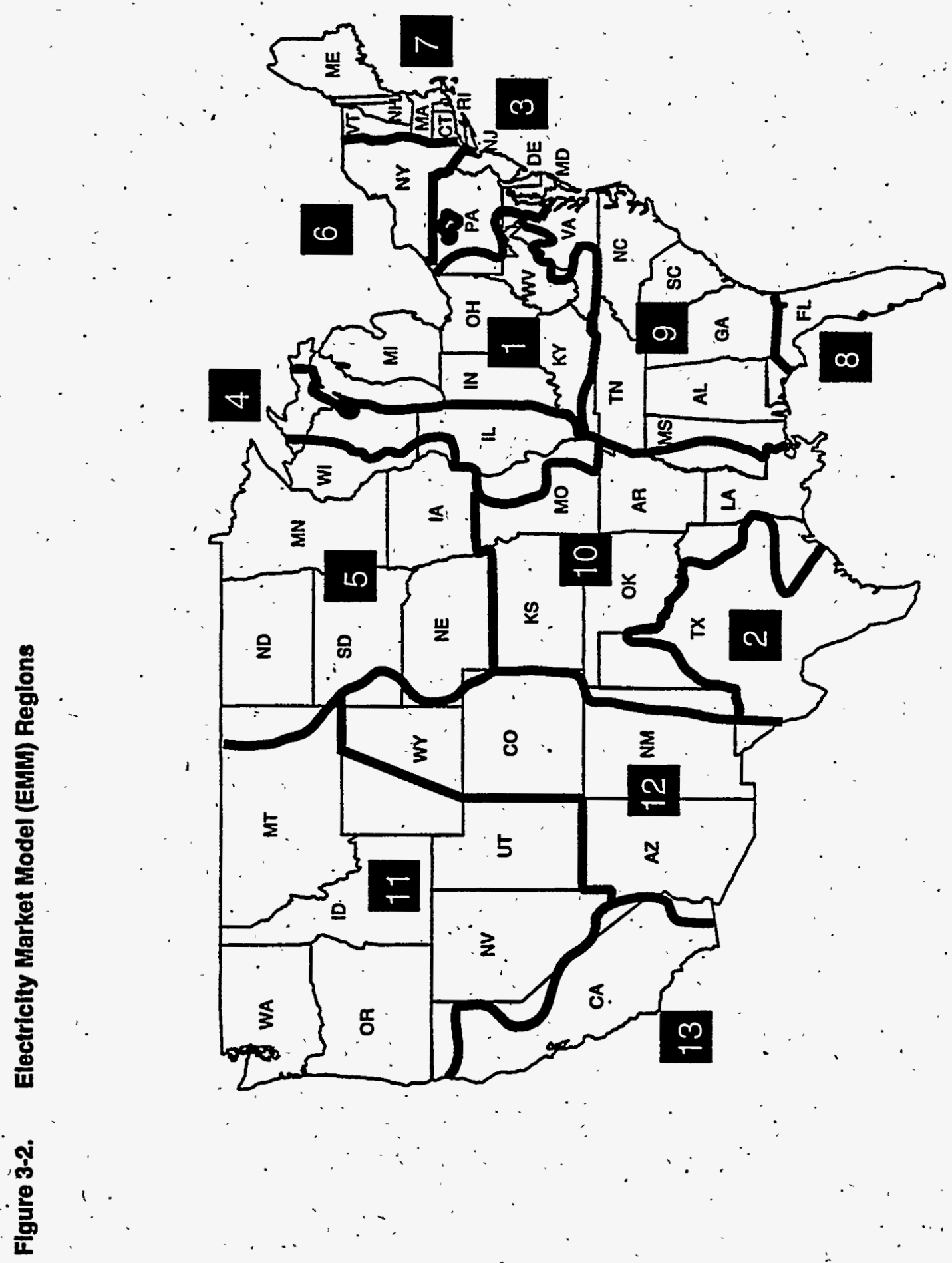


Figure 3-3. Natural Gas Transmission and Distribution Model/Electricity Market Model (NGTDMEMM) Regions

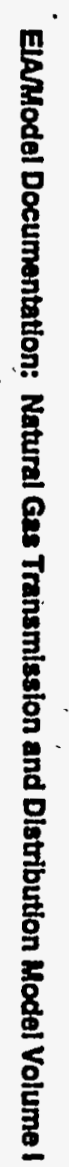

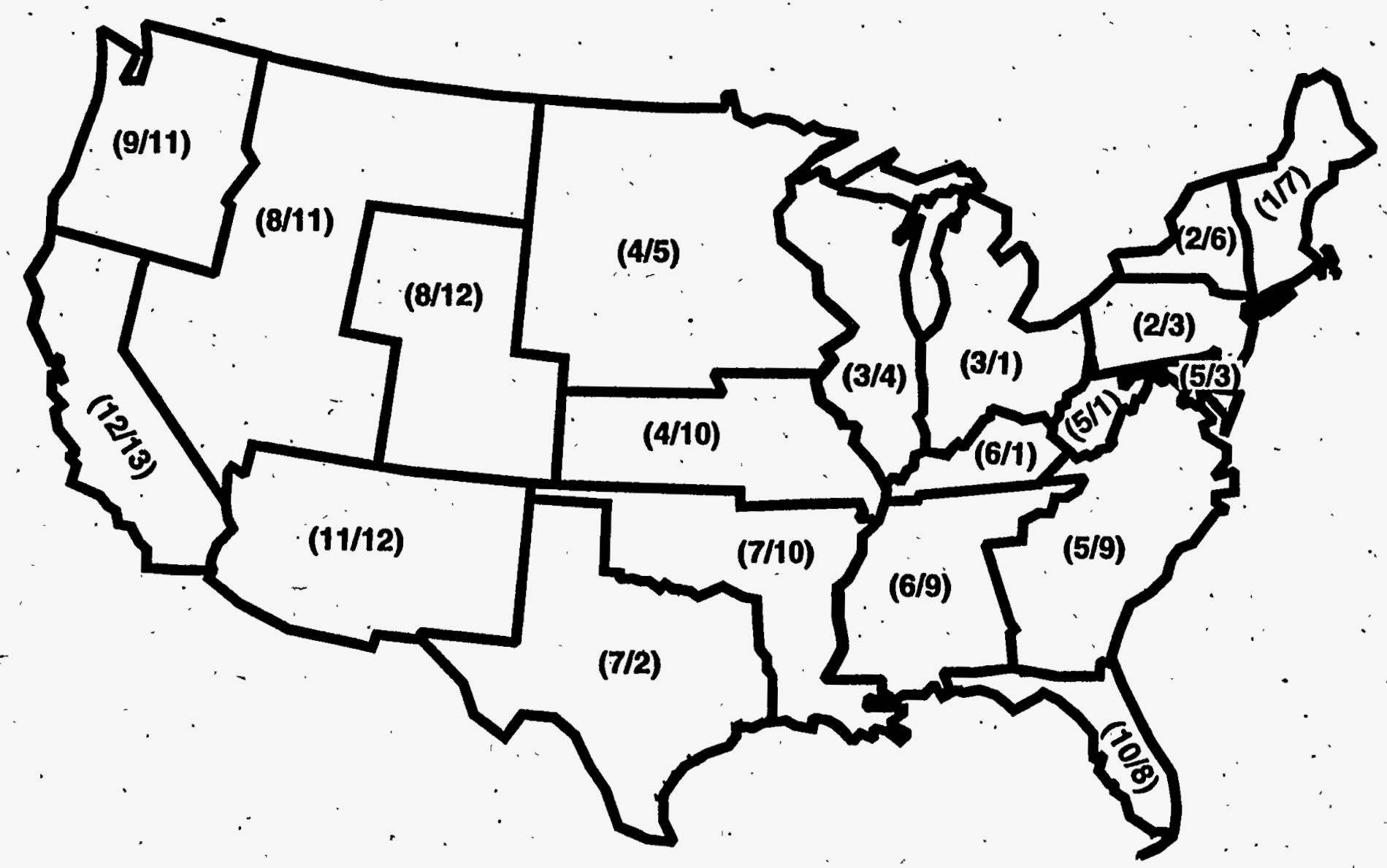

(NGTDM Region Number/EMM Region Number)

$\Phi$ 
demand curve equation to zero). These demand curves are defined within a limited range around the price/quantity pair solved for during the most recent NEMS iteration. The form of the demand curves for the firm transmission service type. for each nonelectric sector and region is:

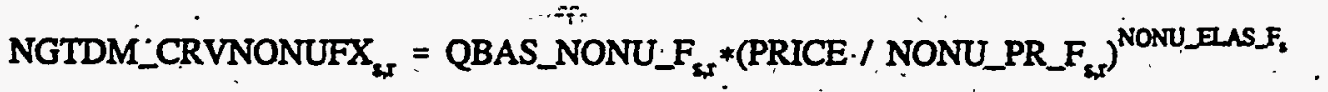

where,

$$
\begin{aligned}
& \text { NONU_PR_F } F_{2 x}=\text { end-use price to core sector } s \text { in NGTDM region } r \text { in the previous NEMS iteration } \\
& \text { (dollars per Mcf) } \\
& \text { QBAS_NONU_F } F_{\text {SS }} \quad \text { natural gas quantity which the NEMS demand models indicate would be consumed at } \\
& \text { price NONU_PR_F by core sector } s \text { in NGTDM region } r \text { (Bcf) } \\
& \text { NONU_ELAS_F }{ }_{3}=\text { short-term price elasticity of demand for core sector s (Appendix E) } \\
& \text { Note: Demand curves can be represented with fixed consumption levels by setting } \\
& \text { elasticities equal to zero. } \\
& \text { PRICE = end-use price at which demand is to be evaluated (dollars per Mct) } \\
& \text { NGTDM_CRVNONUFX }{ }_{s} \quad=\text { estimate of the natural gas which would be consumed by core sector } \mathrm{s} \text { in region } \mathrm{r} \text { at the } \\
& \text { price PRICE (Bcf) ' } \\
& s=\text { core sector (1-residential, 2-commercial, 3-industrial, 4-transportation) }
\end{aligned}
$$

The form of the demand curve for the nonelectric intermptible transmission service type is identical, with the following variables substituted: NGTDM_CRVNONUIX; NONU_PR_I, QBAS_NONU_I, and NONU_ELAS_I.

\section{Natural Gas Demand Curves for Electric Generators}

Natural gas demand by electric generators is represented somewhat differently in the NGTDM from the nonelectric demands because of greater cross price affects. Within the EMM natural gas consumption in the short-term depends first on the dispatch order of the gas burning plants, which is a function of the price of gas relative to the price of fuels burned by other powerplants, and second, on the percentage of gas used in dual-fired plants. If a change in the relative fuel prices results in a change in the dispatch order (relative to a base), the associated consumption level for natural gas burned by electric generators is likely to change as well. However, with the general exception of the competitive-withresidual fuel plant types, the gas consumption level of electric generators is unlikely to respond to changes in the gas price that do not affect the dispatch order. The dispatching of powerplants is represented in the EMM, not in the NGTDM. Therefore, in the NGTDM the gas consumption by electric generation within the core and competitive-withdistillate service types is fixed at the values calculated by the EMM in the previous NEMS iteration.

In the EMM, natural gas consumption by plants classified as competitive-with-residual fuel can change significantly in response to a different price even with no switch in the merit order (the order plants are dispatched for the generation of electricity). Consumption levels can change because these plants can switch between burning natural gas and burning residual fuel oil, which has historically been priced competitively with natural gas. A representation of the natural gas demand response within the EMM for the competitive-with-residual fuel plant types is incorporated in the NGTDM using parameters provided by the EMM. This.representation will be relatively accurate within a range of natural gas prices which do not lead to a merit order change.

Since the demand for natural gas in the competitive-with-residual fuel class within the EMM is a function of the relative price of the two competing fuels, the demand curve to represent this customer class is specified within the NGTDM as a function of the price of natural gas relative to the price of residual fuel oil to electric generators, as illustrated in Figure 3-4. For a given demand for electricity and a given dispatch order for a region within the EMM, there is a maximum (GSHRMAX) and a minimum (GSHRMIN) level of natural gas which would be consumed by the competitive-with-. residual fuel class (represented by the vertical lines in the figure). GRATMIN is the lowest price ratio which would result in a consumption level equal to GSHRMIN, and GRATMAX is the highest price ratio which would result in a consumption level equal to GSHRMAX. For each NGTDM/EMM region, the EMM provides these price/quantity pairs to the NGTDM based on the dispatch order from the current NEMS iteration. These are two of the four price/quantity pairs provided by the EMM, which the NGTDM connects to form a piece-wise linear demand curve for the competitivewith-residual fuel class within the electric generation sector. The EMM also provides the quantity of gas (GSHRPAR) 


$$
\sqrt{E}
$$


that would be consumed at the price ratio which represents parity (GRATPAR), and the quantity of gas that would be consumed at the natural gas price (converted to a price ratio in the NGTDM) which was sent to the EMM in the previous NEMS iteration (SHROLD and RATOLD). Within the NGTDM the residual fuel oil price to electric generators. (used in converting the price ratio into a natural gas price) is held constant at the level established in the previous NEMS iteration and is calculated as a quantity-weighted average of the low-sulfur and high-sulfur residual fuel prices (QRLELGR, QRHELGR) to the electric generation sector.

\section{Natural Gas Supply Interface}

The primary categories of natural gas supply represented in the NGTDM for the contiguous Lower 48 States are nonassociated and associated-dissolved gas from onshore and offshore regions, pipeline imports from Mexico and Canada, liquefied natural gas imports, gas transported via the Alaskan Natural Gas Transportation System (ANGTS), synthetic natural gas produced from coal and from liquid hydrociarbons, and other supplemental supplies. The only supply categories from this list which are allowed to vary within the NGTDM in response to a change in the current year's natural gas price are synthetic natural gas produced from liquid hydrocarbons and nonassociated gas from onshore and offshore regions. The supply levels for the remaining categories are fixed at the beginning of each forecast year.(i.e., before market clearing prices are determined), with the exception of associated-dissolved gas (determined in OGSM) which varies with a change in the oil production in the current forecast year. The annual'oil production level is determined in the Petroleum Market Model and can vary between each iteration of NEMS.

Within the OGSM, natural gas supply activities are modeled for the 12 supply regions ( 6 onshore, 3 offshore, and 3 Alaskan geographic areas) shown in Figure 3-5. A separate component of the OGSM models the foreign sources of natural gas which are transported via pipeline from Canada and Mexico, and by way of oceanic vessels in liquefied form (liquefied natural gas). Six Canadian and three Mexican border crossings demarcate the foreign pipeline interface between the OGSM and the NGTDM. Supplies from the four existing liquefied natural gas terminals are also represented (as supply points) in the NGTDM, although only two of the four existing terminals are currently in operation. The annual levels of liquefied natural gas imports are determined in the OGSM and are provided to the NGTDM at the beginning of each forecast year. Similarly the OGSM establishes the level of gas which will flow into the contiguous United States via the ANGTS.

\section{Supplemental Gas Sources}

Sources for synthetically produced natural gas are geographically specified in the NGTDM based on current plant locations. Synthetic gas from coal is exogenously specified (Appendix E, SYNCOAL5), independent of the price of natural gas in the current forecast year. The forecast represents assumed future natural gas production from the Great Plains Coal Gasification Plant in North Dakota. To represent synthetic gas production from liquid hydrocarblons (currently produced only in Illinois) a statistically estimated price responsive supply curve is incorporated within the NGTDM:

$$
\text { VAL }=\text { SNGA1 } * \text { VALUE }{ }^{\text {SNGA2 }}
$$

where,

$$
\begin{aligned}
& \text { VAL }=\text { synthetic gas production from liquid hydrocarbons in Ilinois (Bcf) } \\
& \text { VALUE = firm service natural gas market price in the East North Central Census Division (which } \\
& \text {, contains Illinois), (dollars per Mcf) } \\
& \text { SNGA1, SNGA2 = estimated parameters (Appendix F, Table F3) }
\end{aligned}
$$

- The synthetic gas production level resulting from the above equation is limited to be no less than an exogenously specified minimum (Appendix E, SNGMIN) and not to increase by more than 50 percent above the level in the previous forecast year. Synthetic gas production from liquid hydrocarbons in Hawaii is held constant throughout the forecast at 
Figure 3-5. Oil and Gas Supply Model (OGSM) Regions
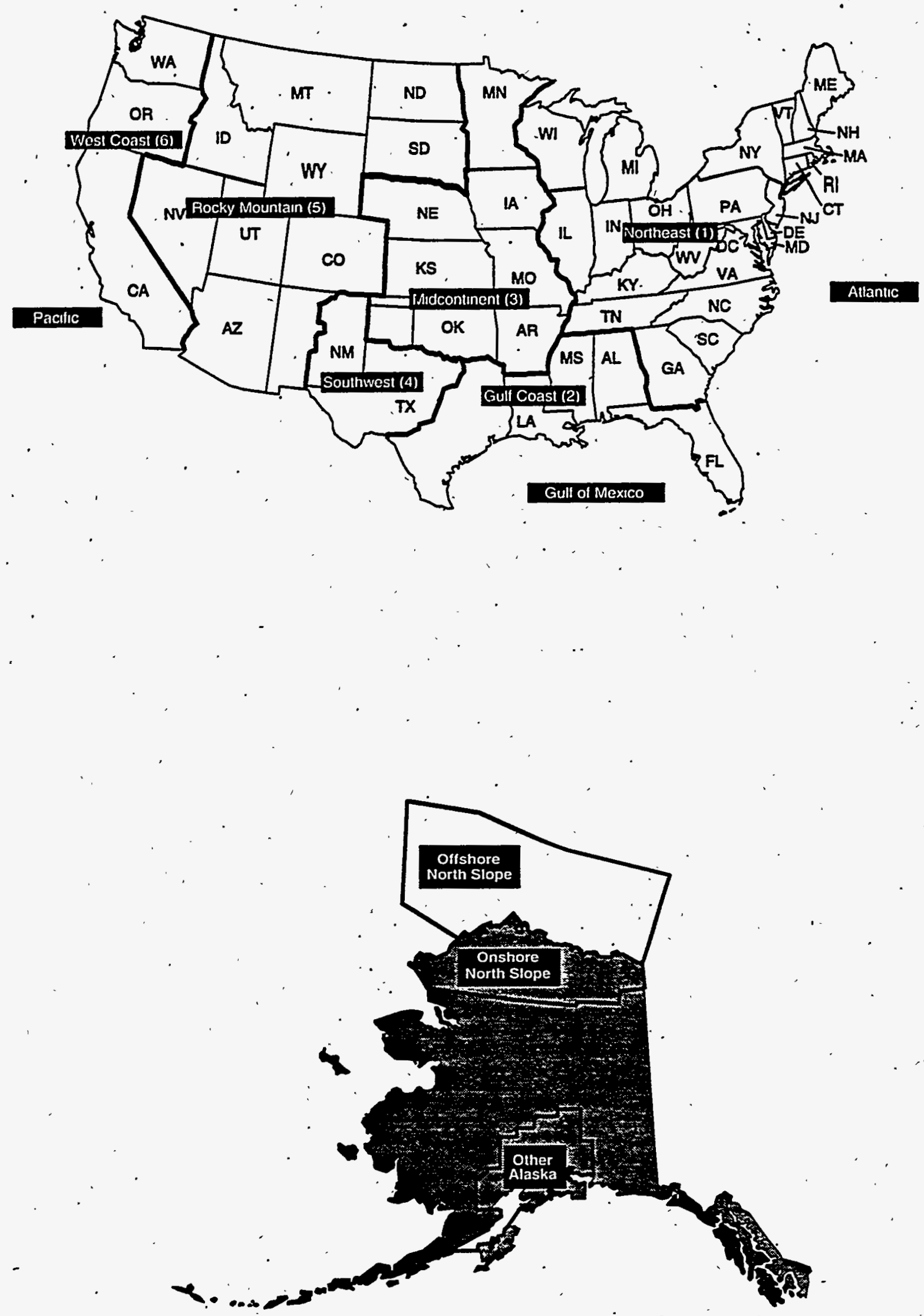
an historically based level (Appendix E, SNGHI), as are other supplemental supplies ${ }^{21}$.(Appendix E, OSUP_TOT, OSUP_RSHR).

\section{Natural Gas Imports Via.Pipeline}

The OGSM provides most of the parameters used in the NGTDM for representing the imports of gas from Mexico and Canada into the United States by pipeline. Border crossing points are established at each NGTDM region adjoining an international border. The annual import levels for gas from Mexico are generated exogenously and passed to the NGTDM via the OGSM. The OGSM also provides parameters for defining a national Canadian natural gas supply curve, an exogenous forecast for consumption of natural gas in Canada, and additional parameters for representing the transmission system for.gas within Canada. The NGTDM exogenously sets a forecast of the physical capacity of natural gas pipelines crossing the border from Canada into the United States. This physical capacity limit is then multiplied by set of exogenousiy specified utilization rates (with parameters for setting an assumed annual growth rate) to establish maximum effective capacity limits for these pipelines. "Effective capacity" is defined as the maximum annual physically sustainable capacity of a pipeline times the assumed maximum utilization rate, based on the expected seasonal demand profiles of the customers being served. The functional form of the Canadian natural gas supply curve is represented as follows:

$$
\begin{aligned}
& \text { CN_PRODUC }= \text { OGRESCAN }_{2, y} * \text { OGPRRCAN } \\
& \therefore \quad\left(1+\text { OGELSCAN }_{2,1} * \frac{\text { CN_WELPRC-CN_WPRCLAG }}{\text { CN_WPRCLAG }}\right)
\end{aligned}
$$

where,

$$
\begin{aligned}
& \text { CN_PRODUC = Canadian domestic natural gas production in year y (Bcf) } \\
& \text { OGRESCAN }_{2 y}=\text { Canadian natural gas reserves in beginning-of-year y (from OGSM in Bcf) } \\
& \text { OGPRRCAN }_{2 y} \text { = expected natural gas production-to-reserves ratio in Canada in year y (from OGSM as } \\
& \text { fraction) } \\
& \text { OGELSCAN }_{2,}=\text { estimated short run price elasticity of extraction for Canada (from OGSM). } \\
& \text { CN_WELPRC }=\text { average.Canadian wellhead price in year y (dollars per Mcf) } \\
& \text { CN_WPRCLAG = average Canadian wellhead price in year y-1 (dollars per Mcf) [for the first forecast } \\
& \text { - year this is set to CN_WELPRC89, (Appendix E)] }
\end{aligned}
$$

A limit is imposed on Canadian production (MAX_CN_PRODUC) equal to the product of OGRESCAN, OGPRRCAN, and the assumed value for PARM_MAXPR (Appendix E). The amount of natural gas available to flow into the United States from Canada is calculated as:

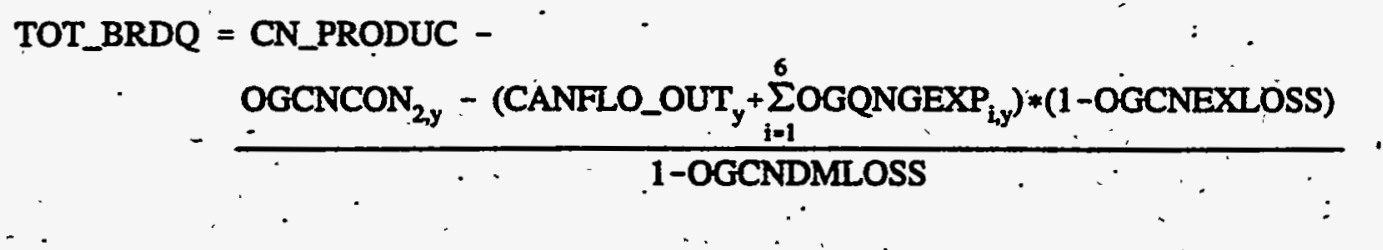

where,

$$
\begin{aligned}
& \text { TOT_BRDQ = total gas available to flow into the United States from Canada (measured at the } \\
& \text { wellhead), (Bcf) } \\
& \text { CN_PRODUC }=\text { Canadian domestic natural gas production in year } \mathrm{y}(\mathrm{Bcf}) \\
& \text { OGCNCON }_{2 y}=\text { consumption of natural gas in Canada (from OGSM in Bcf) }
\end{aligned}
$$

\footnotetext{
${ }^{-21}$ Other supplemental supplies include propane-air, refinery gas, coke oven gas, manufactured gas, biomass gas, and air injection
} for Btu stabilization. 


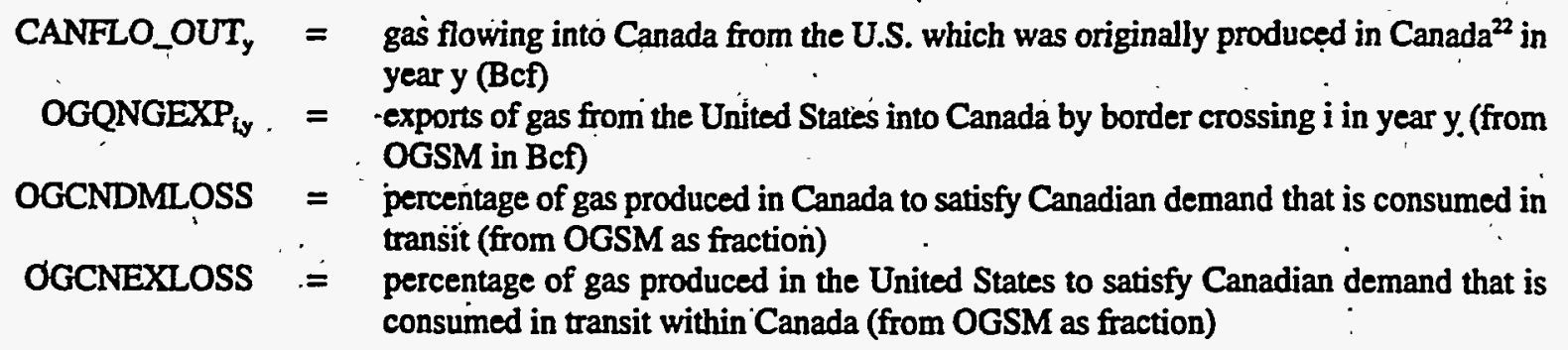

This formulation is based on an allocation method presented in the SRI-GÜLF Energy Model by Decision Focus Incorporated. If the value of TOT_BRDQ exceeds the total effective capacity of the natural gas pipelines used to flow gas into the United States from Canada, then it is assumed that the share of TOT_BRDQ which will flow across each of the representative border crossings in the model (CN_FLOSHR) will be equivalent to that border crossing's share of the total effective capacity. Under most likely model scenarios this has been shown to be true through the 2020 time frame. However, if available Canadian supplies are less than total effective pipeline capacity across the border, the allocation of TOT_BRDQ to each of the six border crossings is calculated as follows:

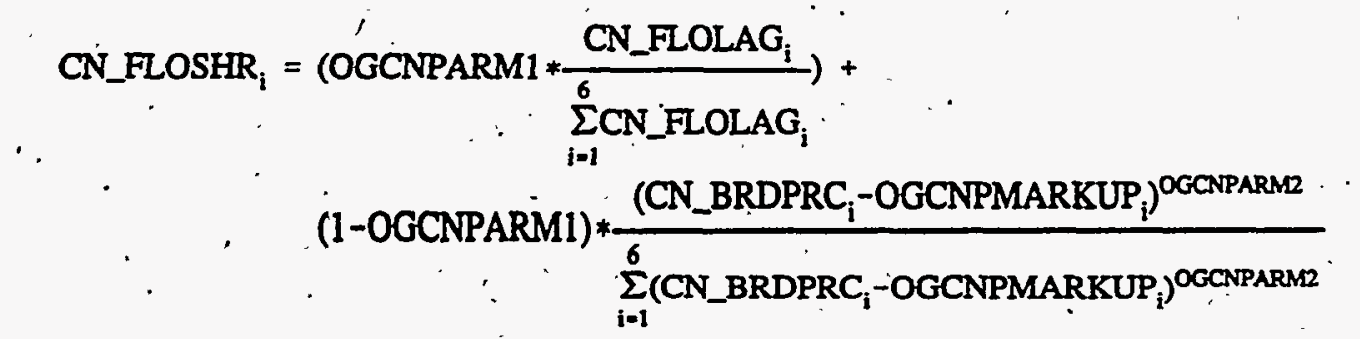

where,

$$
\begin{aligned}
& \text { CN_FLOSHR }=\text { the share of the gas available to flow from Canada into the United States to flow across } \\
& \text { border crossing i (fraction) } \\
& \text { CN_FLOLAG }=\text { the amount of gas which flowed from Canada into the United States across border } \\
& \text { crossing } i \text { in the previous year. (adjusted for pipeline additions? in year } y \text { ), (Bcf) } \\
& \text { OGCNPARMI = parameter which reflects the importance of the historical flow pattern in the } \\
& \text { determination of actual allocation of gas (from OGSM, } 0<\text { OGCNPARM1 }<1 \text { ) } \\
& \text { OGCNPARM2 = parameter which reflects the responsiveness of the flow pattern to differentials in } \\
& \text { border prices netbacked to the wellhead (from OGSM, OGCNPARM2 =1) } \\
& \text { CN_BRDPRC } C_{1}=\text { the market price at border crossing } \mathrm{i} \text { (dollars per Mcf) } \\
& \text { OGCNPMARKUP }_{\mathrm{i}}=\text { assumed markup from the average Canadian wellhead price to border crossing } \mathrm{i} \text { (from } \\
& \text { OGSM in dollars per Mcf) }
\end{aligned}
$$

If the resulting shares indicate flow levels across some border crossings which exceed their maximum effective capacity level, then the "unflowable" portion is made available at border crossings with available pipeline capacity, and, the values for the variable CN_FLOSHR are adjusted accordingly. These shares are ultimately used in the calculation of the Canadian wellhead price:

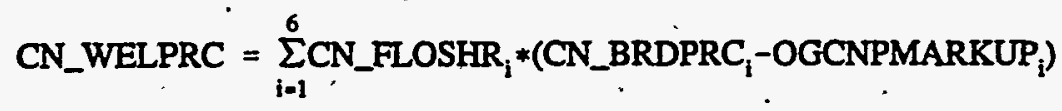

where,

$$
\text { CN_WELPRC = Canadian wellhead price (dollars per Mct) }
$$

\footnotetext{
${ }^{22} \mathrm{~A}$ significant amount of natural gas flows into Minnesota from Canada on an annual basis only to be routed back to Canada through Michigan.(and a very small amount through Montana). The amount of gas entering the United States that is not imported from Canada, and the percentage of this amount which travels back through Michigan, are set at exogenously specified levels for the forecast (Appendix E-CANFLO_IN, CANFLO_SHR).

${ }^{22}$ The 1990 capacity additions for the Canadian import ares are specified exogenousiy (Appendix E, CN_NEWCAP90).
} 


\section{CN_FLOSHR $\mathrm{i}_{\mathrm{i}}=$ the share of the gas available to flow from Canada into the United States to flow across border crossing $\mathfrak{i}$ (fraction') \\ $\mathrm{CN}_{2} \mathrm{BRDPRC}_{\mathrm{i}}$. = the market price at border crossing $\mathrm{i}$ (dollars per-Mcf) \\ OGCNPMARKUP $_{\mathbb{1}}$ = assumed markup from the average Canadian wellhead price to border crossing $\mathrm{i}$ (from OGSM in dollars per Mcf)}

The system of equations which represents the pricing and flow of gas from Canada into the United States.can not be solved in a top/down fashion; but requires an iterative process due to the interrelationships involved. Furthermore, the solution algorithm used within the NGTDM requires prespecified supply curves (or fixed supply levels) at each border crossing before solving. A short-term supply curve is generated for a single border crossing point, through the use of the equations shown above, by holding the border prices for the other crossing points at their solution values from the previous NEMS iteration (or the previous year, in the first iterátion). ${ }^{24}$

\section{Supply Curves for Domestic Dry Gas Production}

Most of the parameters for generating short-term supply curves for dry natural gas production are provided to the NGTDM by the OGSM. The six onshore OGSM regions within the contiguous United States. do not generally share common borders with the NGTDM regions. As was done with the EMM regions, the NGTDM represents onshore supply for the 17 regions resulting.from overlapping the OGSM and NGTDM regions (Figure 3-6).

These supply curves are defined as being net of lease and plant fuel consumption (i.e., the amount of dry gas available for market after any necessary processing and before being transported via pipeline). Within the NGTDM, dry gas production is delineated by two categories, nonassociated and associated-dissolved. Nonassociated gas is largely defined as gas that is produced from gas wells, and is assumed to vary in response to a change in the natural gas price. Whereas, associated-dissolved gas is defined as gas that is produced from oil wells, and can be classified as a byproduct in the oil production process.

Total domestic natural gas production is the sum of nonassociated and associated-dissolved production. Associateddissolved gas production is provided by OGSM for the 17 NGTDM/OGSM onshore regions and the 3 offshore regions, while production parameters are provided by OGSM for the NGTDM to generate nonassociated gas production curves for the same regions. Within the NGTDM, total natural gas production curves are generated by adding the associateddissolved production to the nonassociated gas production curves, effectively shifting the production curves to the right along the quantity axis. ${ }^{25}$

The NGTDM includes the option of selecting one of three different functional forms for the supply curve for nonassociated dry natural gas production (net of lease and plant fuel) in the domestic onshore and offshore regions. All three forms are constructed from a common key point (or price/quantity pair) which is based on an expected extraction rate, estimated in the OGSM. The "expected" or-base production level from an onshore region is calculated as follows:

- BASE_ $_{\mathrm{r}}=$ OGRESNGON $_{\mathrm{r}} *$ OGPRRNGON $_{\mathrm{r}} *$ PER

where,

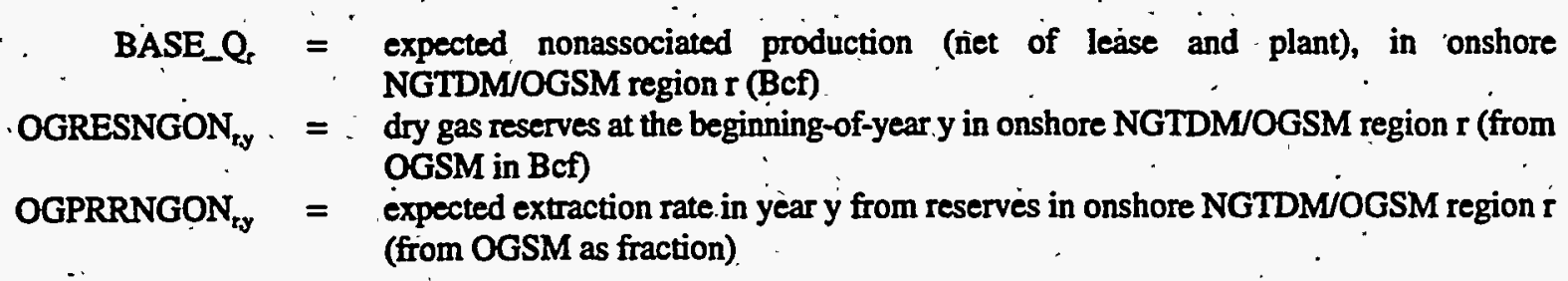

${ }^{24}$ An initial value is exogenously specified for CN_BRDPRC (Appendix E, CN_BRDPRC90).

${ }^{25}$ For convênience in the code, the synthetic production of gas from coal is similarly added to the total production curve. 

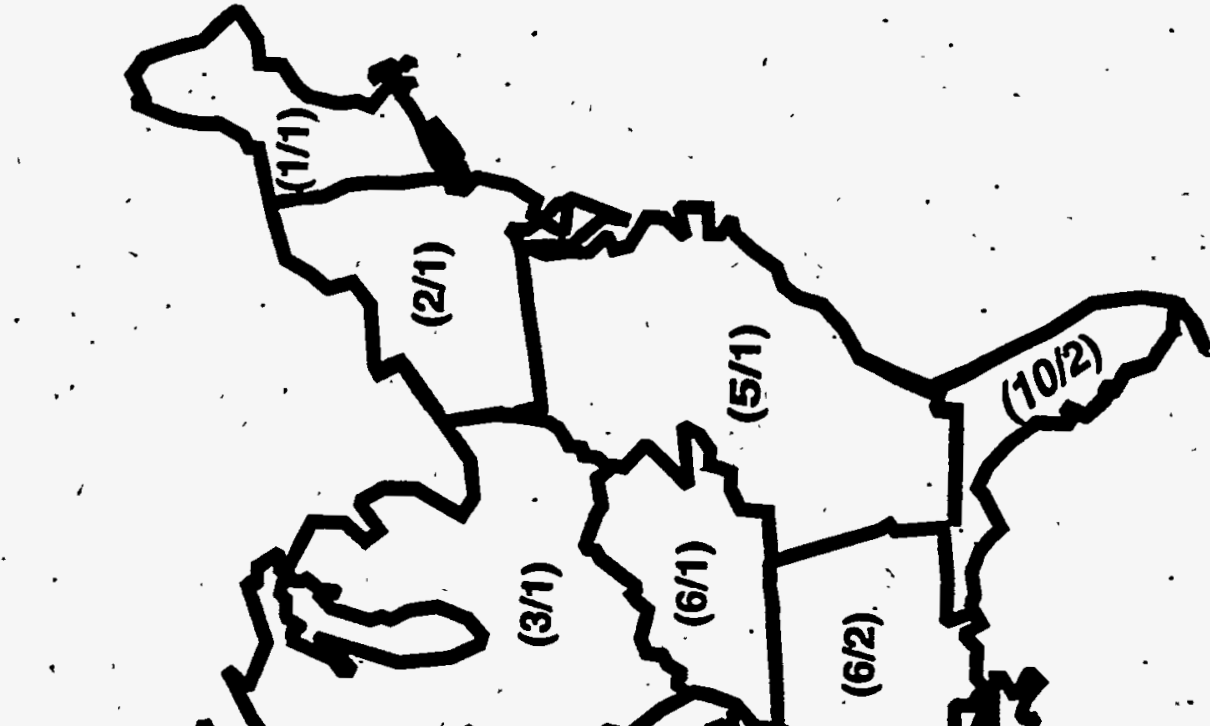


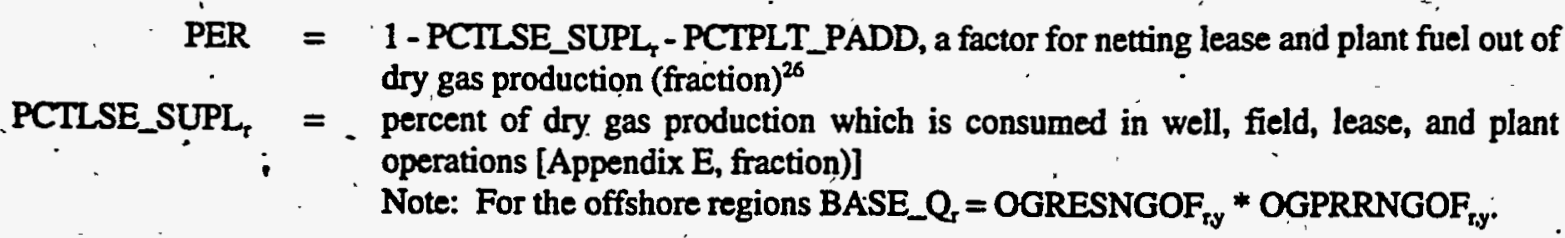

The price (BASE_P) associated with BASE_Q is a function of the previous year's wellhead price ${ }^{27}$ and a multiplicative benchmark factor (PSHIFT_SCALE). The benchmark factor is used to calibrate the model to an historical (or forecasted, as represented in the Short-Term Energy Outlook (STEO)) national average natural gas wellhead price. ${ }^{23}$ This benchmark factor represents the ratio between the national average. wellhead price solved by the model and the corresponding historical or STEO wellhead price. It is endogenously defined within the NGTDM. The portion of the factor attributable to STEO calibration is phased out over a five to ten year period (Appendix E, STPHAS_YR). The amount the production will vary from BASE_Q is a function of how different the wellhead price (at which the function is being evaluated) is from BASE_P. The calculation of the additional quantity of production (DEL_Q_) ${ }^{29}$ which would result at a given wellhead price (VALUE) is different under each of the three options..$^{30}$. Options one and two are presented below, with option 3 following.

Option 1

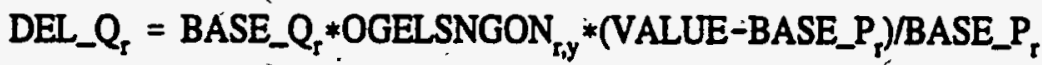

where,

OGELSNGON $\because=$, estimated short-term price elasticity (from OGSM), for offshore regions the variable OGELSNGOF is used

Option 2:

$$
D E L \_Q_{r}=B A S E \_Q_{r} * E L A S *\left(V A L U E-B A S E \_P_{r}\right) / B A S E \_P_{s}
$$

where,

If VALUE $\geq$ BASE_P $n$ ELAS $=$ PARM_SUPCRV2 $2_{1}$, (short-term price elasticity 1 , Appendix E)

If VALUE $<$ BASE_P $r$ ELAS $=$ PARM_SUPCRV2, $2_{2}$ (short-term price elasticity 2, Appendix E)

Option 1 is symmetric for price increases and decreases. Option 2 assumes production responds more strongly to price declines than to increases. The justification for incorporating a different elasticity above and below the "expected" production level on the supply curve is that producers have a vested interest in selling close to their planned for or expected production level. Much lower than anticipated gas sales do not allow the producer the necessary cash flow to stay in business. In such cases, prices would be lowered enough to increase sales and resulting revenues. However, there are practical upper limits on the rates of extraction from reserves, causing an upward push on the price when there are market pressures to produce at elevated extraction rates.

Option 3 is a combination of Options 1 and 2. In a close range around the base point (plus or minus an assumed percentage -PARM_SUPCRV $3_{1}$ - of the base quantity), the short-term wellhead price elasticity (PARM_SUPCRV3 ${ }_{2}$ ) does not change from one side of the base point to the other (as in Option 1), but is assumed to be highly inelastic.

\footnotetext{
${ }^{26}$ In previous versions of the model lease and plant fuel factors were represented in separate variables. In the AEO98 version of the NGTDM the PCTLSE_SUPL variable accounts for both lease and plant fuel consumption and the PCTPLT_PADD variable is set to zero.

${ }^{27}$ For the first forecast year, the value for BASE_P is set to the 1989 national average wellhead price (Appendix E -.WPRLAGON, WPRLAGOF).

${ }^{25}$ For the $A E O 98$ reference case, the 1997 and 1998 model results were calibrated to the natural gas wellhead price published in the Short-Term Energy Outlook (3rd Quarter), DOE/EIA-0202(97,3Q), September update.

${ }^{2}$ If DEL_Q is negative, the resulting production level will be less than BASE_Q

${ }^{30} \mathrm{~A}$ model user can select one of the three functional forms for the supply curves by setting the variable TYP_SUPCRV equal to either 1,2, or 3, accordingly. For.generating the forecast published in the Aninual Energy Outlook 1998, option 3 was selected.
} 
Outside of this range, the short-term price elasticities are set to the same values used under Option 2. However, these segments of the curve are shifted (left, below the base price, and right, above the base price) to intersect the end points of the segment of the curve running through the base point, as follows:

\section{Option 3}

$$
\left.D E L \_Q_{t}=\left(B A S E_{\perp} Q_{r} * P A R M\right)+(1+P A R M) * \text { BASE_Q }_{r} * E L A S * \frac{(\text { VALUE-BASE_P }}{r}\right)
$$

where,

If VALUE is within the range BASE_P \pm (BASE_P ${ }_{r} *$ PARM_SUPCRV $3_{1} /$ PARM_SUPCRV $3_{2}$ )

PARM $=0$.

ELAS = PARM_SUPCRV3 ${ }_{2}$

If VALUE is greater than BASE_P $+\left(B A S E \_P_{r} *\right.$ PARM_SUPCRV $3_{1} /$ PARM_SUPCRV $_{2}$ )

PARM = + PARM_SUPCRV3,

ELAS = PARM_SUPCRV2

If VALUE is less than BASE_P $-\left(B A S E \_P_{t} *\right.$ PARM_SUPCRV $3_{1} /$ PARM_SUPCRV $\left.3_{2}\right)$

PARM = -PARM_SUPCRV $3_{1}$

ELAS $=$ PARM_SUPCRV2 2

The assumed values for all of the parameters and elasticities shown above are referenced in Appendix E. Figure 3-7 graphically depicts an' example of how a region's supply curve would appear under each of the three options.

After establishing a value for DEL_Q $Q_{r}$ for a specified wellhead price in a given region, the corresponding total dry gas production would be calculated as:

NGPRD_LA8 $=$ BASE_Q $Q_{\mathrm{r}}+$ DEL_Q $\mathrm{Q}_{\mathrm{r}}+\left(\left(\right.\right.$ ADGPRDON $_{\mathrm{r}}+$ OGCCAPPRD $\left._{\mathrm{r}}\right) *$ PER $)$

where,

\footnotetext{
NGPRD_L48 $={ }^{*}$. dry gas production in onshore NGTDM/OGSM region $\mathrm{r}$ (BCF)

OGCCAPPRD $=$ dry gas production in onshore NGTDM/OGSM region $\mathrm{r}$ attributable to the Climate Change Action Plan's coalbed methane outreach program, as set in OGSM (BCF)
}

For an offshore region, the corresponding variables used in the code are NGPRD_OCS and ADGPRDOF (with PER set to 1).

For control purposes, upper and lower limits are placed on the nonassociated dry gas production levels established within the NGTDM. The lower and upper limits imposed on nonassociated gas production in each NGTDM/OGSM onshore and offshore region are BASE_Q times PARM_MINPR and PARM_MAXPR, respectively (Appendix E).

\section{Alaskan Natural Gas Module}

The NEMS demand models provide a forecast of natural gas consumption for the total Pacific Census Division, which includes Alaska. Currently natural gas which is produced in Alaska cannot be transported to the Lower 48 States via pipeline. Therefore, the production and consumption of natural gas in Alaska is handled separately within the NGTDM from the contiguous States. Estimates of contiguous Pacific Division consumption levels are derived within the NGTDM by first estimating Alaskan natural gas consumption for all sectors, and then subtracting these from the core market consumption levels in the Pacific Division provided by the NEMS demand models. The use of natural gas in compressed natural gas vehicles in Alaska is assumed to be negligible. The consumption of gas by Alaskan residential customers is a function of a forecast for the number of customers (exogenously derived): 


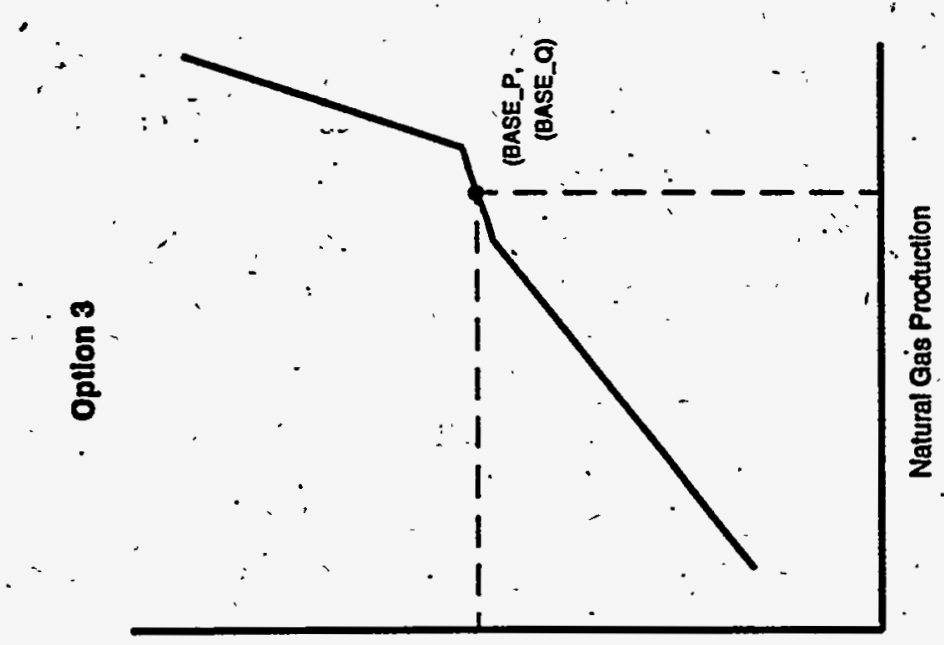

OONd PEQYIIEM SES REIMEN

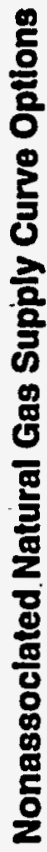

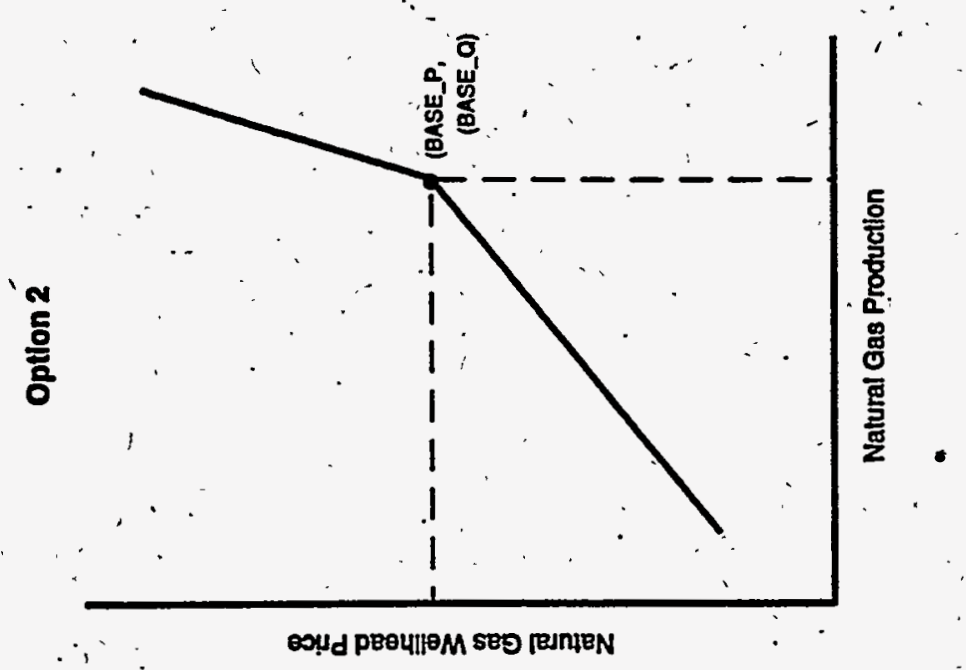

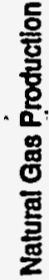
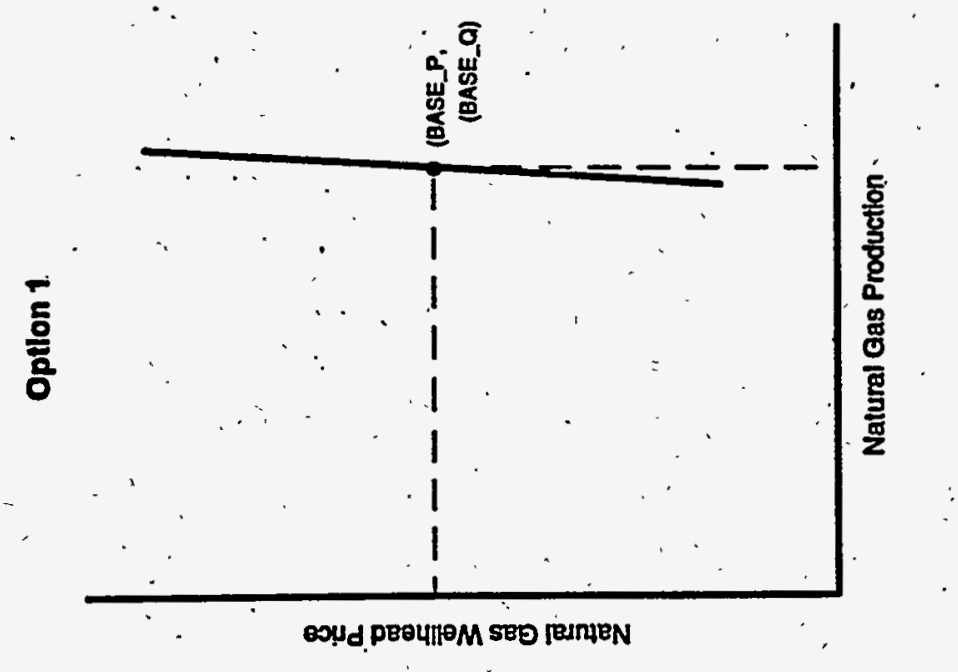
(res): QALK_NONU_F $=\operatorname{EXP}\left(A K_{-} \_C_{1}\right) * A K \_R N_{y}^{A K} C_{2} / 1000 . \cdots \quad: \quad \cdot$

where,

QALK.

QALK_NONU_F $=$ consumption of natural gas by residential ( $d=1$ ) customers in Alaska (Bcf)

AK_C = estimated parameters for residential consumption equation (Appendix $F$, Table $F 1$ )

$A K \_R N_{y}=$ number of residential customers (exogenously specified, Appendix F, Table F2)

Gas consumption by Alaskan commercial customers is a function of the previous year's consumption level and the number of commercial customers in the current and previous forecast year, as follows:

(com):

$$
\begin{aligned}
& \text { QALK_NONU_F } F_{d}=\operatorname{EXP}\left(A K \_D_{1}\right) *\left(1000 . * P R E V \_Q A L K_{z y-1}\right){ }^{A K} \_D_{z_{*}} \\
& \text {. } A K \_C N_{y}^{A K D D_{3}} * A K \_C N_{y-1}^{A K D} D_{4} / 1000 \text {. }
\end{aligned}
$$

where,

$$
\begin{aligned}
& \text { QALK_NONU_F } F_{d}=\text { consumption of natural gas by commercial }(\mathrm{d}=2) \text { customers in Alaska in the current } \\
& \text { forecast year (Bcf) } \\
& \text { PREV_QALK }=\text { consumption of natural gas by commercial }(d=2) \text { customers in Alaska in the previous } \\
& \text { forecast year (Bcf) } \\
& \text { AK_D = estimated parameters for commercial consumption equation (Appendix F, Table F1) } \\
& \mathrm{AK}_{\mathrm{CN}} \mathrm{y}=\text { number of commercial customers (exogenously specified, Appendix F, Table F2) }
\end{aligned}
$$

Gas consumption by Alaskan industrial customers is a function of time and the level of industrial consumption in the previous forecast year, as follows:

$$
\begin{aligned}
\text { QALK_NONU_F } & \left(\operatorname{EXP}\left(A K_{d} E_{1}\right) *\left(1000 * \operatorname{PREV}_{\text {QALK }_{d y-1}}\right)^{A K E_{2}} *\right. \\
& \left.T^{A K E_{3}} *(T-1)^{A K E_{4}}\right) / 1000 .
\end{aligned}
$$

where,

$$
\begin{aligned}
& \text { QALK_NONU_F }=\text { consumption of natural gas by industrial customers }(d=3) \text {, (Bcf) } \\
& \text { PREV_QALK }=\text { consumption of natural gas by industrial }(d=2) \text { customers in Alaska in the previous } \\
& \text { forecast year (Bcf) } \\
& A K \_E=\text {. estimated parameters for industrial consumption equation (Appendix F, Table F1) } \\
& \mathrm{T}=\text { time parameter, where } \mathrm{T}=1 \text { for } 1969 \text { (the first historical data point) and } \mathrm{T}=\mathrm{CNTYR}+21 \\
& \text { in forecast year CNTYR (where CNTYR equals } 1 \text { for 1990). }
\end{aligned}
$$

At a sectoral level, Alaskan consumption is disaggregated into the total delivered to customers in South Alaska • (AK_CONS_S) versus a North Alaska (AK_CONS_N) total using historically derived shares (Appendix E, AK_PCTSOUTH). This distinction is needed for the derivation of natural gas production forecasts for the north and south regions [not accounting for the additional production necessary should the Alaskan Natural Gas Transportation System (ANGTS) open], as follows:

$$
\begin{aligned}
& \text { (S. AK): AK_PROD }{ }_{r=1}=\frac{\text { (EXPJAP+AK_CONS_S-AK_DISCR) }}{\left(1-\text { AK_PCTLSE }_{r=1}-\text { AK_PCTPLT }_{r=1}-\text { AK_PCTPIP }_{r=1}\right)}
\end{aligned}
$$

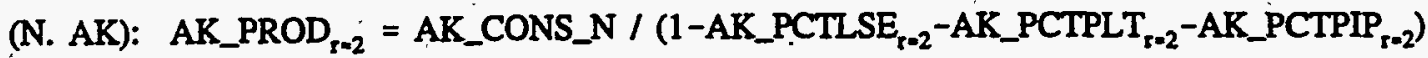

where,

AK_PROD $\mathrm{r}=$ dry gas production in South $(r=1)$ or North $(r=2)$ Alaska (Bcf)

AK_CONS_S $=$ total gas consumption by customers in South Alaska (Bcf)

AK_CONS_N $=$ total gas consumption by customers in North Alaska (Bcf)

EXPJAP = quantity of gas liquefied and exported to Japan (from OGSM in Bcf) 


$\begin{aligned} \text { AK_DISCR }= & \begin{array}{l}\text { Discrepancy, the historically based difference in reported supply levels and } \\ \text { consumption levels in Alaska (Bcf) }\end{array} \\ \text { AK_PCTLSE } & =\begin{array}{l}\text { assumed percent of gas production which is consumed in lease operations in region } r \\ \text { (fraction) }\end{array} \\ \text { AK_PCTPLT } & =\begin{array}{l}\text { assumed percent of gas production which is consumed in plant operations in region r } \\ \text { (fraction) }\end{array} \\ \text { AK_PCTPIP } & =\begin{array}{l}\text { assumed percent of gas production which is. consumed as pipeline fuel in region } r \\ \text { (fraction) }\end{array}\end{aligned}$

The forecast values for the variable for AK_DISCR are set at the value from the last historical year with data available (Appendix E). The variables' for AK_PCTLSE, AK_PCTPLT, and AK_PCTPIP are based on historical percentages (Appendix E) and are held constant throughout the forecast, with the exception that PCTLSE is decreased by 50 percent should ANGTS become fully operational. (These variables are also used to estimate the consumption levels for pipeline fuel and lease and plant fuel in Alaska.) The OGSM provides a forecast of natural gas exports to Japan, the level of flow through ANGTS which would reach the contiguous U.S. border when and if it is connected, and the maximum production level for South Alaska (currently used only as a verification check in the NGTDM). The production of natural gas in Alaska which is necessary to support ANGTS (AK_PROD ${ }_{r=3}$ ) is derived in the NGTDM using the flow level at the border established in OGSM, and assumed values for PCTLSE, PCTPLT, and PCTPIP related to production to be marketed via ANGTS.

Estimates for natural gas wellhead and end-use prices in Alaska are roughly estimated in the NGTDM for proper accounting, but have a very limited impact on the NEMS system. The average Alaskan wellhead price over the North and South regions (not accounting for the impact should ANGTS be connected) is calculated as:

$$
A K \_W P R C=\left(A K \_F_{1} * W P R L A G\right)+\left(A K \_F_{2} *\left(A K \_C O N S \_S+A K \_C O N S \_N\right)\right)
$$

where,

$$
\begin{aligned}
\text { AK_WPRC } & =\text { average Alaskan natural gas wellhead price (dollars per Mcf) } \\
\text { AK_CONS_S } & =\quad \text { total gas consumption by customers in South Alaska (Bcf) } \\
\text { AK_CONS_N } & =\text { total gas consumption by customers in North Alaska (Bcf) } \\
\text { WPRLAG } & =\begin{array}{l}
\text { average Alaskan natural gas wellhead price in previous forecast year (dollars per Mcf) } \\
\text { [the } 1989 \text { value used in forecast year } 1990 \text { is WPR89, Appendix E] }
\end{array} \\
\text { AK_F } & =\text { estimated parameters (Appendix F, Table F1) }
\end{aligned}
$$

However, if ANGTS is connected, the wellhead price in North Alaska is overwritten to be equal to the price at the U.S./Canadian border crossing point, most representative of where ANGTS will connect, plus an assumed markup (Appendix E, ANGTS_TAR). With the exception of the industrial sector, end-use prices are set equal to the average wellhead price resulting from the equation above plus a fixed markup (Appendix E - AK_RM, AK_CM, AK_EM). The Alaskan industrial sector price is calculated as:

$$
\text { PALK_NONU_F }=A R_{s} G_{1}+\left(A K \_G_{2} * \text { WOPCUR }\right)
$$

where,

$$
\begin{aligned}
\text { PALK_NONU_F } & =\text { price of natural gas to Alaskan industrial customers (s=3), (dollars per Mcf) } \\
\text { WOPCUR } & =\text { landed price of crude oil in current forecast year (dollars per, barrel) } \\
\text { AK_G } & =\text { estimated parameters (Appendix F, Table F1) }
\end{aligned}
$$

Historically, the industrial price was shown to vary more in response to the crude oil price and much less in response to the natural gas wellhead price. 


\section{Overview of Solution Methodology.}

The previous chapter described the function of the NGTDM within the NEMS. This chapter will present an overview of the NGTDM model structure and of the methodologies used to represent the natural gas transmission and distribution industries. First, a detailed description of the network used in the NGTDM to represent the U.S. natural gas pipeline system is presented. Next, a general description of the interrelationships between the modules within the NGTDM is presented, along with an overview of the solution methodology used by each module.

\section{NGTDM Regions and the Pipeline Flow Network}

\section{General Description of the NGTDM Network}

In the NGTDM, a transmission and distribution network (Figure 4-1) simulates the interregional flow of gas in the contiguous United States. This network is a simplified representation of the physical natural gas pipeline system and establishes the possible interregional transfers to move gas from supply sources to end-users. Each NGTDM region contains one transshipment node- a junction point representing flows coming into and out of the region. Nodes have also been defined at the Canadian and Mexican borders. Ares connecting the transshipment nodes are defined to represent flows between these nodes; and thus, to represent interregional flows. Each of these interregional arcs represents an aggregation of pipelines that are capable of moving gas from one region into another region. Bidirectional flows are allowed in cases where the aggregation includes some pipelines flowing one direction and other pipelines flowing in the opposite direction. ${ }^{31}$ Bidirectional flows can also be the result of directional flow shifts within a single pipeline system due to seasonal variations in flows.

Flows are further represented by establishing ares from the transshipment node to each demand sector/subregion represented in the NGTDM region. A demand group in a particular NGTDM region can only be satisfied by gas flowing from that same region's transshipment node. Similarly, ares are also established from supply points into transshipment nodes. The supply from each NGTDM/OGSM region is directly available to only one transshipment node, through which it must first pass if it is to be made available to the interstate market (at an adjoining transshipment node).

Figure 4-2 shows an illustration of all possible flows into and out of a transshipment node. Each transshipment node has one or more arcs to represent flows from or to other transshipment nodes. The transshipment node also has an arc representing flow to each end-use sector in the region (residential, commercial, industrial, electric generators, and transportation), including separate arcs to each electric generator subregion. Arcs are also established from nodes at the international borders to represent exports. Each transshipment node has one or more arcs flowing in from each supply source represented. These supply points may represent onshore or offshore production, liquefied natural gas imports, synthetic natural gas production, gas produced in Alaska and transported via the Alaska Natural Gas Transportation System, or Canadian or Mexican imports in the region. In addition, each onshore supply region also includes any synthetic natural gas produced from coal, as well as other supplemental supplies. Finally, annual net underground storage withdrawals, transported under firm and interruptible service, are accounted for at each transshipment node. Also accounted for but not presented in Figure 4-2 are discrepancies (i.e., historically observed differences between independently reported natural gas supply and disposition levels).

Once-all of the types of end-use destinations and supply sources are defined for each transshipment node; a general network structure results. Each transshipment node does not necessarily have all supply source types flowing in, or all demand source types flowing out. For instance, the transshipment nodes at the Canadian border may only have Canadian supply defined going into the node. Also, some transshipment nodes will have liquefied natural gas available while others will not. The specific end-use sectors and supply types specified for each transshipment node in the network are

\footnotetext{
${ }^{31}$ Historically, one out of each pair of bidirectional ares in Figure 4-1 represents a relatively small amount of gas flow during the year. These arcs are referred to as "the bidirectional ares" and are identified as going from 9 to 8,11 to 8,4 to 8,11 to 7,4 to 7,3 to 4,5 to 6,5 to 3,2 to 3,2 to 5,6 to 7, and 1 to 2 . Minimum flows constraints are established for these ares at historically observed flow levels.
} 


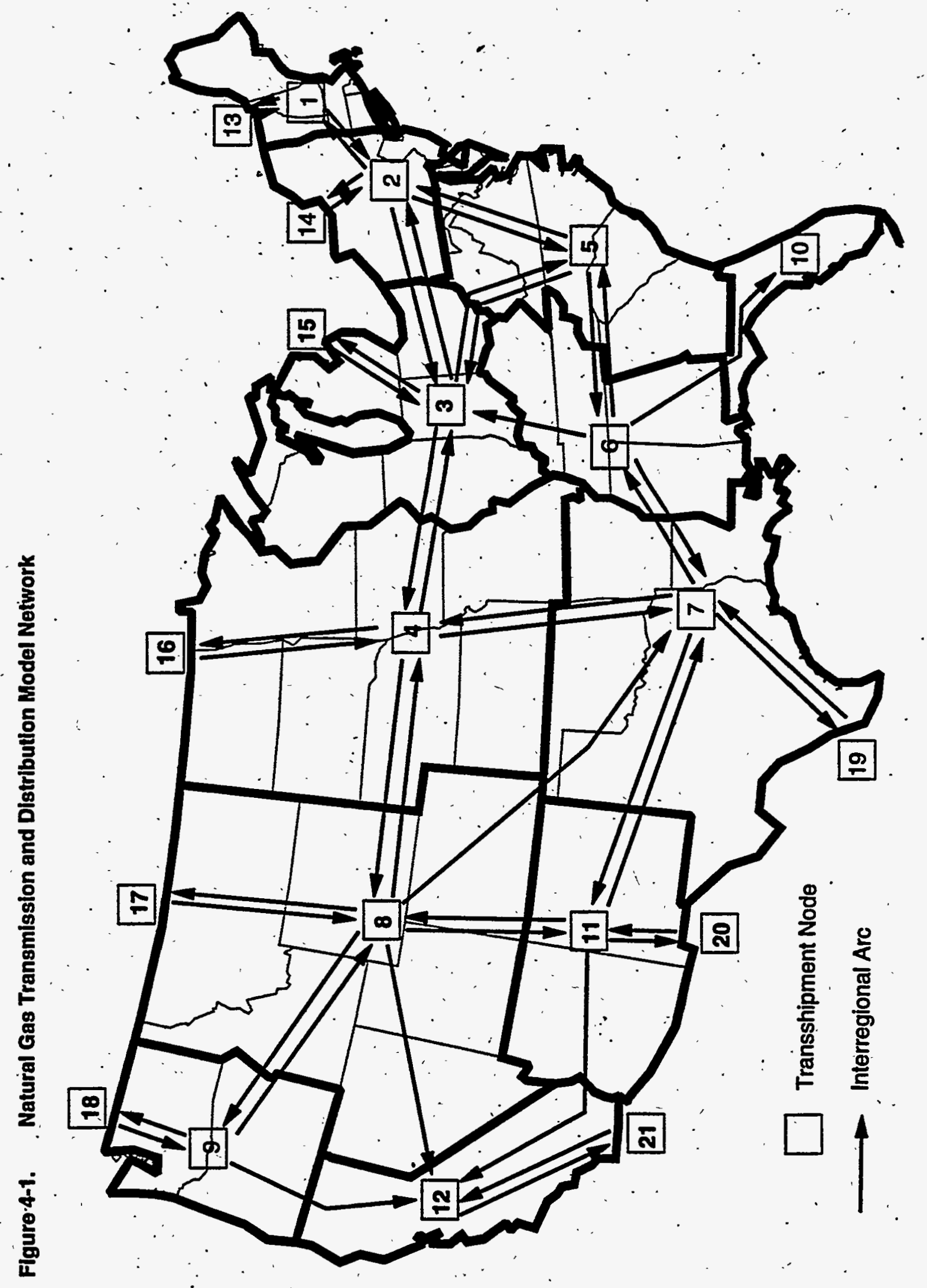


Figure 4-2. Transshipment Node

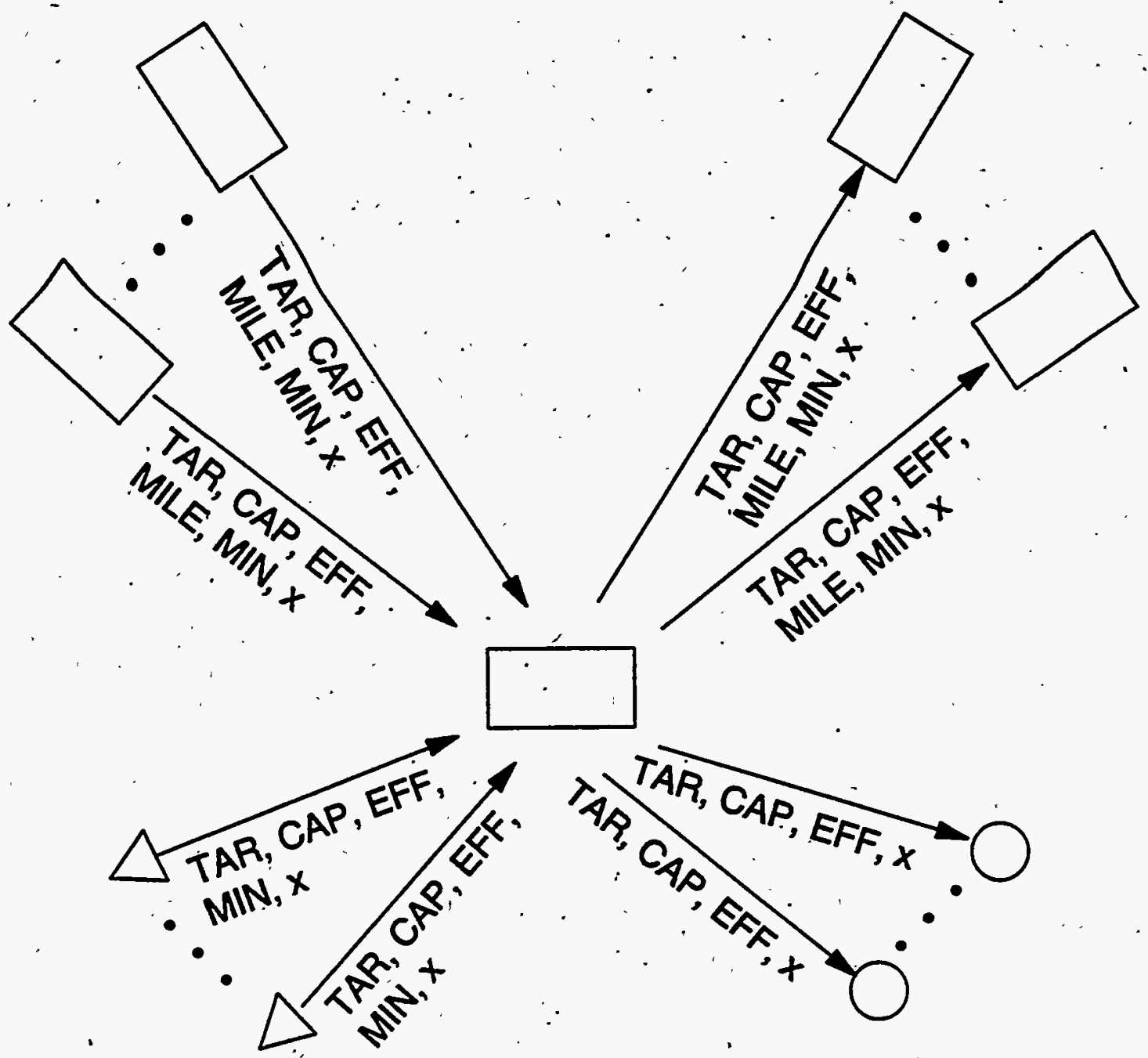

Parameters: (model inputs)

- Transshipment Node

- Supply Point

- Demand Point
TAR - Tariff

EFF - Efficiency

CAP - Capacty

MILE - Mileage

MIN - Minumum Flow

- Direction

Variables: (model outputs)

$$
x \text { - Flow }
$$

ElAModel Documentation: Natural Gas Transmission and Distribution Model Volume I

43 
listed in Table 4-1. This table also indicates in tabular form the mapping of Electricity Market Model regions and Oil and Gas Supply Model regions to NGTDM regions, (Figures 3-4. and 3-7 in Chapter 3).

As described in earlier chapters, there are significant differences in market structure and dynamics between the firm and interruptible service markets. The basic network structure separately represents the flow of gas within the firm and interruptible service markets within the Annual Flow Module. Conceptually this can be thought of as two parallel networks, with three areas of overlap. First, the firm and interruptible transmission service flows along each arc are interrelated and their sum is constrained to the pipeline capacity available along the arc: Second, the firm and interruptible service networks share common supply sources. At each supply source there is a single price regardless of whether the supplies are used to meet core or noncore demand (or both), because it is assumed that the supply component of the market will remain fully competitive. ${ }^{32}$ Third, the quantity of net injections transported under interruptible service into underground storage is equal to the net withdrawals from storage in the same region that are to be transported under firm service. The actual levels of underground storage injections and withdrawals associated with the firm and interruptible service markets are determined within the Capacity Expansion Module (since it contains a seasonal representation) and used within the Annual Flow Module.

\section{Specifications of a Network Arc}

Each arc of the network has associated parameters (inputs) and model variables (outputs). The parameters that define an arc are the pipeline direction, available capacity, the tariffs, the percentage of gas which travels on the arc that is lost -or used (in power compressor stations) along the way, a mileage indicator, and a minimum flow level (Figure 4-3). In the case of bidirectional ares, the are with an historically lower flow rate is identified as a "bidirectional" arc for special handling.

Once a model solution has been reached (i.e., the quantity of the natural gas flow along each interregional arc is determined), pipeline fuel use associated with interregional transfers (from transshipment node to transshipment node) can be computed for each arc by multiplying the percentage loss of gas (given by the efficiency parameter) by the flow along the arc.

For the firm service market the pipeline tariff (indicated as "TAR" in subsequent equations) is a function of two basic parameters: a usage fee and a reservation fee (collected from customers who have reserved capacity on the pipeline). Since the NGTDM does not explicitly represent the capacity reserved on a pipeline, the reservation fee is a function of a revenue requirement forecast, an associated pipeline utilization rate, and the actual flow of gas during the previous forecast year (as a proxy for the current forecast year), as described in Chapter 8. The total pipeline tariff for the firm service market is the sum of the usage fee and the resulting reservation fee. For the interruptible service market, the tariff parameter is simply a per-unit usage fee (as specified by the Pipeline Tariff Module). It is not necessary for the firm and interruptible usage fees to be equal.

For the arcs from the transshipment nodes to the end-use sectors, the parameters defined are capacities, tariffs, and the percentage of gas used in compressor stations. The tariffs here represent the sum of several charges or adjustments, including interstate pipeline tariffs in the region, intrastate pipeline tariffs, and distributor markups wher applicable. The model variable associated with each of these arcs is the flow along the arc, which is equal to the amount of demand satisfied plus gas consumed in compressor stations. For ares from supply points to transshipment nodes, the parameters are capacities, tariffs, minimum flows, and compressor station usage. In this case the tariffs theoretically represent gathering.charges, but in actuality are used to align model results with historical prices in each region. Minimum flows are set on supply arcs by splitting the assumed minimum production levels for each source (described in Chapter 3 ) into firm and interruptible components based on the relative levels of core and noncore consumption in the Lower 48 States. Although capacity limits can be set for the ares to and from end-use and supply points, respectively, the current version of the model does not impose such limits on the flows along these arcs.

\footnotetext{
${ }^{32}$ Due in part to the seasonal load differences.between core and noncore consumption, there are reasons to believe that the supply prices to the two markets are different on an annual basis. Structurally, the model is designed to handle such a supply price differential, but the supporting datá have yet to be developed. However, more recent trends show less, variation in seasonal wellhead prices than had previously been observed.
} 
Table 4-1. Demand and Supply Types at Each Transshipment Node in the Network

\begin{tabular}{|c|c|c|}
\hline $\begin{array}{l}\text { Transshipment } \\
\text { Node }\end{array}$ & Demand Types & Supply Types \\
\hline 1 & $R, C, I, T, U(1 / 7)$ & $P(1 / 1)$, LNG Everett Mass. \\
\hline 2 & $R, C, I, T, U(2 / 6), U(2 / 3)$ & $P(2 / 1)$ \\
\hline 3 & $R, C, I, T, U(3 / 1), U(3 / 4)$ & $P(3 / 1)$, SNG \\
\hline 4 & $R, C ; 1, T, U(4 / 5), U(4 / 10)$ & $P(4 / 3), P(4 / 5)$ \\
\hline 5 & $R, C, I, T, U(5 / 1), U(5 / 3), U(5 / 9)$ & $\begin{array}{l}\text { P(5/1), LNG Cove Pt Maryland, LNG Elba } \\
\text { Island Georgia, Atlantic Offshore }\end{array}$ \\
\hline 6 & $R, C, I, T, U(6 / 1), U(6 / 9)$ & $P(6 / 1), P(6 / 2)$ \\
\hline 7 & $R, C, 1, T, U(7 / 2), U(7 / 10)$ & $\begin{array}{l}P(7 / 2), P(7 / 3), P(7 / 4) \text {, LNG Lake Charles } \\
\text { Louisiana, Offshore Louisiana, Gulf of } \\
\text { Mexico }\end{array}$ \\
\hline 8 & R, C, $1, T, U(8 / 11), U(8 / 12)$ & $P(8 / 5)$ \\
\hline 9 & $R, C, I, T, U(9 / 11)$ & $P(9 / 6)$ \\
\hline 10 & $R, C, I, T, U(10 / 8)$ & $P(10 / 2)$ \\
\hline 11 & $\mathrm{R}, \mathrm{C}, \mathrm{I}, \mathrm{T}, \mathrm{U}(11 / 12)$ & $P(11 / 4), P(11 / 5)$ \\
\hline 12 & $R, C, I, T, U(12 / 13)$ & P(12/6), Pacific Offshore \\
\hline 13 & Canadian Exports & Canadian Imports \\
\hline 14 & Canadian Exports & Canadian Imports \\
\hline 15 & Canadian Exports & Canadian Imports \\
\hline 16 & Canadian Exports & Canadian Imports \\
\hline 17 & Canadian Exports & Canadian Imports \\
\hline 18 & Canadian Exports & Canadian Imports, Alaskan Supply \\
\hline 19 & Mexican Exports & Mexican Imports \\
\hline 20 & Mexican Exports & Mexicán Imports \\
\hline 21 & Mexican Exports & Mexican Imports \\
\hline
\end{tabular}

R - Residential demand; C - Commercial demand; I - Industrial demand; T - Transportation demand

$U(n 1 / n 2)$ - Electric generator's demand in NGTDM/EMM region (n1/n2) as shown in Figure 3-3

$P(n 1 / n 2)$ - Production in NGTDM/OGSM region (n1/n2) as shown in Figure 3-6 (also includes synthetic natural gas from coal and other supplemental supplies)

SNG - Synthetic Natural Gas from liquid hydrocarbons

LNG - Liquified Natural Gas 
Figure 4-3. Network Parameters and Variables

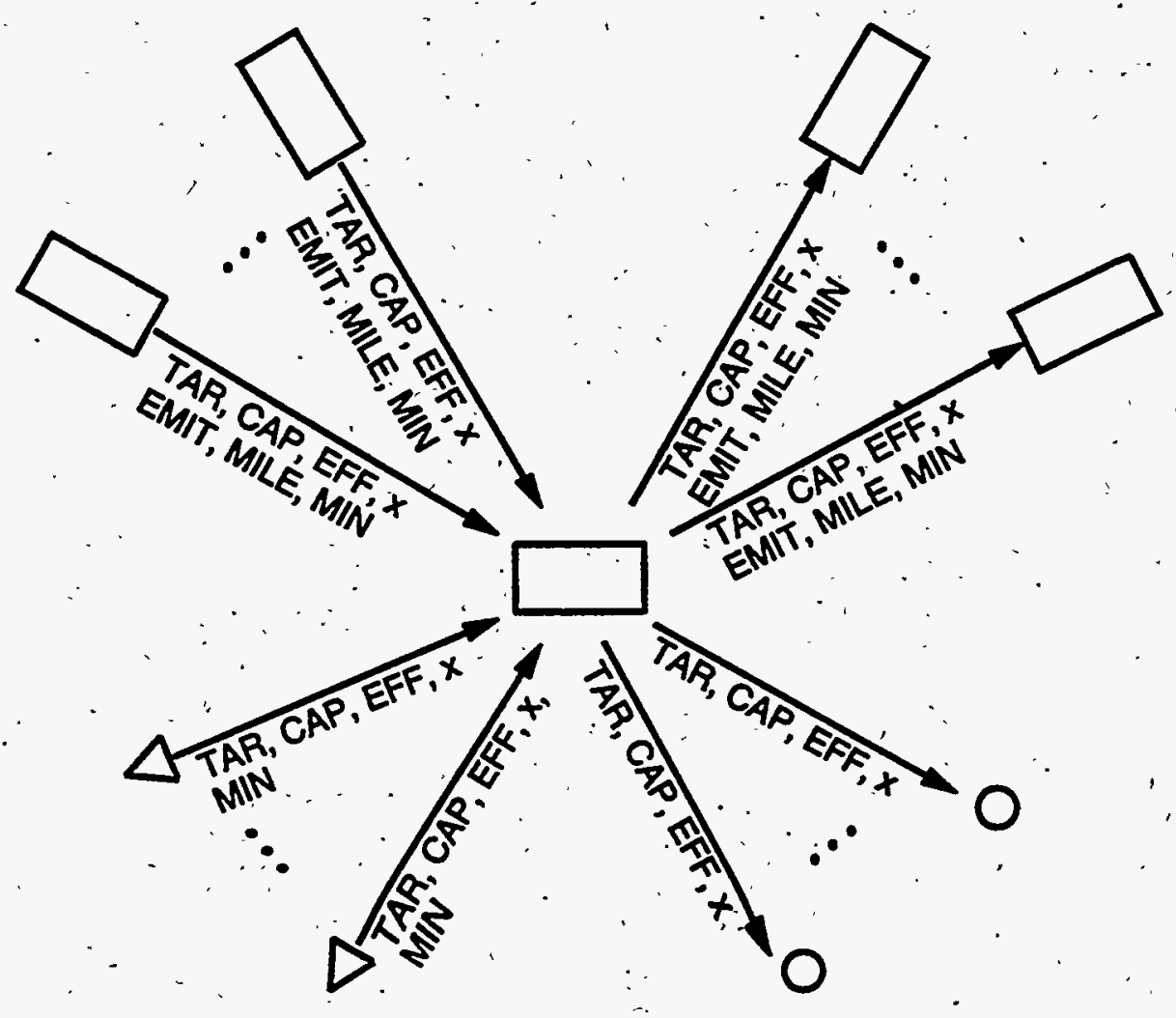

Parameters: (model inputs)

TAR - Tariff

EFF - - Efficiency

CAP - Capacity:

$\Delta$ - Supply Point

MILE - Mileage -

o. Demand Point

EMIT - Emissions

MIN - Minimum Flow

$\longleftarrow$ - Direction

Variables: (model outputs)

$x$ - Flow 
In an effort to represent potential interruptions in transportation service to the noncore market, a "relief valve" was put in the system. The noncore demand requirements can optionally be met through a highly priced "backstop" supply source, which is made directly available at the end-user nodes. Backstop supply is designed to be used only in the event that pipeline capacity (existing plus capacity to be built for the firm service market) is not sufficient to meet the noncore demand requirements. Backstop supply displaces noncore consumption which would be expected not to transpire in the Annual Flow Module due to fuel switching or generally lower consumption levels in response to higher gas prices. The incorporation of backstop supply is a modeling tool and is not intended to represent a real supply source.

Note that any of the above parameters, supplies, or demands may be set equal to zero. For instance, some pipeline arcs may be defined in the network that currently have zero capacity where new capacity is expected in the future. On the other hand, some ares such as those to end-use sectors are defined with infinite pipeline capacity because the model does not forecast limits on the flow of gas from transshipment nodes to end users.

\section{Overview of the NGTDM Modules and Their Interrelationships}

The NEMS generates an annual forecast of the outlook for U.S. energy markets for the years 1990 through 2020. Although the NGTDM is executed for each iteration of each forecast year solved by the NEMS, it is not necessary that all of the individual components of the model be executed for all iterations. Of the NGTDM's four components or modules, the Capacity Expansion Module and the Pipeline Tariff Module are executed only once per forecast year. The Annual.Flow Module and the Distributor Tariff Module are executed every iteration of each forecast year. A process diagram of the NGTDM is provided in Figure 4-4, showing the general calling sequence.

The primary function of the Capacity Expansion Module is to forecast interregional pipeline and underground storage expansions and produce annual pipeline load profiles based on seasonal loads. Using this information from the Capacity Expansion Module and other data, the Pipeline Tariff Module uses an accounting process to derive interregional and intraregional pipeline tariffs for firm and interruptible transmission service to be used in the Annual Flow Module and the Capacity Expansion Module. The Distributor Tariff Module provides distributor tariffs for use in the Annual Flow Module and the Capacity Expansion Module. The Distributor Tariff Module must be called each iteration because some of the distributor tariffs are based on consumption levels which may change from iteration to iteration. Finally, using the information provided by other NGTDM modules and other NEMS models, the Annual Flow Module solves for natural gas prices and quantities which reflect a market in equilibrium for the current forecast year. A brief summary of each of the NGTDM modules follows.

\section{The Annual Flow Module}

The Aninual Flow Module (AFM) is considered the central module within the NGTDM, with the Capacity Expansion Module, Pipeline Tariff Module, and Distributor Tariff Module (in addition to other NEMS models) providing it with critical information. Its objective is to determine the market equilibrium associated with natural gas supplies, demands, and transportation costs, thereby generating supply and end-use prices and production levels for use by other NEMS models. Formulated as a linear program, the AFM determines a market equilibrium by maximizing the sum of consumer and producer surplus, while minimizing transmission and distribution charges, subject to system constraints. As the name indicates, it has been designed to represent annual flows from supply points to demand points traveling along a pipeline network. As defined above, the network in the AFM represents firm and interruptible service markets separately along parallel networks, connected only at the supply points and through capacity constraints along the network arcs.

To accomplish its goal, the AFM uses regional price curves to represent regional supplies and demands. These curves represent linear approximations of the price response that can be expected from the more detailed NEMS models that provide the parameters used to build the curves. Each forecast year the Oil and Gas Supply Model provides the parameters to build the supply curves, and each iteration the demand models provide the parameters to build the demand curves. 
Figure 4-4. NGTDM Process Dlagram

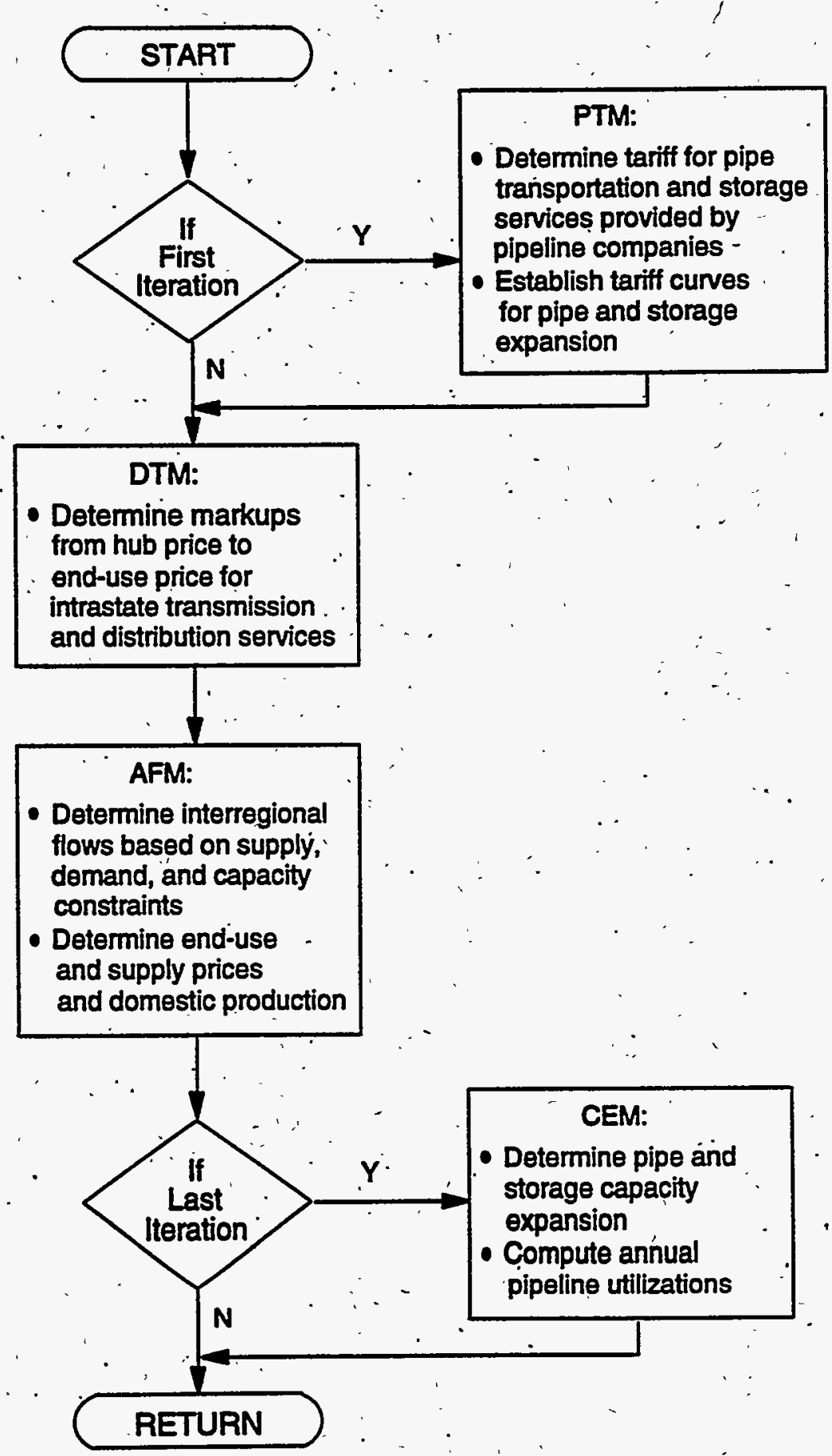


The Capacity Expansion Module, Pipeline Tariff Module, and Distributor Tariff Module also provide data required by the AFM. The Capacity Expansion Module provides pipeline capacity additions, pipeline utilizations for firm flows and total flows, and net storage withdrawal levels assóciated with the firm and interruptible service markets. The Pipeline Tariff Module calculates interregional and intraregional pipeline tariffs for both firm and interruptible service. Similarly, the Distributor Táriff Module provides the AFM with markups for local distribution and intrastate transportation services.

Annual flow results from the AFM are provided to the Pipeline Tariff Module and the Capacity Expansion Module. The Capacity Expansion Module uses firm flows to set minimum flows for its capacity expansion forecasts, and the Pipeline Tariff Module uses both firm and interruptible flows in conjunction with cost estimates to set unitized pipeline tariffs.

\section{The Capacity Expansion Module}

The Capacity Expansion Module (CEM) is the only module in the NGTDM that includes a seasonal representation of the natural gas market. In each NEMS forecast year, the.CEM determines incremental pipeline and storage capacity required to'satisfy expected firm service demands in a future year based on an analysis of the expected supply, storage, and transportation requirements. The peak and off-peak seasons are analyzed, concurrently within the CEM, to determine pipeline and storage capacity needs. The storage decișion affects the need for pipeline capacity upstream from the storage facility and influences the relative utilization of the pipeline between the peak and off-peak seasons. A brief description of the seasonal network used in the CEM is presented next, followed by an overview of the model solution methodology.

\section{Seasonal Network Representation in the Capacity Expansion Module}

The basic network structure defined for the CEM is nearly identical to the general NGTDM network described above, with the exception that a two-period (peak and off-peak) representation of the annual market is now being modeled. The "peak period" is defined as the months in the year with distinctly higher levels of natural gas consumption on a national basis. ${ }^{33}$ As in the Annual Flow Module, interregional flows to satisfy firm transmission service are handled separately from the flows to satisfy intemuptible service, both in the peak and off-peak periods.

Conceptually the Capacity Expansion Module consists of four parallel networks. Each network represents the flow of gas either during the peak period under firm service, the off-peak period under firm service, the peak period under interruptible service, or the off-peak period under interruptible service. Interaction between the two periods occurs primarily through the use of storage. Arcs are established from each off-peak firm and interruptible transshipment node to the storage point in the region to represent storage injections. Likewise, arcs are established from each storage point into the associated transshipment nodes in both the firm and interruptible peak period networks. These arcs represent storage withdrawals in the peak period to be transported under firm and interruptible service to satisfy core and noncore demands, respectively. An additional link between the two periods occurs due to the existence of annual supply sources as opposed to separate peak and off-peak supply. Thus, supply from each supply source in a region is available to both the peak and off-peak transshipment node in the region, and ares are established to allow for these flows. An illustration of the two-period network is shown in Figure 4-5 for a base network with three transhipment nodes. For simplicity, the example does not show the further disaggregation of the network into its firm and interruptible components.

\section{Overview of the CEM Solution Methodology.}

- The functional requirement for the CEM is to make natural gás pipeline and storage capacity expansion decisions and to estimate corresponding pipeline and.storage utilization levels based on assumptions similar to those used by the natural gas industry. The CEM has been designed as a seasonal natural gas transportation model, with storage serving as a link between supplies and seasonal demands. As with the Annual Flow Module, both firm and interruptible services are also represented. Formulated as a linear program, the objective is to minimize production and transportation costs, as well as costs associated with pipeline and storage expansion decisions. Although the basic network structure, its parameters

\footnotetext{
${ }^{33}$ The data inputs to the Capacity Expansion Module define the months designated as peak versus offpeak. Currently the data in the Capacity Expansion Module reflect a peak period from December through April. Due to a lag in the reporting of monthly consumption data, November falsely appears to be a "nonpeak" month. This should be corrected in the future once a method is developed for generating adjusted monthly consumption data.
} 


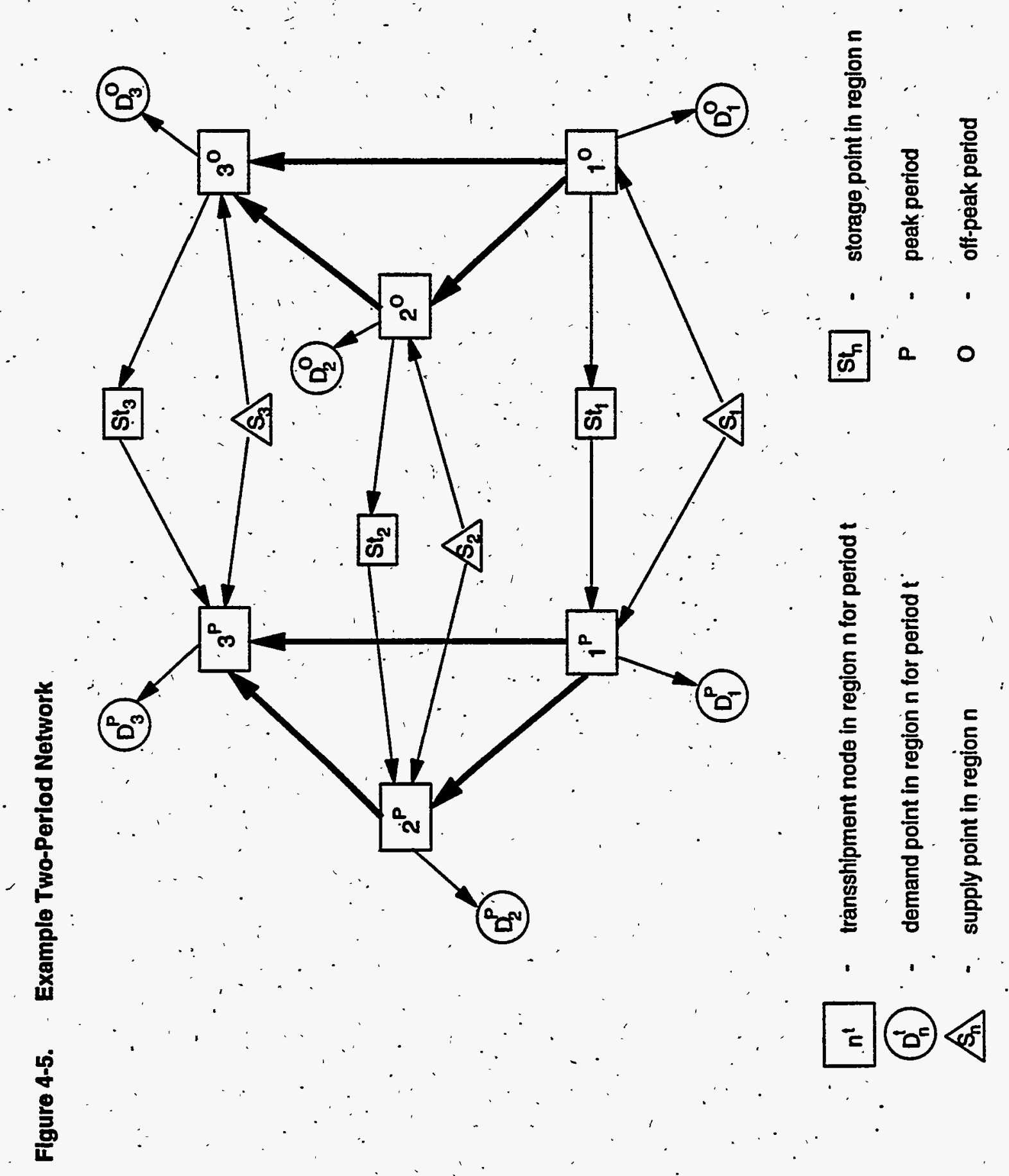


(inputs), and its model variables (outputs) have been designed to be similar to that in the Annual Flow Module, some clements had to be defined as seasonal.

The CEM is executed within the NGTDM once at the end of each forecast year to determine the pipeline and storage expansion which will come on line " $n$ " years in the future. Capacity is expanded to accommodate the transmission service needs of core consumers that are expected to occur in that year. The parameter " $n$ " represents the average number of years in which the decision to expand capacity cannot be reversed due to contractual obligations. The results generated by the CEM during the current forecast year do not affect the current forecast year's market solution, but. are used in the Annual Flow Module and the Pipeline Tariff Module when the NGTDM determines a natural gas market equilibrium solution for the $\mathrm{n}^{\text {th }}$ year in the future.

The data inputs for the CEM from the NEMS system include macroeconomic parameters from the Macroeconomic Activity Model of NEMS, as well as expected values for natural gas consumption levels in future years. The NEMS Integration Routine provides the CEMM with estimates of future natural gas consumption levels for the nonelectric sectors. ${ }^{34}$ Consumption forecasts for the core and noncore electricity generating sector are a function of the estimates provided by the Electricity Market Model. Parameters are provided by the Oil and Gas Supply Model to the CEM for estimating potential future supply levels. In addition, minimum interregional firm service flow constraints (based on Annual Flow Module solution values in the previous forecast year) are set in the CEM to represent the inertia of core customers from annually switching pipeline routes used in transporting their natural gas (e.g., due to long-term contract commitments).

The CEM uses the same regions and end-use sectors defined within the Annual Flow Module. However, the Annual Flow Module is an annual model; whereas, the CEM requires a seasonal analysis to represent more accurately the decision to expand pipeline and/or storage capacity to meet peak-day core market demands. The CEM includes a methodology for converting from annual to seasonal (peak and off-peak) consumption levels, as well as a means for capturing core peak-day requirements in the capacity expansion decision. The factors for estimating seasonal load patterns are historically based model inputs which are held constant throughout the forecast in the current model. Future model enhancements may allow for the representation of structural changes in seasonal consumption patterns (e.g., demand side management, changing building structures, and/or technological innovations).

Dry gas production is represented in the CEM with a price responsive equation (or curve) developed from inputs from the Oil and Gas Supply Model. Although the supply representation within the CEM reflects annual levels, the formulation allows for upper bounds on the level of supply available within the peak or off-peak period from each supply source (formulated as the annual supply times the percentage of the year represented by the given period).

Imports from Mexico and Canada are represented as constant supplies and tracked at a seasonal level (peak and offpeak). Mexican imports are provided by the Oil and Gas Supply Model and are supplied to the core market only. Canadian imports are available to both core and noncore markets and are determined from exogenously specified Canadian pipeline capacities and utilizations: Also, Canadian produced natural gas which passes through the United States on its way to Canadian markets (as described in Chapter 3) is split into peak and off-peak levels based on assumed shares.

Storage is used to satisfy peak seaśon consumption by injecting gas into storage in the off-peak period and withdrawing the gas during the peak season. Thus, storage is considered a supply source in the peak period, and a demand requirement in the off-peak period. This limits the amount of off-peak capacity that is available on an interruptible basis for consumption in the period. In addition, regional historically observed reporting discrepancies are accounted for in the model, with seasonal splits based on national consumption in the peak and off-peak periods.

The Pipeline Tariff Module provides interregional pipeline tariffs and storage charges associated with existing and incremental expansion of regional pipeline and storage facilities. This information is sent to the CEM in the form of storage and pipeline "capacity supply curves." These "capacity supply curves" are based on exogenously specified capital cost curves for expansion and on macroeconomic parameters from the NEMS Macroeconomic Activity Model.

34 These expected consumption levels are based on annual growth rates in previous historical or forecast years, capped by maximum allowable growth rates within the NGTDM. 
If the CEM determines that pipeline (or storage) capacity will be added, the Pipeline Tariff Module will in turn adjust the associated revenue requirements (and resulting tariff parameters) for the year in which the new capacity is scheduled to come on-line to account for the expansion costs. In addition, the pipeline capacities and seasonal utilization patterns established in the CEM are used in defining maximum annual interregional flow constraints in the Annual Flow Module, reflecting the impact of the variation in seasonal consumption on pipeline loads: The seasonal storage injections and withdrawals are used as a basis for setting annual net storage withdrawals by core and noncore customers in the Annual -Flow Module. The Pipeline Tariff Module also uses the levels of storage and pipeline capacity expansion established in the CEM when determining the associated capital expenditures (an input to the Macroeconomic Activity Model of the NEMS).

The NGTDM has an option available which allows the user to either (1) run the CEM described above (used for AEO98), (2) use a designated data file (created by the CEM during a previous run) which contains the capacity and utilization data needed by the NGTDM, or (3) first use a designated data file for a user-specified number of years and then run the CEM code for the remaining forecast years. This is controlled by the input parameter EXCEM. If the parameter is set to the model base year' (e.g., 1990), then option 1 is selected; if it is set to a large number (e.g., 9999), then option 2 is selected; if it is set to an interim forecast year (e.g., 2000), then option 3 is invoked. Under option 3 the designated data file is used prior to the specified year and the CEM is run for the remaining forecast years.

\section{The Pipeline Tariff Module}

The Pipeline Tariff Module (PTM) is executed within the NGTDM once each forecast year to calculate pipeline and storage tariffs for the Annual Flow Module, the Capacity Expansion Module, and the Distributor Tariff Module. The tariffs calculated within the PTM are computed for individual pipeline companies and are then aggregated as required. An accounting system is used to track costs and compute rates under various rate design and.regulatory scenarios. Tariffs are computed for both storage and firm and interruptible transportation services. Transportation tariffs are computed for interregional arcs defined by the NGTDM network, as well as intraregional connections. These network tariffs represent an aggregation of the tariffs for iridividual pipeline companies supplying the network arc. Storage tariffs are defined at regional NGTDM network transhipment nodes, and likewise, represent an aggregation of individual storage company tariffs. These tariffs are for transmission services only and do not inciude the price of gas.

More specifically, the PTM computes (1) reservation costs as̀signed to firm transportation service customers, (2) usage fees for firm transportation service, (3) minimum, maximum, and reference level (a function of pipeline capacity utilization, but between the minimum and maximum) transportation rates for interruptible service, and (4) rates for storage service. For firm service, cost-of-service based revenue requirements are computed by the PTM as a basis for generating a reservation fee to be used within the Annual Flow Module to price transportation services. Where markets are competitive or are loosely regulated (i.e., interruptible transportation), the Annual Flow Module uses the reference level transportation rate set by the PTM as a lower bound for service in determining the actual rate charged. The resulting rate (dependent on marginal costs) should be within the bounds of the minimum and maximum rates computed by the PTM. ${ }^{35}$

The impacts of the capacity expansion decisions made in the Capacity Expansion Module are reflected in the pipeline tariffs computed by the PTM. The Capacity Expanșion Module determines the location and quantities of additional pipeline capacity and storage facilities at the aggregate level represented by the NGTDM network. Interregional pipeline or regional annual storage capacity expansion requirements are provided to the PTM by the Capacity Expansion Module. Also, since capacity expansion decisions need to take into account the marginal changes in pipeline tariffs in response to increased capital requirements, the PTM initially establishes tariffs (reservation fee) associated with a series of incremental expansions. Many of the calculations of components of the revenue requirements require the use of macroeconomic variables that are provided by the NEMS Macroeconomic Activity Model.

\footnotetext{
${ }^{35}$ The NGTDM compares the effective tariff (i.e., the difference between the price at two adjoining nodes) to ascertain if the limit was violated. Currently the model does not have a correcting mechanism, if the constraint is violated and simply, reports the occurrence in a report. FERC recently lifted this limit when competitive markets can be demonstrated.
} 


\section{The Distributor Tariff Module,}

The Distributor Tariff Module (DTM) determines regional and sector-specific markups that are applied to regional hub prices ${ }^{36}$ to derive regional end-use prices for each sector and market type (core and noncore). The end-use markups are comprised of four separate cost components: distributor tariffs, intraregional pipeline tariffs, intrastate pipeline tariffs, and a citygate benchmark factor. The distributor tariff component represents the tariff for services provided by local distribution companies from the citygate to end-users, and is determined within the DTM. Intraregional and intrastate tariffs are regional charges by pipeline companies for intraregional interstate and intrastate transportation services, respectively. Intraregional interstate tariffs are determined by the Pipeline Tariff Module, and intrastate tariffs are specified exogenously. Citygate benchmark factors are determined endogenously to the model, and serve to align the model with core and noncore historical citygate prices. These markups from the hub to each end-use sector are used within both the Annual Flow Module and the Capacity Expansion Module.

The DTM uses different methodologies to estimate regional core and noncore distributor tariffs. For the noncore customers in the electric generator and industrial sectors, distributor tariffs are based on the corresponding historical tariffs, and were assumed not to vary across the forecast for $A E O 98$. However, the annual change in core distributor tariffs (excluding the transportation ${ }^{37}$ and electric generator sectors) are a function of the annual change in nonelectric core consumption and in costs of capital and wages, the noncore contribution to core revenues, and technological efficiency improvements. The annual change in the core electric generator margins are assumed equal to a fraction of the annual percentage change in the corresponding consumption. Not accounting for taxes, core distributor tariffs associated with the compressed natural gas fleet vehicle sector are a function of historical distributor tariffs, while those associated with the personal vehicle sector are based on the industrial core market distributor tariffs with an assumed dispensing cost. Distributor tariff's are calculated within the model each iteration of each forecast year, with historical levels used during historical years.

${ }^{36}$ The hub price is equal to the market clearing price of all supplies at the transhipment node in the region in which the gas is consumed.

${ }^{37}$ The core transportation sector is comprised of fleet vehicle and personal vehicle consumption of compressed natural gas. 


\section{Annual Flow Module Solution Methodology}

As a key component in the NGTDM, the Annual Flow Module (AFM) determines the market equilibrium between supply and demand of natural gas. This translates into finding the price such that the quantity of gas that consumers would desire to purchase equals the quantity that producers would be willing to sell, accounting for the transmission and distribution costs, pipeline fuel use, capacity limitations, and mass balances. Structurally, the AFM consists of a network of regions connected by a parallel system of pipelines designed to service two types of customers, core and noncore. Supplies are defined as total regional supplies available to both parallel networks, while demands are defined separately as core or noncore regional demands. Because of the characteristics of these two markets, pipeline tariffs are rated differently along the same arc. To achieve market equilibrium, the AFM has been formulated as a linear program which maximizes consumer plus producer surpluses while minimizing transportation costs. ${ }^{38}$ Supply and demand prices and quantities, as well as resulting flow patterns, are obtained from the linear programming solution and sent to other NGTDM modules or other NEMS models after some processing. A simple system diagram of the information flowing to and from the AFM is presented in Figure 5-1. A brief explanation of how supplies and demands are represented in the AFM, how the linear program has been formulated for the AFM, and how the AFM results are processed for the other NGTDM modules and NEMS models is presented below:

\section{Network Characteristics in the AFM}

As described earlier, the AFM network consists of -two parallel networks (firm and interruptible service), each containing 12 regions (or nodes), 6 Canadian border crossing nodes, and 3 Mexican border crossing nodes. Net storage withdrawals are represented at 10 of the 12 regional nodes for both firm and interruptible services. Ares connecting the nodes are characterized by pipeline efficiencies, physical capacities, pipeline tariffs, minimum flows, and maximum utilizations. The efficiencies are exogenously defined ${ }^{39}$ and represent reduction in flows due to pipeline fuel consumption. Pipeline tariffs (defined in the Pipeline Tariff Module) represent fees for moving gas along pipelines. Pipeline tariffs in the firm market include reservation and usage-fees while pipeline tariffs in the interruptible market are composed solely of usage fees. Minimum flows are defined for each arc in order to maintain continuity in flows from one model year to the next. Maximum pipeline utilizations (established in the Capacity Expansion Module) are defined to maintain consistency between capacity expansion decisions and flow patterns. Finally, a designated percentage of the pipeline capacity is not allowed to be used, to represent the capacity that would not be released, and is held as a safety margin under normal weather conditions (Appendix E, WTHRFAC).

\section{Supply and Demand Representations}

Supply and demand are represented as price curves in each region in the AFM network. These curves represent estimates of short term responses that can be expected from the NEMS models that provide the AFM with regional supply and demand levels. Demand is defined as core or noncore and tied exclusively to either the firm or intermuptible service network, respectively; while supply is defined as total supply available (in most cases) to either network, constrained by minimum flows along selected supply ares going to each of the two networks. The supply and demand types are addressed below.

Supply in the AFM includes associated-dissolved and nonassociated production sources (onshore, offshore, and Alaska), imports (Canadian and Mexican by.pipeline, and as liquefied natural gas), synthetic natural gas (from liquids and coal), and other supplemental supply. Of these, the associated-dissolved production, liquefied natural gas, Mexican imports, Alaska production, and other supplemental supply categories are considered to be constant (or fixed). With the exception of associated-dissolved natural gas, supplies with fixed levels are assumed to be available nly to the firm network; while supplies with variable levels (i.e., relatively price responsive in the short-term) are available to either network.

\footnotetext{
${ }^{38}$ Adapted from the Project Independence Evaluation System (PIES) model.

${ }^{39}$ Almost every arc in the NGTDM nerwork has an associated efficiency variable. With the exception of the interstate pipeline arcs, all of these factors are set to 1.0 (Appendix E -- NEFF_PIPE, UEFF_PIPE, SEFF_PIPE, MEXEFF, CANEFF, AEFF_PIPE, AEFF_PIPE_SCALE93).
} 
Figure 5-1. Annual Flow Module System Diagram

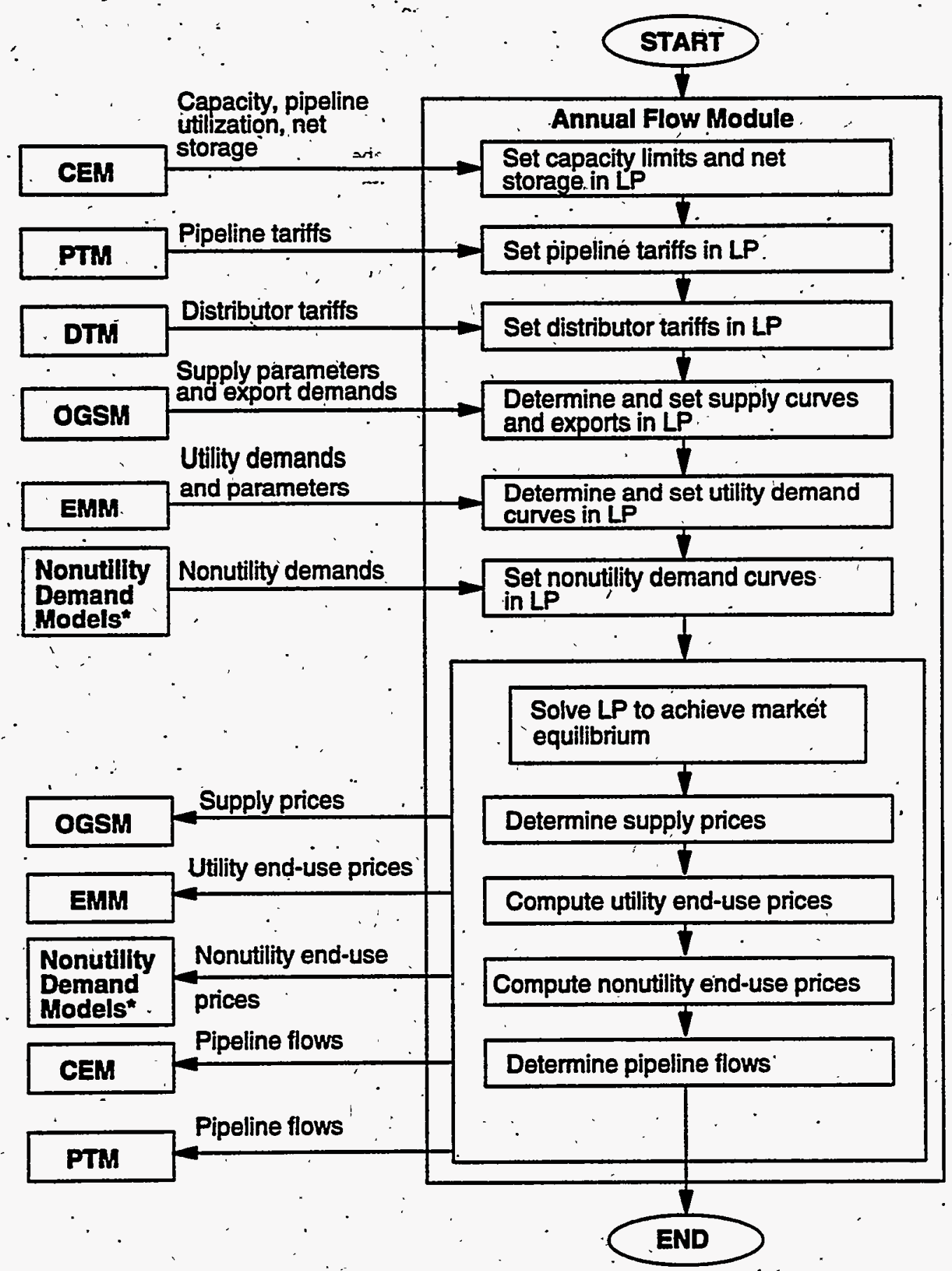

"Residential Demand Model, Commerical Demand Model, Industrial Demand Model, and Transportation Demand Model 
Some supply quantities are provided directly by the Oil and Gas Supply Model and/or other NEMS models, while others are determined within the NGTDM, as described in Chapter 4. For example, onshore and offshore nonassociated natural gas production and Canadian imports are determined within the NGTDM based on parameters provided by the Oil and Gas Supply Model, whereas the Oil and Gas Supply Model establishes the level of natural gas flowing into the contiguous United States via the Alaskan Natural Gas Transportation System (ÁNGTS). The Oil and Gas Supply Model also defines the liquefied natural gas quantities imported through the four gasification terminals modeled by the NGTDM, as well as the level of associated-dissolved gas production. Synthetic natural gas from liquids in Illinois is determined by the NGTDM (as a function of the associated region's market price), with synthetic natural gas from Hawaii held constant throughout the forecast. Synthetic natural gas from coal in North Dakota is set exogenously based on analyst .judgement. Finally, other supplemental supplies are set to historical levels by the NGTDM and held constant throughout the forecast. Table 4-1 provides more detail on the regional representation of natural gas supply in the NGTDM.

Another type of supply (or pseudo supply) available is backstop supply; however, it is undesirable for the system to use this supply source. Backstop supply is designed to be used only if the system has insufficient supply or pipeline capacity to meet a minimum level of demand. If it is used, a high price is sent to the demand models which, in turn, are expected to respond by sending lower demand levels. Backstop supply is priced high ${ }^{40}$ in order to prevent it from becoming economically attractive.

Demand includes end-use sector demands as well as exports (Canadian and Mexican), defined for both core and noncore customers. Although both types of customers are represented by demand curves, core demands are. kept nearly constant while noncore demands are allowed to vary more depending on sector type. Export levels.are set exogenously in the Oil and Gas Supply Model and are assigned as core or noncore within the NGTDM using exogenously specified shares (Appendix E-CANFRMITR_SHR, MEXFRMITR_SHR).

\section{AFM Linear Program Formulation}

A linear programming aigorithm has been developed to determine the least cost approach to achieving an equilibrium between the supply and demand for natural gas in the AFM. Equilibrium occurs when the price at which consumers are willing to purchase a product is equal to the price at which producers together with transporters are willing to supply the product to the end-user. Economically, this is the point where the sum of consumers' surplus and producers' surplus is maximized. ${ }^{41}$ The methodology employed in solving the natural gas supply and demand equilibrium assumes that marginal costs are the basis for determining market-clearing prices to noncore customers and that core customers are charged the average price of gas delivered to the associated region. The problem is based on a transmission and. distribution system composed of two parallel networks. These two networks serve as a means of distinguishing between firm and interruptible transmission and distribution services, and are interconnected only at supply points and through capacity constraints. This section defines the linear programming methodology used to establish a market equilibrium in the AFM, from which supply and end-use prices are obtained. First, the representation of consumer plus producer surplus used in the objective function is derived, then a general description of the entire formulation is presented, followed by the explicit mathematical equations.

\section{Derivation of the Representation of Consumer and Producer Surplus}

The objective of the linear program designed for the AFM is to determine a market equilibrium between the supply and demand of natural gas. As mentioned above, this occurs when the sum of consumers' surplus and producers' surplus has been maximized. Figure 5-2 illustrates this sum as the area under the demand curve $(A+B+C)$ minus the area under the supply curve (C) to the left of the point of market equilibrium $(P, Q)$. This section describes the computation of the area under the supply and demand curves that are used in the objective function equation.

A method for determining the area under the demand curve is established by first representing the demand curves as step functions, as shown in Figure 5-3. A base quantity and price are given and $\mathrm{n}$ steps on either side of the base point are

"The backstop supply price is a user input (Appendix E, NG_BKSTOP_PR).

"Adapted from the Project Independence Evaluation System (PIES) model. 
Figure 5-2. . Supply and Demand Curves

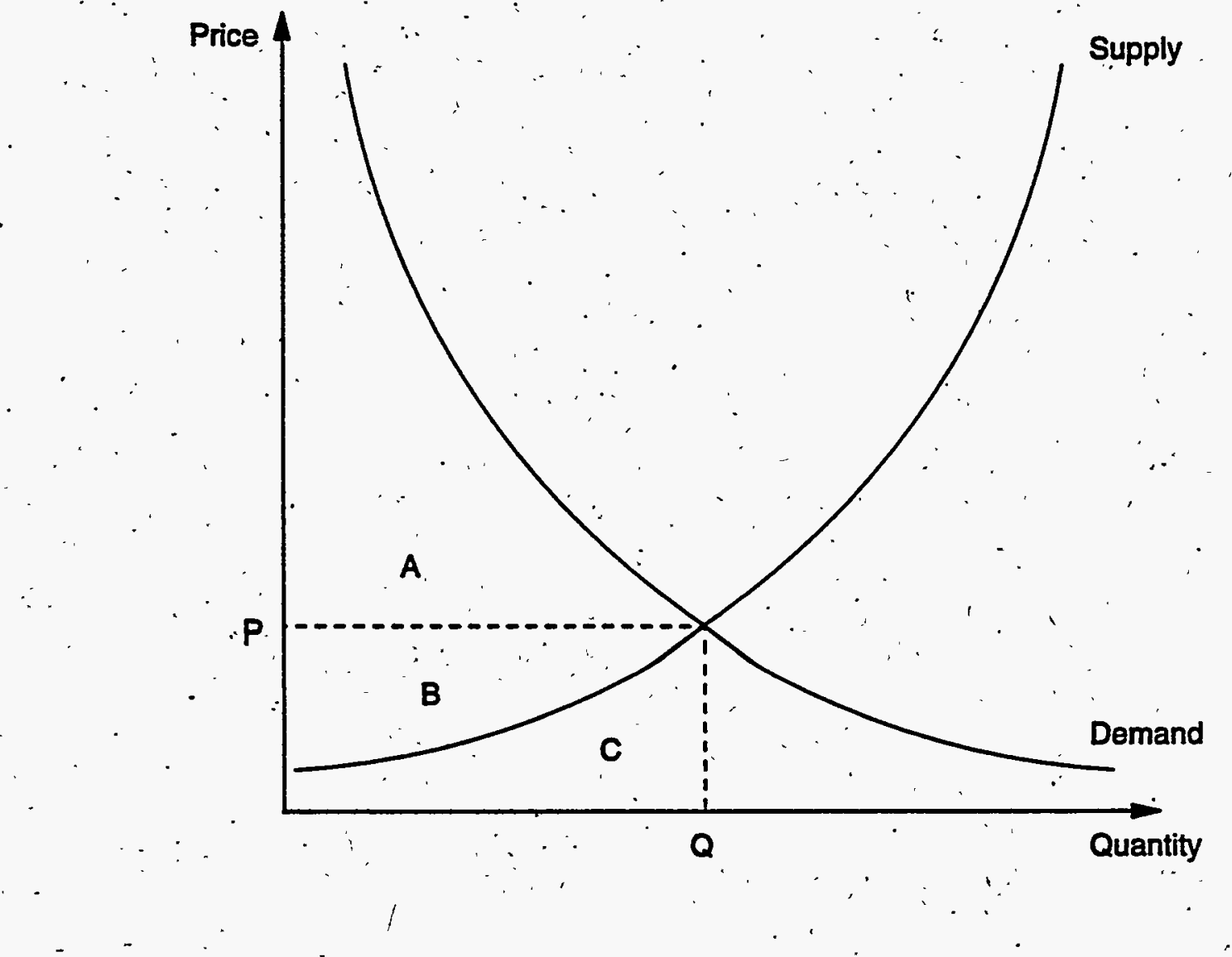

Area A: Consumers' Surplus

Area B: Producers' Surplus

Area C: Total Cost to the Producers

P: Price at Market Equilibrium

Q: Quantity at Market Equilibrium 
Figure 5-3. Approximation of Area Under the Demand Curve

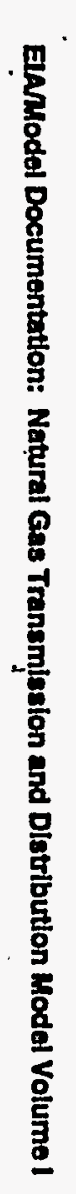
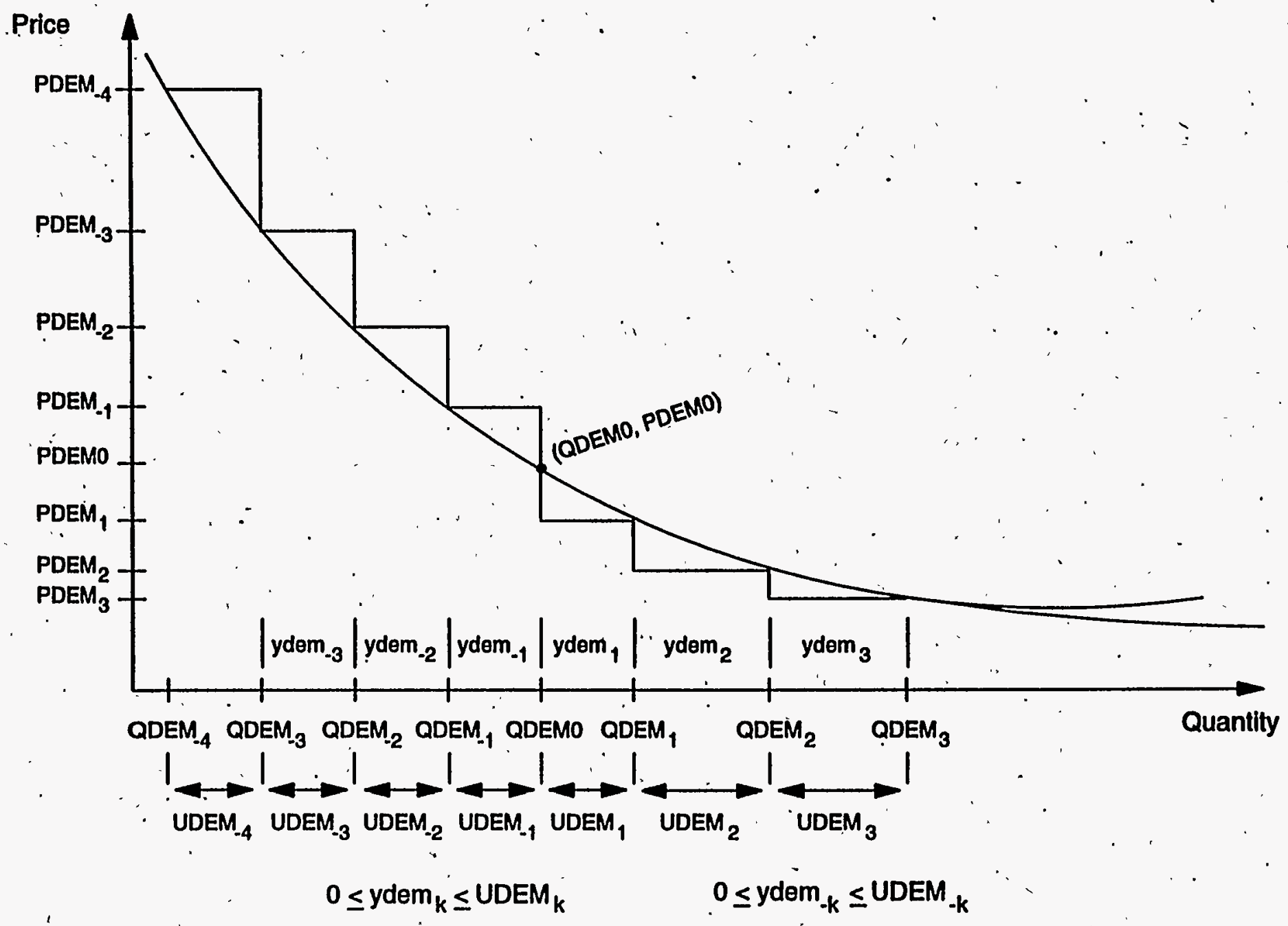

\& 
defined. Toward this end, let (QDEM0,PDEM0) represent a known point (the base point) on the curve and an estimate of where the model will solve. The parameters $\mathrm{UDEM}_{+}$and UDEM are defined as the incremental quantities represented by each step on the curve (i.e., the length of each step on the demand curve), and PDEM and $_{*}$ PDEM represent the corresponding actual prices. Note that the subscript $k$ identifies the $\mathbf{k}^{\text {th }}$ step on the curve to the right of the point (QDEM0,PDEM0), and the subscript $-k$ corresponds to the $k^{\text {th }}$ step on the curve to the left of (QDEM0,PDEM0).

The variable ydem is defined as the total deviation from the base point, and the set of model variables ydem $_{k}$ and ydem are used to define ydem. Each variabie represents a portion of the length of the specified step, such that:

$$
\begin{aligned}
0 & \leq \text { ydem }_{k} \leq \text { UDEM }_{k} \\
0 & \leqslant \text { ydem }_{-k} \leq \text { UDEM }_{-k}
\end{aligned}
$$

and,

$$
\text { . ydem }=\sum_{k=1}^{\mathrm{a}} \mathrm{ydem}_{\mathrm{k}}^{-}-\sum_{k=1}^{\mathrm{a}} \mathrm{ydem}_{-\mathbf{k}}
$$

In order for ydem to represent the distance either to the right or left'of the initial point (QDEM0,PDEM0), the following conditions must hold. If ydem is greater than zero, then each ydem ${ }_{+}$is at the lower bound of zero; and, if ydem is less . than zero, then each ydem $m_{k}$ is equal to zero. If ydem is equal to zero, then each ydem ${ }_{k}$ and $y d e m_{\star}$ is equal to zero, and the model solved at (QDEM0,PDEM0).

In short, the demand curve is represented.as a step function by defining an initial point on the curve (PDEMO,QDEM0), $n$ ydem variables, $n$ ydem $_{+}$variables, and the corresponding prices.

Given the above conditions for the relationship between $y^{\prime} m_{k}$ and ydem, the area under the demand curve is approximated by:

$$
\sum_{k=1}^{n}\left(P^{\circ}{ }^{*} \text { ydem }_{k}-\text { PDEM }_{-k}^{*} \text { ydem }_{-k}\right)+C
$$

where,

$$
\begin{aligned}
C & =\text { the area under the demand curve from } 0 \text { to QDEMO } \\
\Sigma \text { PDEM }_{k}^{*} \text { ydem }_{k} & =\text { the area under the demand curve from QDEMO to step } k \\
\Sigma \text { PDEM }_{*}^{*} \text { ydem }_{*} & =\text { the area under the demand curve from step -k to QDEMO }
\end{aligned}
$$

Note that $C$ is a constant since the demand curve and QDEM0 are given. The variable ydem represents the distance either to the right or left of the initial point (QDEMO,PDEM0), and the equation approximates the integral evaluated from zero to that point.

The area under the demand curve as calculated in the above equation is incorporated in the objective function of the linear program with some modifications. First, the model is formulated as a minimization problem requiring the signs of the coefficients on the equation representing the area under the demand curve to change. Second, since the inclusion of a constant in the objective function does not change the model solution, the $C$ term is excluded from the objective function. As a result, the following term becomes a part of the objective function:

$$
\sum_{k=1}^{n}\left(\operatorname{PDEM}_{-k} * \dot{y}^{\prime} m_{-k}-\operatorname{PDEM}_{k}^{*} \text { ydem }_{k}\right)
$$

When the area to the right of QDEMO (ydem greater than zero) ${ }^{42}$ is calculated, the following properties must hold:

(1) At most one ydem is not equal to zero or UDEM.

\footnotetext{
${ }^{42}$ The analogous properties hold for the left of QDEMO (ydem less than zero).
} 
(2) If ydem is not equal to one of its limits, then $y \mathrm{yem}_{\mathrm{j}}$, for all $\mathrm{j}$ less than $\mathrm{k}$, is equal to its upper limit UDEM; and ydem $m_{j}$, for all $j$ greater than $k$, is equal to its lower limit of zero.

At optimality, the conditions listed above for ydém can be shown to hold. ${ }^{43}$ If the optimal quantity satisfied is on step $k$ of the demand curve, i.e., ydem ${ }_{k}$ is not at either of its bounds, then ydem, for $j$ less than $k$ must be at its upper bound (UDEM), because it will always be more beneficial to bring in more of quantity ydem than to bring in any of ydem since the coefficient of $y d e m_{j}$ is negative and $\mathrm{PDEM}_{j}$ greater than $\mathrm{PDEM}_{\mathrm{k}}$. Similarly, $y d e \mathrm{~m}_{j}$ for $\mathrm{j}$ greater than $k$ will be zero because it will not be beneficial to bring in any of ydem, before bringing in all of ydem since the coefficient of ydem is negative and PDEM 3 is less than PDEM : Furthermore, ydem for all $j$ will be zero because it will not be beneficial to bring in any of ydem $_{. j}$ since its coefficient is positive.

Likewise, if the optimal quantity satisfied corresponds to step $-k$ (some quantity must be subtracted from the base demand), where ydem $m_{k}$ is not at either of its bounds, then ydem $_{3}$, for $j$ less than $k$, must be at its upper bound (UDEM ${ }_{f}$ ). because it will always be more beneficial to subtract more of quantity ydem $_{f}$ than to subtract any ydem, since the coefficient of ydem is positive and PDEM, is less than PDEM $_{k}$. Similarly, ydem , for $j$ greater than $k$, will be zero because it will not be beneficial to subtract any of ydem, $_{j}$ before subtracting all of ydem $_{k}$, since the coefficient of ydem ${ }_{-j}$ is positive and $P D E M_{f}$ is greater than PDEM $_{*}$. Furthermore, $y_{\text {dem }}$ for all $j$ will be zero even though the coefficient of ydem, is negative. This can be deduced by observing that if the quantity at ydem were above zero, the increase in quantity would have to be negated by increasing ydem $_{\star}$, which has a higher price, thus causing the objective function to rise.

\section{Supply Curves}

As with the demand curves, the area under the supply curve can be estimated by first representing the supply curves as step functions and then summing the area under the steps on each curve. This is accomplished in a manner similar to the methodology used for demand curves; however, the base point (QSUPO,PSUPO) is assumed to be at QSUP0 equals zero. Thus, the ysup is represented only by ysup $p_{k}$ and the supply term in the objective function becomes $\Sigma$ PSUP $_{k}^{*}$ ysup $_{k}$ The base point (QSUPO, PSUPO) is set at the solution value (gas production, wellhead price) resulting from the previous NEMS iteration. The size of each ysup is set progressively larger as $k$ increases; therefore allowing for smaller gradations-around the base point (to better approximate the original supply curve). For the first two NEMS iterations, the size of each ysup is exogenously specified. Subsequently, the step sizes are decreased (as the NEMS converges to an equilibrium solution) based on the difference in the wellhead price solutions from the previous two NEMS iterations.

\section{General Description of the AFM Linear Program Formulation}

The objective of the linear program designed for the AFM is to determine a market equilibrium between the supply and demand of natural gas. Since the network consists of multiple supply sources, multiple demand points, and transshipment arcs, transportation costs also must be included. Thus, system equilibrium, will occur when the sum of all the consumers' surplus, all the producers' surplus, and all the transportation costs (negative) is maximized. After translating this into a cost minimization problem, the follow objective function results.

$$
\begin{array}{ll}
\text { minimize } & \{\text { transportation costs }-(\Sigma \text { (consumer surplus) }+\Sigma \text { (producer surplus) ) \} } \\
\text { where, } & \\
& \\
& \text { (the area under the demand curve to the left of equilibrium)- } \\
\text { (the area under the supply curve to the left of equilibrium) }
\end{array}
$$

Capacity flow constraints are defined for each interregional arc in the overall network. Two types of constraints have been defined. One limits total annual flows along an are and the other serves to limit annual firm service flows along the arc. The total flow constraint is an inequality constraint defined to insure that total flow (firm plus interruptible)

${ }^{43}$ See page B-16 in the PIES model documentation for a complete description. 
along an are does not exceed the maximum allowable annual flow along the pipeline. The maximum allowable flow is defined as the maximum physical capacity (adjusted for normal weather representation) times the maximum total utilization (defined by the Capacity Expansion Module). for that arc. Similarly, the firm flow constraint is an inequality constraint defined to ensure that firm flow along an are does not exceed the maximum allowable annual firm flow along the pipeline. The maximum allowable firm flow is defined as the maximum physical capacity (adjusted for normal weather representation) times the maximum firm utilization (defined by the Capacity Expansion Module) for that arc. The resulting constraints are given below for each interregional arc.

For each interregional arc $i, j$ :

(flow on the are to satisfy the core market) + (flow along an are to satisfy the noncore market) $s$ ((physical capacity on the arc) * ( 1 - weather adjustment factor for normal weather) * (annual capacity utilization factor for total flow))

(flow on the arc to satisfy the core market) $\leq$ ((physical capacity on the arc) * $(1$ - weather adjustment factor for normal weather) * (annual capacity utilization factor for firm flow))

A mass balance constraint exists for each transshipment node in each parallel network to ensure that the total input to a node equals the total output from the node (incliding net storage withdrawals, discrepancies, and losses). In general, gas flowing into a transshipment node comes from other transshipment nodes, supply points, and (in some cases) storage, while gas flowing from a transshipment node goes to demand points; other transshipment nodes, and (in some cases) storage. Storage flows in the AFM are assumed to be constant for a particular year (defined by the Capacity Expansion Module) and are represented as net withdrawals (i.e., natural gas flowing out of storage to a node minus natural gas flowing into storage from a node). Net storage withdrawals are defined separately for the firm and interruptible networks. Discrepancies represent the difference between historically reported supply versus disposition values (i.e., the balancing item). ${ }^{44}$ The model incorporates an exogenous forecast of the national discrepancy, ${ }^{45}$ shared out to regions based on historically based shares (Appendix E - NATL_DISCR, STEO_DISR_SHR). A general transshipment node mass balarice constraint is listed below for both networks.

For each firm service transshipment node i:

(flow into a transshipment node from another firm service transshipment node) + (flow into a transshipment node from supply points in the region) + (net storage withdrawals corresponding to firm service) - (losses) = (flow out of the transshipment node to other firm service transshipment nodes) + (flow out of the transshipment node to core market demand points in the region) + (discrepncy)

For ẹch interruptible service transshipment node i:

(flow into a transshipment node from another interruptible service transshipment node) + (flow into a transshipment node from supply points in the region) + (net storage withdrawals corresponding to interruptible service) - (losses) $=$ (flow out of the transshipment node to other interruptible service transshipment nodes) + (flow out of the transshipment node to noncore demand points in the region) + (discrepancy)

A mass balance constraint also is included for each core and noncore demand point. This constraint insures that the quantity allocated to an end-use point equals the quantity demanded at that point. Consumption in the AFM is defined by region and is represented by demand curves. It is the linear approximations to these curves that are used to represent demands.in the linear programming problem. Although these curves allow consumption to drop to levels below base levels in an effort to achieve a market equilibrium, supply or pipeline utilization limits may prevent some regional demands from being met. In order to prevent the linear program from going infeasible, a highly priced backstop supply is available at each demand point. If backstop supply is needed, high prices result and the other NEMS models will

\footnotetext{
Mistorically, the level of the balancing item in the accounting of natural gas supply and disposition are not insignificant. If the natural gas consumption forecast is in line with history and the balancing item is not accounted for, the production forecast in the model will be significantly out of line with (below) history. Therefore the model incorporates an exogenously specified forecast of this balancing item or diserepancy (Appendix E, NATL_DISCR).

${ }^{45}$ For the years 2000 to $2020,35 \mathrm{BCF}$ was exogenously subtracted from the national discrepancy forecast to represent fugitive emissions savings from the Climate Change Action Plan. For 1999 oniy 28 BCF was subtracted.
} 
respond with lower demands. General transshipment node mass balance consistraints are listed below for both parallel networks.

(flow out of a transshipment node to core market demand points in the region) + (flow from a backstop supply point to core market demand points in the region) - (losses) $=$ (quantity consumed at that node for firm service)

(flow out of a transshipment node to noncore demand points in the region) + (flow from a backstop supply point to noncore demand points in the region) - (losses) $=$ (quantity consumed at that node for interruptible service)

Each supply point also has a mass balance constraint represented. Since gas may flow from a supply point to a transshipment node (in the same region) in either the firm or interruptible network, this constraint insures that the total quantity flowing from the supply point equals the amount supplied. The constraint states that total supply is equal to the portion of supply flowing to the firm network plus the portion of supply flowing to the internuptible network. The general constraint is presented below.

(quantity supplied from the supply curve) $=$ (flow from the supply point to a transshipment node to satisfy the core market) + (flow from the supply point to the transshipment node to satisfy the noncore market) ${ }^{-}$.

Due to the nature of a linear program, an optimal solution will not allow flow to occur simultaneously on a primary arc from Region A to Region B and on its bidirectional arc from Region B to Region A because such a situation would incur higher transportation costs (as compared with a case where flow occurs only in one direction and represents net flow). Since an arc in the network may represent an aggregation of some pipelines flowing one direction and other pipelines flowing the opposite direction, flows along bidirectional ares need to be explicitly represented. This is accomplished by setting minimum flows along the bidirectional ares in both the firm and interruptible networks equal to historically observed levels (Appendix E - AFL.OW_F; AFLOW_I). The general equations are presented below.

(flow along the bidirectional are to satisfy the core market) $\geq$ (minimum firm flow requirement for the arc)

(flow along the bidirectional arc to satisfy the noncore market) $\geq$ (minimum interruptible flow requirement for the arc)

Minimum levels are also set for flows along primary arcs within the firm network. These minimum flows help to generate some continuity in flow patterns (which may not always occur in a linear programming environment) that are generally associated with core market contract demands. These minimum levels are a percentage (Appendix E, APCT_MINF) of flows resulting from last year's solution, ${ }^{46}$ and are defined as lower bounds on the flow variables. The general bound equation follows.

(flow along the primary arc to satisfy the core market) 2 (minimum firm flow requirement for the arc)

Nominal minimum flows are also defined for flows along primary arcs in the interruptible network. As with the firm network, the minimum flows are set equal to a percentige (Appendix E, APCT_MINI) of the flows resulting from the last forecast year's solution, and are defined as lower bounds on the flow variables. This is represented in the following bound equation.

(flow along the primary arc to satisfy the noncore market) $\geq$ (minimum interruptible flow requirement for the arc)

Minimum flows are defined on the arcs (to the firm and interruptible transshipment nodes) from the supply sources which are not already specifically targeted for either the firm or interruptible network. This is done to insure that each of these sources supplies a reasonable mix of natural gas to both the firm and interruptible networks. The sum of the minimum flows from each of these supply sources is set equal to the associated minimum supply level (described in Chapter 3). The firm/interruptible split used in setting minimum flows for all of these ares is equal to the national core and noncore

${ }^{45}$ In the first forecast year, minimum flows are assigned as a percentage of historically derived flows for 1990 (Appendix E AFLOW_F, AFLOW_I). 
consumption split (after accounting for the supplies specifically targeted to a particular firm or interruptible network). This is represented in the following bound equation.

(flow along the supply are to satisfy the core market) $\geq$ (minimum firm flow requirement for the arc)

(flow along the supply are to satisfy the noncore market) 2 (minimum interruptible flow requirement for the arc)

Finally, a number of bound constraints are needed to completely describe the step functions for the supply and demand curves. These bounds serve to define the lengths of each of the steps on the linearized curves.

\section{Mathematical Specification of the AFM Linear Program Formulation}

This section presents the set of equations which completely defines the linear programming formulation for the AFM, ineluding an objective function, flow constraints, mass balance constraints, and bounds on model variables. The objective function has been defined as the market equilibrium between natural gas supplies and demands, including relevant transportation costs and backstop supply. This is represented in the following objective function equation:

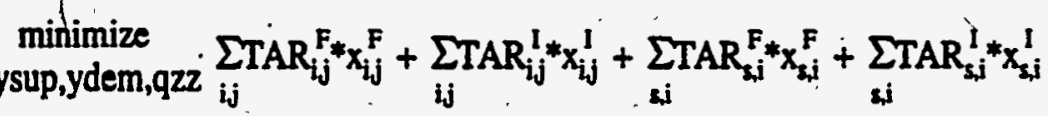

$$
\begin{aligned}
& +\sum_{i, d} \operatorname{TAR}_{i, d}^{F}{ }^{*} x_{i, d}^{F}+\sum_{i, d} \operatorname{TAR}_{i, d}^{1}{ }^{*} x_{i, d}^{1}+\sum_{i d d} P Z Z_{i, d}^{F}{ }^{*} q z z_{i, d}^{F}+\sum_{i, d} \operatorname{PZZ}_{i, d}^{1}{ }^{*} q z z_{i, d}^{1}
\end{aligned}
$$

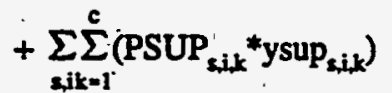

$$
\begin{aligned}
& -\sum_{i, d k=1}^{\mathrm{a}}\left(\mathrm{PDEM}_{\mathrm{i}, \mathrm{d}, k}^{\mathrm{F}}{ }^{*} \mathrm{ydem}_{i, d, k}^{\mathrm{F}}-\mathrm{PDEM}_{\mathrm{i}, \mathrm{d}-\mathrm{k}}^{\mathrm{F}}{ }^{*} \mathrm{ydem}_{\mathrm{i}, \mathrm{d},-k}^{\mathrm{F}}\right)
\end{aligned}
$$

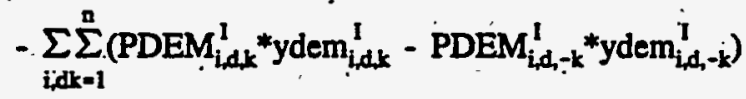

where the subscripted indices are:

$$
\begin{aligned}
& i, \mathbf{j} \text {, and } m=\text { transshipmient node } \\
& \mathrm{d}=\text { demand point } \\
& s=\text { supply point } \\
& \text { st }=\text { storage point } \\
& \mathrm{k}=\text { step on the curve } \\
& \text { c }=\text { number of steps on the supply curve } \\
& \mathrm{n}=\text {. number of steps represented to the left or right of the initial demand point } \\
& \text { (QDEMO,PDEM0) } \\
& i, j=\text { arc connecting transshipment nodes } i \text { and } j \\
& \mathrm{i}, \mathrm{d}=\text { are from transshipment node } \mathrm{i} \text { to demand point } \mathrm{d} \\
& s, i=\text { arc from supply point } s \text { to transshipment node } i \\
& \text { st, } i_{\text {. }}=\text { are from transshipment node st to storage point } i \\
& \text { i,st }=\text { arc from transshipment node i to storage point st }
\end{aligned}
$$

the superscripted indices are:

$$
\begin{aligned}
& F \doteq \text { firm } \\
& I \doteq \text { interruptible }
\end{aligned}
$$


the parameters are:

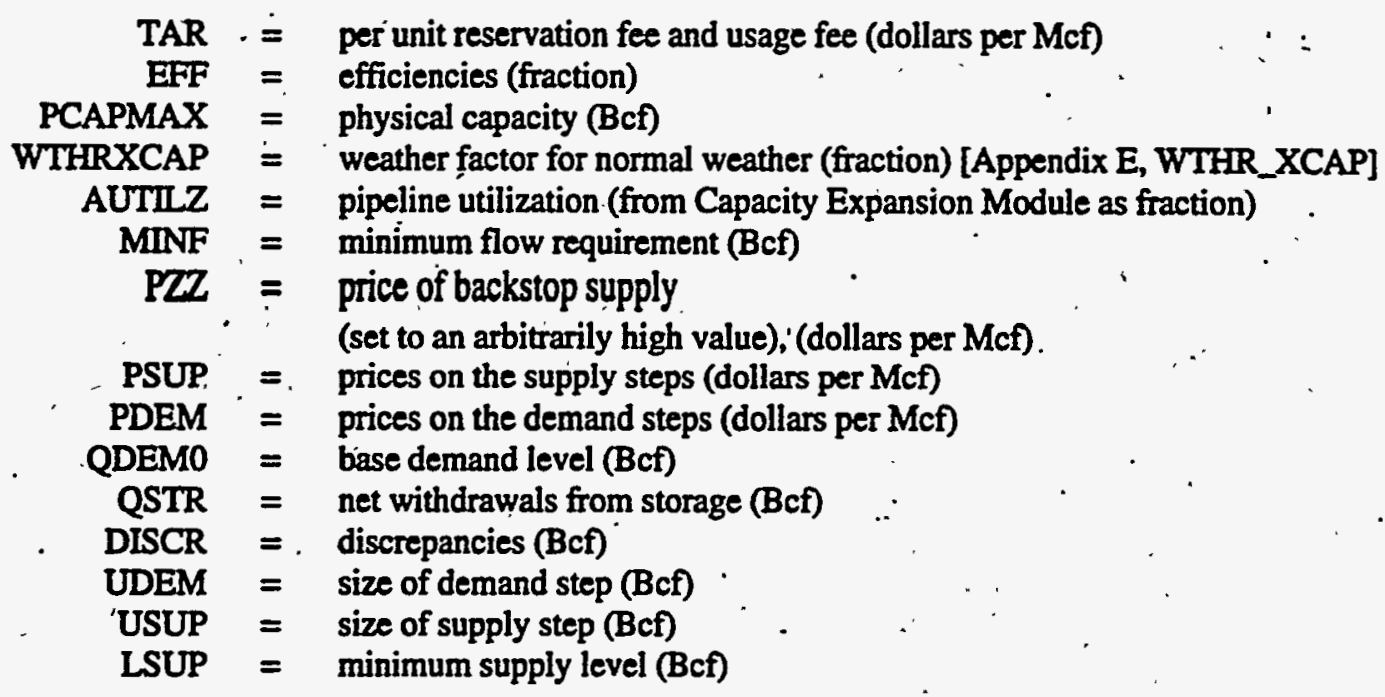

the variables are:

$$
\begin{aligned}
x_{i j} & =\text { flow from } i \text { to } j(B c f) \\
\operatorname{ydem}_{i d k} & =\text { for demand point (i,d), amount of corresponding demand step taken (Bcf) } \\
\operatorname{ysup}_{s i k} & =\text { for supply point }(s, i), \text { the amount of supply step } k \text { taken }(B c f) \\
\text { qzz }_{i d d} & =\text { amount of backstop supply used for demand point (i,d), (Bcf) }
\end{aligned}
$$

Capacity Constraint Along Each Arc i,j:

$$
\begin{aligned}
x_{i, j}^{F}+x_{i, j}^{1} & \leq \operatorname{PCAPMAX}_{i, j} *\left(1-\text { WTHRXCAPי }_{i, j}\right) * \operatorname{AUTIIZ}_{i, j}^{T} \\
x_{i, j} & \leq \operatorname{PCAPMAX}_{i, j} *\left(1-\text { WTHRXCAP }_{i, j}\right) * \operatorname{AUTIIZ}_{i, j}^{F}
\end{aligned}
$$

Mass Balance Constraints at Each Transshipment Node (m):

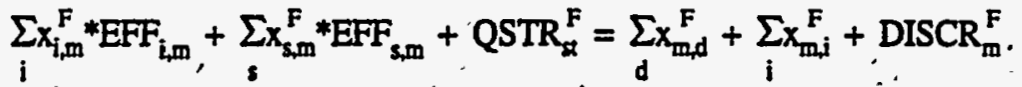

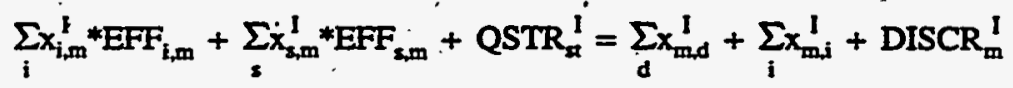

Mass Balance Constraints at Each Demand Point $(\mathrm{i}, \mathrm{d})$ :

$$
\begin{aligned}
& x_{i, d}^{F}{ }^{F} E F F_{i, d}+q z z_{i, d}^{F}=Q D E M 0_{i, d}^{F}+\sum_{k=1}^{\mathbb{Z}}\left({\left.y d e m_{i, d k}-y d e m_{i, d,-k}^{F}\right)}^{F}\right.
\end{aligned}
$$

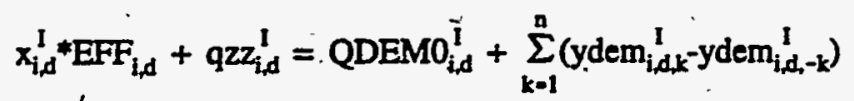

Mass Balance Constraint at Each Supply Point (s,i):

$$
\sum_{k=1}^{c} y \sup _{2, i x}=x_{2, i}^{F}+x_{2, j}^{1}
$$


Minimum Bounds on Flows Along Bidirectional Arcs $(\mathrm{i}, \mathrm{j})$ :

$$
: \mathbf{x}_{\mathbf{i j}}^{\mathbf{F}} \geq \mathrm{MNNF}_{\mathbf{i j}}^{\mathbf{F}}
$$

Minimum Bounds on Flows from Each Designated Supply Point $(s, i)$ :

$$
\begin{aligned}
& x_{2, j}^{F} \geq \operatorname{MNF}_{s, i}^{F} \\
& x_{2, i}^{l} \geq M^{\prime} M_{s, i}^{I}
\end{aligned}
$$

Minimum Bounds on Flows Along Primary Ares (i,j):

$$
\begin{aligned}
& x_{i j}^{F} \geq \operatorname{MINF}_{i, j}^{F} \\
& x_{i, j}^{I} \geq \operatorname{MINF}_{i, j}^{l}
\end{aligned}
$$

The following bound constraints also must be defined for the steps on the supply and demand curves:

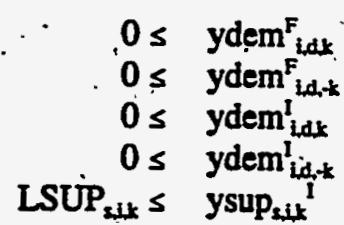

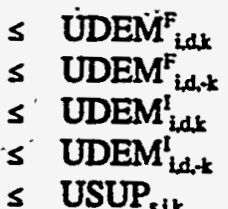

For the most part LSUPP is zero, except on the first step of the supply curve where a minimum supply level may be defined.

Thus, the above equations mathematically specify the linear program objective function and the model constraints. The linear programming solution is obtained using a commercial software package (see Appendix A) designed to solve theseproblems.

\section{Processing of AFM Results}

The AFM is responsible for providing other models within NEMS with natural gas end-use.and supply prices and quantities which correspond to a market equilibrium between natural gas supply and demand. In addition, the AFM must provide NEMS with resulting pipeline fuel consumption, lease and plant consumption, and emissions levels associated with the network results. Once the linear programming problem is solved, these principal model forecast results are processed using information extracted from the resulting matrix. For example, since the AFM solves at a regional level which differs somewhat from the NEMS Census divisions and other model's regional definitions (as described in Chapter 3), the AFM results must be aggregated into the regions required by the receiving models prior to being passed to NEMS. Another major processing step is the calculation of average market prices to the core customers. The various methodologies used to generate these model results are presented below.

\section{Supply Prices and Quantities}

The AFM provides wellhead prices and quantities for onshore, offshore, Alaska, and Canadian production, for Canadian, Mexican, and liquefied natural gas imports (at the border crossing), and for synthetic.natural gas and other supplemental supplies. With the exception of Canadian import and wellhead prices, these values are obtained directly from the linear programming solution with little or no processing required. For example, wellhead prices obtained from the model solution need to be translated from one regional representation to another. The Mexican and LNG import prices as extracted from the LP are adjusted using item-specific benchmark factors that remain constant throughout the forecast 
year. Each benchmark factor represents the difference between the model solution (in the last historical year) and the - related historical regional import price. Somie of these results are passed to the Oil and Gas Supply Model, the Petroleum Market Model and the Coal Market Model for processing, while others are passed to the integrating routine of NEMS for convergence and reporting purposes.

To determine Canadian import and wellhead prices, a netback pricing routine is used in conjunction with benchmark factors. For Canadian import prices, this involves taking the price at the node nearest to the border crossing node, reducing it by the tariff along the arc.connecting the two nodes, and then adding a benchmark factor. For example, since Canadian imports from border crossing node 13 go into node 1 on the AFM network (see Chapter 4), the netback price at node 13 is the node price at node 1 , minus the tariff along are 13 to 1 . A benchmark factor is then added to the result to arrive at the Canadian import price. As with the Mexican and LNG import prices, the benchmark factor represents the difference between the netback pricing model result (in the last historical year) and the corresponding historical Canadian import price. Similarly, Canadian wellhead prices are determined by first taking each of the resulting Canadian imports prices (at the border crossing) and subtracting the corresponding Canadian markups from the wellhead, and then taking a quantity-weighted average of the results (adjusted for losses).

\section{End-Use Prices}

The AFM provides regional end-use prices for the Electricity Market Model (electric generation sector) and the other NEMS demand models (nonelectric sectors). For the nonelectric sectors, prices correspond to core and noncore service at the Census Division level. However; for the electric generation sector, prices are determined for three types of customers, (core segment, noncore segment competitive-with-residual fuel oil, and noncore segment competitive-withdistillate fuel oil), at two different regional leveis (the Census Division level and the NGTDM/EMM subregion level). End-use prices for some sectors/segments within the model are easily determined from the AFM linear programming solution, while others are determined through more rigorous procedures.

End-use prices corresponding to the noncore, nonelectric sector for each Census Division are easily determined from the NGTDM regional prices produced by solving the AFM linear program. Once retrieved from the linear programming solution, the NGTDM regional prices are aggregated into Census Division level results (using a simple quantity-weighted averaging technique) and converted into the appropriate units.

End-use prices for core services cannot be taken directly from the linear programming solution because the linear program prices natural gas at the margin, while the model assumption is that prices for the core segment be represented as average prices. A methodology has been established to calculate average regional transshipment node prices, from which average end-use prices for the core segment can be determined. This methodology is based on the premise that the NGTDM network (discounting bidirectional flows) can be viewed as having a quasi "tree" structure, with the primary supply sources at the bottom (or root) and the more distant demand regions at the top. Using this tree structure, average firm transshipment node prices are calculated starting from the root and moving up to the top branches. At each regional transshipment node, the average price is calculated as a quantity-weighted average of gas coming from other regions and gas.produced within the region. Gas produced from other regions is priced at the average transshipment node price in the other region, plus the assigned tariff to move the gas from the other region. Note that average prices are calculated after the linear program has been solved. This should not directly impact other NGTDM model results (e.g., interregional flows) since core demands are relatively inelastic to price changes (reflected in the fact that the model assumes a price elasticity of zero for the core demand curves).

End-use prices for core customers in a region are then set by adding the intraregional tariff, the intrastate tariff, the distributor tariff, and a citygate benchmark factor to the average regional transshipment node price (see Chapter 6 for details). These regional prices are then aggregated to the Census Division level using a simple quantity-weighted average technique and converted to the appropriate units. Note that regional core transportation end-use prices are determined in a similar fashion but are defined individually for fleet vehicles.(PGFIRFV) and personal vehicles (PGFIRPV). A quantity-weighted averaging routine is used to determine the combined end-use price for the core transportation sector.

Electric generation sector prices are sent to the Electricity Market Model at the NGTDM/EMM subregion level and to NEMS (for.convergence and reports) at the Census Division level. The Electricity Market Model requires prices to be reported for all three market segments, while NEMS requires that prices for the competitive markets be combined into 
an average noncore price. Different methodologies are used to determine the delivered natural gas price to each of the three electric generation market segments. Electric generation sector prices to core customers in each NGTDM/EMM region are determined by adding the intraregional tariff, the intrastate tariff, the distributor tariff, and a citygate benchmark factor to the average associated NGTDM regional firm transshipment node price (defined above), processed to represent the appropriate regions (NGTDM/EMM subregions for the Electricity Market Model and Census Divisions for NEMS), and converted into the proper units. Two user-defined options exist for determining electric generation sector prices to the competitive (residual and distillate) segments: (1) the sum of interruptible transshipment node price, the intraregional, intrastate, and distributor tariffs, and a benchmark factor (used for $A E O 98$ ), or (2) a function of their corresponding competitive fuel price. See Chapter 6 för details. Next, a quantity-weighted averaging routine is used to combine the two competitive segments into a single average end-use price to send to NEMS.

\section{Pipeline Fuel Consumption and Realized Pipeline Tariffs}

For each arc of the network, pipeline fuel consumption is calculated by multiplying the flow on the arc by the percentage (specified as a fraction) lost due to pipeline fuel use. This percentage lost is 1 minus the efficiency specified along the arc. The efficiency term is defined using input data in conjunction with a multiplicative scaling factor which is used to calibrate the results to equal the most recent national historical or STEO pipeline fuel consumption. The pipeline fuel use along each arc of the network must be translated to fuel use by NGTDM region. This disaggregation is accomplished by multiplying the fuel use on each arc by regional shares based on the mileage of pipe in a given region (Appendix $E$, NG_ARCSLZE). A similar loss factor is applied along each intraregional are to account for losses accrued.in the 'distribution process:

Pipeline fuel consumption is used as a basis for calculating the emissions which result from pipeline compressor engine use. Both reciprocating engines and gas turbines are used to power compressors. The latter engines outnumber the former by a factor of approximately 3.3, primarily because they accommodate higher capacity flows at a greater efficiency. However, the reciprocating engines allow for greater variation in flows and are able to send flows in both directions along the pipe. According to estimates by Argonne National Laboratory (presented in the NES Environmental Analysis Model (NESEAM): ANL Technical Memorandum, Section "Natural Gas" of the Appendix C), 77 percent of the engines used for pipeline transportation are gas turbines and 23 percent are reciprocating piston cempression engines.

The Pipeline Tariff Module provides the AFM with a minimum and maximum usage fee, as well as an estimated usage fee for use in the model for transporting gas between regions under interruptible service. Once the linear program is solved, the realized tariff along each arc in the network equals the differerice between the market clearing prices at the two connected transshipment nodes. If the natural gas flow along the are is less than its capacity limit, the realized tariff equals the usage fee assigned when the linear program was formulated. If the flow along the arc is at its limit, the realized tariff will be greater than (or possibly equal to) the usage fee originally specified and could exceed its maximum allowed level. A check is made to identify any realized tariff greater than its allowed maximum: Currently no adjustment is made within the model if this maximum is exceeded, although it typically is not. The Federal Energy Regulatory Commission (FERC) has recently lifted this regulatory limit on interruptible tariffs when a competitive market can be demonstrated. 


\section{Distributor Tariff Module Solution Methodology}

-

.1: :

This chapter discusses the solution methodology for the. Distributor Tariff Module (DTM) of the Natural Gas Transmission and Distribution Model (NGTDM). The DTM develops distributor tariffs and the corresponding markups that are applied to regional hub prices to derive end-use prices within a region. The hub prices are equal to either the market clearing price for supplies to noncore-customers or average market prices for supplies to core customers. These. markups include an intraregional interstate, an intrastate, and a sector specific distributor tariff, as well as a benchmark factor. The intraregional interstate tariffs are provided by the Pipeline Tariff Module. The intrastate tariffs are set exogenousiy; ${ }^{47}$ and the benchmark factors are established endogenously to calibrate citygate prices to historical values. ${ }^{48}$ Distributor tariffs are assigned within the DTM.

Distributor tariffs, and therefore markups, are determined separately for the residential, commercial, industrial, electric generator, and transportation (compressed natural gas vehicle) sectors. Distributor tariffs for the industrial sector and electric generators are segmented by core and noncore markets, whereas residential, commercial, and natural gas vehicle customers are classified as core. It is assumed that core customers receive all of their natural gas under firm (or nearfirm) transportation agreements and that noncore customers transport their gas under interruptible or short-term capacity release transportation agreements. As described in Chapter 3, the noncore electric generation sector has been further divided into two customer classes within NEMS: dual-fired electric generating units that are switchable to residual fuel oil (competitive-with-residual fuel), and gas turbines and dual-fired turbines that are switchable to distillate fuel oil (competitive-with-distillate). Consequently, distributor tariffs, markups, and end-use prices are defined separately for these two noncore service types. Similarly, the core transportation sector is composed of two categories of compressed natural gas (CNG) consumers (fleet vehicles and personal vehicles) and also has separate pricing components.

The primary task of the DTM is to determine regional core and noncore (where applicable) distributor tariffs for each end-use sector. Distributor tariffs to residential, commercial, and industrial core customers are based on estimates of (1) the cost of providing service to the core end user, (2) recovery of fixed costs from the noncore segment of the market, (3) industry efficiency improvements, and (4) bypass by large industrial and electric utility consumers. Electric generator and noncore industrial distributor tariffs are based on historical tariffs, with annual growth or decline rates. A primary factor in the selection of methodologies for developing distributor tariffs was the lack of publicly available data to develop a detailed cost-based accounting methodology similar to the approach used for interstate pipeline tariffs in the Pipeline Tariff Module.

The calculation of the following are discussed in the remainder of this chapter in the given order: the end-use prices by sector, the price markups from the hub to the end-user by sector, and finally the components of these markups (primarily the distributor tariffs).

\section{Markups and End-Use Pricing in Natural Gas Markets}

\section{End-Use Prices}

End-use prices for the residential, commercial, industrial, transportation, and electric generation sectors are comprised of five components: (1) the regional hub price of natural gas, (2) the tariff for intraregional movements of natural gas on the interstate network, (3) a tariff for intrastate pipeline services, (4) a tariff covering the costs of distribution services, and (5) a citygate benchmark factor. The latter four components are consolidated into a markup. In establishing the final end-use price, both the markup and the supply price at the hub are adjusted using an "efficiency" factor to account for the use of fuel in transporting natural gas from the regional hub to the end user.

\footnotetext{
47The intrastate tariffs are currently set to zero and are indirectly accounted for within the distributor tariffs.

4if the option is selected, the citygate benchmark factors are also used to align the end-use prices more closely to the residential and electric generator prices published in the Short-Tem Energy Outlook.
} 


\section{Nonelectric Sector End-Use Prices}

The primary equations for determining core and noncore natural gas end-use prices for the nonelectric sectors are provided below. (The transportation sector is presented separately following these equations.)

\section{Core}

$$
\text { NONU_PR_F } F_{i j}=\left(N G \_A V G P R \_F_{j}+L_{1} \text { PMU_NONU_F }{ }_{i, j}\right) /\left(\text { NEFF_PIPE }{ }_{i j} * \text { AEFF_PIPE }{ }_{j, j}\right)
$$

Noncore

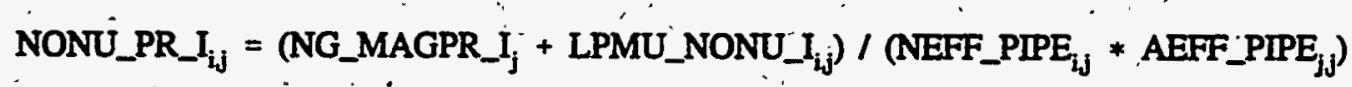

where,

$$
\begin{aligned}
& \text { NONU_PR_F = natural gas end-use price to the-core nonelectric sectors (dollars per Mcf) } \\
& \text { NG_AVGPR_F }=\text { hub price for firm service [derived from Annual Flów Module solution matrix (dollars } \\
& \text { per Mcf)] }{ }^{49} \\
& \text { LPMU_NONU_F = markup from firm service hub price to core nonelectric sectors, before adjusting for } \\
& \text { pipeline fuel use (dollars per Mct) } \\
& \text { NONU_PR_I = natural gas end-use price for noncore nonelectric sectors (dollars per Mcf) } \\
& \text { NG_MAGPR_I }=\text { hub price for interruptible service [from Annual Flow Module solution matrix (dollars } \\
& \text { per Mcf)] } \\
& \text { LPMU_NONU_I = markup from interruptible service hub price to noncore nonelectric sectors, before } \\
& \text { NEFF_PIPE }=\begin{array}{l}
\text { adjusting for pipeline fuel use (dollars per MCf) } \\
\text { efficiency factor for accounting for fuel use to transport natural gas from the regional }
\end{array} \\
& \text { hub to end-use customers [Appendix E] } \\
& \text { AEFF_PIPE = efficiency factor for accounting for fuel use in the intraregional interstate transport of } \\
& \text { gas [Appendix E] } \\
& i=\text { end-use sector index } \\
& j=\text { region index ( } j, j \text { equates to intraregional activity). }
\end{aligned}
$$

Before completing the processing of nonelectric end-use prices, the DTM checks the prices against a minimum threshold price of $\$ 0.00001$ per Mcf. The purpose of this check is to send a nonzero price to the NEMS Integrating Module in situations where there is no gas consumption by a sector in a given region. Should the end-use price be very small, the price is reset to the last price that is available (either from a previous iteration, model year, or historical period) for the sector and region.

Regional transportation sector end-use prices (assumed to be core) are determined in a similar fashion, but are defined individually for fleet vehicle and personal vehicle use.

Core fleet vehicles

$$
\text { TRFV_PR_F }{ }_{j}=\left(N G \_A V G P R \_F_{j}+\text { LPMU_TRFV_F }\right) i\left(\text { NEFF_PIPE }_{i=4 j} * A_{-} \text {AEFF_PIPE }{ }_{j, j}\right)
$$

Core personal vehicles

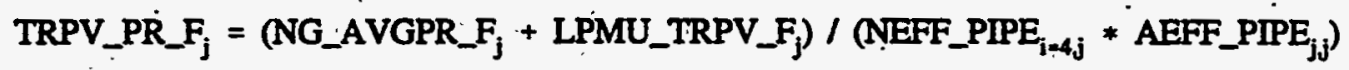

where,

TRFV_PR_F = natural gas end-use price for the fleet vehicle sector (dollars per $\mathrm{Mcf}$ ) .

LPMU_TRFV_F = markup from firm service, hub price to the fleet vehicle transportation sector, before adjusting for pipeline fuel. use (dollars per Mcf)

TRPV_PR_F = natural gas end-use price for the personal vehicle transportation sector (dollars per Mcf)

${ }^{49} \mathrm{~A}$ description of the calculation of an average hub (or transshipment node) price is presented in Chapter 5. 


$$
\begin{aligned}
& \text { LPMU_TRPV_F '= markup from firm service hub price to the personal vehicle transportation sector, before } \\
& \text { adjusting for pipeline futel use (dollars per.Mcf) } \\
& \text { NG_AVGPR_F }=\text { hub price for firm service [derived from Annual Flow Module solution matrix (dollars } \\
& \text { per Mcf)] } \\
& \text { NEFF_PIPE = efficiency factor to account for fuel used to transport natural gas from the regional hub } \\
& \text { AEFF_PIPE }=\text { efficiency factor to account for fuel used for the intraregional tranisport of natural gas } \\
& \begin{array}{l}
\mathbf{i}=\quad \text { end-use sector index ( } \mathrm{i}=4 \text { for transportation sector) } \\
\mathbf{j}=\text { region index (j,jequates to intraregional activity). }
\end{array}
\end{aligned}
$$

If the regional end-use price of CNG for personal vehicles (TRPV_PR_F) is greater than the regional commercial sector motor gasoline price (defined by the Petroleum Market Model), then the resulting price is determined to be the greater of the following:

$$
\begin{aligned}
& \text { 1: } \quad \text { PMGCM } * \text { CFNGN } \\
& \text { 2: TRPV_PR_F }-(\text { RETAII_COST * RETAIL_PCT) } \\
& \text { PMGCM = commercial sector motor gasoline price (dollars per MMBtu). } \\
& \text { TRPV_PR_F = " end-use price of CNG consumed by personal vehicles (dollars per Mcf) } \\
& \text { RETAIL_COST }=\text { dispensing charge above fuel cost (dollars per Mcf) [Appendix E] } \\
& \text { RETAII_PCT = discount on dispensing charge (fraction - 0.20) } \\
& \text { CFNGN }=\text { conversion factor (=1.031 MMBtu per Mcf) } \\
& \mathbf{j}=\text { region index. }
\end{aligned}
$$

\section{Electric Sector End-Use Prices}

An equation similar to that used for the nonelectric sectors is used for determining core end-use prices for the electric generation sector:

$$
\text { UTIL_PR_F } F_{j, n}=\left(N G \_A V G P R \_F_{j}+\text { LPMU_UTIL_F }{ }_{j, n}\right) /\left(U E F F \_P I P E_{j, n} * A E F F \_P I P E_{j, j}\right)
$$

where,

$$
\begin{aligned}
\text { UTIL_PR_F } & =\quad \begin{array}{l}
\text { end-use price for core electric generator sector (dollars per Mcf) } \\
\text { hub price for firm service [derived from Annual Flow Module solution matrix (dollars } \\
\text { per Mcf)] }
\end{array} \\
\text { LPMU_AVGPR_F } & \begin{array}{l}
\text { markup from the firm service hub price to the core electric generator sector, before } \\
\text { adjusting for pipeline fuel.use (dollars per Mcf) }
\end{array} \\
\text { UEFF_PIPE } & =\begin{array}{l}
\text { efficiency factor to account for fuel used to transport natural gas from the regional hub } \\
\text { to electric generator customers [Appendix E] } \\
\text { efficiency factor to account for fuel used for intraregional transport of natural gas }
\end{array} \\
\text { AEFF_PIPE } & \text { [Appendix E] }
\end{aligned}
$$

The end-use prices for the two categories of the noncore electric generator sector are calculated as follows:

Competitive-with-residual fuel

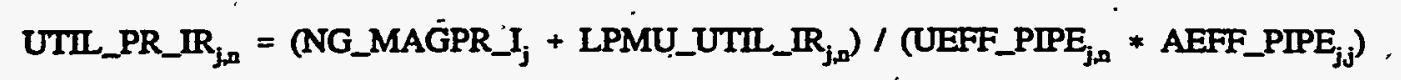

Competitive-with-distillate

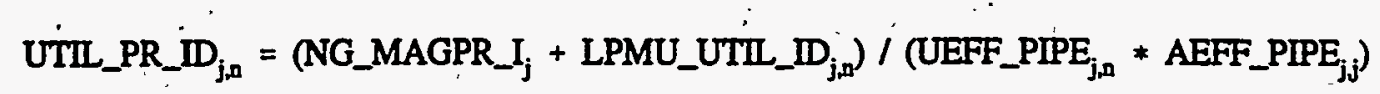

where, 


$$
\begin{aligned}
& \text { UTIL_PR_IR = natural gas end-use price for noncore competitive-with-residual fuel electric generation } \\
& \text { sector (dollars per Mcf) } \\
& \text { LPMU_UTH_IR. = ..markup from interruptible hub price to the noncore competitive-with-residual fuel } \\
& \text { - electric generation sector, before adjusting for pipeline fuel use (dollars per Mcf) } \\
& \text {. UTIL_PR_ID = - natural gas end-use price for nóncore competitive-with-distillate electric generation } \\
& \text { LPMU_UTIL_ID = markup from intermuptible hub price to the noncore competitive-with-distillate electric } \\
& \text { NG_MAGPR_I = : hub price for interruptible service [from Annual Flow Module solution matrix (dollars } \\
& \text { per Mcf)] } \\
& \text { UEFF_PIPE = . efficiency factor to account for fuel used to transport natural gas from the regional hub } \\
& \text { to end-use customers [Appendix E] } \\
& \text { AEFF_PIPE = efficiency factor to account for intraregional transport of natural gas [Appendix E] }
\end{aligned}
$$

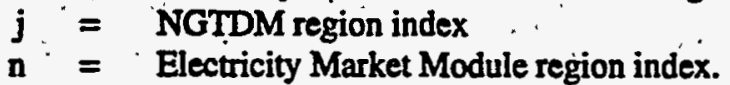

An option for a second methodology for setting noncore electric generator prices is available and has been used in the past. The specific equations follow:

Comperitive-with-residual fuel

$$
\text { UTIL_PR_IR } \mathbb{R}_{\mathrm{j}, \mathrm{i}}=\text { PR_MIN } \mathrm{j}_{\mathrm{j}, \mathrm{R}} \text {. }
$$

where,

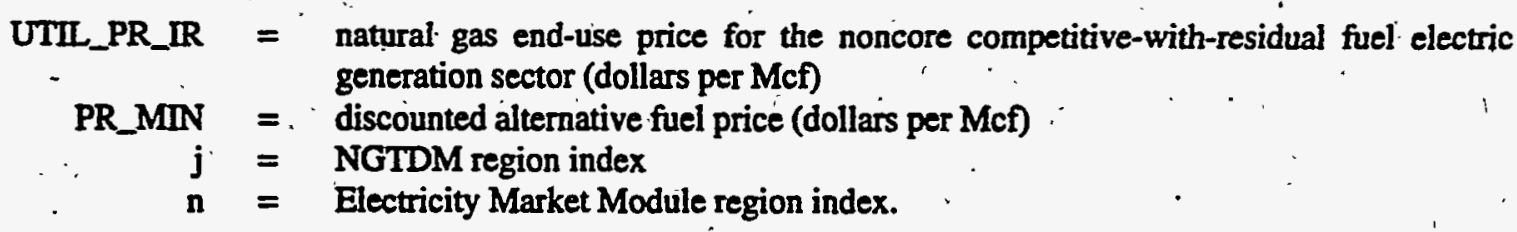

The'discounted alternative fuel price is the product of the alternative fuel price (residual fuel oil) times a discount factor. The discount factor is the lesser of the natural gas-to-residual fuel oil price ratio provided by the Electricity Market Module (GRATMAX, equal to the price at which electric generators will burn the maximum amount of gas as opposed to residual fuel oil) or the natural gas-to-residual fuel oil price ratio specified within the NGTDM (Appendix E, NGRATMAX).

Competitive-with-distillate

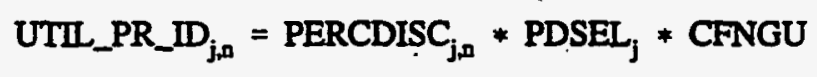

where;

$$
\begin{aligned}
\text { UTIL_PR_ID } & =\text { natural gas end-use price for noncore competitive-with-distillate electric generation } \\
\text { PDSEL } & =\text { sector (dollars per Mef) } \\
\text { PERCDISC } & =\text { alternative fuel price (distillate fuel oil) to the electric generation sector (dollars per } \\
\text { CFNGU } & =\text { convent discount off alternative fuel price (Appendix E, UPDP1) } \\
\mathbf{j} & =\text { NGTDM region index } \\
\mathbf{n} & =\text { Electricity Market Module region index. }
\end{aligned}
$$

Under this alternative option, the effective distributor tariff resulting from setting the end-use price based on the alternative fuel is checked against an assumed minimum (Appendix E - URFLOOR, UDFLOOR). If the minimum is violated the end-use price is adjusted accordingly. Under both options, an aggregate noncore end-use price for the electric generation sector (UTIL_PR_D) is calculated as the quantity-weighted average of both components. 


\section{Markups}

All of the markups from the firm or interruptible hub to the end-use price mentioned above are comprised of four separate cost components - distributor tariffs, intraregional tariffs, intrastate tariffs, and a citygate benchmark factor. These tariff and benchmark components are presented in Figure 6-1. The distributor tariff component is region and sector specific, while the other components are only region specific. Distributor tariffs are calculated within the model each iteration of each forecast year, with historical levels used during historical years. The methodologies used to calculate distributor tariffs for core and noncore customers are defined in the next two section of this chapter. Intraregional pipeline tariffs are provided by the Pipeline Tariff Module each forecast year, while the intrastate tariffs are input assumptions that remain constant throughout the forecast. Citygate benchmark factors are determined endogenously to the model.

\section{Figure 6-1. Tariff and Benchmark Components of Regional Markups}

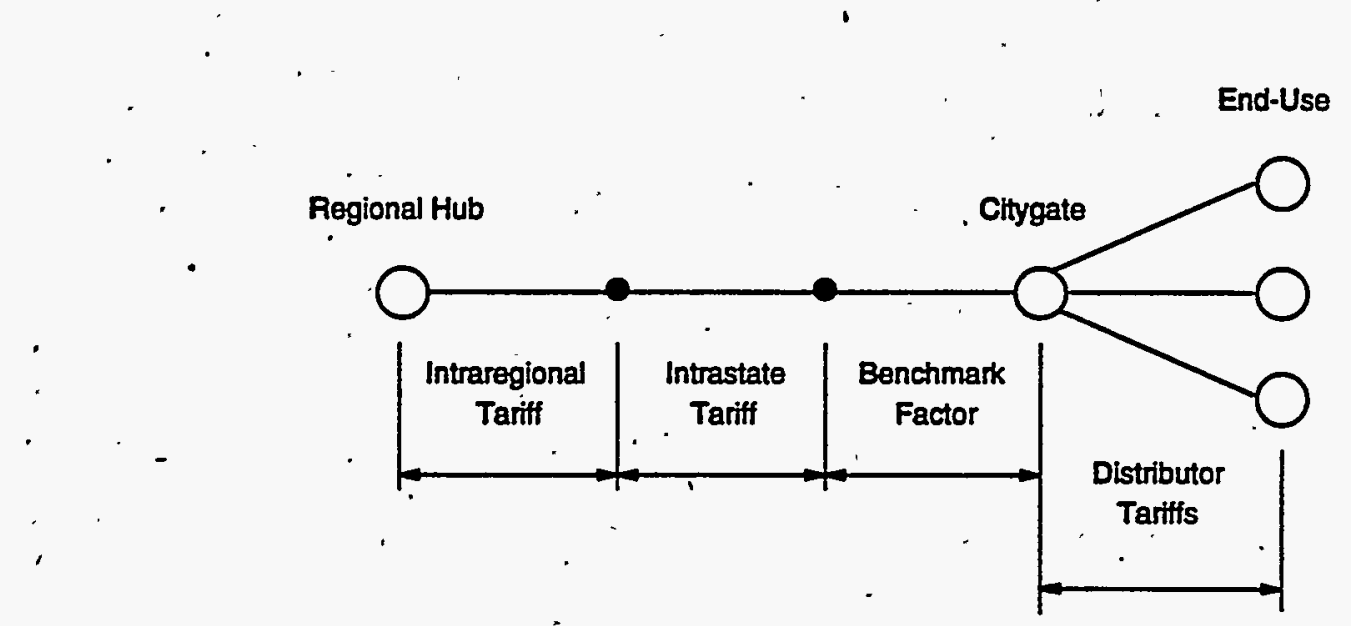

The generic equation for the markups from a hub price to an end-user follows:

$$
\mathrm{LPMU}_{\mathrm{j}}=\mathrm{DTAR}_{\mathrm{j}}+\mathrm{PTAR}_{\mathrm{j}, \mathrm{j}}+\mathrm{INTRA}_{-} \mathrm{TAR}_{\mathrm{j}}+\mathrm{CGBENCH}_{\mathrm{j}}
$$

where,

$$
\begin{aligned}
\text { LPMU } & =\begin{array}{l}
\text { markup from an either firm or interruptible hub price to either the core or noncore end- } \\
\text { use price for a given sector within region } \mathbf{j}
\end{array} \\
\text { DTAR } & =\begin{array}{l}
\text { distributor tariff for either the core or noncore category of a given end-use sector within } \\
\text { region } \mathbf{j}
\end{array} \\
\text { PTAR } & =\begin{array}{l}
\text { tariff for intraregional (firm-PTAR_F or interruptible-PTAR_I) service provided by } \\
\text { interstate pipelines within region } \mathbf{j}
\end{array} \\
\text { tariff. for (firm-INTRA_TARF or interruptible-INTRA_TARD) intrastate, pipeline } & \text { services [Appendix E] }
\end{aligned}
$$

The specific variables used in the NGTDM and referenced in the documentation for each of the sectors/categories represented are shown below (where s represents a sector index): 


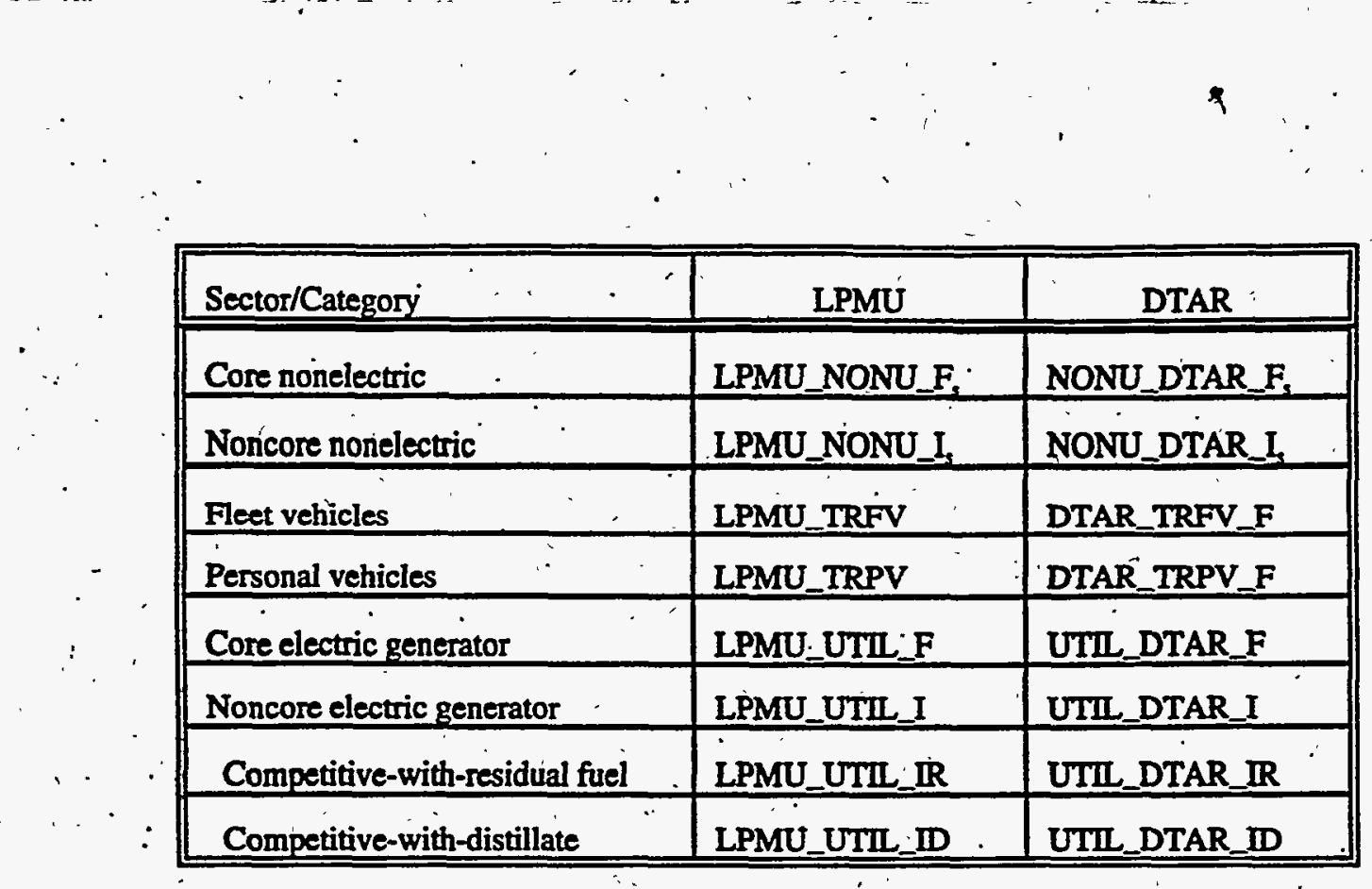

,

\section{Core Distributor Tariffs}

The algorithm that sets distributor tariffs for residential, commercial, and industrial core customers is responsive in part to revenues generated from the noncore segment of the market, user-specified industry efficiency improvements, and user-specified assumptions on bypass by large industrial and electric utility consumers. The methodology is based on * the concept that a portion of the revenues from interruptible customers are used to offset firm revenue requirements as viewed by a local distribution company (LDC). The transportation sector is not included among the sectors for which this algorithm is used because of the current nature of the market: the use of compressed natural gas as a vehicle fuel. is evolving from government/industry sponsored demonstration programs to large scale commercial use. The core electric generation sector is also not included in these calculations because in most cases they do not buy gas through a local distribution company. Therefore, a separate methodology is used to determine distributor tariffs for the transportation and electric generation sectors. These are described separately below.

\section{Residential, Commercial, and Industrial Sectors}

In general, the new DTM algorithm estimates the annual change in total costs associated with providing distribution $\therefore$ services to core ${ }^{50}$ customers, accounts for any recovery of fixed costs from the noncore segment of the market, and adjusts the previous year's distributor tariffs for each of the end-use sectors to reflect the resulting annual change in revenue requirement. First, regional core market revenue requirements (RR_F) are set based on an endogenously derived total cost (TC_F F ) for core distribution services and an assumed noncore markét contribution (ICC) ) to fixed costs. Next, core distributor tariffs (EST_DTAR_F $F_{r, s}$ ) are estimated for each sector and region based on the core distributor tariff (NONU_DTAR_FPREV ${ }_{\mathrm{ts}}$ ) from the previous year and the annual percentage change in natural gas volumes consumed by core customers (QBAS_NONU_F $F_{2 s}$ ). These tariffs are then used to estimate the revenue requirements (EST_RR_F) that would be met from core customers if these estimated distributor tariffs (EST_DTAR_F r) were charged. Finally, core distributor tariffs (NONU_DTAR_F $F_{r e}$ ) for the current forecast year are set by adjusting these estimated regional core distributor tariffs by apportioning the associated difference in revenue requirements (RR_RATIO) between the forecasted and estimated values to the sectors represented based on their relative contribution to the total revenue requirement. The following equations describe this process in mathematical terms:

\section{Variable Definitions}

The variables used in the subsequent equations are defined as follows.

so In this section "core" refers only to the residential, commercial, and core industrial sectors. 
Subscripts and Superscripts

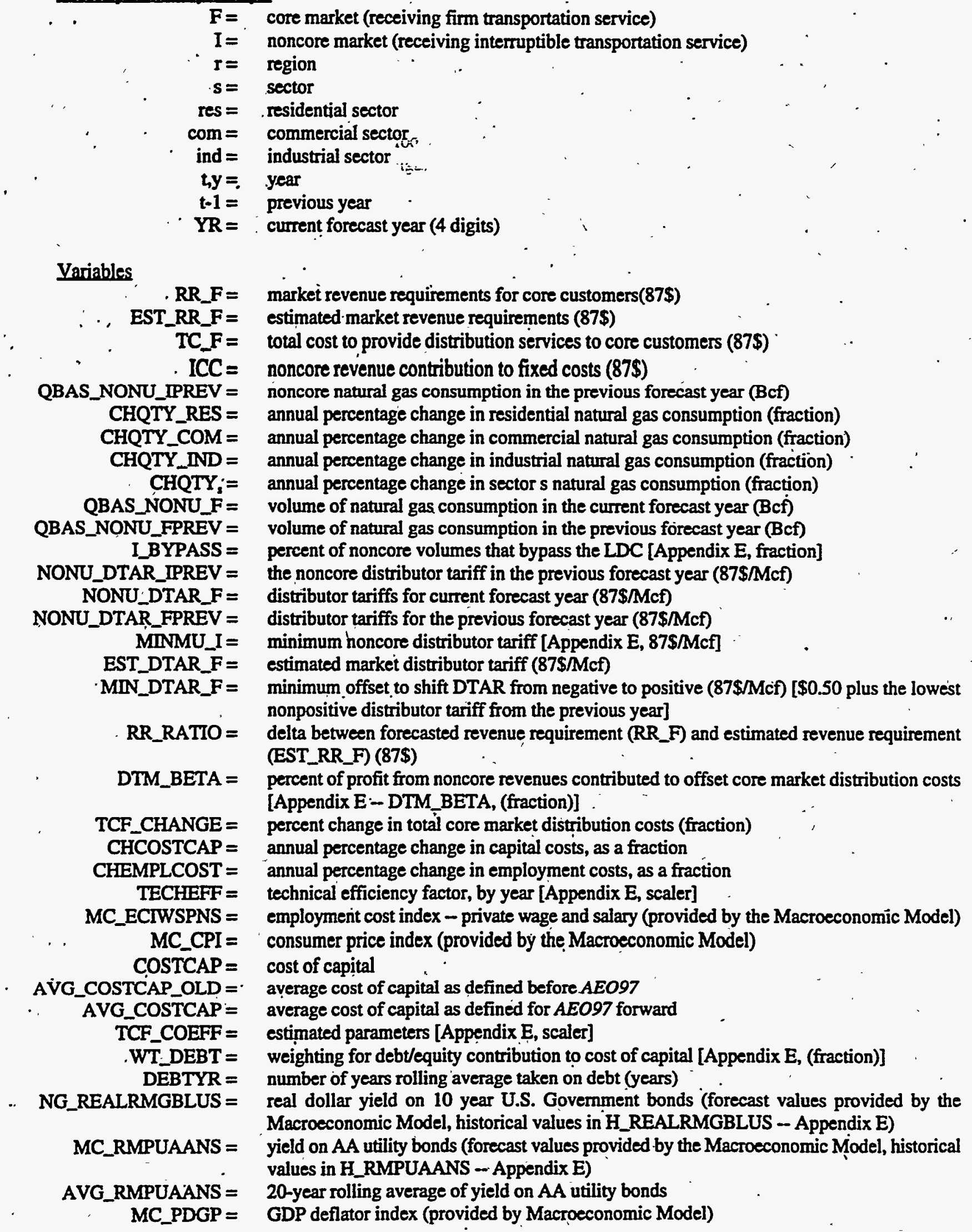


Determine Regional Core Revenue Requirements

Regional core revenue requirements are a function of total core customer related costs and the recover of fixed costs from noncore customers within the region.

Regional core revenue requirements $=$ regional total firm costs - regional noncore contribution to fixed costs

$$
\dot{R R}_{-} F_{\mathrm{r}}=\text { TC_F } F_{\mathrm{r}}-\mathrm{ICC} \dot{C}_{\mathrm{r}}
$$

The following relationship is built on the assumptions that a portion (I_BYPASS) of the norcore customers bypass the LDC, ${ }^{\text {s1 }}$ that the regional noncore recovery of fixed costs is a proportion DTM_BETA of the regional noncore profits collected by the LDC, and that noncore profits represent noncore revenues that exceed the cost of providing noncore services, as follows:

Regional noncore contribution to fixed costs $=[$ total regional noncore volume * $(1-$ LDC bypass) * (regional noncore distributor tạiff - minimum regional noncore distributor tariff) * DTM_BETA

$$
\begin{aligned}
& \mathrm{ICC}_{t}=\sum_{s}\left[\text { QBAS_NONU_IPREV } v_{t, s}^{*} \text { * }\left(1-\text { I_BYPASS }_{\mathrm{r}}\right)\right. \text {, } \\
& \text { (NONU_DTAR_IPREV } \left.{ }_{\mathrm{r}, \mathrm{s}}-\text { MINMU_l) }\right\} \text { * DTM_BETA }
\end{aligned}
$$

Due to the lack of available data for regional costs related to core distributor services, historical values for these costs are derived from the data that are available and annual changes in costs are forecast using model input parameters. Some of these parameters were based on statistical estimates presented by Mary Lashley Barcella in her paper, "Wholesale and Retail Analysis for Estimating the Price Effect of Natural Gas Conservation." The paper presents a total distributor cost equation with parameters estimated on the basis of data from 64 local gas distribution companies covering the period 1969 through 1993. Selected parameter estimates (TCF_COEFF) from her work have been used to forecast the annual change in total regional distributor costs associated with core customers, as shown below:

$$
\begin{aligned}
& \text { TCF_CHANGE }=\left[\text { TCF_COEFF } 1 \text {.CHQTY_RES }+ \text { TCF_COEFF }{ }_{2} * \text { CHQTY_COM } r\right. \\
& \text { TCF_COEFF } 3 * \text { CHQTY_IND }+ \text { TCF_COEFF }_{4} * \mathrm{CHCOSTCAP}_{5}+ \\
& \text { TCF_COEFF }{ }_{5} \text { *CHEMPLCOST, ] }
\end{aligned}
$$

The CHQTY_RES, CHQTY_COM, and CHQTY_IND terms represent percentage change in volume, calculated as follows:

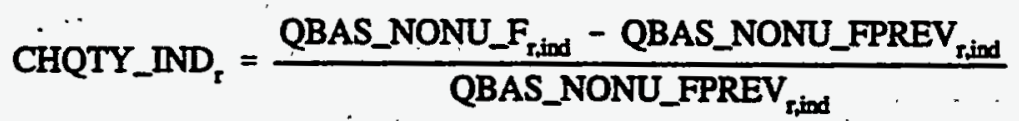

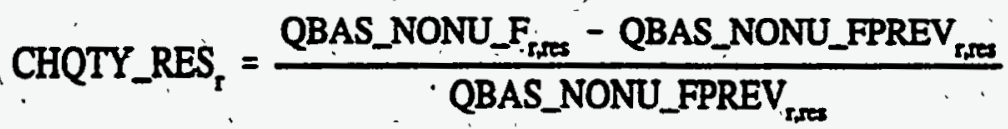

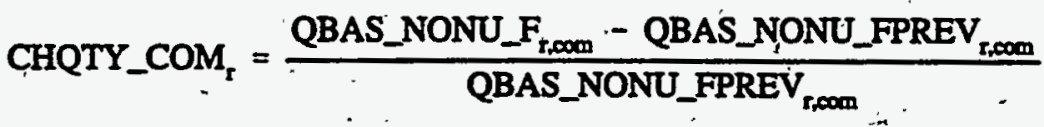

The percentage change in employment costs (CHEMPLCOST) is calculated using the variables MC_ECIWSPNS and MC_CPI, set within the Macroeconomic Model of the NEMS, as follows:

\footnotetext{
${ }^{51}$ Only noncore customers are assumed to bypass the local distribution companies.
} 


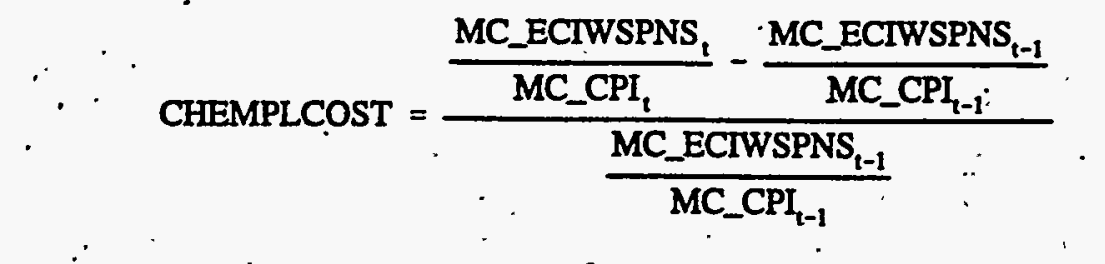

Before the AEO97 version of the model, the percentage change in cost of capital (CHCOSTCAP) was obtained using an average cost of capital (represented as a three year rolling average). The cost of capital was approximated using a weighted average of the yield on AA bonds (20-year rolling average, DEBTYEAR) and the yield on 10-year government bonds. For the AEO97 version forward, the actual historical series for the average cost of capital that was used in the total cost estimation was obtained from Mary Barcella. Then, an equation was estimated (Appendix F, Table F5) to forecast this series (AVG_COSTCAP) as a function of the previously used series for the average cost of capital (AVG_COSTCAP_OLD), The corresponding equations are:

$$
\text { CHCOSTCAP }=\frac{\text { AVG_COSTCAP, }- \text { AVG_COSTCAP }_{t-1}}{\text { AVG_COSTCAP }_{t-1}}
$$

where,

$$
\begin{aligned}
& \text { AVG_COSTCAP }_{\mathbf{t}}=7.44691+1.22689 * \text { AVG_COSTCAP_OLD }_{\mathbf{t}}+71.60079 *(\mathrm{YR}-1979)^{-0.7} \\
& A_{\text {AVG_COSTCAP_OLD }}=\frac{\operatorname{COSTCAP}_{t}+\operatorname{CosTCAP_{t-1}+\operatorname {COSTCAP}}{ }_{t-2}}{3} \\
& \operatorname{COSTCAP}_{\mathrm{t}}=\text { WT_DEBT *AVG_RMPUAANS }{ }_{\mathrm{t}}+ \\
& \left(1-W T \_D E B T\right) * \text { NG_REALRMGBLUS }
\end{aligned}
$$

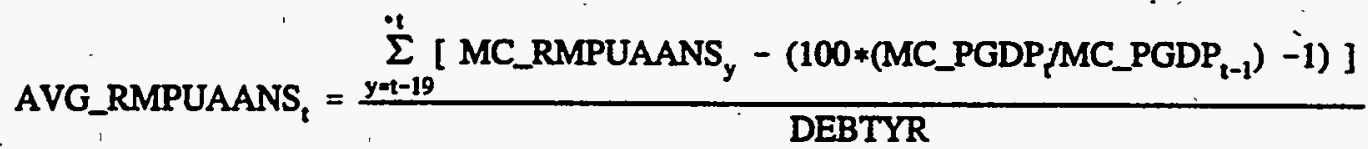

Finally, the total cost for distributor service to core customers for the forecast year, by region, is:

$$
\text { . TC_ } F_{\mathrm{r}}=\mathrm{TC}_{-} \mathrm{F}_{\mathrm{r}, \mathrm{-1}} *\left(1+\mathrm{TCF}_{-} \mathrm{CHANGE}_{\mathrm{g}}\right) * \mathrm{TECHEFF}_{\mathrm{t}}
$$

The TECHEFF term is present to capture the impact of advances in technical efficiencies.

\section{Estimate Core Distributor Tarriffs and Corresponding Revenue Requirements}

Regional core distributor tariffs are estimated for each end-use sector as a function of corresponding firm tariffs in the previous year and the annual percentage change in core consumption or volumes.

$$
\begin{aligned}
& \text { EST_DTAR_F } F_{s, s, t}=[(\text { NONU_DTAR_FPREV } \\
& \left.\left(T_{C F} \text { COEFF } ; ~ * \text { CHQTY }_{r, s} * T_{2} F_{r, t-1}\right)\right] / \text { QBAS_NONU_F } F_{r, s}
\end{aligned}
$$

where TCF_COEFF (Appendix E) are the various parameter estimates for the end-use sector terms from Mary Lashley Barcella's study (also used in equation 48). The annual change in the EST_DTAR_F value is limited to a user specified level (Appendix E, MAXCHNG) to prevent an unreasonable adjustment from one year to the next. These distributor tariffs are then used to obtain an estimate of regional core revenue requirements: 


$$
\begin{aligned}
& \text { EST_RR_F }=\text { EST_DTAR_F } F_{\mathrm{r}, \mathrm{ses}} * \text { QBAS_NONU_F } \\
& \text { EST_DTȦR_F } \\
& \text { EST_DTAR_F } F_{\text {rind }} * \text { QBAS_NONU_F }
\end{aligned}
$$

\section{Determine Final Core Distributor Tarifis}

- Final core distributor tariffs for each region are determined by adding an adjustment factor to the estimated distributor tariff to account for the difference between the forecasted and estimated core revenue requirements. This adjustiment factor (adjDTAR) is set by apportioning this difference in revenue requirements to the represented sectors based on an estimate of.each sector's relative contribution to the total revenue requirement, as follows:

$$
\begin{aligned}
& R R_{-} \text {RATIO } \mathrm{r}=\text { RR_F }- \text { EST_RR_F }
\end{aligned}
$$

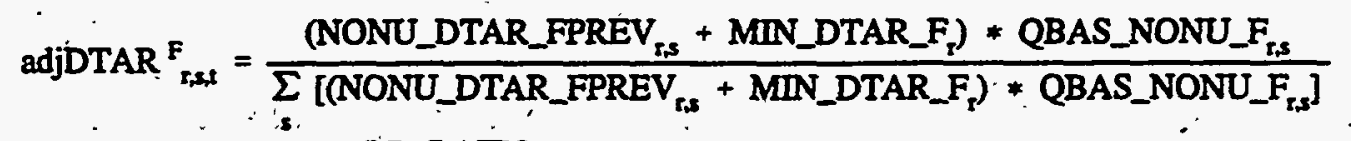

$$
\begin{aligned}
& \text { * } \frac{\text { RR_RATIO }}{\text { QBAS_NONU_F }} \\
& \text { NONU_DTAR_F } F_{r, s}=\text { EST_DTAR_F } F_{r, s}+\operatorname{adjDTAR}{ }_{r, s, s t}^{F_{1}}
\end{aligned}
$$

The.MIN_DTAR_F term was added to counter the impact of having any negative tariffs in the equation. It is set equal to the absolute value of the largest negative distributor tariff across the three sectors (residential, commercial, and industrial) in a given region. If there are no negative distributor tariffs, MIN_DTAR_F is set to zero.

\section{Determine Base Year Total Core Market Distribution Costs}

Total core market distribution costs need to be established in the base year (1995 for $A E O 98$ ) to provide a lagged value for total costs in equation 58 . This can be calculated using a form of equation 46 above:

$$
T_{C} F_{r}=R R_{-} F_{r}+I C C_{r}
$$

For the base year, the model reads historical firm citygate prices by region (Appendix E, HCGPR_F) and historical enduse prices for the residential and commercial sectors by region. Historical interruptible citygate prices are assumed to equal the regional average wellhead price plus a small value (Appendix E, CGPR_MUI). Historical prices for the industrial and electric generator sectors are derived endogenously based on data inputs (Appendix F, Tables F6 and F7), however these calculations could have also been done exogenously. From these data core and noncore distributor tariffs are derived for each sector in each region. Given user spécified assumptions for I_BYPASS, MINMU_I, and DTM_BETA, equation 47 above can be used to derive ICC $r$ Then, assuming that regional revenue requirements are equal to firm revenues, firm revenue requirements (RR_F ) can be estimated as the product of firm distributor tariffs and volumes. Thus, base year total costs are derived.

\section{Electric Generation Sector}

The distributor tariffs for the core electric generation sector are initially set to values reflective of the last historical year (1996 for AEO98). Each forecast year (beyond 1996) one or two adjustments are made to these initial tariffs based on analyst judgement. First, in regions were the initial values are exceptionally low (probably due to specially arranged deals that are not reflective of market conditions), it was assumed that these low levels would not be retained indefinitely. Therefore, an assumed annual growth rate (0.95) is applied whenever the previous year's tariff is less than $-\$ 1.00$. Second, for all regions, an adjustment factor is added to reflect additional costs incurred for expanded infrastructure (not captured elsewhere in the model) to support increased electric generator consumption. This adjustment factor is a function of the annual percentage change in the regional electric generator consumption, as follows: 
UTIL_DTAR_F $=$ UTIL_DTAR_FPREV ${ }_{\mathrm{r}} *($ growth factof $)+$ CHQTY $_{\mathrm{s}} * 0.05$

where,

UTIL_DTAR_F = distributor tariff for core electric generation sector in current forecast year (\$/Mcf)

UTIL_DTAR_FPREV = distributor tariff for core electric generation sector in previous forecast year (\$/Mcf)

growth factor $=$ set to 0.95 if UTIL_DTAR_FPREV is less than $-\$ 1.00$, else set to 1.0

CHQTY = annual percentage change in core electric generator consumption (fraction).

$\mathbf{r}=$ region

The percentage change in core electric consumption is limited to be between -2 and 2 and is set as follows:

$$
\mathrm{CHQTY}_{\mathrm{s}}=\frac{\text { QGFELGR }_{\mathrm{r}, t}-\text { QGFELGR }_{\mathrm{rtt-1}}}{\text { QGFELGR }_{\mathrm{r}, t-1}} .
$$

where,

$$
\text { QGFELGR = core electric generator consumption in indicated year (MMBtu) }
$$

In historical years, UTIL_DTAR_F is set to historically based values, historical end-use prices (Appendix F, Table F6, HPGFELGR) minus historical citygate prices (Appendix E, HCGPR_F).

\section{Transportation Sector}

Consumers of compressed natural gas (CNG) have been classified into two end-use categories within the core transportation sector: fleet vehicles and personal vehicles. Two different pricing methodologies are defined for determining distributor tariffs to these two end-use categories, with the sector average (NONU_DTAR_Fimjiregios) being determined as a quantity weighted average of both end-use categories. Distributor tariffs associated with fleet vehicles are a function of the historical distributor tariffs, a decline rate, and state and federal taxes, as shown:

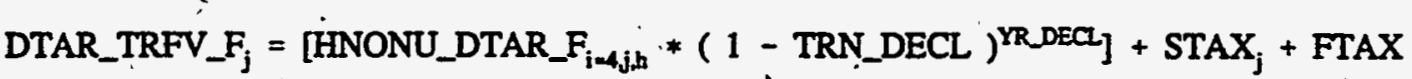

where,

$$
\begin{aligned}
& \text { DTA } \dot{R}_{-} \text {TRFV_F }=\text { distributor tariff for the fleet vehicle transportation sector, before adjusting for pipeline } \\
& \text { fuel use (dollars per Mcf) } \\
& \text { HNONU_DTAR_F = historical distributor tariff for the transportation sector (assumed to be primarily for } \\
& \text { fleet vehicles), before adjusting for pipeline fuel use (dollars per Mcf) } \\
& \text { TRN_DECL = fleet vehicle distributor decline rate, set to zero for AEO98 [Appendix E, (fraction)] } \\
& \text { YR_DECL = difference between the current year and the last historical year over which the decline } \\
& \text { rate is applied } \\
& \text { STAX = CNG state taxes (dollars per Mcf) } \\
& \text { FTAX : = CNG federal tax (dollars per Mcf) } \\
& i=\text { end-use sector index } \\
& \mathrm{j}=\text { region index } \\
& \mathrm{h}=\text { index for last year historical data are available. }
\end{aligned}
$$

The methodology used to determine distributor tariffs for CNG consumed by personal vehicies is called the full cost price method. Under this method, the distributor tariff is derived as a function of the full cost of delivering CNG to these altemate fuel vehicles. Thus, the distributor tariff is set equal to the sum of the core industrial distributor tariff, the cost of dispensing CNG at a high volume service station, State motor vehicle fuel tax applied to CNG, and Federal motor vehicle fuel tax applied to CNG, as shown in the following equation:

$$
\text { DTAR_TRPV_F } F_{j}=\text { NONU_DTAR_F } F_{i=3 j}+\text { RETAII_COST }+S T A X_{j}+\text { FTAX }
$$

where, 
DTAR_TRPV_F $=\therefore$ distributor tariff for the personal vehicle transportation sector, before adjusting for pipeline fuel use (dollars per Mcf)

NONU_DTAR_F · = distributor tariff for the core industrial sector, $\mathrm{i}=3$ (dollars per Mcf)

RETAIL_COST. $=$ cost of dispensing CNG [Appendix E, (dollars per Mcf)]

STAX : = State motor.vehicle fuel tax applied to CNG [Appendix E, (dollars per Mcf)]

FTAX = Federal motor vehicle fuel tax applied to CNG [Appendix E, (dollars per Mcf)]

$i=$ end-use sector index ( $i=3$ for the industrial sector)

$\mathbf{j} \cdot=$ region index.

\section{Noncore Distributor Tariffs}

The specific methodology used for setting noncore distributor tariffs for both the industrial and electric generator sectors is described below. For both sectors, the historical distributor tariffs are calculated as the historical end-use price minus an assumed citygate price for the internuptible market. Within the model, the historical interruptible citygate prices are set as the wellhead price, in a region, plus a small exogenously specified value (A'ppendix E, CGPR_MUI). Historical end-use prices for the industrial and electric generator sectors are also set in the model, as described in Tables F6 and F7 of Appendix F.

\section{Industrial Sector}

Regional distributor tariffs for noncore industrial customers are established by applying a decline rate to the regional historical distributor tariffs that correspond to the last year historical data are available. Note that a small delta has been added to the historical tariff and then subtracted from the declined tariff in order to reverse the impact of a decline rate on the negative historical tariffs (if any). The corresponding equation is:

$$
\begin{aligned}
& \text { NONU_DTAR_I } I_{i=3 j}=\left[(1 .- \text { NONU_DTARI_DECL })^{\text {YRPECI * }}\right. \text { * } \\
& \text { ( (HNONU_DTAR_I } \mathrm{i}_{\mathrm{i}-3, \mathrm{j}, \mathrm{h}}+\text { CGDELTA_N } \mathrm{N}_{\mathrm{j}} \text { )] - CGDELTA_N } \mathrm{N}_{\mathrm{j}}
\end{aligned}
$$

where,

NONU_DTAR_I = distributor tariff for the noncore industrial sector $(\mathrm{i}=3)$, before adjusting for pipeline

fuel use (dollars per Mcf) :

HNONU_DTAR_I = historical distributor tariff for the noncore industrial sector, $\mathrm{i}=3$ (dollars per Mcf)

NONU_DTARI_DECL $=$ decline rate, set to zero for $A E 098$ [Appendix E, (fraction)]

- YRDECL $=$ difference between the current year and the last historical year over which the decline rate is applied

CGDELTA_N = delta to reverse the impact of a decline rate on any negative historical tariffs (set to the absolute value of the largest riegative value of HNONU_DTAR_L $3, j$ for all $j$ regions in the last historical year) [dollars per Mef]

$i=$ end-use sector index ( $i=3$ for industrial sector)

$\mathbf{j}=$ region index

$\mathrm{h}=$ index for last year historical data are available.

\section{Electric Generator Sector}

The methodology used to define distributor tariffs for both the competitive-with-distillate and the competitive-withresidual fuel categories of the noncore electric generator sector is similar to that used for the noncore industrial sector. A decline rate is applied to the regional historical tariffs that corresponds to the last year historical data are available. Again, a small delta has been added to the historical tariff and then subtracted from the declined tariff in order to reverse the impact of a decline rate on any negative historical tariff, as follows: 
Competitive-with-residual fuel

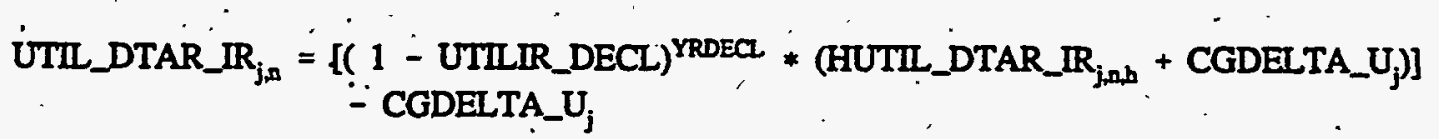

Competitive-with-distillate

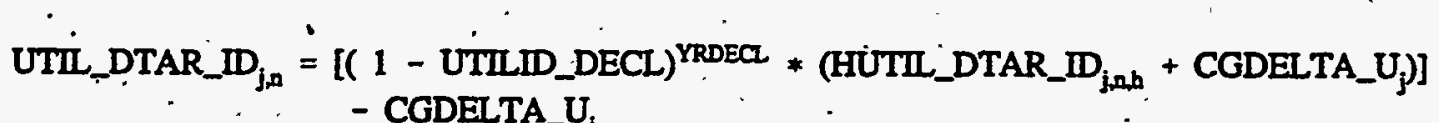

where,

$$
\begin{aligned}
& \text { UTIL_DTAR_IR = distributor tariff for the noncore competitive-with-residual fuel electric sector, before } \\
& \text { adjusting for pipeline fuel use (dollars per Mcf) } \\
& \text { HUTIL_DTAR_IR = historical distributor tariff for the noncore competitive-with-residual fuel electric sector } \\
& \text { UTILIR_DECL = . decline rate for competitive-with-residual fuel distributor tariff, set to zero for } A E O 98 \\
& \text { [Appendix E, (fraction)] } \\
& \text { UTIL_DTAR_ID = distributor tariff for the noncore competitive-with-distillate electric sector, before } \\
& \text { HUTIL_DTAR_ID = } \quad \begin{array}{l}
\text { adjusting for pipeline fuel use (dollars per Mcf) } \\
\text { historical distributor tariff for the noncore competitive-with-distillate electric sector }
\end{array} \\
& \text { (dollars per Mcf) } \\
& \text { UTILID_DECL = decline rate for competitive-with-distillate distributor tariff, set to zero for AEO98 } \\
& \text { [Appendix E, (fraction)] } \\
& \text { YRDECL }=\text { - difference between the current year and the last historical year over which the decline } \\
& \text { rate is applied } \\
& \text { CGDELTA_U = delta to reverse the impact of a decline rate on a negative historical tariff (set to the } \\
& \text { absolute value of the largest negative value of HUTIL_DTAR_IR and } \\
& \mathbf{j}=\text { region index } \\
& \mathrm{n}=\text { Electricity Market Model region index } \\
& \mathrm{h}=\text { index for last year historical data are available. }
\end{aligned}
$$

If a region's distributor tariff for the competitive-with-distillate category in the last historical year is below $\$ 0.05$, it is progressively scaled upward each year so that it equals $\$ 0.05$ by the last forecast year (2020).

\section{Regional Citygate Benchmark Factors}

Regional citygate benchmark factors are established for each year that historical and Short-Term Energy Outlook (STEO) data are available, and are used to calibrate the model to historical and STEO values. In historical years, citygate benchmark factors represent the differences between historical citygate prices and citygate prices derived by the NGTDM for the historical years. Given the mathematical relationships in the model, the differences between the historical and model core citygate prices are equal to the differences between the historical and model residential (defined as core) prices. Therefore, the firm citygate benchmárk factors are calculated as followș:

$$
\text { CGBENCHF }_{j, t}=\left(\text { HPGFRSGR }{ }_{j, t}-\text { NONU_PR_F } F_{i=1, j, t}\right) * N_{1}
$$

where,

$$
\begin{aligned}
\text { CGBENCHF } & =\begin{array}{l}
\text { citygate benchmark factor (dollars per Mct) } \\
\text { HPGFRSGR }
\end{array} \\
\text { historical natural gas end-use price for the residential sector [Appendix E, (dollars per } & \begin{array}{l}
\text { Mcf)] } \\
\text { model solution for the natural gas end-use price for the residential sector, i=1 (dollars }
\end{array} \\
\text { NEFF_PIPE } & =\begin{array}{l}
\text { per Mcf) } \\
\text { efficiency factor to account for fuel used to transport natural gas from the regional hub } \\
\text { to end-use customers [Appendix E]. }
\end{array}
\end{aligned}
$$


AEFF_PIPE $=$ efficiency factor to account for fuel used for intraregional transport of natural gas

$$
\begin{aligned}
& \mathbf{t}=- \text { model year index } \\
& \mathbf{i}=\cdots \text { end-use sector index (i=1 for residential sector) }: \\
& \mathbf{j}=\text { region index, }
\end{aligned}
$$

An equivalent method for calculating the interruptible benchmark factor was used. The differences in the historical and'. model noncore industrial end-use prices equal the differences in historical and model citygate prices. Therefore, the interruptible benchmark factors are calculated as follows: ' .

$$
\text { CGBENCHI }_{j, t}=\left(\text { HPGINGR }_{j, r}-\text { NONU_PR_I } I_{i=3,2, k}\right) * N E F F \_P I P E_{i=3, j} * \text { AEFF_PIPE }
$$

where,

$$
\begin{aligned}
& \text { CGBENCHI = citygate benchmark factor (dollars per Mct) } \\
& \text { FPGIINGR = historical natural gas end-use price for the noneore industrial sector [Appendix F, Table } \\
& \text { F7, (dollars per Mcf)] } \\
& \text { NONU_PR_I = model solution for the natural gas end-use price for the noncore industrial sector, } i=3 \\
& \text { NEFF_PIPE = efficiency factor to account for fuel use to transport natural gas from the regional hub } \\
& \text { : to end-use customers [Appendix E] } \\
& \text { AEFF_PIPE = efficiency factor to account for fuel use for the intraregional transport of natural gas } \\
& \mathrm{t} \text {. }=\text { [Appendix E] : } \\
& i=\text { end-use sector index ( } i=3 \text { for industrial sector) } \\
& \mathbf{j}=\text { region index. }
\end{aligned}
$$

For the first iteration of the first model forecast year (1990) of the simulation, the benchmark factors are set to zero within the DTM. For subsequent iterations and years of the historical period (1990 through 1996), the NGTDM computes benchmark factors as described above. In the STEO years (1997 and 1998) a similar process was applied. However, since the STEO only provides national level forecasts for the residential and electric generation sectors, regional STEO end-use prices were derived by scaling the regional model results accordingly. In addition, the scaied noncore electric -generation end-use prices were used instead of noncore industrial prices. After the STEO years, the portion of the citygate benchmark factors attributable to benchmarking to STEO is progressively phased out, so that by the year STPHAS_YR (Appendix E); CGBENCHF and CGBENCHI equal their values in the last historical year. 


\section{Capacity Expansion Module Solution Methodology}

The Capacity Expansion Module (CEM) is a component of the Natural Gas Transmission and Distribution Model (NGTDM). Its function is to determine future interstate pipeline and storage capacity expansion requirements, firm and total pipeline utilization estimates, and net storage withdrawal levels to meet core and noncore demand. This information is subsequently used by the Annual Flow Module and/or the Pipeline Tariff Module. A flow diagram illustrating the general structure of the CEM is provided in Figure 7-1. These results are determined based on an equilibrium between - expected changes in gas consumption levels and supply availability corresponding to a CEM forecast year (represented as the Annual Flow Module model year " $t$ ", plus " $n$ " look-ahead years)..$^{52}$ Like the Annual Flow Module, it is structured as a transportation network servicing both core and noncore customers; however, it bases its capacity and storage utilization/expansion decisions on seasonal firm service loads, thus accounting for peak period and off-peak period consumption requirements. This two-period network structure allows for a more accurate representation of the capacity build decișions and storage requirements, as well as a mechanism for setting maximum utilization levels for the Annual . Flow Module.

Formulated as a linear program, the CEM determines the capacity expansion and flow decisions which correspond to the least cost solution for achieving an equilibrium between expected supply and demand levels for natural gas. It is designed to determine pipeline and storage expansion and utilization levels that correspond to satisfying core and noncore demands represented in both the peak and off-peak periods. Price curves for storage and pipeline expansion are employed to represent the costs associated with expansion options. The decision to expand capacity in the model is based on the criterion that peak period firm service requirements for design weather conditions ${ }^{33}$ must be met. Thus, when current capacity levels are fully utilized, the model simultaneously determines the relative difference in price to the consumer among the following activities: (1) adding more pipeline capacity, (2) adding more storage capacity to enable the transfer of gas to a core customer in the peak period, (3) adding no more pipeline or storage capacity but taking an alternate route, and/or (4) temporary interruptions of supplies to some noncore customers. Given that the price to the consumer is a combination of the wellhead price, the transportation charge, and the storage fee, the availability of supply and its relative regional price are included in this determination. The location and amount of pipeline and/or storage capacity expansion determined by the CEM serve to satisfy the Nation's expected firm service requirements for the lowest price to the consumer.

For this model to operate properly, a number of parameters are derived. Some are derived from data passed from other NEMS models, such as supply curve coefficients and expected core and noncore consumption levels. Others are based on the results from other NGTDM modules, such as the price (or tarifi) curves for interregional pipeline and storage capacity expansion provided by the Pipeline Tariff Module. Finally, some of the parameters for the CEM are based on exogenously determined relationships and are assigned directly within the module.

The following sections present the CEM in more detail. The methodologies used to represent supply, demand, pipeline capacity price curves, and storage capacity price curves used in the CEM are presented first. Then, a general description of the CEM linear program is presented, followed by a mathematical specification. Finally, the methodologies used to calculate the maximum pipeline utilizations and the net storage flows used by the Annual Flow Module are provided. The variables for which the CEM solves are: (1) the flows along each arc (including flows associated with storage), (2) the incremental pipeline capacity expansion required for each arc, and (3) the storage capacity expansion required for each region.

\footnotetext{
Díne lök-ahead year $n$ (currently set to 2) is an input parameter that represents the minimum planning horizon for constructing - new pipeline and storage capacity in the CEM (i.e., the time between the final decision to build and the time when the facility is fully operational).

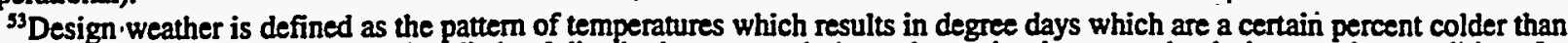
normal. Firm service customers (primarily local distribution companies) use demand estimates under design weather conditions for assessing their. future need for firm pipeline transportation service.
} 
Figure 7-1. Capacity Expansion Module System Diagram

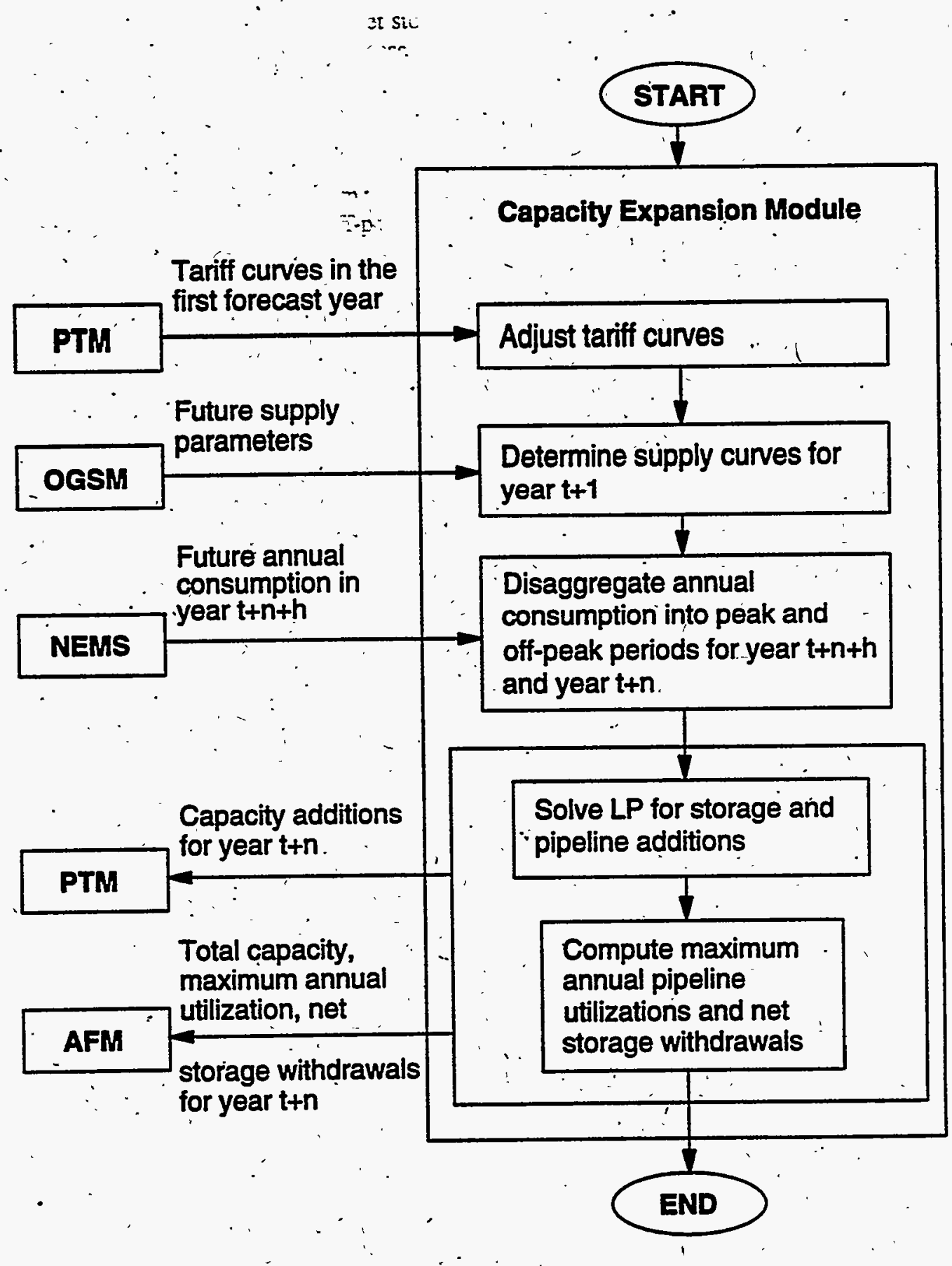




\section{Supply Representation}

As with the Annual Flow Module, natural gas supply sources have been classified into the following basic categories: nonassociated and associated-dissolved onshore and offshore dry gas production, Canadian and Mexican imports, liquefied natural gas imports, Alaskan gas transported via the Alaskan Natural Gas Transportation System, synthetic natural gas, and other supplemental supplies. Of these categories, all except nonassociated onshore and offshore, and synthetic natural gas production are considered to be constant (or fixed) supplies within the CEM. The approach used to represent variable $e^{54}$ supply sources is similar to that used in the Annual Flow Module. When a supply source is designated as fixed, the annual production is split into peak and off-peak levels based on assumed shares (Appendix E, SUP_PKSHR). When a supply source is designated as variable, the portion of the annual production that can be used in either period is capped at assumed percentages of the annual production (Appendix E -. SUP_PUTILZ, SUP_OUTILZ).

\section{Dry Gas Production}

Both onshore and offshore dry gas production levels are a function of regional beginning-of-year natural gas reserve levels and expected production-to-reserves ratios, with functional forms identical to those used in the Annual Flow Module. The parameters defining these supply curves (provided by the Oil and Gas Supply Model) correspond to production levels for the year following the Annual Flow Module forecast year (current model year plus 1) and, therefore, serve as an approximation for supplies available to the CEM in the CEM forecast year (defined as current model year plus $\mathbf{n}$ ): As in the Annual Flow Module, maximum and minimum supply levels are represented for each region. The minimum supply is defined as a specified percentage (Appendix E, PARM_MINPR) below the product of the reserves and the production-to-reserves ratio. Likewise, the maximum supply is determined to be a specified percentage (Appendix E, PARM_MAXPR) above the product of the reserves and the production-to-reserves ratio.

\section{Natural Gas Pipeline Imports}

Imports from Mexico and Canada for each CEM forecast year are represented for each border crossing nodè as fixed supply sources. Mexican imports are made available to the firm network only. These imports are provided directly by the Oil and Gas Supply Model as annual supplies. The CEM then uses exogenously defined values (Appendix E, SUP_PKSHR) to split these annual numbers into seasonal supply levels (peak and off-peak splits). Canadian peak/offpeak and firm/interruptible imports are determined from Canadian pipeline capacities and utilizations (annual and seasonal). Canadian pipeline capacities are exogenously defined by pipeline (Appendix E, CANCAP), and then aggregated to the six border crossing ares within the NGTDM network. Seasonal utilizations (Appendix E CAN_UTILZ) are exogenously defined for the NGTDM and kept constant until a user-defined year (Appendix E, CAN_UTIL_SYRI), after which the peak and off-peak utilizations are increased based on a growth rate (Appendix E, CAN_UTIL_GRW1) and their approach to an exogenously defined maximum utilization (Appendix E, CAN_UTIL_MAX). In a subsequent year (Appendix E, CAN_UTIL_SYR2) the growth rate is changed to CAN_UTIL_GRW2 (Appendix E). The peak firm utilization is set as a fraction (Appendix E, CAN_UTIL_PF_P) of the peak utilization. Annual utilizations are approximated using the AFM output values from the most recent forecast year. The Canadian produced natural gas which passes through the United States on its way to Canadian markets (as described in Chapter 3) is split into peak and off-peak levels based on assumed shares (Appendix E, CANFLO_PFSHR).

\section{Liquefied Natural Gas Imports and the Alaskan Natural Gas Transportation System}

The levels of liquefied natural gas imports into the four designated entry points, and the level of gas entering the United States via the Alaskan Natural Gas Transportation System, are provided to the CEM, as well as the Annual Flow Module, by the Oil and Gas Supply Model. For both of these sources, the level of supply assumed in the CEM for a future

\footnotetext{
price.

The production levels for variable supply sources are endogenously determined within the CEM as a function of the natural gas
} 
forecast year, is the level of supply the Annual Flow Module will actually see in that forecast year, (i.e., the CEM operates under perfect foresight with regard to these two supply categories).

The solution price from the Annual Flow Module at the nearest associated marketnode is provided to the Oil and Gas Supply Model at the end of each forecast year, and is used as a basis for deciding whether or not the capacity at the associated gasification plant will be expanded. The Oil and Gas Supply Model assumes that any added capacity will not be available for use until at least " $n$ " years (as defined in the CEM) after the decision is made to expand. The decision to build is not reversed, even if the price in intervening years falls below the originally required threshold price. The utilization rates for the gasification plant capacities are set exogenously. Because of the lead time for these builds, the Oil and Gas Supply Model is able to provide the CEM with the import levels for liquefied natural gas for " $n$ " years beyond the current forecast year.

Within the Oil and Gas Supply Model; the initial build (for those segments not already in existence) and the potential expansion decisions for the Alaskan Natural Gas Transportation System (ANGTS) is structurally identical to the method used for endogenously forecasting the expansion of liquefied natural gas gasification facilities. Therefore, the representation of the ANGTS in the CEM likewise is similar to the approach taken for representing liquefied natural gas imports in the CEM. Natural gas supplied through the ANGTS is provided by the Oil and Gas Supply Model based on the border price at the U.S./Canadian border adjoining the Pacific Census Division. The Oil and Gas Suppiy Model assumes that the final pipeline connection (and any subsequent expansions) of the ANGTS will be completed at least " $n$ " years after the referenced border price is high enough to recover costs for the completion of the project.

\section{Associated-Dissolved Gas, Synthetic Natural Gas, and Other Supply Sources}

Within the CEM (as in the AFM) associated-dissolved gas, synthetic natural gas from coal, and other supplemental supplies are fixed quantities. Associated-dissolved gas production is provided by the Oil and Gas Supply Model and synthetic natural gas from coal is set exogenously within the NGTDM. The levels of natural gas used in the CEM for these two categories are from the most recent forecast year solved by the Annual Flow Module. Since both of these supply categories correspond to current year levels, they serve as an approximation for synthetic natural gas from coal and associated-dissolved gas available to the CEM in the CEM forecast year (defined as Annual Flow Module forecast year plus $n$ ). Synthetic natural gas produced from liquid hydrocarbons is treated as a variable supply type within the CEM and is calculated as a function of the market price for natural gas, with the same functional form and constrainits used in the-Annual Flow Module. Finally, since other supplemental supplies are assumed to remain constant throughout the forecast in the Annual Flow Module, they also are assumed constant in the CEM. (Appendix E - OSUP_TOT, OSUP_RSHR).

\section{Demand Representation}

Demands within the CEM include end-use consumption, export demands, and pipeline fuel consumption. As with the Annual Flow Module, end-use and export demands for forecast years beyond the current model year are defined by other models within NEMS, while pipeline fuel is accounted for through exogenously defined pipeline efficiencies (Appendix E, AEFF_PIPE). End-use consumption levels are provided on an annual basis by region (Census or NGTDM/EMM) and type of customer (core versus noncore ${ }^{55}$ ), and are represented as consumption levels in the CEM, unlike the demand curves used in the AFM. Similarly, natural gas export forecasts are provided on an annual basis for each border crossing node and are defined to be fixed; however, Canadian exports are assumed to service noncore customers only while Mexican exports service only core customers.

$\therefore$

Since the CEM is a seasonal model, each of the annual levels must be separated into peak and off-peak consumption. The CEM contains exogenously specified percentages for disaggregating these annual consumption levels into peak and off-peak periods. These shares (Appendix E - NON_POSHR_F, NON_POSHR_I, UTIL_POSHR_F, UTIL_POSHR_I, UTI__POSHR_C for consumption; EXP_PSHR for exports) have been estimated using historical monthly consumption

\footnotetext{
${ }^{35}$ For the electric generator sector, the noncore customer' class is further subdivided into "competitive-with-distillate" and "competitive-with-residual fuel oil," as described in Chapter 3.
} 
data reported by sector and region, combined with annual estimates of demands for firm and interruptible service. A future model enhancement may be to establish these peak/off-peak shares endogenously. For example, seasonal shifts in the demand for electricity (as represented within the Electricity Market Model) could be used as a basis for endogenously determining shifts in seasonal demands for natural gas by the electric generator sector. Likewise, seasonal shares for the other sectors could be specified at a more disaggregate level, such as by type of end-use (e.g., space heating).

The forecast years and regions representing end-use sector consumption in the CEM differ from one sector to another. For the industrial, transportation, and electric generators sectors, forecast consumption levels correspond to " $\mathrm{n}$ " years beyond the current model year, while residential and commercial consumption levels correspond to " $n+h$ " years beyond the current model year. The " $n$ " represents the number of years required to construct a pipeline and the " $h$ " corresponds to the planning horizon used by a local distribution company when assessing capacity requirements. ${ }^{36}$ As for regional representation, electric generators consumption forecasts are defined by NGTDM/EMM regions (Chapter 3), while consumption forecasts for the other end-use sectors are specified by Census Divisions. As in the Annual Flow Module, estimates of Alaskan natural gas consumption are generated in the CEM in order to derive separate consumption levels for the Pacific Contiguous Division. Similarly, consumption levels within three of the Census Divisions are further subdivided to form separate NGTDM regions using the same fixed historically derived shares as are used in the Annual Flow Module. These splits include: Florida split from the rest of the South Atlantic Division, Califomia split from the rest of the Pacific Contiguous Division, and Arizona and New Mexico split from the rest of the Mountain Division.

Consumption forecasts are provided by a number of different sources. The NEMS system provides consumption forecasts for the core industrial sector and all the noncore end-use sectors with the exception of the electricity generating sector. Consumption forecasts for the core and noncore electricity generating sector are a function of the estimates provided by the Electricity Market Model. The consumption forecasts for the core residential, commercial, and transportation customer classes are provided by the NEMS system based on the observed annual growth rates in previous forecast years. However, within the NGTDM a limit is placed on how much these consumption levels can increase on an annual basis beyond the current forecast year. It is also assumed that consumption will not decline.

\section{Pipeline Capacity Price Curve}

Initial pipeline capacity price curves are developed by the Pipeline Tariff Module at the beginning of the forecast. These curves are based on estimates of capital costs of expansion and parameters (such as interest rates) from the NEMS macroeconomic model. (See Chapter 8 for a complete description of how these tariffs are calculated:) Each cost curve represents the per unit reservation charge on a particular interregional arc based on the annual physical capacity (design day capacity ${ }^{57}$ times 365 ). The base quantity (initial step) represents the existing pipeline capacity for the base year (Appendix E, PCAP_MAX): The corresponding price is the base year reservation charge (i.e., the demand charge) expressed on a per unit basis. Subsequent steps represent incremental expansion and the corresponding incremental tariff. It is assumed that the price curve is nondecreasing to prevent the model from deciding to build just to lower costs. To keep the curve increasing when additional capacity is expected to result in declining prices (such as when incremental capacity expansion is the result of added compression), the step on the curve associated. with this additional capacity is held at the price associated with the previous step, i.e., the step representing the level of capacity without the addition. A generic pipeline capacity price curve is presented in Figure 7-2. The QCAP represents the capacity along an arc, and the PCAP represents the corresponding unit cost. The UCAP is the maximum capacity that can be used on each step (the length of the step), and the ycap represents how much capacity was needed for a given solution.

In forecast year $t$; the CEM determines the capacity expansion for year $t+n$ (the CEM forecast year): Therefore, each year the CEM must adjust the price curves based on capacity expansion which was determined in the previous CEM forecast year, and set to come on-line in year $t+n-1$. Specifically, the quantity associated with the base step on the curve will be adjusted to equal the capacity which will exist on the are at the end of year $t+n-1$. Note that adjustments to the curve have already been made in previous CEM forecast years to reflect expansion in any of the intervening years to year $t+n-1$. The associated base level tariff is determined as a quantity weighted average of the tariffs corresponding to the

\footnotetext{
${ }^{56}$ These variables were defined as follows in the Annual Energy Outlook 1998: $\mathrm{n}=2, \mathrm{~h}=0$.

${ }^{77}$ A pipeline's design day capacity (or certificated capacity) represents a level of service that can be maintained over an extended period of time and may not represent the maximum throughput capability of the system on any given day.
} 
ふั

Figure 7-2. Pipeline Capacity Price Curve

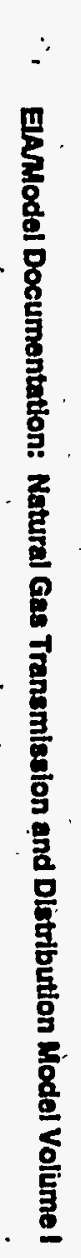

Reservation

Fee/Unit

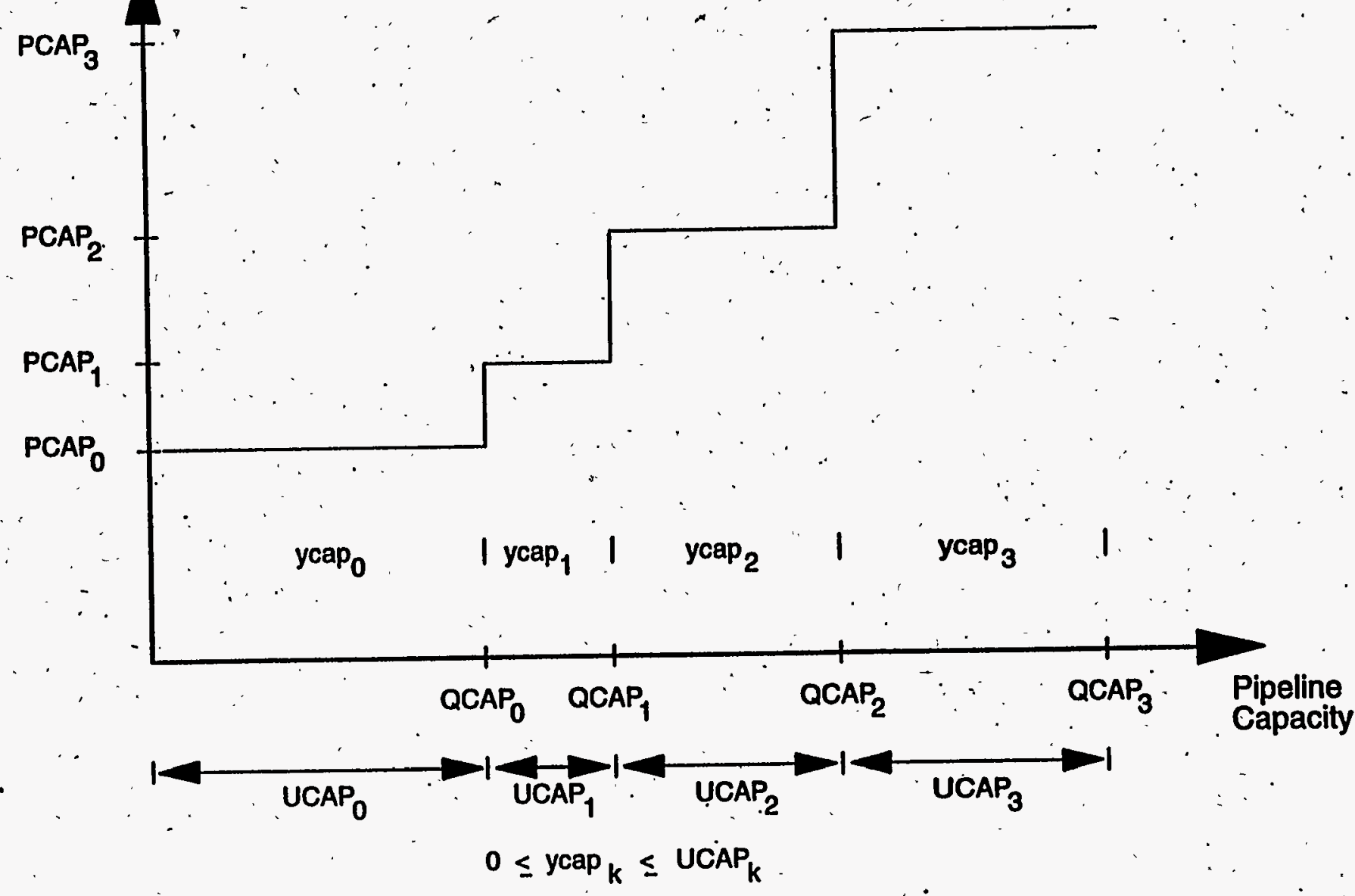


current year ( $t$ ) capacity and the capacity additions made during years $t+1, t+2, \ldots t+n-1$. The original tariff levels defined for the remaining steps (i.e., the capacity addition steps) are then adjusted upward by a specific price delta (Appendix E; DELPR_CAP) to ensure that existing pipeline capacity is sufficiently utilized (on a national level) before a decision : to add new capacity is made.

\section{Storage Capacity Price Curve}

Initial working gas storage capacity price curves are determined by the Pipeline Tariff Module at the beginning of the forecast. These curves are based on estimates of capital costs of expansion, costs of holding base gas in storage, and parameters (such as interest rates) from the NEMS macroeconomic model. (See Chapter 8 for a complete description of how these tariffs are calculated.) Each cost curve represents the storage charge per unit (PSTR) as a function of the annual working gas capacity for a particular region. This storage charge is exclusive of any transportation costs to move gas to or from storage areas. The base quantity (initial step) represents the existing working gas storage capacity (Appendix E, WORKT). The corresponding price is the initial storage charge per unit. Subsequent steps represent incremental expansion and the corresponding incremental charge. The final step on the curve represents an upper limit on working gas storage capacity expansion due to known physical limits in a region (Appendix E, NODFAC) or other nonprice dependent factors. A generic working gas storage capacity price curve. is presented in Figure 7-3. The QSTR represents the storage capacity at a node, and the PSTR represents the corresponding unit storage cost. The USTR is the maximum storage capacity that can be used on each step (the length of the step), and the ystr represents how much storage was needed for a given solution.

Each year the CEM must adjust these working gas storage price curves based on the current capacity levels, similar to the adjustment made to the pipeline capacity price curves. Specifically, the quantity associated with the base step on the curve is adjusted to equal the working gas storage capacity which exists in the region at the end of year $t+n-1$, where $t$ is the current model year and $n$ is the number of years beyond the current model year for which the CEM is determining expansion. Since in model year $t$ the capacity expansion for year $t+n$ is being determined, the base step includes working gas capacity for current year $t$ as well as the capacity expansions defined in years $t+1, t+2, \ldots, t+n-1$. The associated base level tariff is determined as a quantity-weighted average of the tariff associated with the existing capacity and the tariffs for each of the previously determined expansions for years $t+1, t+2, \ldots, t+n-1$, as well as the original base storage capacity in model year $t$. As with the pipeline capacity price curves, the original tariff levels defined for the remaining steps are then adjusted upward by a specific price delta (Appendix E, DELPR_STR). This measure ensures that existing storage capacity is sufficiently utilized (on a national level) before new storage capacity gets added.

\section{Linear Program Formulation}

A linear programming (LP) framework is used in the CEM as the basis for determining expansion requirements for pipeline and storage facilities. As described in Chapter 4, the CEM structure is based on a natural gas transmission and distribution system composed of four parallel networks interconnected at the supply points and the storage points. These networks serve to represent the seasonal nature (peak and off-peak) and types of service (firm and interruptible) associated with the natural gas market. Thus, peak firm, peak interruptible, off-peak firm, and off-peak interruptible service are modeled by the four networks. The CEM LP is solved in two phases: The first phase establishes pipeline and storage capacity expansion requirements, and the second establishes final firm, interruptible, peak and off-peak flows. This section describes the CEM LP formulation, the process used to determine the pipeline and storage capacity expansion requirements; and the methodology used to define annual pipeline utilizations and net storage results.

\section{General Description of the Linear Program Formulation}

The objective of the linear program designed for the CEM is to minimize the cost of supplying and transporting natural gas to the end-user, subject to operational and supply constraints, with the requirement to satisfy all demand for firm service under design weather conditions. This section gives a general description and justification of the linear programming formulation (objective function and constraints), and a subsequent section includes the explicit mathematical equations representing the formulation. 


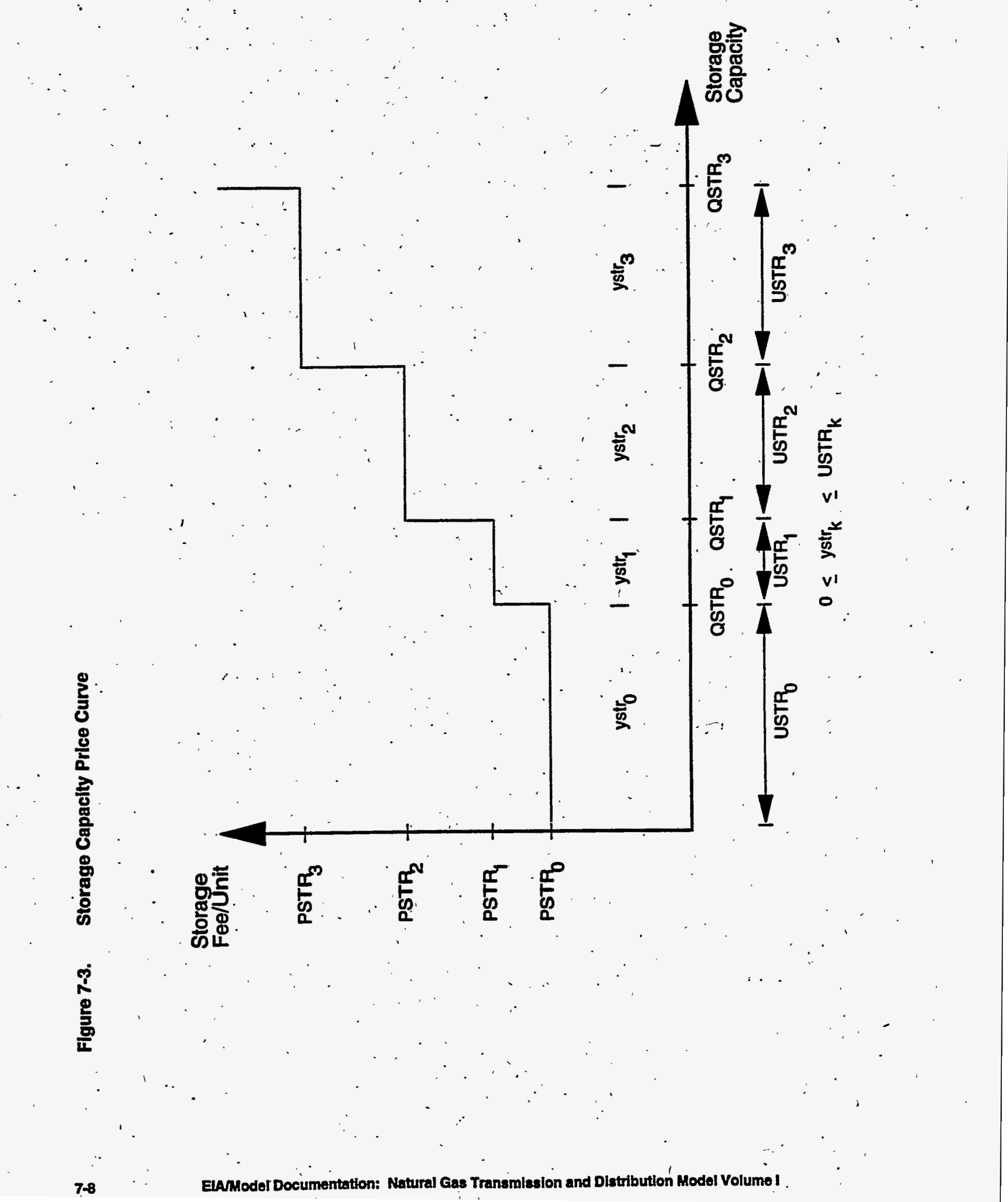


The objective function has been formulated to minimize costs. These costs include the costs of supplies, transportation along the established network, and costs of additional pipeline and storage capacity. The objective function can be represented as follows:

minimize

[transportation costs + supply costs + pipeline expansion costs + storage expansion costs + backstop supply costs\}

A mass balance constraint is included for each transshipment node. This constraint ensures that the total input to the node equals the total output from the node. In general, gas flowing into a transshipment node comes from other transshipment nodes, supply points, and (in some cases) storage, while gas flowing from a transshipment node goes to demand points, other transshipment nodes, and (in some cases) storage. Flows into and out of storage have been defined to be network dependent because gas generally is injected into.storage in the off-peak period and used to satisfy core customer demand during the peak period. (Peak nonicore customers also may draw from storage if it is not needed for core customers.) Therefore, in the linear program formulation, gas flows into a regional storage point from transshipment nodes (in the same region) on the off-peak firm and/or interruptible service networks, and flows out of the same storage point to transshipment nodes (again in the same region) on the peak firm and/or interruptible service networks. As in the AFM, the mass balance equations in the CEM include discrepancies or balancing items that are historically seen between production and consumption data collection efforts. The national level exogenous forecast for discrepancy, as used in the AFM, is split between the four networks and 12 regions based on the CEM consumption splits. A general transshipment node mass balance constraint is listed below for each of the four parallel networks:

For each peak period firm service network transshipment node:

(flow into the transshipment node from other peak period firm service network transshipment nodes) + (flow into the transshipment node from supply points in the region) + (flow into the transshipment node from storage in the region) + (peak firm discrepancies) - (losses) = (flow out of the transshipment node to peak period core demand points in the region) + (flow out of the transshipment node to other peak period firm service network transshipment nodes)

For each peak period interruptible service network transshipment node:

(flow into the transshipment node from other peak period interruptible service network transshipment nodes) + (flow into the transshipment node from supply points in the region) + (flow into the transshipment node from storage in the region) + (peak interruptible discrepancies) - (losses) $=$ (flow out of the transshipment node to peak period noncore demand points in the region) + (flow out of the transshipment node to other peak period interiuptible service network transshipment nodes)

For each off-peak period firm service network transshipment node:

(flow into the transshipment node from other off-peak period firm service network transshipment nodes) + (flow into the transshipment node from supply points in the region) + (off-peak firm discrepancies) - (losses) $=$ (flow out of the transshipment node to storage in the region) + (flow out of the transshipment node to off-peak period core demand points in the region) + (flow out of the transshipment node to other off-peak period firm service network transshipment nodes)

For each off-peak period interruptible service network transshipment node:

(flow into the transshipment node from other off-peak period interruptible service network transshipment nodes) ' + (flow into the transshipment node from supply points in the region) + (off-peak interruptible discrepancies) (losses) $=$ (flow out of the transshipment node to storage in the region) + (flow out of the transshipment node to off-peak period noncore demand points in the region) + (flow out of the transshipment node to other off-peak period interruptible service network transshipment nodes)

A mass balance constraint also is included for each storage point. This constraint ensures that in a forecast year the total gas input into storage equals the total gas output from storage, net of losses (Appendix E, EFF_STR). As mentioned above, gas flows to storage from the off-peak period firm and/or interruptible service networks, and gas flows out of storage to the peak period firm and/or interruptible service networks. The flow comes from and goes to the transshipment 
node comesponding to the same region as the storage point. Unlike forecast years, in historical years total net storage withdrawais are not zero. Therefore actual net storage withdrawal levels are accounted for in these mass balance equations when historical years are being represented. . A mass balance constraint for storage in a forecast year is presented below.

For each storage point:

(flow of gas into a storage point from the off-peak period firm service network transshipment node) + (flow of gas into a storage point from the off-peak period interruptible service network transshipment node) - (losses) $=$ (flow of gas out of the storage point to the peak period firm service network transshipment node) +(flow of gas out of the storage point to the peak period interruptible service network transshipment node)

Each demand point also has a mass balance constraint represented. This constraint ensures that the quantity allocated to the end-use point equals the expected consumption level associated with that point. All expected core market consumption (peak and off-peak) must be satisfied; however, pipeline and storage facilities can only be built to meet peak core demands. It is assumed that the resulting capacity levels will be sufficient to accommodate flows to satisfy core offpeak period requirements. Since new facilities are not built for the satisfaction of noncore demand, a backstop supply is a modeling structure introduced to represent the portion of the noncore demand for natural gas which cannot be satisfied by conventional supply sources and must be interrupted. A general demand node mass balance constraint is listed below for each of the four parallel networks.

For each peak period core demand point:

(flow from a peak period firm service network transshipment node in a region to a peak period core demand point in the region) - (losses) $=$ (quantity consumed at that peak period core demand point)

For each peak period noncore demand point:

- (flow from a peak period intermuptible service network transshipment node in a region to a peak period noncore demand point in the region) + (backstop supply) - (losses) = (quantity consumed at that peak period noncore demand point)

For each off-peak period core demand point:

(flow from an off-peak period firm service network transshipment node in a region to an off-peak period core demand point in the region) - (losses) = (quantity consumed at that off-peak period core demand point)

For each off-peak period noncore demand point:

(flow from an off-peak period interruptible service network transshipment node in a region to an off-peak period noncore demand point in the region) + (backstop supply) - (losses) $=$ (quantity consumed at that off-peak period noncore demand point)

Supply utilization constraints are inclided for each supply point, and are represented as peak supply constraints and offpeak supply constraints. Since gas may flow from a supply point to a transshipment node (in the same region) in any of the four.parallel networks, these supply constraints ensure that the flows (including losses) do not exceed the total amount supplied at that point. The constraints also ensure that the quantity flowing from the supply point has been properly split between the peak and off-peak period during any one year. The peak supply constraint states that, for any supply type and any supply level, a specified portion (Appendix E, SUP_PUTILZ) of the annual supply flow must be used to supply peak demands. Similarly, the off-peak supply constraint states that a specified portion of the annual supply flow must be used to supply off-peak demands (Appendix E, SUP_OUTIZZ). The latter constraint is defined slightly differently for onshore and offshore dry gas production: the supply quantity supplied to the off-peak networks must be less than or equal to a specified portion of the total annual dry gas production level. The constraints are as follows. 
For each supply point:

(flow from the supply point to a peak period firm service network transshipment node) + (flow from the supply point to a peak period internuptible service network transshipment node $)=($ peak share of total supply) * (total annual quantity supplied from the supply curve)

- For each onshore and offshore supply point:

(flow from the supply point to an off-peak period firm service network transshipment node) + (flow from the supply point to an off-peak period interruptible service network transshipment node) s (off-peak share of total supply) * (total annual quantity supplied from the supply curve)

For each supply point excluding onshore and offshore supplies:

(flow from the supply point to an off-peak period firm service network transshipment node) + (flow from the supply point to an off-peak period interruptible service network transshipment node) $=$ (off-peak share of total supply) * (total annual quantity supplied from the supply curve)

Capacity expansion and flow constraints are defined for each interregional are in the overall network. These constraints ensure that pipeline capacity is built, as riecessary,-to satisfy only core peak period demand, and that the total flows along the interregional ares are less than or equal to the available capacities (base $e^{58}$ plus added capacity). Within these constraints, seasonal maximum arc utilization rates are used to capture the variation in load patterns and operational limitations throughout the season. Constraints have been established for firm service peak period flows, total peak period flows, and total off-peak period flows for each interregional arc in the network. In general, maximum seasonal pipeline utilizations are set equal to the fraction of the year represented by the season times an assumed maximum utilization rate for the type. of service represented (Appendix E - ARC_PUTILZ, ARC_PFUTILZ, ARC_OUTILZ) times a factor representing the percentage of the pipe reserved to account for the potential of abnormal weather (Appendix $E$, WTHRFAC).

It is the firm service peak period capacity constraint that ensures that no pipeline capacity is built beyond what is needed to satisfy peak period core market requirements. It states that total peak firm flow along an are must equal total capacity (base plus added capacity) times a maximum peak firm are utilization rate. It is the equality requirement that does not allow new capacity to be built unless peak core demands require additional quantities to flow along the specific arc(s). The peak total (firm and interruptible) period capacity constraint has been established as an inequality constraint to ensure that the flows to satisfy noncore peak period requirements are less than or equal to the remaining peak season effective capacity (i.e., total capacity times the maximum peak season utilization rate) once the core market requirements have been met. In addition, an off-peak period capacity constraint (also as an inequality constraint) has been developed to ensure that the total off-peak season flows on the arc are less than or equal to the off-peak season effective capacity (i.e., total capacity times the maximum off-peak season utilization rate). The resulting constraints are given below for each interregional arc.

' For each peak firm service interregional arc:

(flow along the are to satisfy core market peak period requirements) = (level of base capacity used + level of pipeline capacity expansion) * (peak period interregional arc maximum utilization rate for firm service)

For each peak firm and interruptible service interregional arc:

(flow along the are to satisfy noncore peak period requirements) + (flow along the arc to satisfy core market peak period requirements) $\leq$ (base capacity + level of pipeline capacity expansion) * (peak period interregional arc maximum utilization rate)

\footnotetext{
${ }^{s t}$ Recall from previous sections that capacity expansion levels are being determined for year $t+n$; therefore, the base capacity refers
} to the capacity existing at the end of the year $t+n-1$. 
For each off-peak firm and interruptible service interregional arc:

(flow along the arc to satisfy noncore off-peak period requirements) + (flow along the arc to satisfy çore market off-peak period requirements ) $\leq$ (base capacity + level of pipeline capacity expansion) * (off-peak period interregional arc maximum utilizátion rate).

Storage expansion and flow constraints are defined for each node in the lower 48 -State portion of the network. These constraints ensure that storage capacity is built, as necessary, to satisfy peak period core market requirements and that the flows from storage are less than or equal to the total available storage capacity (base $e^{39}$ plus added capacity). Constraints have been established for firm service peak period flows and total peak period flows from storage locations at each node. Storage utilization rates (Appendix E - STR_UTILZ, STR_FUTILZ) have been used to define the. maximum storage levels used for peak firm service and total peak storage. The peak firm service constraint has been established as an equality constraint to ensure that no storage capacity is built beyond what is needed to satisfy peak period core market requirements. The total peak constraint has been established as an inequality constraint to ensure that the flows to satisfy noncore requirements are less than or equal to the effective storage capacity remaining after the core market requirements have been met. The resulting constraints are given below.

For each storage point:

(flow from the storage point to the peak period firm service network transshipment node) $=$ ((level of base storage capacity used) $+($ storage capacity expansion) $) *($ peak period maximum storage utilization rate for firm service)

For each storage point:

(flow from the storage point to the peak period interruptible service network transshipment node) + (flow from the storage point to satisfy core market requirements) s ((base storage capacity) + (storage capacity expansion)) * (peak period maximum storage utilization rate for total peak service)

Similar to the AFM, minimum interstate pipeline flow have been defined for the CEM firm service networks (in the form of lower bounds on the flow variables). These minimum flows are defined to be a fraction of the resulting firm flows in the AFM in the current model year plus an estimated utilization of the new capacity added between the current model year $(t)$ and the beginning of the CEM forecast year $(t+n)$. As in the.AFM, this fraction is exogenously specified (Appendix E - APCT_MINF, APCT_MINI) and is intended to represent the level of flexibility core customers exhibit in changing their selected routes for transporting natural gas from year-to-year, even if relative costs would indicate a change would be prudent (e.g., flexibility would be lessened due to the existence of long-term contracts). Finally, maximum utilization rates are used in estimating firm flows from the last. AFM solution for the peak and off-peak periods while accounting for the potential impact of new capacity builds over the next " $n$ ". years. The resulting constraints are described below.

For each interregional arc on the peak firm service.network:

peak firm flow 2 (minimum flow fraction) * (estimated firm flow) * (peak period share of firm flow)

For each interregional arc on the off-peak firm service network:

off-peak firm flow 2 (minimum flow fraction) * (estimated firm flow) * (off-peak period share of firm flow)

Additional constraints are represented as lower and/or upper bounds on the flow variables. These include lower bounds set for flow along all ares (and networks) with bidirectional flows, ${ }^{60}$. as well as upper and lower bounds set on all flows into (off-peak firm and interruptible) and out of (peak firm and interruptible) storage. The upper and lower bounds on

\footnotetext{
${ }^{9}$ Recall from previous sections that storage capacity expansion levels represent working gas capacities and are being determined for year $t+n$; therefore, the base storage refers to the working gas storage capacity existing at the end of the year $t+n-1$.

${ }^{60}$ Minimum flows for bidirectional ares in the CEM are set by multiplying the corresponding minimum flows established in the Annual Flow Module by assumed peak shares (Appendix E - BIARC_PFSHR, BIARC_PISHR).
} 
storage flows are set to a fraction ${ }^{61}$ of approximated firm and interruptible net flows into and out of storage in a period. These approximations are based on the last historical year's peak/off-peak values (Appendix E-PKNETSTR), adjusted for changes in the physical storage additions over the forecast period, and split into firm and interruptible categories using exogenous shares (Appendix E - PKSTFR_F, OPPSTFR_F). Finally, a number of bound constraints are needed to completely describe the step functions for the supply, capacity expansion, and storage expansion curves. These bounds serve to define the lengths of each of the steps on the curves.

Thus, the linear program solves for the level and location of storage and pipeline capacity expansion, as well as the associated peak and off-peak flows. Note that the amount of capacity expansion is a continuous function. Although, for a given pipeline company, capacity may be added only through discrete projects, the arcs in the CEM represent aggregates of pipeline companies. Taken together these companies can add capacity in virtually any desired quantity through combinations of additional compressor capacity, looping, or other means.

\section{Mathematical Specification of the Linear Programming Formulation}

This section presents the set of equations which established the linear programming formulation for the CEM. This set is comprised of an objective function, flow constraints, and bound on model variables.

$$
\begin{aligned}
& \underset{x, y s u p, y c a p, y s t, q z z}{\operatorname{minimize}} \sum_{i, j} \operatorname{TAR}_{i, j}^{F} *\left(x_{i, j}^{P F}+x_{i, j}^{O F}\right)+\sum_{i j} \operatorname{TAR}_{i, j}^{I} *\left(x_{i j}^{P I}+x_{i j}^{O I}\right)+\sum_{2, j} \operatorname{TAR}_{s, j}^{P} *\left(x_{2, j}^{P F}+x_{s, j}^{P I}\right) \\
& +\sum_{s, i} \operatorname{TAR}_{s, i}^{O} *\left(x_{s, i}^{O F}+x_{2, i}^{O I}\right)+\sum_{i, d} \operatorname{TAR}_{i, d}^{P F} * x_{i, d}^{P F}+\sum_{i, d} \operatorname{TAR}_{i, d}^{P 1_{i} * x_{i, d}^{P I}} \pm \sum_{i d} \operatorname{TAR}_{i, d}^{O F} * x_{i, d}^{O F} \\
& +\sum_{i d d} \operatorname{TAR}_{i, d}^{\text {ol }} * x_{i, d}^{\text {ol }}+\sum_{s, j} \sum_{k=1}^{c} \operatorname{PSUP}_{2, i, k} * \operatorname{ysup}_{s, i, k}+\sum_{i j} \sum_{k=0}^{c} \operatorname{PCAP}_{i, j k} * \text { ycap }_{i, j k}
\end{aligned}
$$

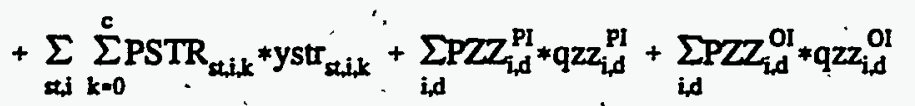

where,

the subscripted indices are: :

$$
\begin{aligned}
\mathbf{i}, \mathbf{j}, \text { and } \mathbf{m} & =\text { transshipment node } \\
\mathbf{d} & =\text { demand type } \\
\mathbf{s} & =\text { supply type } \\
\mathbf{s t} & =\text { storage } \\
\mathbf{k} & =\text { step on the curve } \\
\mathbf{c} & =\text { number of steps on the curve } \\
\mathbf{i}, \mathbf{j} & =\text { arc connecting transshipment nodes i.and } \mathbf{j} \\
\mathbf{i , d} & =\text { arc from transshipment node } i \text { to demand point } d
\end{aligned}
$$

\footnotetext{
${ }^{6}$ The fractions used to set the minimum storage flow constraints for the peak firm, peak intermptible, off-peak firm, and off-peak interuptible ares are $0.80,0.70,0.80,0.65$, respectively. The fractions used to set the maximum storage flow constrains are 1.3 , 1.25 , 1.9 , and 1.9 for the same arcs.
} 
$\mathrm{s}, \mathrm{i}=$ arc from supply point $\mathrm{s}$ to transshipment node $\mathrm{i}$

st, $\mathrm{i}=$ arc from transshipment node i to storage point st

. $i_{p} s t=$ arc from transshipment node $\mathrm{i}$ to storage point st

the superscripted indices are:

$$
\begin{aligned}
\mathbf{P} & =\text { peak period } \\
\mathbf{O} & =\text { off-peak period } \\
\mathbf{F} & =\text { firm } \\
I & =\text { interruptible }
\end{aligned}
$$

the parameters are:

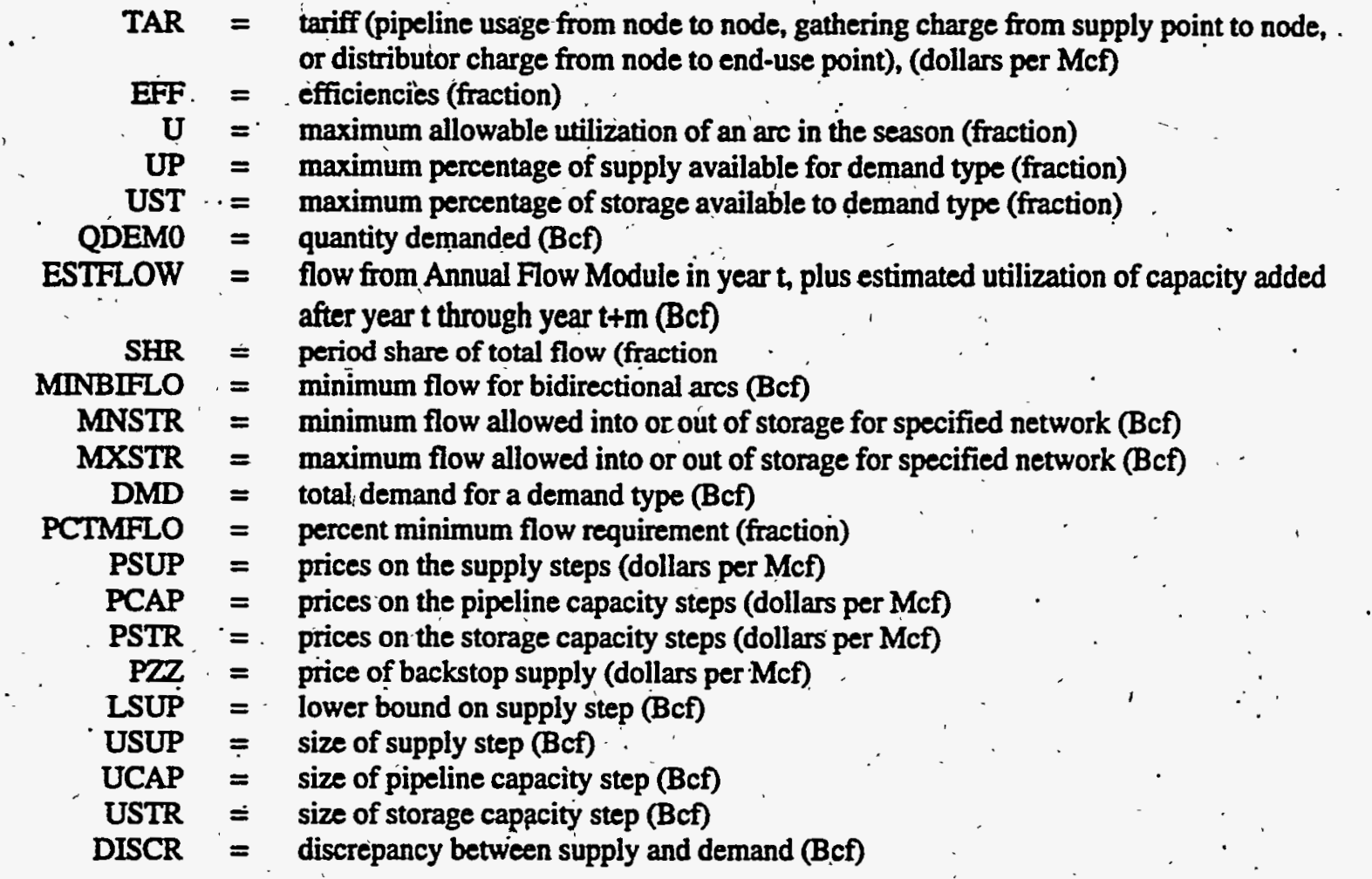

the variables are:

$$
\begin{aligned}
& \text { - } \quad x_{i j}=\text { flow from } i \text { to } j \text { (Bct) } \\
& \text { ysup }_{x i 1}=\text { for supply point }(s, i) \text {, the amount of supply step } k \text { taken (Bcf) } \\
& \text { ycap }_{i j k}=- \text { for arc } i, j \text {, the amount of pipeline capacity step } k \text { built (Bct) } \\
& \text { - } \text { ycap }_{\text {ij, }}=\text { for are } i, j \text {, the amount of base pipeline capacity taken (Bcf) }
\end{aligned}
$$

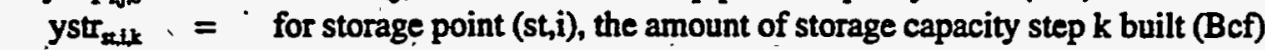

$$
\begin{aligned}
& \text { - } \mathrm{yst}_{z, 10}=\text { for storage point (st,i), the amount of base capacity taken (Bcf) } \\
& \mathrm{qzz}_{\mathrm{Ld}}=\text { amount of backstop supply used for demand point (i,d), (Bct) }
\end{aligned}
$$

Mass Balance Constraints at Each Transshipment Node (m):

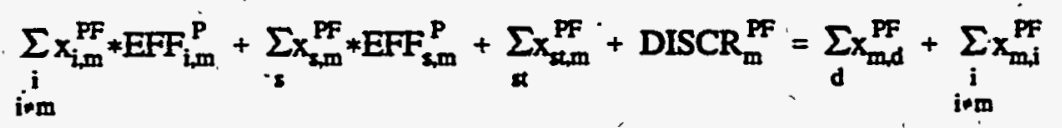




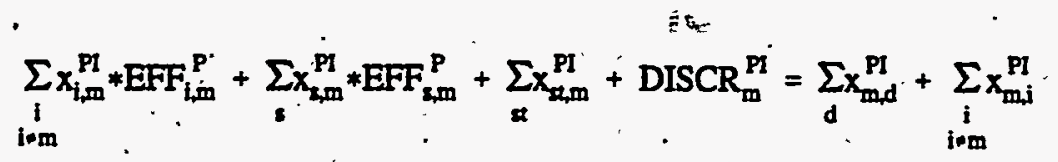

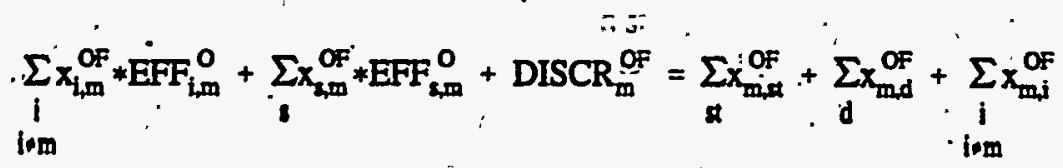

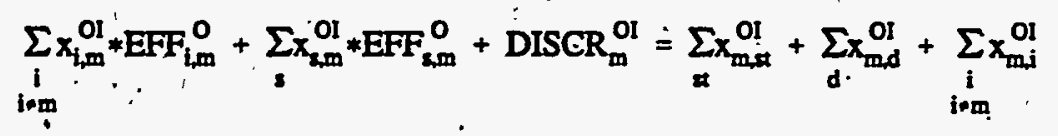

Mass Balance Constraints at Each Storage Point (st,i):

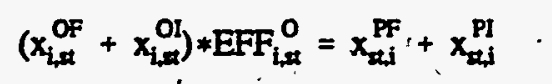

Mass Balance Constraints for Demand Points (i,d):

$$
\begin{aligned}
& \mathrm{x}_{i, d}^{\mathrm{PF}} * \mathrm{EFF}_{i, \mathrm{~d}}^{\mathrm{P}}=\mathrm{QDEM} 0_{i, d}^{\mathrm{PF}} \\
& x_{i d}^{P I} * E F F_{i d}^{P}+q 2 z_{i d}^{P I}=Q^{P D E M} 0_{i d}^{P I} \\
& x_{i d d}^{O F} * E_{F F}^{O}=Q_{i d d}^{O D E M O} 0_{i d d}^{O F} \\
& x_{i, d}^{o l} * E F F_{i, d}^{o}+q z z_{i, d}^{o l}=Q^{o D E M 0_{i, d}^{O I}}
\end{aligned}
$$

Supply Utilization Constraints at Each Supply Point (s,i):

$$
x_{s, i}^{\mathrm{PF}}+x_{s, i}^{\mathrm{PI}}=\sum_{k=1}^{c} y_{s u p_{s, i, k}} * U P_{s, i}^{P}
$$

For onshore and offshore supply types only,

$$
\text { - } x_{2, j}^{\text {OF }}+x_{2, j}^{\text {Ol }} \leq \sum_{k=1}^{c} y \sup _{2, i, j} * U P_{2, j}^{O}
$$

For all supply types other than onshore and offshore,

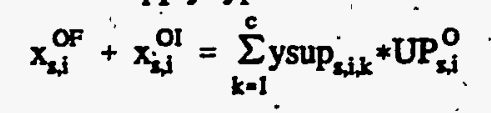

Pipeline Capacity Constraints for Each Arc (i,j):

$$
\begin{aligned}
& \left.x_{i j}^{\mathrm{PF}}=U_{\mathrm{ij}}^{\mathrm{PF}} * \text { ycap }_{i, j, 0}+\sum_{k=1}^{\mathrm{c}} \text { ycap }_{i, j, k}\right) \\
& x_{i, j}^{P I}+x_{i, j}^{P F} \leq U_{i, j}^{P} *\left(\text { ycap }_{i, j, 0}+\sum_{k=1}^{c} y^{\prime} a p_{i, j, k}\right)
\end{aligned}
$$

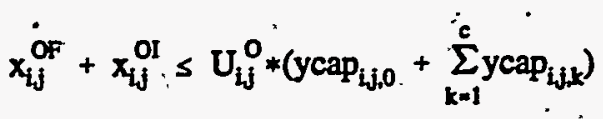


Storage Capacity Constraint for Each Region (st,i):

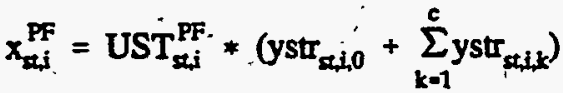

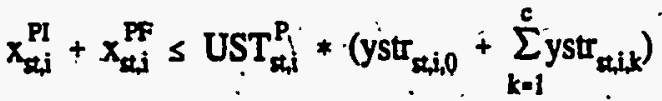

Minimum Bounds on Peak and Off-peak Firm Flows for each Arc (i,j):

$$
\begin{aligned}
& x_{i, j}^{\text {PF }} \geq \text { PCTMFLO }_{i j}^{F} * \text { ESTFLOW }_{i, j}^{F} * \operatorname{SHR}_{i, j}^{\text {PF }} \\
& x_{i, j}^{\text {OF }} \geq \text { PCTMFLO }_{i, j}^{F} * \text { ESTFLOW }_{i, j}^{F} * \operatorname{SHR}_{i, j}^{O F}
\end{aligned}
$$

Other bound constraints set minimum flows along bidirectional arcs, as well as minimum and maximum flows into and out of storage:

$$
\begin{aligned}
& x_{i j} \geq \text { MINBIxx }
\end{aligned}
$$

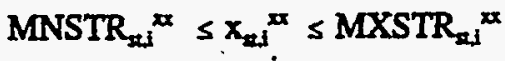

for each bidirectional flow arc $(i, j)$, and each network $(x x=P F, P I$, $\mathrm{OF}, \mathrm{OI})$

for each flow $(x x=\mathrm{PF}, \mathrm{PI}, \mathrm{OF}, \mathrm{OI})$ into and out of storage $(\mathrm{st}, \mathrm{i})^{62}$

The following bound constraints also are defined for the steps on the supply, capacity expansion, and storage expansion curves:

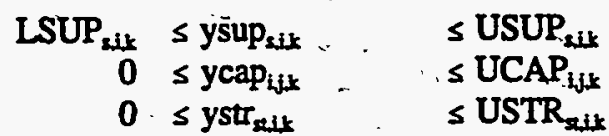

for each supply point (s,i), and $k=1,2, \ldots, n$.

for each arc $i, j$, and $k=0,1,2, \ldots, n$.

for each storage point (st,i), and $k=0,1,2, \ldots, n$.

In general LSUP is zero, except on the first step of the supply curve where a minimum supply level may be defined.

Thus, the above equations and bounds mathematically specify the linear program objective function and the key mode] constraints. A commercial software package ${ }^{63}$ designed to solve linear programining problems is utilized to modify and solve the linear program matrix, and to access the resulting solution.

\section{Implementation of the Linear Program Within the CEM}

The CEM linear program solves for the level and location of pipeline and storage capacity expansion, as well as the corresponding peak and off-peak flows associated with firm and interruptible service. To provide this information, the linear program matrix is solved in two phases-the first establishes the pipeline and storage expansion levels, and the second establishes the final flows.

In the first phase of the CEM, the linear program is defined according to the equations above, and solved. From this solution, pipeline and storage capacity expansions and peak firm flows are established. However, base capacity on some pipeline ares and in some regional storage locations may not be fúlly utilized because of insufficient peak core demand requirements. Given how the model is formulated, this under utilization, in turn, restricts the amount of off-peak and interruptible flows that can occur along the under utilized arcs, and into/out of under utilized storage facilities. This occurrence is dictated by the pipeline and storage capacity constraints. The second phase serves to remove this connection between peak firm flows and other flows, while still maintaining the peak firm flow levels resulting in the first phase.

\footnotetext{
62The variables MNSTR and MXSTR are not used in the source code directly, but represent the result of a set of equations.

${ }^{63}$ All of the linear programming problems within the NEMS will be solved using the Optimization and Modeling Library (OML), a product of Ketron Management Science, a Division of Bionetics Corporation [Ketron, 1992].
} 
In the second phase, the peak period capacity constraints (equations 88 and 91 ) must be represented such that interruptible volumes can flow along the unused capacity: To accomplish this, pipeline and storage capacities (ycap ${ }_{1 j}$ and ystr ${ }_{z i}$ ) are held constant and set equal to the solution levels (YCAP and YSTR) from the first CEM phase (base utilization plus added capacity). This, is represented with the changes in the equation from 'ycap' to 'YCAP' and from 'ystr' to 'YSTR.' Also, a constant term is added to the constraint that identifies the unused base capacity which may be used for interruptible flows only. The corresponding equations are presented below.

Pipeline Capacity Constraint for Peak Period Flows on Arc (i,j):

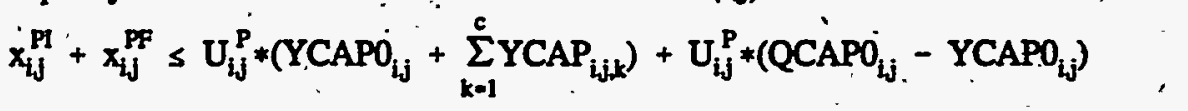

Storage Capacity Constraint for Peak Period Flows in Each Region (st,i):

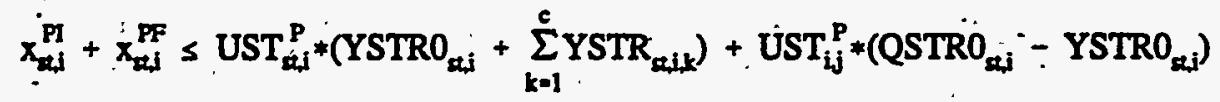

where,

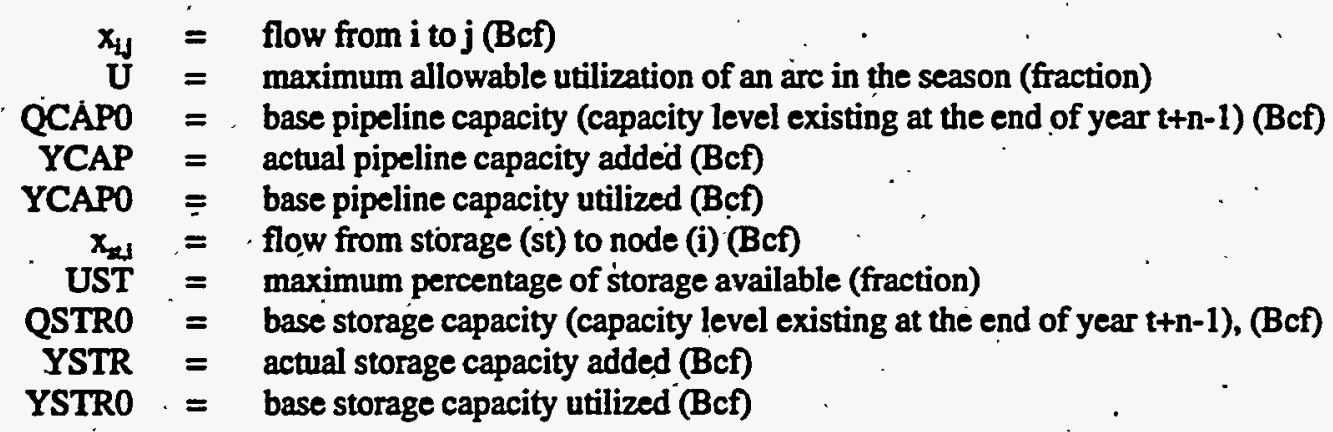

With the completion of the second phase, the CEM has generated pipeline and storage capacity expansion results, as well as seasonal flows corresponding to core and noncore markets. The capacities are used directly in the Annual Flow Module, while the flows are used to generate annual pipeline capacity utilization factors for use in the Annual Flow Module. The procedure to generate annual capacity utilization factors is presented in the next section.

\section{Processing of CEM Results}

The primary purpose of the CEM is to provide the Annual Flow Module and Pipeline Tariff Module each year with a forecast of physical pipeline capacity and working gas storage capacity for forecast year $t+n$, to determine maximum pipeline capacity utilizations corresponding to annual firm and total interregional flows (to be used in the maximum annual flow constraints within the Annual Flow Module), and to determine firm and interruptible net storage withdrawals (to be used in the node mass balance constraints within the Annual Flow Module). Capacity expansion results are used to determine the forecasted capacity levels; firm and total flows are used to determine pipeline utilizations; and, seasonal firm and interruptible flows into and out of storage are used to calculate firm and interruptible net storage withdrawals. These calculations are presented below.

Pipeline and storage capacity expansion levels for forecast year $t+n$ are generated by solving the CEM linear program, and are used to determine forecasted capacities. Physical pipeline capacity along the interregional arc from transshipment node $\mathrm{i}$ to node $\mathrm{j}$ is calculated as the base capacity (including planned expansions - Appendix $\mathrm{E}$, PNEW_CAP) ${ }^{\text {st }}$ plus the corresponding level of expansion in year $t+n$.

\footnotetext{
The data for planned capacity additions just indicates the capacity per day and the year the pipeline will come on line. The majority of pipelines tend to come on line towards the beginning of the heating season. Therefore, in order to approximate the annual pipeline capacity in the year the pipeline comes on line, its capacity level is multiplied by 365 and an assumed fraction of the year it is available (Appendix E, PER_OPEN_YR). In the following year, the annual capacity level is increased to reflect full access throughout the year.
} 


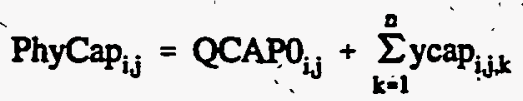

Likewise, regional working gas storage for year $t+n$ is calculated as base working gas (including planned expansions Appendix E, PNEW_STRX) plus the corresponding level of expansion in year $t+n$.

$$
\operatorname{StrCap}_{s, i}=\mathrm{QSTRO}_{\mathrm{st,i}}+\sum_{k=1}^{\mathrm{n}} \mathrm{ystr}_{\mathrm{st,i,k}}
$$

Since loads on a pipeline tend to be variable throughout a year (with full utilization more prevalent during the peak season and lower utilization during the off-peak season), the purpose of the maximum annual flow constraints in the Annual Flow Module is to better represent seasonal flows on an annual basis. This is accomplished by using the seasonal flow patterns resulting in the CEM and translating them into annual pipeline utilizations. The CEM calculates both firm and total annual pipeline utilizations to be used within the maximum annual flow constraints for both firm and total flows in the Annual Flow Module. A graphical depiction of the load curve that represents seasonal flows is presented in Figure $7-4$.

Firm annual utilizations are a function of peak firm flows, off-peak firm flows, and peak firm utilization rates. Peak firm utilization rates (Appendix E, ARC_PFUTIZ) define the maximum portion of total physical annual capacity available to the peak firm service network along a specific arc, and are used in conjunction with other utilizations to establish arc-

Figure 7-4. Example of a Seasonal Flow Pattern Along an Arc

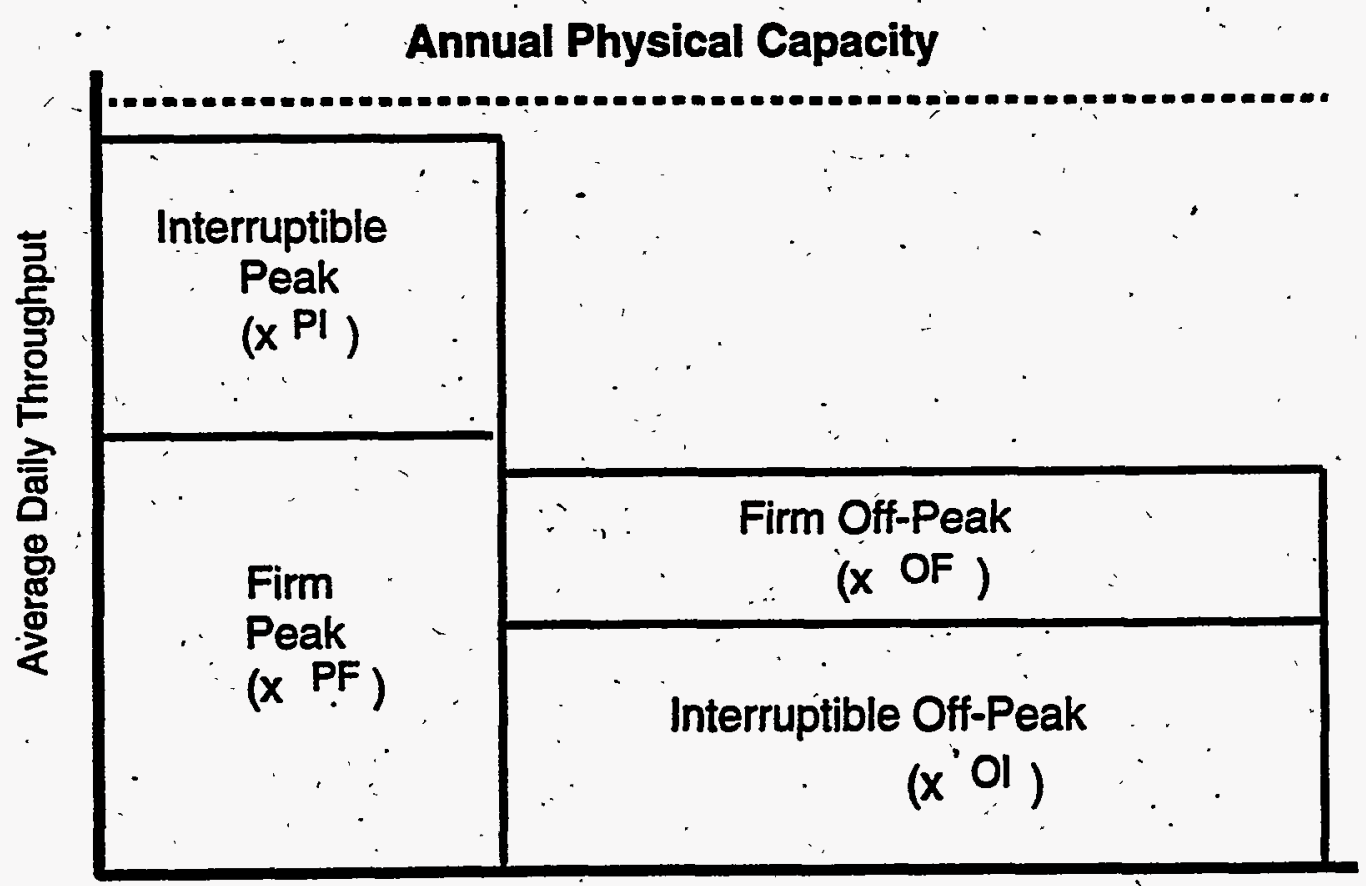

Days 
specific load duration curves represented in the CEM. Assuming that the resulting peak firm flow reflects full utilization of the capacity available to the core market during the peak season, an equivalent maximum annual capacity available

to the core market can be calculated by dividing the peak firm flow by the peak firm utilization. Next, dividing the total firm flow (peak and off-peak) by this maximum annual firm capacity produces maximum firm annual utilizations used by the Annual Flow Module. The following equations result.

For the core market, along each arc $i, j:$

AUTIL $Z_{i j}^{F}=$ ((the flow along the are to satisfy peak period core market) + (the flow along the arc to satisfy off-peak period core market)) / (equivalent annual firm capacity)

given, equivalent annual firm capacity = (the flow along the are to satisfy peak period core market) $/$ (peak firm utilization rate)

$$
\begin{aligned}
\operatorname{AUTII} Z_{i, j}^{F} & =\frac{\left(x_{i, j}^{P F}+x_{i j}^{O F}\right)}{\operatorname{ECAP}_{i, j}^{F}} \\
\operatorname{ECAP}_{i, j}^{F} & =\frac{x_{i, j}^{P F}}{U T I L Z_{i, j}^{P F}}
\end{aligned}
$$

where,

$$
\begin{aligned}
& \text { AUTIL } Z_{j_{j}}=\text { annual firm capacity utilization rate along arc } i, j \text { (fraction) } \\
& x_{i j}=\text { peak firm flow along arc } i, j \text { (Bcf) } \\
& x_{1 j} \text { of }=\text {, off-peak firm flow along arc } i, j \text { (Bcf) } \\
& \mathrm{ECAP}_{1, j}{ }^{\mathrm{F}}=\text {. equivalent capacity available to core market along arc i,j (Bcf) } \\
& \text { UTIL }_{i j}=\text { peak firm capacity utilization rate along arc } i, j \text { (fraction) }
\end{aligned}
$$

Likewise, total capacity utilization rates are a function of peak firm flows, off-peak firm flows, peak interruptible flows, off-peak interruptible flows, and peak utilization rates. Peak utilization rates (Appendix E, ARC_PUTIIZ) define the maximum portion of total physical annual capacity available in the peak period along a specific arc, and are used in conjunction with other utilizations to establish arc-specific load duration curves represented in the CEM. Assuming that the resulting peak flows reflect full utilization of the capacity available during the peak season, an equivalent maximum annual capacity available to the natural gas market can be calculated by dividing the total peak flow by the peak utilization. Next, dividing the total flow (peak and off-peak, firm and interruptible) by this maximum annual capacity . produces maximum annual total utilizations used by the Annual Flow Module. The following equations result.

For the total natural gas market, along each arc $i, j$ :

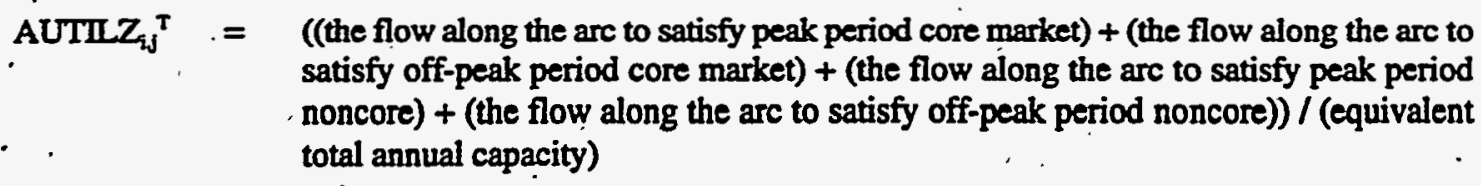

given; . equivalent total annual capacity = ((the flow along the are to satisfy peak period core market) + (the flow along the arc to satisfy peak period noncore) / (peak utilization rate)

$$
\begin{aligned}
\operatorname{AUTIL} Z_{i, j}^{T} & =\frac{\left(x_{i, j}^{\mathrm{PF}}+x_{i, j}^{\mathrm{OF}}+x_{i, j}^{\mathrm{PI}}+x_{i j}^{\mathrm{OJ}}\right)}{\operatorname{ECAP}_{i, j}^{\mathrm{T}}} \\
\operatorname{ECAP}_{i, j}^{\mathrm{T}} & =\frac{\left(x_{i j}^{\mathrm{PF}}+x_{i, j}^{\mathrm{PI}}\right)}{U T I Z_{i, j}^{\mathrm{P}}}
\end{aligned}
$$

where, 


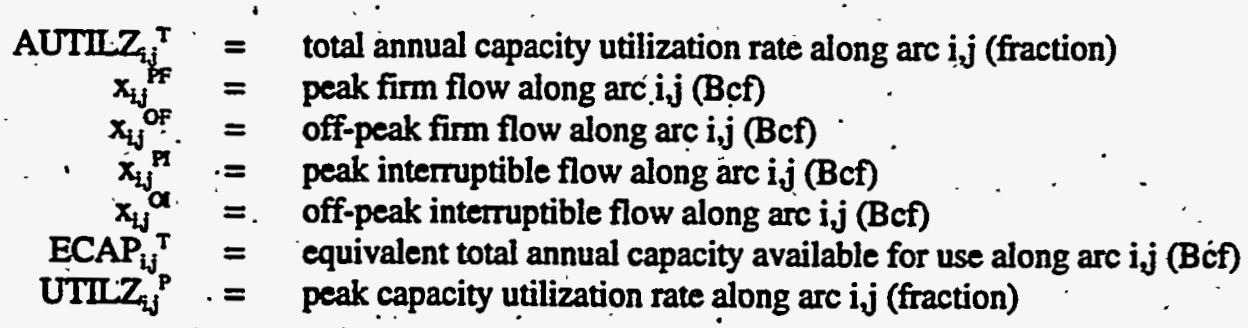

Contingencies have been written into the code to ensure that the total utilization remains greater than the firm, and that the total utilization is above a minimum threshold utilization.

Finally, net ștorage withdrawals are determined by subtracting off-peak flows going into storage from peak flows going out of storage. This is done at each node for each class of customer (i.e., firm or interruptible). Thus, an annual representation of the seasonal flow patterns established by the CEM is generated for use by the Annual Flow Module. This is defined by the following equations:

$$
\begin{aligned}
& \mathrm{NETSTR}_{\mathrm{i}}{ }^{\mathrm{F}}=\mathrm{x}_{\mathrm{sed}, \mathrm{i}}^{\mathrm{PF}}-\mathrm{x}_{\mathrm{s}, \mathrm{i}}^{\mathrm{OF}} \\
& \operatorname{NETSTR}_{i}{ }^{1}=x_{s, i}^{P I}-x_{s, i}^{\text {ol }}
\end{aligned}
$$

where,

$$
\begin{aligned}
& \text { NETSTR }_{i}^{F}=\text { net storage at node i for firm market (Bcf) } \\
& \text { NETSTR }_{1}^{1}=\text { net storage at node i for interruptible market (Bcf) } \\
& x_{x i j}{ }^{p F}=\text { peak firm flow out of storage at node } i(B c f) \\
& x_{\text {sit }}^{\text {of }}=\text { off-peak firm flow into storage at node } i \text { (Bcf) } \\
& x_{x, i}=\text { peak interruptible flow out of storage at node } i \text { (Bcf) } \\
& x_{x+1} \text { o }=\text { off-peak interruptible flow into storage at node } i \text { (Bcf) }
\end{aligned}
$$




\section{. 8. Pipeline Tariff Module Solution Methodology .}

This Chapter discusses the solution methodology for the Pipeline Tariff Module (PTM) of the Natural Gas Transmission and Distribution Model (NGTDM). In this Module, for fully regulated services, the rates developed by the methodology are used as actual costs for transportation and storage services. Where interruptible services are more loosely regulated or where markets are deemed competitive, the methodology computes maximum and minimum rates for service. The minimum rate is used as a lower bound on the price of services. The actual price charged for these more loosely

$\therefore$ regulated services or the "market clearing price" is determined by the Annual Flow Module. Under current regulatory policy, the maximum price computed by the methodology (the 100-percent load factor rate) will act as a cap on the market clearing price. This "price cap" will not be enforced if deregulation of service is assumed or if Federal Energy Regulatory Commission provides for alternative pricing/cost recovery mechanisms.

The PTM tariff calculation is divided into two phases: a base-year initialization phase and a forecast year update phase. These two phases include the following steps: (1) determine the total cost of service, (2) classify line items of the cost of service as fixed and variable costs, (3) allocate fixed and variable costs to rate component (reservation and usage fee, [volumetric charge]) based on the rate design, (4) aggregate costs to the network arc/network node, (5) for transportation services, allocate costs to type of service (firm and interruptible), ${ }^{65}$ and (6) compute arc-specific (node-specific) rates. For the base-year phase, the cost of service is developed from the financial data base while for the forecast year update phase the costs are estimated using a set of econometric equations. These steps are used to determine (1) transportation rates for the Annual Flow Module, (2) transportation rates for the Capacity Expansion Module to determine pipeline capacity expansion, and (3) storage rates for the Capacity Expansion Module to determine storage capacity expansion. A general overview of the methodology for deriving rates is presented in the box on the next page, while the PTM system diagram is presented in Figure 8-1:

\section{Base-Year Initialization Phase.}

The purpose of the base-year initialization phase is to provide, for the base year of the NEMS forecast horizon (currently 1990), an initial set of NGTDM network-level transportation and storage revenue requirements and tariffs. The base-year information is developed from existing pipeline company transportation and storage data. The base-year initialization process draws heavily on two data bases developed by the Office of Oil and Gas, EIA. These data represent the existing physical pipeline and storage system. The physical system is at a more disaggregate level than the NGTDM network. The first data base provides detailed company-level financial, cost, and rate base parameters. This financial data base contains information on capital structure, rate-base, and revenue requirements by major line item of the cost of service for the base year of the model. The second data base covers the physical attributes of the natural gas pipelines, including contract demand and pipeline layout. The physical pipeline layout data are used, along with the contract data, to derive the allocation and billing determinants. These factors subsequently are used to compute unit rates for transportation services along each arc (and for storage services at each node) of the NGTDM network.

This section discusses three separate processes that occur during the base-year initialization phase: (1) the computation of the cost of service and rates for services, (2) the construction of capacity expansion cost/tariff curves, and (3) manipulations required to pass the rates to the Annual Flow Module and curves to the Capacity Expansion Module.

The computation of base-year cost of service and rates for services involves six distinct procedures as outlined in the box below. Each of these procedures is discussed in detail below.

In order to facilitate capacity expansion decisions in the Capacity Expansion Module, the PTM constructs cost/tariff curves which relate incremental pipeline or storage facility capacity expansion to corresponding rates. These curves are developed from historically based estimates of capital and revenue requirements for capacity expansion projects using the computational procedures for determining base-year cost of service and rates.

${ }^{65}$ This step is not carried out for storage service because no distinction is made betwcen firm and interruptible storage servicès. 


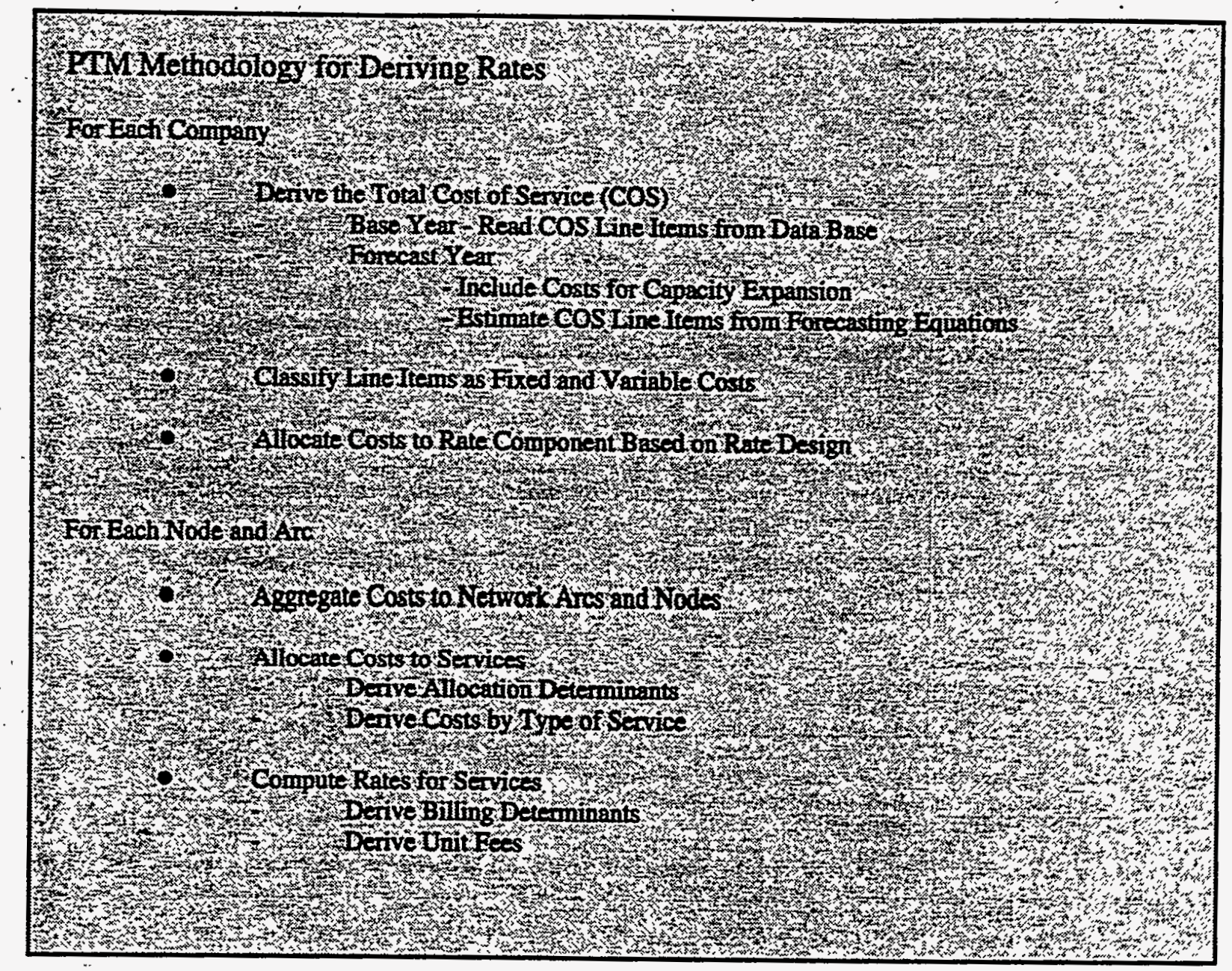

Prior to passing the rates to the Annual Flow Module and Capacity Expansion Module, the PTM rates must be adjusted to maintain consistency among the three modules. PTM rates are calculated in nominal dollars and then converted to real dollars for use in the Annual Flow Module and Capacity Expansion Module.

\section{Computation of Rates}

An overview of the processing of costs in the PTM ratemaking procedure is illustrated in Figure 8-2. In the base-year initialization phase of the PTM, rates are computed using the six-step process outlined above. The first three steps are performed for the transportation and storage functions at the company level: (1) derivation of the total cost of service; (2) classifying line item costs as fixed and variable costs, and (3) allocation of fixed and variable costs to rate components based on rate design. The fourth step is to transform the costs from the company level to the network (are and node) level. Allocation of costs to services (Step 5) and computation of rates (Step 6) are carried out at the arc level for transportation and the node level for storage. Step 5 is only executed for the transportation function because there is only one type of storage service represented in the PTM.

The equations apply, in general, to both transportation and storage functions. However, not all variables used in an equation are defined for both functions. For example, costs associated specifically with transportation services, such as compressor station labor costs are set to zero when the equation is used to determine storage-related costs. 
Figure 8-1. Pipeline Tariff Module System Diagram

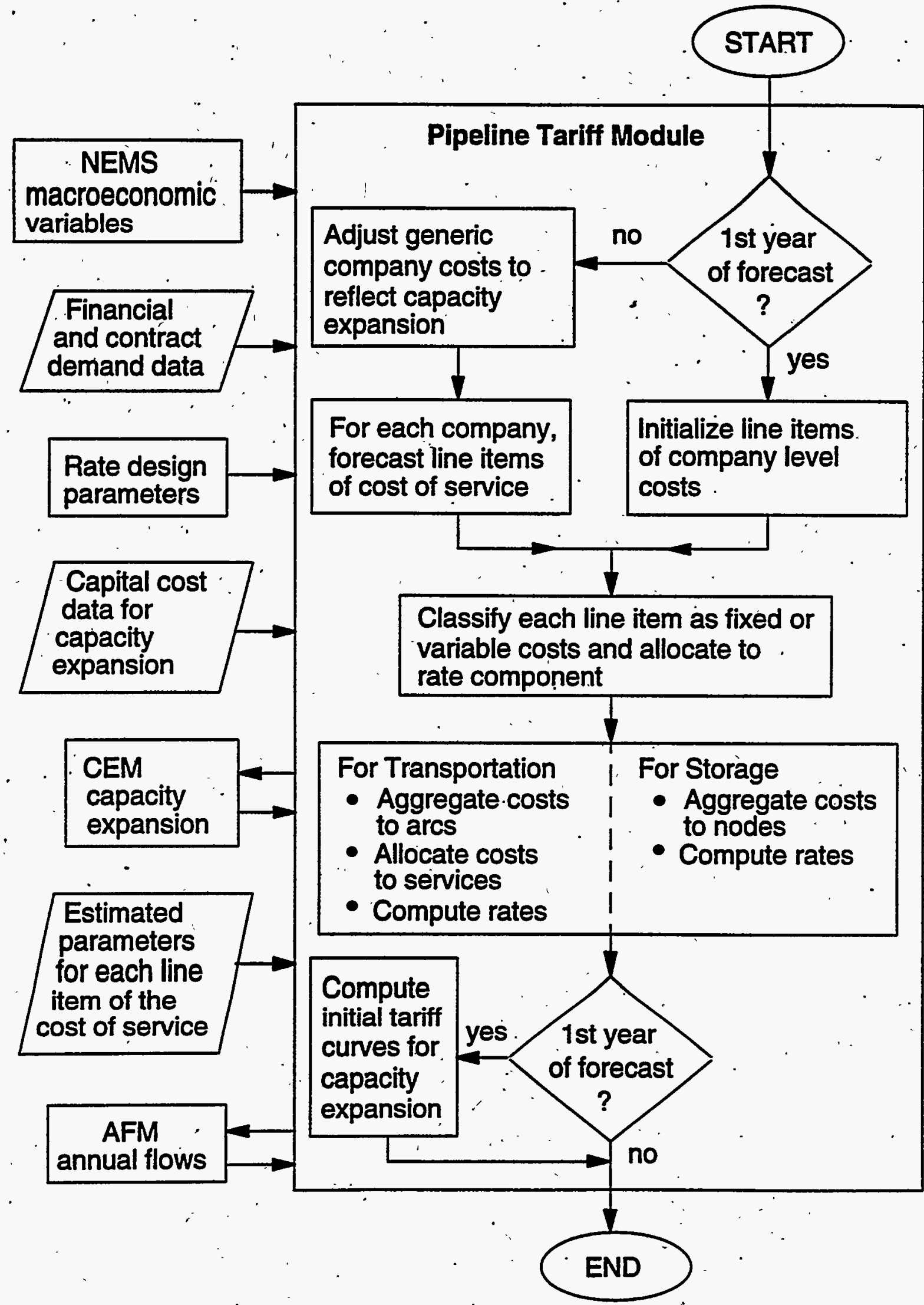


Figure 8-2. Processing Transportation Service Costs in the Ratemaking Process

Company Level
Arc Lovel

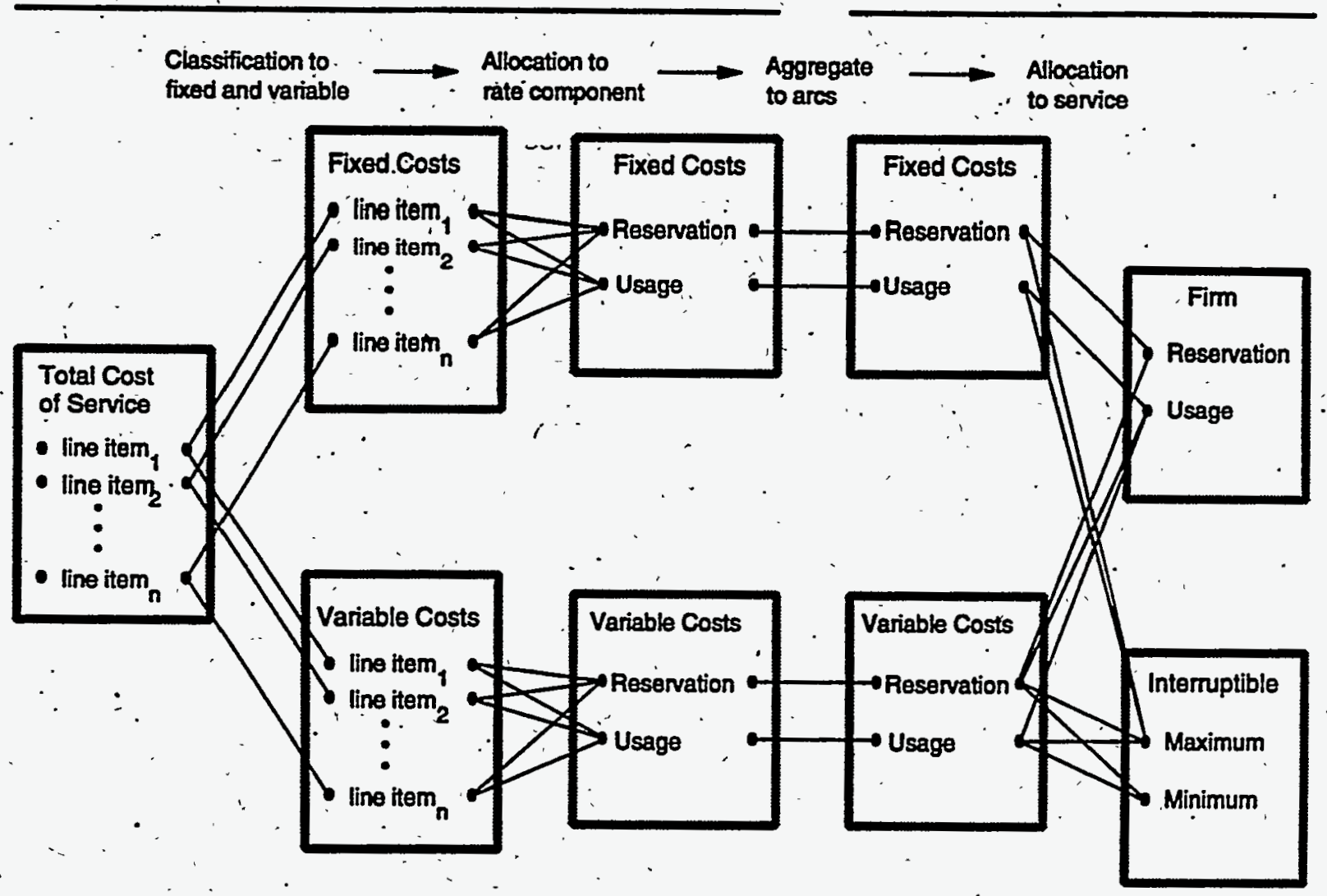

\section{Step 1: Derivation of the Total Cost-of-Service}

The total cost-of-service for a pipeline company is computed as the revenue requirement minus any revenue credits. The total revenue requirement (TRR) consists of a just and reasonable return on the rate base plus normal operating expenses. Revenue credits reflect revenues generated by nonjurisdictional services and one time costs that are outside of the scope of the PTM. Therefore, the total cost of service is computed as follows:

$$
\begin{aligned}
& \text { TCOS = TRR - REVC } \\
& \text { TRR = TRRB + TNOE } .
\end{aligned}
$$

where,

$$
\begin{aligned}
\text { TCOS } & =\text { total cost-of-service (dollars }{ }^{66} \text { ) } \\
\text { TRR } & =\text { total revenue requirement (dollars) } \\
\text { TNOE } & =\text { total normal operating expenses (dollars) } \\
\text { REVC } & =\text { revenue credits to cost-of-service (dollars) (Appendix E) } \\
\text { TRRB } & =\text { total return on rate base (dollars) }
\end{aligned}
$$

${ }^{6}$ All costs discussed in this chapter are in nominal dollars, unless explicitly stated otherwise. 
Derivations of return on rate base, total normal operating expenses, and revenue credits are presented in the following subsections.

Just and Reasonable Return. In order to compute the return portion of the cost-of-service, the determination of capital structure and rate base is necessary. Capital structure is important because it determines the cost of capital to the pipeline company. The weighted average cost of capital is applied to the rate base to determine the return component of the costof-service, as follows:

$$
\text { TRRB = WAROR * APRB }
$$

where,

$\mathrm{TRRB}^{\circ}=$ total return on rate base [before taxes, (dollars)]

WAROR = weighted-average before-tax return on capital (fraction)

$A P R B=$ adjusted pipeline rate base (dollars)

In addition, for reporting purposes, the return on rate base is broken out into the three components as shown below.

$$
\begin{aligned}
\text { PFEN } & =(\text { PFES/TOTCAP }) * \text { PFER } * \text { APRB } \\
\text { CMEN } & =(\text { CMESTTOTCAP }) * \text { CMER } * \text { APRB } \\
\text { LTDN } & =(\text { LITS } / T O T C A P) * \text { LTDR } * \text { APRB }
\end{aligned}
$$

where,

$$
\begin{aligned}
\text { PFEN } & =\text { total return on preferred stock (dollars) } \\
\text { PFES } & =\text { value of preferred stock (dollars) } \\
\text { TOTCAP } & =\text { total capitalization (dollars) } \\
\text { PFER } & =\text { coupon rate for preferred stock (fraction) } \\
\text { APRB } & =\text { adjusted pipeline rate base (dollars) } \\
\text { CMEN } & =\text { total return on common stock equity (dollars) } \\
\text { CMES } & =\text { value of common stock equity (dollars) } \\
\text { CMER } & =\text { common equity rate of return (fraction) } \\
\text { LTDN } & =\text { total return on long-term debt (dollars) } \\
\text { LTDS } & =\text { value of long-term debt (dollars) } \\
\text { LTDR } & =\text { long-term debt rate (fraction) }
\end{aligned}
$$

The cost of capital (WAROR) is computed as the value-weighted average cost of capital for preferred stock, common stock equity, and long-term debt, as follows:

$$
\begin{aligned}
& \text { WAROR }=(\text { PFES } * \text { PFER + CMES *CMER }+ \text { LTDS *LTDR }) / T O T C A P \\
& \text { TOTCAP }=\text { PFES + CMES + LTDS }
\end{aligned}
$$

where,

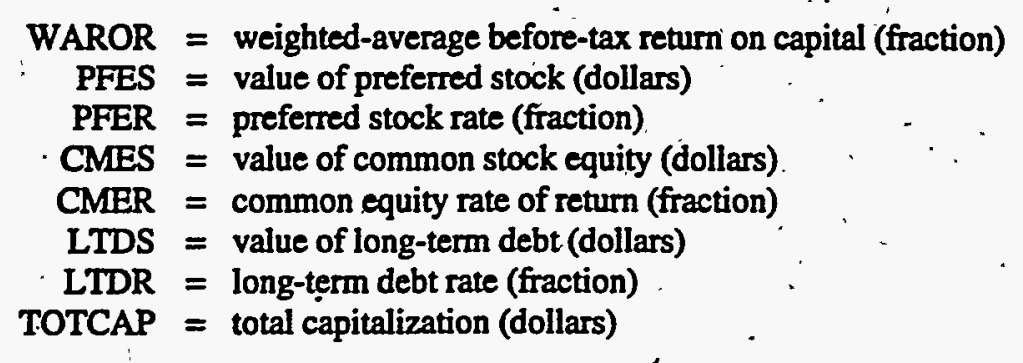

The total rate base is computed as the sum of net plant in service, cash working capital, other working capital and transition expense balance minus accumulated deferred income taxes. That is,

$$
\mathrm{APRB}=\mathrm{NIS}+\mathrm{CWC}+\mathrm{OWC}+\mathrm{TPEB}-\mathrm{ADIT}
$$


where,
$A P R B=$ adjusted pipeline rate base (dollars)
NIS $=$ net capital cost of plant in service (dollars)
CWC = cash working capital (dollars)
OWC $=$ other working capital (dollars)
TPEB = transition expense balance (dollars) ${ }^{67}$
ADIT = accumulated deferred income taxes (dollars)

The net plant in service is the original capital cost plant in service minus the accumulated depreciation.'

$$
\text { NIS = GPIS - ADDA }
$$

where,

$$
\begin{aligned}
\text { NSS } & =\text { net capital cost of plant in service.(dollars) } \\
\text { GPIS } & =\text { original capital cost of plant in service [gross plant in service (dollars)] } \\
\text { ADDA } & =\text { accumulated depreciation, depietion, and amortization (dollars) }
\end{aligned}
$$

Total Normal Operating Expenses. Total normal operating expense line items inciude depreciation, taxes, administrative and general expenses, customer expenses, and operation and maintenance expenses. In the PTM, taxes are disaggregated further into Federal, State, and other taxes and tax credits to permit tax policy analysis. Operation and maintenance expenses also are disaggregated into several categories to enhance accuracy in forecasting expenses by function.

$$
\text { TNOE }=\text { DDA + TOTAX + TAG + TCE + TOM }
$$

where,

$$
\begin{aligned}
\text { TNOE } & =\text { total normal operating expenses (dollars) } \\
\text { DDA } & =\text { depreciation, depletion, and amortization costs (dollars) } \\
\text { TOTAX } & =\text { total Federal and State income tax liability (dollars) } \\
\text { TAG } & =\text { total administrative and general expense (dollars) } \\
\text { TCE } & =\text { total customer expense (dollars) } \\
\text { TOM } & =\text { total operations and maintenance expense (dollars) }
\end{aligned}
$$

Depreciation, depletion, and amortization costs, administrative and general expense, and customer expense are available directly from the financial data base.

Total taxes are computed as the sum of Federal and State income taxes and other taxes, less tax credits, as follows:

$$
\begin{aligned}
& \text { TOTAX = FSIT + OTTAX - FSITC } \\
& \text { FSIT }=\text { FIT + SIT }
\end{aligned}
$$

where,

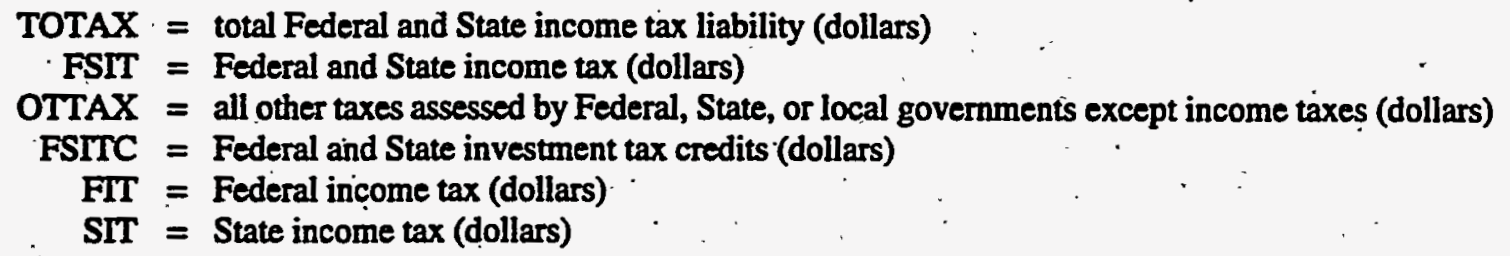

\footnotetext{
${ }^{67}$ The transition expense balance is the remaining balance of approved but yet to be recovered transition costs associated with restructuring gas supply contracts for Order 636 .

${ }^{6}$ Customer expense includes direct payroll distributions of salarięs and wages associated with the following services: customer accounts, customer service, information, and sales.
} 
. Federal income taxes are derived from retums to common stock equity and preferred stock (after-tax profit) and the Federal tax rate. The after-tax profit is determined as follows:

$$
A T P=A P R B *(P F E R * P F E S+C M E R * C M E S) / T O T C A P
$$

where,

$$
\begin{aligned}
\text { ATP } & =\text { after-tax profits (dollars) } \\
\text { APRB } & =\text { adjusted pipeline rate base (dollars) } \\
\text { TOTCAP } & =\text { total capitalization (dollars) } \\
\text { PFER } & =\text { preferred stock rate (fraction) } \\
\text { PFES } & =\text { value of preferred stock (dollars) } \\
\text { CMER } & =\text { common equity rate of return (fraction) } \\
\text { CMES } & =\text { value of common stock equity (dollars) }
\end{aligned}
$$

and the Federal income taxes are

$$
\begin{aligned}
& \text { FIT }=\text { (FRATE } * \text { ATP / 1. - FRATE) } \\
& \text { where, } \quad \\
& \text { FIT }=\text { Federal income tax (dollars) } \\
& \text {.FRATE }=\text { Federal income tax rate (fraction) (Appendix E) } \\
& \text { ATP }=: \text { after-tax profits (dollars) }
\end{aligned}
$$

State income taxes are computed by multiplying the sum of taxable returns and the associated Federal income tax by a weighted-average State tax rate associated with each pipeline company. The weighted-average State tax rate is based on peak service volumes in each State delivered by the pipeline company. State income taxes are computed as follows:

$$
\text { SIT }=\text { SRATE } *(\text { FIT }+ \text { ATP })
$$

where,

$$
\begin{aligned}
\text { SIT } & =\text { State income tax (dollars) } \\
\text { SRATE } & =\text { average State income tax rate (fraction) (Appendix E) } \\
\text { FTT } & =\text { Federal income tax (dollars) } \\
\text { ATP } & =\text { after-tax profits (dollars) }
\end{aligned}
$$

Total operations and maintenance expense consists of three major categories: supervision and engineering expenses, compressor station expenses, and other operations and maintenance expenses. ${ }^{\circ}$. Compressor station expenses are disaggregated further into two categories: compressor station operating and maintenance labor expenses and compressor station operating and maintenance non-labor expenses. That is, total operating and maintenance expense (TOM) equals

$$
\text { TOM = SEOM + CSOML + CSOMN + OTOM }
$$

where,

$$
\begin{aligned}
\text { TOM } & =\text { total operations and maintenance expense (dollars) } \\
\text { SEOM } & =\text { supervision and engineering expense (dollars) } \\
\text { CSOML } & =\text { compressor station operating and maintenance labor expense (dollars) } \\
\text { CSOMN } & =\text { compressor station operating and maintenance non-labor expense (dollars) } \\
\text { OTOM } & =\text { other operations and maintenance expense (dollars) }
\end{aligned}
$$

Revenue Credits. The revenue requirement is reduced (increased) by various revenuie credits (expenses) to determine the total cost-of-service. These credits may relate to one-time expenditures that are outside the scope of the other cost categories. After the determination of the total cost of service, each line item is classified as a fixed or variable cost as described in Step 2.

\footnotetext{
${ }^{6}$ Some expenses in this category apply only to transportation costs. Consequently, compressor-related and similar expenses will not be calculated for storage facilities.
} 


\section{Ștep 2: Classification of Cost of Service Line Items as Fixed and Variable Costs}

The PTM classifies each line item of the cost of service (computed in Step 1) as a fixed and variable cost. Fixed costs are independent of storage/transportation usage, while variable costs are a function of usage. Fixed and variable costs are computed by multiplying each line item of the cost of service by the percentage of the cost that is fixed and the percentage of the cost that is variable. The classification of fixed and variable costs is defined by the user as part of the scenario specification. The classification of line item $\operatorname{cost} R_{\mathrm{q}}$ to fixed and variable cost is determined as follows:

$$
\begin{aligned}
& R_{L f}=A L L_{t} * R_{\mathrm{t}} / 100 \\
& R_{i, v}=A L L_{v} * R_{i} / 100
\end{aligned}
$$

where,

$$
\begin{aligned}
\mathbf{R}_{L g} & =\text { fixed cost portion of line item } R_{f} \text { (million dollars) } \\
A L L_{i} & =\text { percentage of line item } R_{i} \text { representing fixed cost } \\
R_{i} & =\text { total cost of line item } i \text { (million dollars) } \\
R_{L_{v}} & =\text { variable cost portion of line item } R_{i} \text { (million dollars) } \\
A L L_{v} & =\text { percentage of line item } R_{i} \text { representing variable cost } \\
i & =\text { line item index } \\
\therefore 100 & =A L L_{f}+A L L_{r}
\end{aligned}
$$

An example of this procedure is illustrated in Table 8-1.

\section{Step 3: Allocation of Fixed and Variable Costs to Rate Components}

Allocation of fixed and variable costs to rate components is conducted only for transportation services because storage service is modeled in a more simplified manner using a one-part rate.

The rate design to be used within the PTM is specified by input parameters, which can be modified by the user to reflect changes in rate design over time. The PTM allocates the fixed and variable costs computed in Step 2 to rate components as specified by the rate design. For transportation service, the comporients of the rate consist of a reservation and a usage fee. The reservation fee is a charge assessed based on the amount of the capacity reserved. It typically is a monthly. fee that does not vary with throughput. The usage fee is a charge assessed for each unit of gas that moves through the system. For storage service the rate components are aggregated into one volumetric charge that is based on the amount of working gas capacity. ${ }^{70}$

The-actual reservation and usage fees that pipelines are allowed to charge are regulated by the Federal Energy Regulatory Commission. How costs are allocated determines the extent of differences in the rates charged for different classes of customers for different types of services. In general, the more fixed costs.are allocated to usage fees, the more costs are recovered based on throughput. Thus high load factor customers pay a larger share of system costs. Allocating a larger share of fixed costs to reservation fees, however, leads to low load factor customers bearing a larger share of system costs.

Costs are assigned either to the reservation fee or to the usage fee according to the rate design specified for the pipeline company. The rate design can vary among pipeline companies. Three typical rate designs are described in Table 8-2. The PTM provides two options for specifying the rate design. In the first option, a rate design for each pipeline company can be specified for each forecast year. This option permits different rate designs to be used for different pipeline companies while also allowing individual company rate designs to change over time. Since pipeline company data subsequently are aggregated to the network arc, the composite rate design at the arc-level is the volumetric-weighted average of the pipeline company rate designs. The secind option permits a global specification of the rate design, where all pipeline companies have the same rate design for a specific time period but can switch to another rate design in a

\footnotetext{
${ }^{30}$ This simplified representation of one volumetric charge related to the working gas capacity is designed to include all the costs that in actual practice are recovered through reservation, inventory, injection, and withdrawal charges.
} 
Table 8-1. Illustration of Fixed and Variable Cost Classification

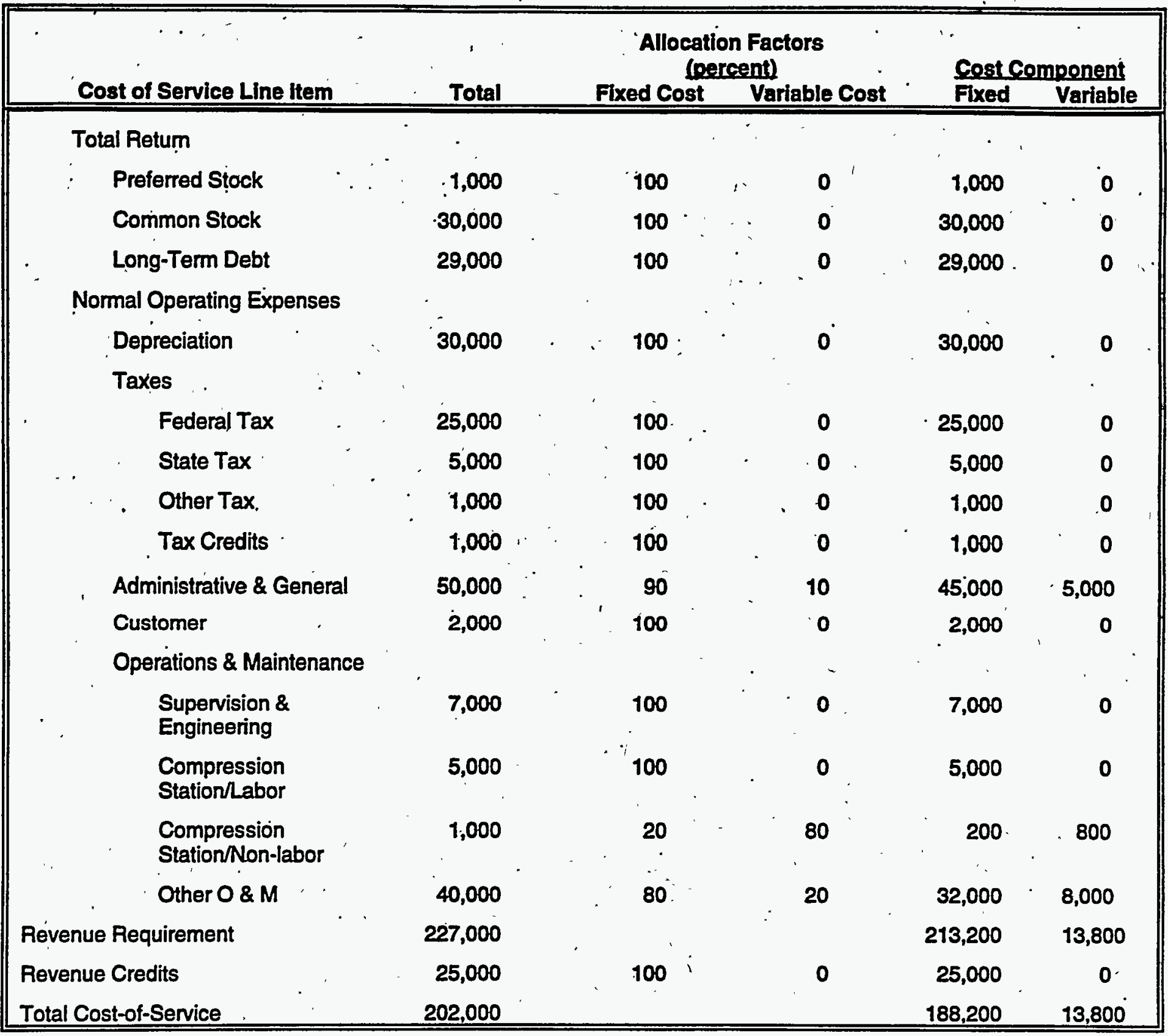


Table 8-2. Approaches to Rate Design

\begin{tabular}{|c|c|c|}
\hline $\begin{array}{l}\text { Modified Fixed Variable } \\
\text { (Three-Part Rate) }\end{array}$ & $\begin{array}{l}\text { Modified Fixed Variable } \\
\text { (Two-Part Rate) }\end{array}$ & $\begin{array}{c}\text { Straight Fixed } \\
\text { Variable } \\
\text { (Two-Part Rate) }\end{array}$ \\
\hline $\begin{array}{l}\text { Two-part reservation } \\
\text { fee. - Retum on equity } \\
\text { and related taxes are } \\
\text { held at risk to achieving. } \\
\text { throughput targets by } \\
\text { allocating these costs to } \\
\text { the usage fee. Of the } \\
\text { remaining fixed costs, } 50 \\
\text { percent are recovered } \\
\text { from a peak day } \\
\text { reservation fee and } 50 \\
\text { percent are recovered } \\
\text { through an annual } \\
\text { reservation fee. } \\
\text { Variable costs allocated } \\
\text { to the usage fee. In } \\
\text { addition, retum on equity } \\
\text { and related taxes are } \\
\text { also recovered through } \\
\text { the usage fee. }\end{array}$ & $\begin{array}{l}\text { Reservation foe } \\
\text { based on peak day } \\
\text { requirements all } \\
\text { fixed costs except } \\
\text { retum on equity and } \\
\text { related taxes } \\
\text { recovered through this } \\
\text { fee. } \\
\text { Variable costs plus } \\
\text { retum on equity and } \\
\text { related taxes. are } \\
\text { recovered through the } \\
\text { usage fee. }\end{array}$ & $\begin{array}{l}\text { One-part capacity } \\
\text { resenvation fee. All fixed } \\
\text { costs are recovered } \\
\text { through the reservation } \\
\text { fee, which is assessed } \\
\text { based on , peak day } \\
\text { capacity requirements. }\end{array}$ \\
\hline
\end{tabular}

The allocation of fixed costs to reservation and usage fees entails multiplying each fixed cost line item of the total cost of service by the corresponding fixed cost rate design classification factor. A similar process is carried out for variable costs. This procedure is illustrated in Tables $8-3 \mathrm{a}$ and $8-3 \mathrm{~b}$ and is generalized in the equations following.

The classification of transportation line item costs $R_{i, s}$ and $R_{h, v}$ to reservation and usage cost is determined as follows:

$$
\begin{aligned}
& \mathbf{R}_{\mathrm{L}, \mathrm{f}, \mathrm{S}}=A L L_{\mathrm{f}, 5} * \mathrm{R}_{\mathrm{L}, \mathrm{f}} / 100 \\
& R_{\mathrm{Lif,u}}=A L L_{f, u} * R_{\mathrm{i},} / 100 \text {. } \\
& \dot{R}_{\mathrm{i}, \mathrm{v}, \mathrm{x}}=A \dot{L} L_{\mathrm{v}, \mathrm{x}} * \mathrm{R}_{\mathrm{i}, \sqrt{ }} / 100 \\
& R_{i, v, v}=A I i_{v, v} * R_{i, v} j 100
\end{aligned}
$$

where, 
Table 8-3a. Illustration of Allocation of Fixed Costs to Rate Components

\begin{tabular}{|c|c|c|c|c|c|}
\hline Cost of Service Line Item & Total & \multicolumn{2}{|c|}{$\begin{array}{c}\text { Allocation Factors } \\
\text { (percent) }\end{array}$} & \multicolumn{2}{|c|}{$\begin{array}{l}\text { Cost Assigned to } \\
\text { Rate Component }\end{array}$} \\
\hline Total Return & & & & & \\
\hline Preferred Stock & $\cdot 1,000$ & 0 & 100 & 0 & 1,000 \\
\hline Commion Stock & 30,000 & 0 & $100-$ & 0 & 30,000 \\
\hline Long-Term Debt & 29,000 & 100 & 0 & 29,000 & 0 \\
\hline Normal Operating Expenses. & & i & & & \\
\hline Depreciation & 30,000 & 100 & 0 & 30,000 & 0 \\
\hline Taxes & & & & & \\
\hline - Federal Tax & -25,000 & ? & 100 & 0 & 25,000 \\
\hline - State Tax & 5,000 & 0 & .100 & 0 & 5,000 \\
\hline Other Tax . & 1,000 & 100 & $\circ$ & 1,000 & 0 \\
\hline Tax Credits & 1,000 & 100 & 0 & 1,000 & 0 \\
\hline Administrative \& General & 45,000 & 100 & 0 & 45,000 & 0 \\
\hline Customer & 2,000 & 100 & 0 & 2,000 & 0 \\
\hline Operations \& Maintenanc & & & & & \\
\hline $\begin{array}{l}\text { Supervision \&: } \\
\text { Engineering }\end{array}$ & 7,000 & 100 & 0 . & 7,000 & 0 \\
\hline $\begin{array}{r}\text { Compression } \\
\text { Station/Labor }\end{array}$ & 5,000 & 100 & 0 & 5,000 & 0 \\
\hline $\begin{array}{l}\text { Compression } \\
\text { Station/Non-labor }\end{array}$ & 200 & 100 & 0 & 200 & 0 \\
\hline Other O \& M & 32,000 & 100 & 0 & 32,000 & 0 \\
\hline Revenue Requirement & 213,200 & & & 152,200 & 61,000 \\
\hline Revenue Credits & 25,000 & 100 & 0 & 25,000 & 0 \\
\hline Total Cost-of-Service & 188,200 & $=$ & & 127,200 & 61,000 \\
\hline
\end{tabular}


Table 8-3b. Illustration of Allocation of Variable Costs to Rate Components

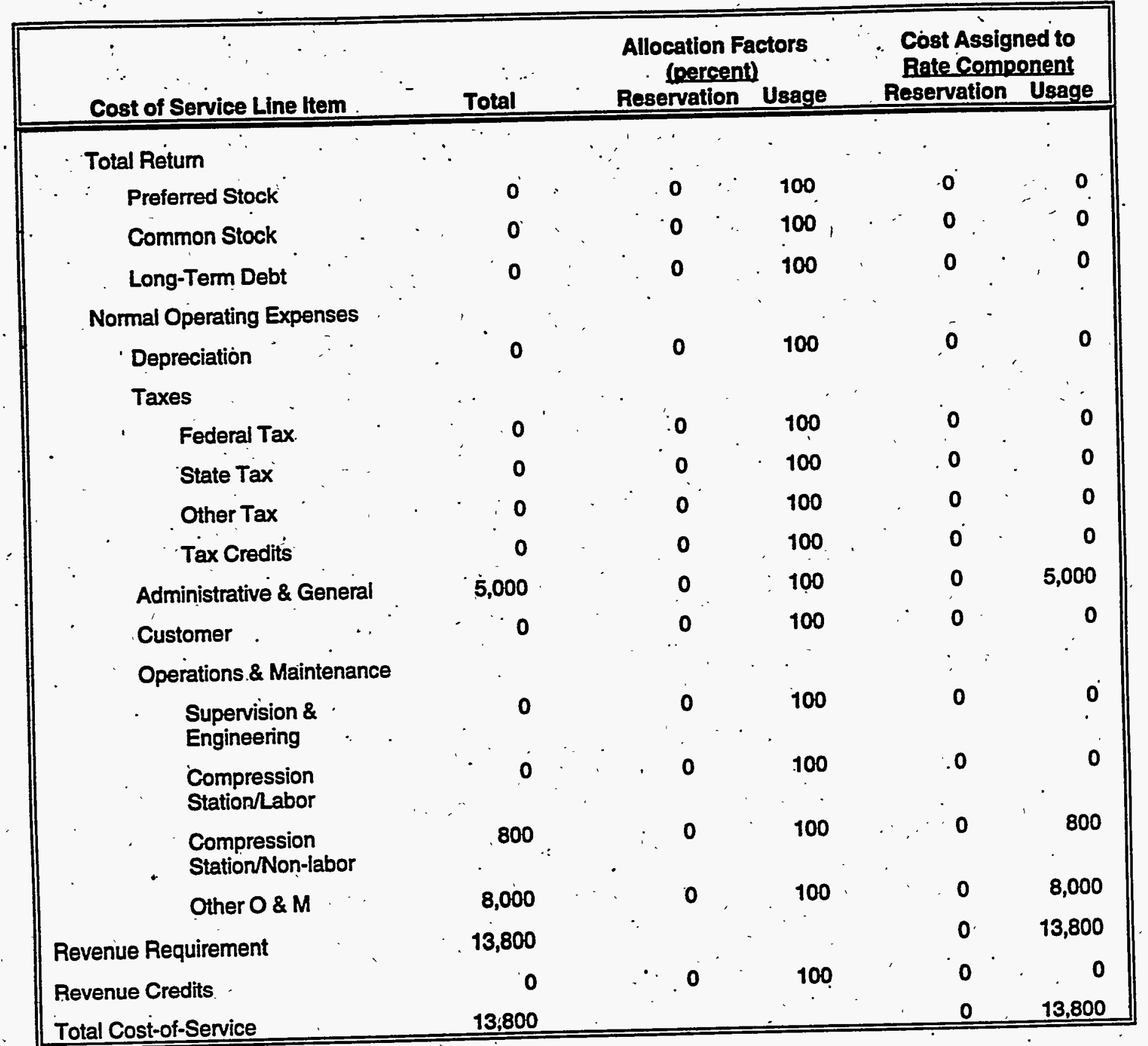




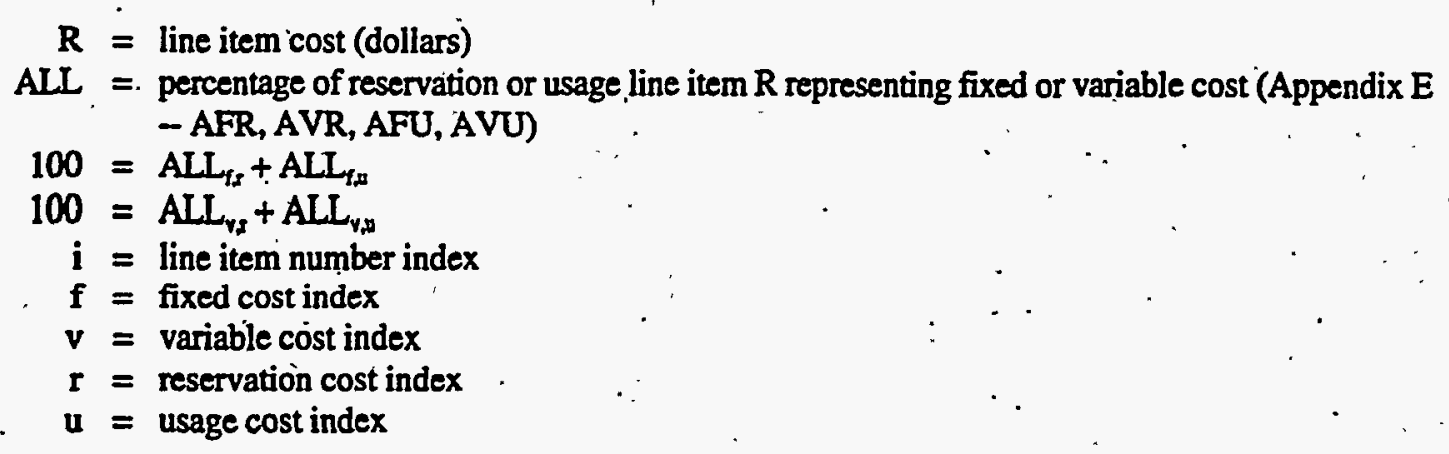

At this stage in the procedure, the line items comprising the fixed and variable cost components of the reservation and usage fees can be summed to obtain total fixed and variable costs allocated to reservation and usage components of the rates.

After ratemaking Steps 1,2 and 3 are completed for each company, company-level costs are transformed to arc-level (node-level) rates for transportation (storage) services. This process, carried out for each arc and node in the NGTDM. network, is accomplished in ratemaking Steps 4,5 and 6 as presented below.

\section{Step 4: Aggregation of Classified Cost of Service to Network Arcs and Nodes}

As discussed above, for transportation services the PTM develops fixed and variable costs and allocates them to reservation and usage rate components at the pipeline company level. The PTM apportions these components to distinct segments of a pipeline path based on the share of the mileage-based capacity reservations on the segment. These pipeline path segments represent the portions of the physical pipeline system that fall within the transshipment nodes that define a network arc. The costs associated with each segment are mapped to the network arc by aggregating the cost information across all pipeline segments identified with an arc." The capacity reservation shares (Appendix E, PS) used to apportion costs to pipeline segments are derived exogenously from the capacity reserved and distances associated with each segment and the capacity reserved and distances for the complete pipeline path. The shares do not change throughout the forecast.

This procedure is illustrated for two hypothetical pipeline companies (Figure 8-3). In the example, it is assumed that the total costs to be distributed to distinct pipeline segments are $R_{A}$ and $R_{B}$ for Company $A$ and Company $B$, respectively. Notice that Company, $A$ is defined by network $a, b, c, d, e$ in the upper portion of Figure 8-3 and Company $B$ is defined by network $a, b, c, d$ in the middle half of the figure. Company A receives $4000 \mathrm{MMBtu} /$ day at point a, discharges 2000 $M M B t w / d a y$ at point $c$ and ships the remaining $2000 \mathrm{MMBtw} /$ day to point e. Company $B$ ships $3,000 \mathrm{MMBtu}$ along its entire route, from point a to point $c$. It is assumed further that segment b-d of Company A's pipeline path and segment b-c of Company B's pipeline path are to be mapped into the network are defined by the transshipment nodes 1-2 at the bottom of Figure 8-3. Note that company A's segment b-d actually is composed of two segments: segment b-c and segment $c-d$.

The mileage-based capacity reservation $(V)$ is determined as the capacity reserved in each pipeline segment multiplied by the length of the pipeline segment. For Company $A$ the reservation on segment b-c is the quantity $(4000 * 50) \mathrm{MMBtu}-$ miles and the reservation on segment $c-d$ is the quantity $(2000 * 150)$ MMBtu-miles per day. For company $B$, the reservation on segment $b-c$ is the quantity $(3000 * 200)$ MMBtu-miles per day. The total reseryation along the pipeline path for company $A$ is the sum of the reservations on each segment, or 1,100,000 MMBtu-miles per day. ${ }^{72}$

Once the reservations on the segments are determined, the pipeline costs are apportioned to each segment as follows. The share of cost $\left(R_{\mathcal{A}}\right)$ allocated to Company $A$ 's pipeline segment $b-c$ is determined as the cost multiplied by the ratio of the reservations on segment $b-c$ to the reservations on the total pipeline path, expressed as follows:

\footnotetext{
${ }^{71}$ In the forecast years, arc-level costs include costs associated with generic companies representing pipeline capacity added subsequent to the base year. Generic companies are discussed in the section describing the forecast year updating process.

${ }^{n}$ Derived based on capacity reservations on are a-b equal to $\left(4000^{*} 100\right)$ MMBtu-miles per day, plus capacity reservations on are b-c of $\left(4000^{*} 50\right) \mathrm{MMBtu}$-miles per day, plus capacity reservations on are c-d of $\left(2000^{*} 150\right)$ MMBtu-miles per day and capacity reservations (2000*100) MMBtu-miles per day on are d-e.
} 
Figure 8-3. . Example of Apportioning Pipeline Costs to Network Arcs

\section{Source:}

4,000 MMBtu/d

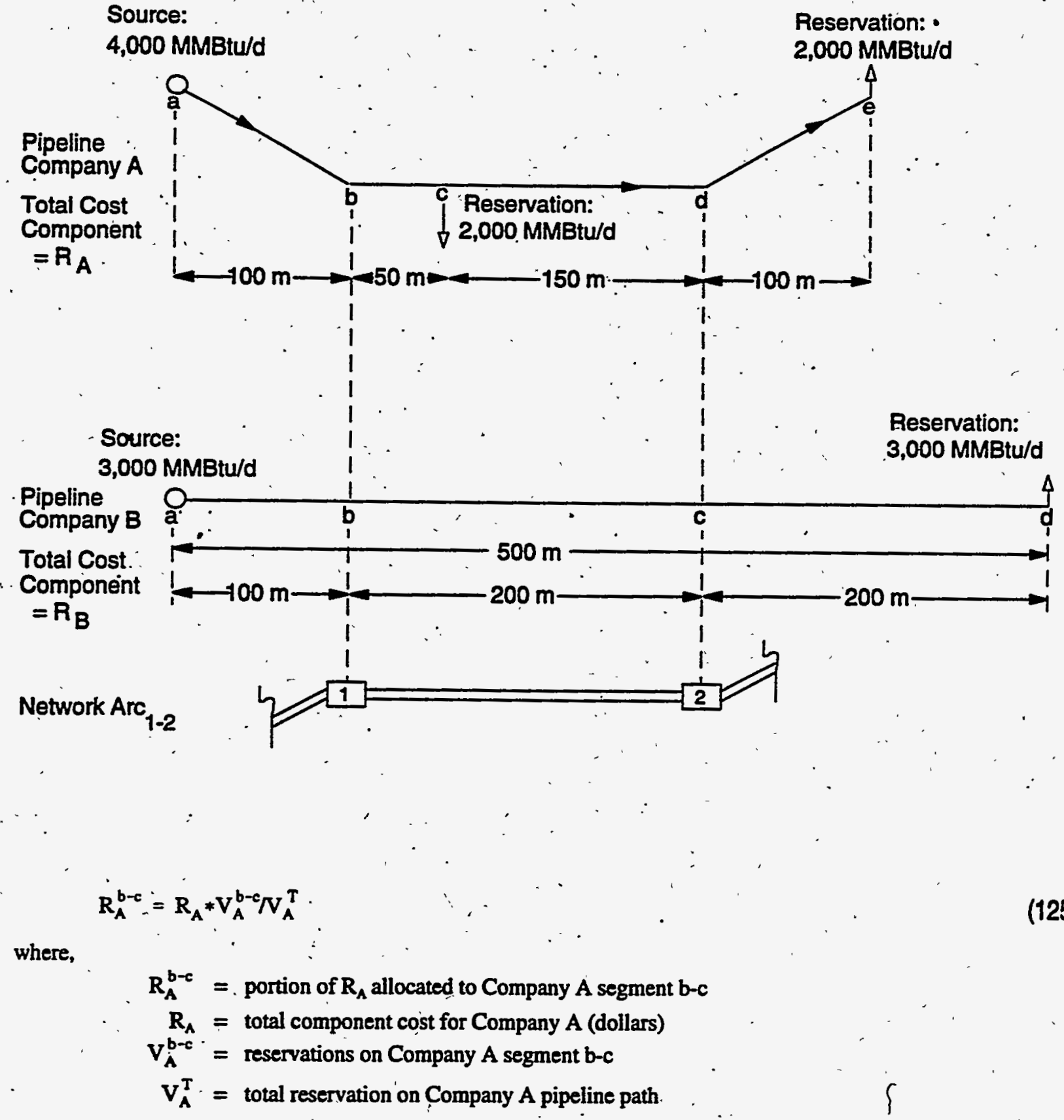

Reservation: •

In this example, $V_{A}^{b-c}$ equals $200,000 \mathrm{MMBtu}$-miles per day and $V_{A}^{\top}$ equals $1,100,000 \mathrm{MMB}$ tu-miles per day.

Similaty, the allocation of ocsts to Company A'ssegnextad $\left[R_{A}^{c-d}=R_{A} *(3 / 11)\right]$ and toCompany B'ssegnentb-c $\left[R_{B}^{b-c}=R_{B} *(6 / 15)\right]$ are obtained. Finally, the costs are aggregated to the network arc by summing all distinct costs for Company A's segment . b-c and segment $c-d$ and Company B's segment $b-c$.

$$
R_{1-2}=R_{A}^{b-c}+R_{A}^{c-d}+R_{B}^{b-c}
$$

where, 


$$
\begin{aligned}
& R_{i-2}=\text { total costs allocated to arc 1-2 } \\
& R_{A}^{b-c}=\text { portion of } R_{A} \text { allocated to Company } A \text { segment } b-c \\
& R_{A}^{c-d}=\text { portion of } R_{A} \text { allocated to Company A segment } c-d \\
& R_{B}^{b-c}=\text { portion of } R_{B} \text { allocated to Company } B \text { segment } b-c
\end{aligned}
$$

Through this procedure, company-level fixed and variable costs are assigned to ares on the NGTDM network and for each arc these costs have been assigned to a rate component. Thus the following variables are defined:

$$
\begin{aligned}
& \mathrm{FCR}_{2}=\text { fixed costs assigned to the reservation component of the rate } \\
& \mathrm{VCR}_{2}=\text { variable costs assigned to the reservation component of the rate } \\
& \mathrm{FCU}_{2}=\text { fixed costs assigned to the usage component of the rate } \\
& \mathrm{VCU}_{2}=\text { variable costs assigned to the usage component of the rate } \\
& \mathrm{a}=\text { arc }
\end{aligned}
$$

Apportioning storage costs to network nodes is a more straightforward process because the costs are simply assigned to the nodes as a function of the share of storage capacity located in each region. Through the procedure provided in the following equations company-level fixed and variable costs are shared out and aggregated to nodes on the NGTDM network.

$$
\begin{aligned}
& \mathrm{FCS}_{\mathrm{n}}=\mathrm{FCS}_{\mathrm{n}}+\left(N S_{\mathrm{p}, \mathrm{n}} * \mathrm{SF}_{\mathrm{p}}\right) \\
& \mathrm{VCS}_{\mathrm{n}}=\mathrm{VCS}_{\mathrm{n}}+\left(\mathrm{NS}_{\mathrm{p}, \mathrm{n}} \neq S \mathrm{SV}_{\mathrm{p}}\right)
\end{aligned}
$$

where,

$$
\begin{aligned}
\mathrm{VCS}_{\mathrm{n}} & =\text { variable costs of storage (million dollars) } \\
\mathrm{FCS}_{\mathrm{n}} & =\text { fixed costs of storage (million dollars) } \\
\mathrm{NS}_{\mathrm{p}, \mathrm{n}} & =\text { share of company } \mathrm{p} \text { gas storage capacity located at the node } \mathrm{n} \text { [Appendix E, (fraction)] } \\
\mathrm{SF}_{\mathrm{p}} & =\text { company } \mathrm{p} \text { fixed costs for storage service (million dollars) } \\
\mathrm{SV}_{\mathrm{p}} & =\text { company p variable costs for storage service (million dollars) } \\
\mathrm{p} & =\text { pipeline company index } \\
\mathrm{n} & =\text { node index }
\end{aligned}
$$

\section{Step 5: Allocation of Arc-Level Transportation Costs to Services}

The arc-level fixed and variable costs are allocated to firm and interruptible transportation services. In allocating these costs, a portion of the fixed costs are assigned to noncore customers. Historically, rate designs have placed some of the recovery of fixed costs at risk by assigning the recovery of these costs to noncore customers. Should the revenues obtained from interruptible service be less than those anticipated in the ratemaking process, the pipeline company would not recover all of its fixed costs. Variable costs are allocated based on total annual throughput for each type of service. The development of the allocation factors is discussed next.

Allocation Factors for Fixed Costs. The allocation factors for fixed costs are based, in part, on the firm capacity reservations and annual interruptible transportation volumes along an arc. The procedure for obtaining arc-level reservations and flows in the base year is comparable to the process described above for aggregating segment costs to an arc. ${ }^{73}$ The allocation' factors for fixed costs are defined as follows. The fixed cost allocation factor for firm service is defined as the annualized peak-day reservations for firm service divided by the sum of the annualized peak-day firm reservations and an adjusted annual throughput volume for interruptible service. In equation form, this allocation factor (FADFS) is defined as follows:

$$
\dot{F A D F S}_{2}=\left(\text { PRESV }_{2} * 365 /\left(\text { PRESV }_{2} * 365+\text { ISERV }_{2} * \text { RADJ }_{2} *\left(1+\text { IEXPCT }_{2} / 100\right)\right)\right)
$$

\footnotetext{
${ }^{73}$ In subsequent years, flow volumes are input to the PTM at the arc-level.
} 
where,

FADFS $=$ allocation factor for fixed costs recovered from firm service (ratio).

PRESV, = peak-day reservations for firm transportation service (Bef per day) [Appendix F, CONDEM]

$\cdot$ ISERV $V_{\mathrm{a}}=$ annual throughput volume for interruptible transportation service (Bcf per year)

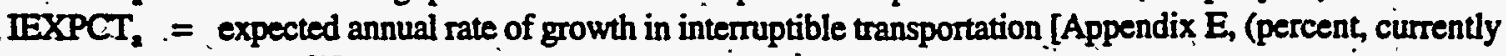
set.to 0)]

$\mathrm{RADJ}_{2}=$ adjustment factor for discounting [Appendix E -BASERADJ, (ratio)]

$\mathbf{a}=\operatorname{arc}$

The interruptible throughput volume is adjusted in the above equation for two reasons. First, the interruptible volumes are adjusted to reflect assumed changes in interruptible transportation volumes using the user-specified IEXPCT parameter. Second, the volume is adjusted downward via the RADJ factor to reflect anticipated discounting of interruptible transportation services. This adjustment factor (RADJ) reflects the degree of discounting that took place in the prior forecast year and is defined as follows:

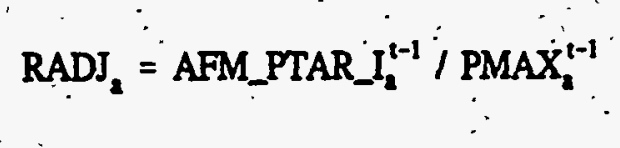

-where,

$\cdot \mathbf{t}=$ current year index

$$
\begin{aligned}
\mathrm{RADJ}_{2} & =\text { adjustment factor for discounting [Appendix E - BASERADJ, (ratio)] } \\
\text { AFM_PTAR_I } & =\text { average interruptible service rate in year t-1 [Appendix E, (dollars per Mct)] } \\
\text { PMAX } & =\text { maximum interruptible service rate in year t-1 (dollars per Mcf) } \\
\mathrm{a} & =\text { arc }
\end{aligned}
$$

Similarly, the allocation factor for fixed costs assigned to interruptible service (FADIS) is defined as

$$
\text { FADIS }_{2}=\frac{\text { ISERV }_{2} * \text { RADJ }_{2} *\left(1+\text { IEXPCT }_{2} / 100\right)}{\text { PRESV }_{2} * 365+\text { ISERV }_{2} * \text { RADJ }_{2} *\left(1+\text { IEXPCT }_{2} / 100\right)}
$$

where,

$$
\begin{aligned}
\text { FADIS }_{a} & =\text { allocation factor for fixed costs assigned to interruptible service [1-FADFS, (ratio)] } \\
\text { ISERV }_{a} & =\text { annual throughput volume for interruptible transportation service (Bcf per year) } \\
\text { RADJ, }_{2} & =\text { adjustment factor for discounting [Appendix E-BASERADJ, (ratio)] } \\
\text { IEXPCT, }_{2} & =\text { expected rate of growth in interruptible transportation [Appendix E, (percent)] } \\
\text { PRESV }_{2} & =\text { peak-day reservations for firm transportation service (Mcf per day) [Appendix E, CONDEM] } \\
\mathbf{a} & =\text { arc }
\end{aligned}
$$

Allocation Factors for Variable Costs. The allocation factors for variable costs are based on the annual firm and interruptible service volumes on the arc. The allocation factor that assigns variable costs to firm service (VADFS) is defined as the annual throughput vohume for firm transportation on the arc (FSERV) divided by the total annual throughput volume for firm and interruptible service on the arc, as follows:

$$
\text { VADFS }_{\mathbf{2}}=\text { FSERV }_{\mathbf{2}}\left(\text { FSERV }_{\mathbf{2}}+. \text { ISERY }_{\mathbf{2}}\right)
$$

where,

$$
\begin{aligned}
\text { VADFS } & =\text { allocation factor for variable costs assigned to firm service (ratio) } \\
\text { FSERV } & =\text { annual throughput volume for firm transportation service (Bcf per year) } \\
\text { ISERV }_{2} & =\text { annual throughput volume for interruptible transportation (Bcf per year) } \\
\mathrm{a} & =\text { arc }
\end{aligned}
$$

The allocation factor that assigns variable costs to interruptible services (VADIS) is defined as the annual throughput volume for interiuptible service divided by the total annual throughput volume for firm and interruptible service, as follows: 


$$
\text { VADIS }_{2}=\text { ISERV }_{2} /\left(\text { FSERV }_{2}+\text { ISERV }_{2}\right)
$$

where,

$$
\begin{aligned}
\text { VADIS }_{2} & =\text { allocation factor for variable costs assigned to interruptible service (ratio) } \\
\text { ISERV }_{2} & =\text { annual throughput volume for interruptible transportation service in (Bcf per year) } \\
\text { FSERV }_{\mathbf{a}} & =\text { annual throughput volume for firm transportation (Bef per year) } \\
\mathbf{a} & =\text { arc }
\end{aligned}
$$

The factors are applied to costs previously allocated to rate components (in Step 4) to derive the costs allocated to the firm transportation rate components. Similarly allocation factors are applied to obtain the costs allocated to interruptible transportation. These procedures are outlined in equation form below.

Derivation of Reservation Costs for Firm Transportation. Costs allocated to the firm transportation reservation fees consist of the firm transportation portion of the fixed and variable costs assigned to the reservation fee. This cost is derived by applying the allocation factors as follows:

$$
\mathrm{RCFS}_{\mathrm{a}}=\left(\mathrm{FADFS}_{\mathrm{a}} * \mathrm{FCR}_{\mathrm{a}}\right)+\left(\mathrm{VADFS}_{\mathrm{a}} * \mathrm{VCR}_{\mathrm{a}}\right)
$$

where,

$$
\begin{aligned}
\text { RCFS }_{2} & =\text { reservation costs assigned to core customers (million dollars per year) } \\
\text { FADFS, }_{2} & =\text { allocation factor for fixed costs recovered from firm service (ratio) } \\
\text { FCR }_{2} & =\text { fixed costs assigned to the reservation component of the rate (million dollars per year) } \\
\text { VADFS }_{2} & =\text { allocation factor for variable costs recovered from firm service (ratio) } \\
\mathrm{VCR}_{2} & =\text { variable costs assigned to the reservation component of the rate (million dollars per year) } \\
\mathrm{a} & =\text { arc }
\end{aligned}
$$

Derivation of Usage Costs for Firm Transportation. Costs allocated to the firm transportation usage fees consists of the firm transportation portion of the fixed and variable costs assigned to the usage fee. This cost is derived by applying the allocation factors as follows:

$$
\mathrm{UCFS}_{\mathbf{2}}=\left(\mathrm{FADFS}_{\mathbf{2}} * \mathrm{FCU}_{\mathbf{2}}\right)+\left(\mathrm{VADFS}_{\mathbf{2}} * \mathrm{VCU}_{\mathbf{2}}\right)
$$

where,

$$
\begin{aligned}
\text { UCFS }_{2} & =\text { usage costs assigned to core customers (million dollars per year) } \\
\text { FADFS }_{2} & =\text { allocation factor for fixed costs recovered from firm service (ratio) } \\
\text { FCU }_{2} & =\text { fixed costs assigned to the usage component of the rate (million dollars per year) } \\
\text { VADFS }_{2} & =\text { allocation factor for variable costs recovered from firm service (ratio) } \\
\text { VCU }_{2} & =\text { variable costs assigned to the usage component of the rate (million dollars per year) } \\
\mathrm{a} & =\text { arc }
\end{aligned}
$$

Derivation of Fixed and Variable Costs Allocated to Interruptible Transportation. Costs allocated to interiuptible transportation service consist of a portion of the fixed and variable costs assigned to the reservation and usage rate components. This cost is derived by applying the allocation factors as follows:

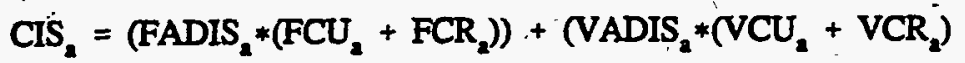

where,

$\mathrm{CIS}_{\mathbf{2}}=$ costs assigned to noncore customers (million dollars per year)

FADIS $_{2}=$ allocation factor for fixed costs recovered from interruptible service (ratio)

$\mathrm{FCU}_{2}=$ fixed costs assigned to the usage component of the rate (million dollars per year)

$\mathrm{FCR}_{2}=$ fixed costs assigned to the reservation component of the rate (million dollars per year)

VADIS $\cdot=$ allocation factor for variable costs recovered from interruptible service (ratio)

$\mathrm{VCU}_{2}=$ variable costs assigned to the usage component of the rate (million dollars per year)

VCR $_{1}=$ variable costs assigned to the reservation component of the rate (million dollars per year)

$\mathrm{a}=\operatorname{arc}$ 
The costs allocated to interruptible transportation service are not used to derive the maximum and minimum rates that may be charged for interruptible service. These costs are presented here to account fully for all costs that make up the total cost of service and to facilitate the discussion of the derivation of the costs allocated to firm transportation service. The computation of rates for firm and interruptible service is presented in Step 6.

\section{Step 6: Computation of Rates}

Firm Transportation Service. Firm transportation service rates (PTAR_F) are composed of arc-level reservation and usage fees (PTAR_REV_F and UFEE), as well as Order 636 transition costs (PTAR_191_F and PTAR_GSR_F). Arclevel reservation and usage fees for firm service are determined by dividing the costs corresponding to each rate component by the appropriate billing factors. Thus, the reservation fee, is determined as the reservation costs recovered from firm service (RCFS) divided by the annualized reservations for firm transportation service. That is,

$$
\mathrm{RFEE}_{\mathrm{a}}=\mathrm{RCFS}_{\mathrm{a}} /\left(\mathrm{PRESV}_{\mathrm{a}} * 365\right)
$$

where,

$$
\begin{aligned}
\text { RFEE }_{2} & =\text { reservation fee for firm service in dollars per Mef of capacity reserved } \\
\cdot \mathrm{RCFS}_{\mathbf{a}} & =\text { reservation costs assigned to.core customers (million dollars per year) } \\
\mathrm{PRESV}_{2} & =\text { peak-day reservations for firm transportation service (Bef per day) [Appendix E, CONDEM] } \\
\mathbf{a} & =\text { arc }
\end{aligned}
$$

However, the NGTDM pipeline network uses tariffs in the form of dollars per Mcf of throughput. The reservation fee component of the pipeline tariff is derived from the following nonlinear firm tariff curve, which computes the reservation $f e e$ as a function of the reservation costs assigned to core customers, the maximum effective firm service capacity, and the throughput volume for firm transportation service in the previous forecast year.

$$
\text { PTAR_REV_F }=\text { PNOD } *\left(\text { PTMD_FFL_/QNOD) }{ }^{\text {TARCRV_ĖAS }}\right.
$$

where,

PTAR_REV_F $=$ reservation fee component of the firm service pipeline tariff (dollars per Mcf of throughput)

QNOD = base quantity on the firm service tariff curve, set as a fraction (Appendix E, PTMDPCTQ0, currently set to 1) of the maximum effective capacity for firm service (PREVFCAP) (Bcf per year)

PNOD = base tariff on the firm service tariff curve, set as the reservation costs assigned to core customers divided by the base quantity (RCFS/QNOD) (doliars per Mcf)

PTMD_FFi $\dot{2}_{2}$ = assumed annual throughput volume for firm transportation (Bcf per year), with a lower limit at a fraction (Appendix E, PTMDPCTFC, currently set to 0.5 ) of the maximum effective capacity for firm service (PREVFCAP) (Bcf per year)

TARCRV_ELȦS" = assumed elasticity defining firm service pipeline tariff curve (Appendix E).

$\mathrm{a}=\operatorname{arc}$.

To ensure that recovery of costs is close to full recovery, the reserve portion of firm tariff is set to be no less than reservation fee (RFEE) divided by firm loading factor (LFAC_F). That is,

$$
\text { PTAR_REV_F } \left.=\text { MAX (PTAR_REV_F } F_{2}, R_{2} F_{\mathbf{a}} / L F A C \_F\right)
$$

where,

PTAR_REV_F $F_{2}=$ reservation fee component of the firm service pipeline tariff (dollars per Mcf of throughput).

RFEE $=$ reservation fee for firm service (dollars per Mcf of capacity reserved)

LFAC_F = load factor for deriving the minimum firm rate (Appendix E)

$a=$ arc

The usage fee is determined as the usage costs recovered from core customers (UCFS) divided by the assumed annual throughput volume for firm service, as follows:

$$
\text { UFEE }_{\mathbf{a}}=\text { UCFS }_{\mathbf{2}} \text { PTMD_FFL }_{\mathbf{z}}
$$


where,

$$
\begin{aligned}
\text { UFEE }_{\mathrm{a}} & =\text { usage fee for firm service (dollars per Mct) } \\
\text { UCFS, }_{\mathbf{a}} & =\text { usage costs assigned to core customers (million dollars per year) } \\
\text { PTMD_FFL, } & =\text { assumed annual throughput volume for firm transportation (Bcf per year) } \\
\mathrm{a} & =\text { arc }
\end{aligned}
$$

The total firm pipeline tariff is the surn of the reservation and usage components as shown below:

$$
\text { PTAR_F }=\text { PTAR_REV_F }+ \text { UFEE }_{\mathbf{a}}
$$

where,

PTAR_F = pipeline tariff for firm service sent to the Annual Flow Module (dollars per Mct)

PTAR_REV_F $=$ reservation fee component of the firm service pipeline tariff (dollars per Mcf of throughput)

$\mathrm{UFEE}_{\mathrm{a}}=$ usage fee for firm service (dollars per Mcf)

a. $=$ arc

To account for regulatory oversight and to assist in stabilizing the tariffs, a check is performed each year to limit the annual increase in the firm tariff components to a user specified escalation rate. This limit is imposed as shown in the following equation:

$$
\text { PTAR_F } F_{2, t}=\text { MIN }\left(\text { PTAR_F } 2, \text { PTAR_F }_{2 t-1} *(1+\text { MAXESC })\right)
$$

where,

PTAR_F $F_{2,}$ = pipeline tariff for firm service sent to the Annual Flow Module (dollars per Mcf)

PTAR_F ${ }_{\text {atel }}=$ pipeline tariff for firm service in previous year (dollars per Mct)

MAXESC = maximum allowable annual escalation rate for tariffs [Appendix E, (fraction)]

$$
\begin{aligned}
& a=\text { arc } \\
& t=\text { forecast year }
\end{aligned}
$$

Various accounting mechanisms have been built into the tariff computation procedures to account specifically for Order 636 transition costs. These mechanisms are implemented in the base year (and subsequent years) and therefore they are presented in this section of the Chapter. ${ }^{74}$

Balances in purchase gas adjustment accounts (otherwise known as Account 191) are collected on a per unit basis of firm throughput. The costs are assumed to be collected over a multi-year period. The Account 191 surcharge is computed as follows:

$$
\text { PTAR_191_F }=(\text { ANUM191 } / \text { FSERV } \mathrm{a} / \text { /A191YRS }
$$

where,

PTAR_191_F $=$ firm tariff surcharge for Account 191 transition costs (dollars per Mcf).

ANUM191 = Account 191 transition costs assigned to are a (million dollars)

FSERV $_{2}=$ annual throughput volume for firm transportation (Bcf per year)

A191YRS = number of years Account 191 costs are assumed to be collected (Appendix E)

$\mathrm{a}=\operatorname{arc}$

Tariff surcharges to collect gas supply realignment costs (GSR costs) are computed in a similar manner; however, flexibility is provided to assign a portion of the costs to core customers and a portion of the costs to noncore customers as follows:

$$
\text { PTAR_GSR_F }_{\mathrm{a}}=\left[\left(\text { AGSRCOSTS }_{2} * \text { SHARE_GSR_F }\right) / \text { FSERV }\right] \text { ! GSRYRS }
$$

where,

${ }^{74}$ The magnitude of Order 636 transition costs, the years during which they are collected and the share of costs assigned to different classes of service are data driven. See reference in Appendix E (PNEWFAC, PSTRANDED) for the default values. 
PTAR_GSR_F $=$ firm tariff surcharge for GSR transition costs (dollars per Mct)

AGSRCOSTS $_{2}=$ GSR transitión costs assigned to are a (million dollars)

-SHARE_GSR_F = fraction of GSR transition costs assigned to firm service (Appendix E)

FSERV, = annual throughput volume for firm transportation (Bcf per year)

GSRYRS = number of years GSR costs are assumed to be collected (Appendix E)

$$
. \mathrm{a}=\operatorname{arc}
$$

The total firm tariff sent to the Annual Flow Module network is the sum of the firm tariff and any Order 636 surcharges. The total tariff is computed as shown below.

$$
\text { PTAR_F }=\text { PTAR_F }+ \text { PTAR_191_F }+ \text { + PTAR_GSR_F }
$$

where,

PTAR_F ${ }_{2}=$ total tariff for firm service passed to the Annual Flow Module (dollars per Mct)

PTAR_191_F : = firm tariff surcharge for Account 191 transition costs (dollars per Mcf)

PTAR_GSR_F: = firm tariff surcharge for GSR transition costs (dollars per Mct)

$$
\mathrm{a}=\operatorname{arc}
$$

This firm tariff is then checked against an upper limit on firm tariff (Appendix E, LIMITFIRM) to prevent the tariff from becoming unrealistically high due to low utilization along the arc.

Interruptible Transportation Service. The actual interruptible transportation rates are determined within the linear programming solution procedure, but are bounded by regulated maximum and minimum rates provided by the PTM. The are-level maximium and minimum rates for interruptible transportation service are derived from variable costs, reservation and usage fees for firm service, and a load factor permitted by FERC for interruptible service (LFAC) (currently set equal to 100 percent). The maximum tariff (MAX ${ }_{2}$ ) is computed as the sum of the reservation fee (divided by the load factor) and the usage fee. That is,

$$
\text { MAX }_{\mathbf{a}}=\text { RFEE } / \text { LFAC_I + UFEE }
$$

where,

$$
\begin{aligned}
\mathrm{MAX}_{\mathrm{a}} & =\text { maximum rate for interruptible service (dollars per } \mathrm{Mcf} \text { ) } \\
\mathrm{RFEE}_{2} & =\text { reservation fee for firm service (dollars per Mcf) } \\
\mathrm{LFAC}_{\mathrm{I}} & =\text { load factor for deriving the maximum interruptible rate [(ratio) =1.00, from RDESIGN] } \\
\text { UFEE }_{2} & =\text { usage fee for firm service (dollars per Mcf) } \\
\mathrm{a} & =\text { arc }
\end{aligned}
$$

Similar to the firm pipeline tariffs, the regulated maximum interruptible tariff is allowed to increase at a rate no greater than a user specified escalation rate, as shown in the equation below:

$$
\operatorname{MAX}_{2, t}=\operatorname{MIN}\left(\operatorname{MAX}_{2, t} ; \operatorname{MAX}_{2, t-1} *(1+\mathrm{MAXESC})\right)
$$

where,

$$
\begin{aligned}
\text { MAX }_{23} & =\text { maximum rate for interuptible service (dollars per Mcf) } \\
\text {MAX }_{2 t-1} & =\text { maximum rate for interruptible service in previous year (dollars per Mct) } \\
\text { MAXESC } & =\text { maximum allowable annual escalation rate for tariffs [Appendix E, (fraction)] } \\
\therefore \quad a & =\text { arc } \\
t & =\text { forecast year }
\end{aligned}
$$

The minimum tariff (MIN,) is computed as the sum of all variable costs associated with the are (VSUM, divided by the * total annual firm and interruptible throughput volume, as follows:

$$
\begin{aligned}
& \text { MIN } \left._{2}=\operatorname{VSUM}_{2} / \text { FSERV }_{2}+\text { ISERV }_{2}\right) \\
& \mathrm{VSUM}_{2}=\cdot \dot{\mathrm{VCR}}_{2}+\mathrm{VCU}_{2}
\end{aligned}
$$

where, 


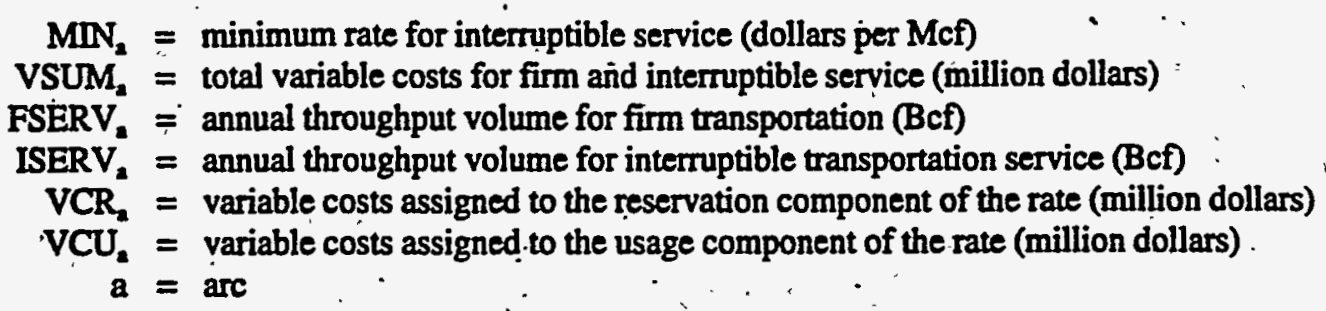

Intermptible transportation rates may also include some surcharge attributable to Order 636 transition costs. Gas supply realignment costs are partially collected through a surcharge on interruptible rates. The computation of this surcharge is shown below.

$$
\text { PTAR_GSR_I }_{2}=\left[\left(\text { AGSRCOSTS }_{2} * \text { SHARE_GSR_I }\right) / \text { ISERV }_{2}\right] / \text { GSRYRS }
$$

where,

PTAR_GSR_I = interruptible tariff surcharge for GSR transition costs (dollars per Mcf)

AGSRCOSTS $_{2}=$ GSR transition costs assigned to arc a (million dollars)

SHARE_GSR_I = fraction of GSR transition costs assigned to interruptible service (SHARE_GSR_I $=1.0$ SHARE_GSR_F)

ISERV $_{2}=$ annual throughput völume for interruptible transportation (Bcf per year)

GSRYRS = number of years GSR costs are assumed to be collected (Appendix E)

$a \cdot=\operatorname{arc}$

The surcharge of gas supply realignment costs on interruptible rates is then checked against the surcharge of gas supply realignment costs on firm rates to ensure that the surcharge on interruptible rates does not exceed the surcharge on firm rates. That is,

$$
\text { PTAR_GSR_I }=\text { MIN (PTAR_GSR_I }, \text { PTAR_GSR_F })
$$

where,

PTAR_GSR_I = interruptible tariff surcharge for GSR transition costs (dollars per Mcf)

PTÁ_GSR_F = firm tariff surcharge for GSR transition costs (dollars per Mcf)

$$
\mathbf{a}=\operatorname{arc}
$$

The interruptible surcharge is then added to the minimum and maximum interruptible rates, when applicable (e.g., during the years GSR costs are assumed to be collected). That is,

$$
\begin{aligned}
& \mathrm{MIN}_{2}=\mathrm{MIN}_{\mathrm{a}}+\text { PTAR_GSR_I } \\
& \text { MAX }_{2}=\text { MAX }_{\mathrm{i}}+\text { PTAR_GSR_I }
\end{aligned}
$$

where,

$$
\begin{aligned}
\text { MAX }_{2} & =\text { maximum rate for interruptible service (dollars per Mcf) } \\
\text { MIN }_{\mathbf{2}} & =\text { minimum rate for interruptible service (dollars per Mct) } \\
\text { PTAR_GSR_I } & =\text { interruptible tariff surcharge for GSR transition costs (dollars per Mcf) } \\
\mathbf{a} & =\text { arc }
\end{aligned}
$$

The interruptible tariff that is computed represents the cost of moving interruptible gas along an arc, and is used in the Annual Flow Module network. The value for this tariff lies between the minimum and maximum interruptible tariffs, and is determined using a scale factor (SCALE_I). The interruptible tariff is calculated by the following equation:

$$
\text { PTAR_I }=\mathrm{MIN}_{2}+\dot{S C A L E}_{\mathrm{a}} \mathrm{I}_{2} *\left(\mathrm{MAX}_{2}-\mathrm{MIN}_{\mathbf{2}}\right)
$$

where,

$$
\begin{aligned}
& \text { PTAR_L } \begin{aligned}
\text { total tariff for internuptible transportation service passed to the Annual Flow Module (dollars } \\
\text { per Mcf) }
\end{aligned} \\
& \text { MAX }_{2}=\text { maximum rate for interruptible service (dollars per Mcf) }
\end{aligned}
$$


$\mathrm{MIN}_{2}^{-}=$minimum rate for interruptible service (dollars per Mcf)

SCALE_I $I_{2}{ }^{\prime}=$ scale factor for interruptible tariff (fraction)

$\mathrm{a}=$ arc

The scale factor (SCALE_D) is a nonlinear function of the interruptible utilization rate on that arc in the previous year. - Its value is between zero and one. If the utilization rate was low last year, the scale factor will be close to zero and, thus, the interruptible tariff closer to the minimum interruptible tariff to encourage more use on this arc. On the other hand, if the utilization was close to full capacity in the previous year, the interruptible tariff will be close to the maximum interruptible tariff to discourage use on this arc. This algorithm reflects the behavior of the pipeline company in a competitive.market where price would quickly react to market changes. The computation of this scale factor is shown below:

$$
\text { SCALE_I } \left.=\text { UTIL_RATE_I } I_{2} * \text { UTIL_RATE_I } I_{2} * e \text { (UTR_RATE } I_{2}-1.0\right)
$$

where,

SCALE_I = scale factor for interruptible tariff (fraction)

UTIL_RATE_I = utilization rate for interruptible service (fraction) $\mathbf{a}=\operatorname{arc}$

Utilization rate is defined based on flows and effective capacity (PREVTCAP, from the previous year.

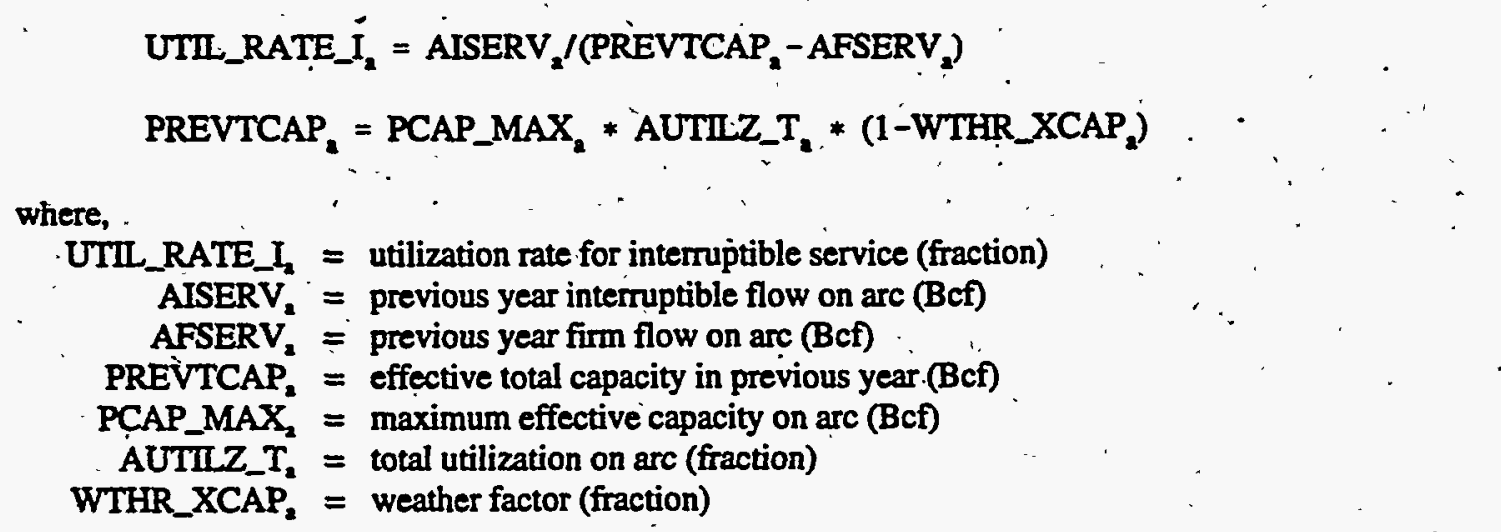

The interruptible tariff resulting from the above calculation is then checked against a maximum interruptible tariff (Appendix E, LIMITINT) to prevent the tariff from becoming unrealistically high due to low utilization along the arc.

Revenue Credit Option. A revenue credit algorithm has been designed and implemented as an option in the PTM. Its purpose is to capture the effects of capacity release on firm pipeline tariffs through the treatment of interruptible revenues. With this algorithm, a pipeline company ${ }^{75}$ is allowed to transfer a portion of their incremental revenuic from interruptible service to firm service. The incremental revenue of interruptible service is defined as the portion above expected revenue which is determined by using a conservative estimate of interruptible flow defined for the pipeline company. The portion transferred to firm service then becomes a credit to firm service, resulting in a reduction in the firm revenue requirements and, thus, firm tariffs. The methodology used to calculate the amount of incremental revenue transferred from interruptible service to firm service, and ultimately used to adjust firm service tariffs, follows.

First, incremental revenue from interruptible service (INC_REV) is calculated as the difference between the actual revenue recovered and the revenue expected to be recovered, both from interruptible service. The actual revenue recovered from interruptible service equals the interruptible flow (ISERV) times a derived interruptible tariff (CAL_TAR_I). The revenue expected to be recovered from interruptible service is also referred to as the cost assigned to interruptible service (CIS). Finally, the derived interruptible tariff along an arc is based on the corresponding marginal node prices produced by the AFM in the previous year. The corresponding equations are as follows:

\footnotetext{
75 According to regulation, revenue crediting can be adopted into the rate making process of an individual pipeline company. However, in the PTM module, revenue crediting is implemented at the arc level, instead.
} 


$$
\begin{aligned}
& \text { NNC_REV }=\text { MISERV } * \text { CAL_TAR_I }-\left(C I S_{2} / M C_{2} \_P G D P_{\imath}\right) \\
& \text { CAL_TAR_I }=\text { NG_MAGPR_I } I_{A T} * \text { AEFF_PIPE } \text { AF,AT }_{2}-\text { NG_MAGPR_I }
\end{aligned}
$$

where,

INC_REV = incremental revenue on arc (millions of 1987 real dollars)

MISERV = interruptible flow from AFM calculated in previous year (1 year lag) (Bct)

CIS = cost assigned to interruptible service in current year (millions of nominal dollars)

MC_PGDP = GDP deflator (from-Macroeconomic Activity Model)

CAL_TAR_I = derived interruptible tariff (\$87/Mcf)

NG_MAGPR_I = marginal node price (from AFM, \$87/Mcf)

AEFF_PIPE = pipeline/arc efficiency [Appendix E, (fraction)]

$\mathrm{a}=\operatorname{arc}$

$A F=$ source node along arc

$A T=$ destination node along arc

Next, incremental costs are defined as incremental flows times the minimum tariff (for interruptible service) needed to recover variable costs. Incremental flows are the difference between interruptible flows along an arc for this year and the previous year. Thus,

$$
\text { INC_COST }_{\mathrm{a}}=\mathrm{INC}_{-} \text {FLOW }_{\mathrm{a}} * \mathrm{MIN}_{\mathrm{a}}
$$

where,

$$
\begin{aligned}
\text { INC_COST } & =\text { incremental cost on are (millions of } 87 \text { dollars) } \\
\text { INC_FLOW } & =\text { incremental flow on arc (Bcf) } \\
\text { MIN } & =\text { the minimum tariff for interruptible service (\$87/Mcf) } \\
\mathbf{a} & =\text { arc }
\end{aligned}
$$

Incremental profit is then calculated as the difference between incremental revenues and incremental costs, as follows:

$$
\text { INC_PRFT }=\text { INC_REV },- \text { INC_COST }
$$

where,

$$
\begin{aligned}
\text { INC_PRFT } & =\text { incremental profit on arc (millions of } 1987 \text { dollars) } \\
\text { INC_REV } & =\text { incremental revenue on arc (millions of } 1987 \text { dollars) } \\
\text { INC_COST } & =\text { incremental cost on arc (millions of } 1987 \text { dollars) } \\
\text { a } & =\text { arc }
\end{aligned}
$$

A portion of this incremental profit is defined as the revenue credited (CREDIT_F) to firm service. This credit is then converted to a rate (RATEADJ_F.) which is used to reduce firm rates (PTAR_F.

$$
\begin{aligned}
& \text { CREDIT_F } F_{2}=\text { RCREDIT_F } F_{2} * \text { INC_PRFT } \\
& \text { RATEADJ_F }=\text { CREDIT_F } / \text { MFSERV }
\end{aligned}
$$

PTAR_F $_{2}=$ PTAR_F $2-$ RATEADJ_F

where,

CREDIT_F = amount of credit transferred to firm service on arc (millions of 87\$)

RCREDIT_F = the percentage of revenue reallocated as revenue credit to firm service [Appendix E, (fraction)]

INC_PRFT = incremental profit (millions of 87\$)

RATEADJ_F = the adjusting rate used to credit firm tariff on arc (\$87/Mcf)

MFSERV = previous year firm flow provided by the AFM, including Alaska flow, in current year (Bcf)

PTAR_F = firm pipeline tariff on arc (\$87/Mcf)

$$
a \cdot=\operatorname{arc}
$$


Once the firm tariff is adjusted, a check is made to ensure that the resulting firm tariff is no less than the minimum interruptible tariff times a scale factor. This test serves to ensure that an unrealistic over-adjustment has not been made.

$$
\text { PTAR_F }=\max \left(\text { PTAR_F }, \text { MIN }_{2} *\right. \text { SCALE_F_MIN) }
$$

where,

PTÁ_F $F_{2}=$ firm pipeline tariff on arc (\$87Mcf)

$\mathbf{M I N}_{\mathbf{2}} \cdot=$ minimum interruptible tariff on arc (\$87/Mcf)

SCALE_F_MIN = scale factor (Appendix E)

$\mathbf{a}=\operatorname{arc}$

Storage Service. Storage facilities are defined in the NGTDM network at regional nodes. In the base-year initialization phase, storage facility costs, capacities, inventories, and other data for existing companies are allocated to regional NGTDM network nodes using storage facility data in FERC and EIA data series. ${ }^{76}$ An interstate pipeline company's total reported storage cost is allocated to NGTDM region nodes according to the regional distribution of natural gas storage capacity in the company's own storage facilities, as reported on Form EIA-191. ${ }^{7}$ 'Because storage costs are related to base gas storage capacity, the cost allocation is based on the company's regional share of base gas storage capacity relative to its total base gas storage capacity. Regional interstate pipeline company-level costs are aggregated to the corresponding NGTDM region node (Equations 127 and 128).

The regional storage costs for interstate pipeline companies are converted to per-unit-capacity costs by dividing the aggregate regional cost-by the aggregate regional base gas storage capacity. The interstate pipeline per-unit storage capacity cost obtained for each region is applied to the non-interstate (intrastate and third party owners) regional storage capacity to obtain their estimated storage costs. These costs are added to the NGTDM region aggregate interstate pipeline company costs (FCS and VCS) to obtain the total storage facility costs (FCST and VCST) at the region node.

Next, the node-level storage tariff is computed as the sum of fixed and variable total costs divided by the working gas capacity, as shown below.

$$
\operatorname{STAR}_{\mathrm{n}}=\text { VSUM }_{\mathrm{n}} / \mathrm{WGCTT}_{\mathrm{n}}
$$

where,

$$
\begin{aligned}
\operatorname{STAR}_{\mathrm{n}} & =\text { storage tariff (dollars per Mcf) } \\
\text { VSUM }_{n} & =\text { total storage costs (million dollars) } \\
\text { WGCTT }_{\mathrm{n}} & =\text { working gas capacity, jurisdictional and non-jurisdictional (Bcf) } \\
\mathrm{n} & =\text { node }
\end{aligned}
$$

The total cost of storage is defined as the sum of all fixed and variable total storage costs as shown below:

$$
\operatorname{VSUM}_{\mathrm{a}}=\mathrm{VCST}_{\mathrm{a}}+\mathrm{FCST}_{\mathrm{a}}
$$

where,

$$
\begin{aligned}
\operatorname{VSUM}_{\mathrm{n}} & =\text { total storage cost (million dollars) } \\
\operatorname{VCST}_{\mathrm{n}} & =\text { variable storage costs (million dollars) } \\
\operatorname{FCST}_{\mathrm{n}} & =\text { fixed storage cost (million dollars) } \\
\mathbf{n} & =\text { node }
\end{aligned}
$$

To account for regulatory oversight and to assist in stabilizing the tariffs, a check is performed each year to limit the annual increase in the storage tariff to a user specified escalation rate. This limit is imposed as shown in the following equation.

${ }^{76}$ FERC Form 2 provides total storage costs for interstate pipeline companies with storage facilities. Form EIA-191 provides injections, withdrawals, inventories, and base and working gas capacity by field/reservoir for storage facilities owned by all storage companies. The Form EIA-191 filings include information that allows facilities to be designated as owned by interstate pipeline and other firms.

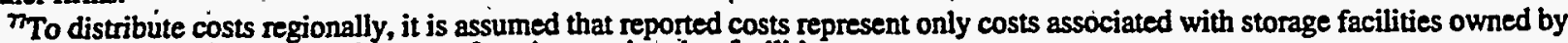
the company and do not include costs of storing gas in other facilities. 


$$
\operatorname{STAR}_{\mathrm{n}, \mathrm{t}}=\operatorname{MIN}\left(\operatorname{STAR}_{\mathrm{a}, \mathrm{l}}, \operatorname{STAR}_{\mathrm{a}, \mathrm{l}-1} *(1+\mathrm{MAXESC})\right)
$$

where,

STAR $_{n, 2}=$ storage tariff (dollars per Mcf)

STAR $_{\text {al-1 }}=$ storage tariff from previous year (dollars per Mć)

MAXESC = maximum allowable annual escalation rate for tariffs [Appendix E, (fraction)]

$\mathbf{n}=$ node

$t=$ forecast year

This method of computing storage tariffs does not conform strictly to industry practices; rather it conforms to the representation of storage in other modules of the NGTDM.

\section{Construction of Capacity Expansion Cost (Pipeline/Storage) Tariff Curves}

As part of the base-year initialization process, the PTM constructs cost (or pipeline/storage tariff) curves for the Capacity Expansion Module. The primary criterion in determining when and where physical pipelines and storage facilities will - need to be expanded is the need of customers purchasing firm service to receive gas on future peak days. A secondary criterion is that the costs associated with pipeline and storage expansion are kept to a minimum. In general, pipeline companies and local distribution companies (LDC) recognize that the high costs incurred in adding pipeline and storage capacity may lead to increased per-unit charges to customers purchasing firm service, which in the short-term may lead to slight decreases in consumption levels. In the long-term, increased delivery costs may lead to much more significant demand shifts when end-use capital purchasing decisions are affected.

To facilitate the cost minimization process in the Capacity Expansion Module, separate cost/tariff curves for incremental pipeline capacity expansion and storage expansion projects are developed for the incremental pipeline and storage services by the PTM and input to the Capacity Expansion Module. These cost/tariff curves relate incremental capacity expansion by arc (region) to corresponding pipeline (storage) tariffs.

The cost/tariff curves are constructed through a process comparable to the base-year initialization procedure described earlier. The PTM has an exogenous data input file of pipeline and storage capacity cost curves that relate capital cost to corresponding capacity expansion. Pipeline and storage capital cost data are developed from the incremental costs required to add an additional increment of capacity along a network arc or to a storage node in the NGTDM. These incremental costs reflect the capital costs associated with adding compressors, looping, ${ }^{78}$ and other means of expanding pipeline capacity, or the capital costs asșociated with adding new or expanding existing natural gas storage fields. The

1. PTM also obtains from an exogenous data base the operating costs, depreciation schedules, and other components of revenue requirements associated with pipeline or storage expansion. The exogenous data are defined by region and are based on historic industry averages.

Construction of the pipeline capacity (storage) tariff cost curves is comparable to the process in which base-year transportation (storage) tariffs are developed. However, instead of using the existing pipeline company data bases, the components of revenue requirements for the capacity expansion cost curves are obtained from a separate exogenous data base containing the capital and revenue requirements for capacity expansion projects. Using these data, together with the base-line initialization equations discussed below, the PTM develops the reservation fee associated with each level of capacity expansion provided by the Capacity Expansion Module. The pipeline capacity (storage) expansion tariff curves are constructed in the base year and are used by the Capacity Expansion Module in all subsequent forecast years. ${ }^{79}$

\section{Passing Rates to the Annual Flow Module and Curves to Capacity Expansion Module}

As discussed in Chapter 5, the PTM passes the following items to the Annual Flow Module: (1)-reservation costs assigned to core customers, (2) usage fees for firm transportation service, (3) minimum transportation rate for interruptible service, (4) maximum transportation rate for interruptible service, and (5) rates for storage service. All PTM

\footnotetext{
${ }^{n}$ Looping is the construction of a pipeline parallel to an existing line to increase the capacity of the system.

The pipeline tariff is in dollars per MMBtu-mile and the storage tariff, including injection and inventory costs, is in dollars per MMBu of working gas capacity.
} 
data elements passed to the Annual Flow Module must be converted to real dollars using the GDP deflators from the - NEMS macroeconomic model. Similarly, when passing the capacity expansion cost tariff curves to the Capacity Expansion Module; the rates must be converted to real dollars.

\section{Forecast Year Update Phase}

The purpose of the forecast year update phase is to project, for each subsequent year of the forecast period, the line items of the cost-of-service discussed above that are used to develop rates. In each remaining year of the simulation, the PTM forecasts the pipeline company-level parameters required to determine the cost of capital, rate-base, operation and maintenance expense, and taxes. Additionally, arc-specific billing determinants are projected for the forecasi year. These parameters are used to calculate the arc-specific (node-specific) rates using the procedure described in the baseyear initialization phase. The forecasting relationships are discussed in detail below.

The PTM also accounts for revenues and volumetric flows for new capacity in the forecast year by assigning these parameters to arc- or region-specific generic pipeline or storage companies. These parameters are forecast at the arclevel in subsequent years. Generic pipeline and storage companies are discussed in more detail below.

After all the line items of the cost-of-service are forecasted, the PIM proceeds to: (1) classify line items of the cost of service as fixed and variable costs, (2) allocate fixed and variable costs to rate component (reservation and usage fee, volumetric charge) based on the rate design, (3) aggregate costs to the network are/network node, (4) for transportation. services, allocate costs to type of service (firm and interruptible), and (5) compute arc-specific (node-specific) rates.

\section{Generic Pipeline and Storage Companies for Capacity Expansion}

The Capacity Expansion Module projects pipeline capacity expansion at the arc level and storage expansion at the regional level, as opposed to determining expansion for individual companies. The PTM creates arc-specific generic pipeline companies and regional, node-specific, generic storage facilities to incorporate the effects of capacity expansion on an are or node. Thus, the PTM tracks costs attributable to capacity added during the forecast period separately from the costs attributable to facilities in service in the base year. The PTM uses an exogenous data base to obtain the capital costs which correspond to the level of capacity expansion provided by the Capacity Expansion Module in the forecast year. ${ }^{80}$ The exogenous data base contains costs in real dollars. These costs must be converted to nominal dollars in the forecast year using the GDP deflators provided by the NEMS macroeconomic model. Other line items of the cost-ofservice for the generic companies are derived from historical industry averages and are provided by an exogenous data base. These costs too must be converted to nominal dollars and also must be scaled to reflect the size of expansion determined by the Capacity Expansion Module.

The new capacity expansion expenditures allowed in the rate-base within the forecast year is derived for each arc and node from the amount of incremental capacity additions determined by the Capacity Expansion Module.as shown below.

$$
\begin{aligned}
& \operatorname{NCAE}_{f}=\sum_{s=2}^{\dot{S}}\left(\text { CAPCST }_{2 s, s}-\text { CAPCST }_{2 s-1, t}\right) *\left(\text { EXPAND }_{2 s, f} / \text { AVAIL }_{2 s, s}\right)
\end{aligned}
$$

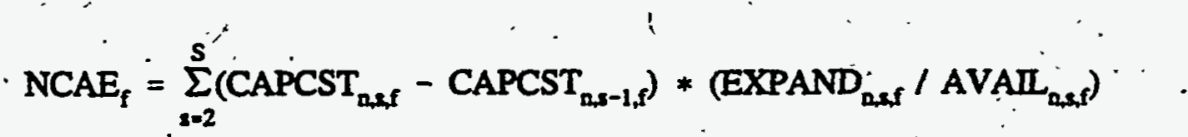

where,

NCAE = new capacity expansion expenditures allowed in the rate base within the forecast year (dollars) CAPCST = total capital cost to expand capacity (dollars)

EXPAND = amount of incremental capacity added by the Capacity-Expansion Module (Bef)

\footnotetext{
${ }^{\circ}$ Capital requirements for new storage capacity expansion are determined from the ińcremental base gas capacity expansion and the wellhead price in the forecast year which is used as cushion gas to maintain adequate pressures.
} 
AVAI' = maximum amount of capacity expansion available (Bcf)

$a=\operatorname{arc}$

$\mathrm{n}=$ node

$s=$ type of expansion, $1=$ existing capacity, $2=$ compression, $3=$ looping, $4,5,6=$ new pipe

$f=$ type of facility (pipeline or storage)

The total capital cost to expand capacity at each pipeline arc is derived below.

$$
\text { CAPCST }_{2<\text { pipe }}=\text { CAPCST }_{2 s-1, \text { pipe }}+\frac{\text { ARCCC }_{2 s} *\left(\left(\text { ARCEX }_{2 s}-\text { ARCEX }_{2 s-1}\right) * 1,000,000\right) * \text { MILES }_{2}}{365}
$$

where,

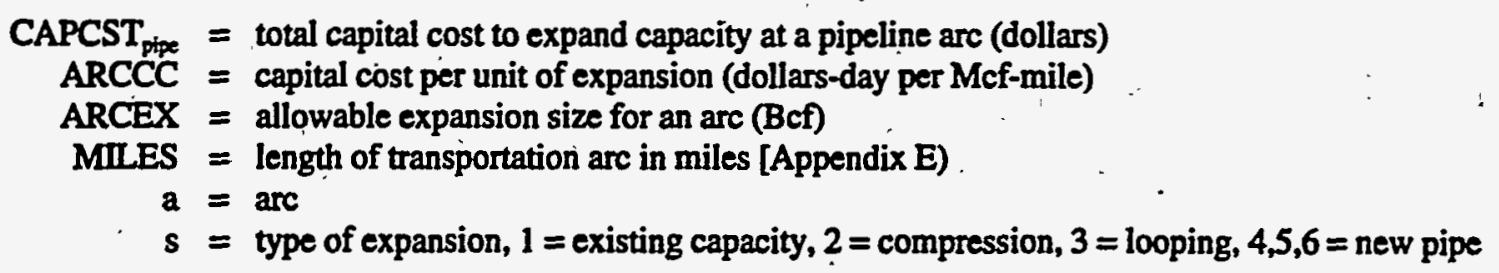

An upper bound limiting the amount of additional capacity that can be achieved through adding compression, looping, and adding new pipe is defined for each are as a function of the base year arc capacity. The bounds are defined as follows:

$$
\operatorname{ARCEX}_{2,5}=\text { PCAP_MAX } * \text { ARCFAC }_{25}
$$

where,

$$
\begin{aligned}
\text { ARCEX } & =\text { maximum allowable capacity expansion (Bct) } \\
\text { PCAP_MAX } & =\text { base year design capacity (Bcf) } \\
\text { ARCFAC } & =\text { arc capacity expansion factor [Appendix E, EXPFAC, (fraction)] } \\
\mathbf{a} & =\text { arc } \\
\mathbf{s} & =\text { expansion step }
\end{aligned}
$$

Unit capital costs for expanding capacity are adjusted to reflect regional differences in costs, as shown below.

$$
\operatorname{ARCCC}_{2,5}=\operatorname{CCOST}_{2,5} *\left(1+\operatorname{CSTFAC}_{2,5}\right)
$$

where,

$$
\begin{aligned}
\text { ARCCC } & =\text { capital cost per unit of expansion (dollars-day per Mcf-mile) } \\
\text { CCOST } & =\text { capital cost to expand } 1 \text { unit of pipeline capacity [Appendix E; (dollars-day per Mcf-mile)] } \\
\text { CSTFAC } & =\text { factor to accommodate regional difference in cost [Appendix E, (fraction)] } \\
\mathrm{a} & =\text { arc } \\
\mathrm{S} & =\text { expansion step }
\end{aligned}
$$

Similar to pipeline capacity expansion, capital costs for expanding storage at each node is derived below.

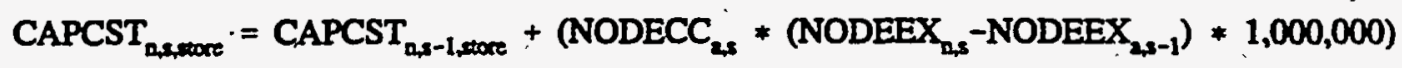

where,

$$
\begin{aligned}
\text { CAPCST }_{\text {xore }} & =\text { total capital cost to expand storage capacity (dollars) } \\
\text { NODECC } & =\text { capital cost per unit of expansion (dollars per Mcf) } \\
\text { NODEEX } & =\text { allowable expansion size for a node (Bcf) } \\
\mathbf{n} & =\text { node } \\
\mathrm{s} & =\text { expansion step }
\end{aligned}
$$

An upper bound limiting the amount of additional storage capacity that can be added at each node is defined as a function of the base year node capacity. The bounds are defined as follows: 


$$
\text { NODEEX }_{n, s}=\left(\text { WGCT }_{n}+\text { WGCNT }_{n}\right) * \text { NODFAC }_{n, S}
$$

where,

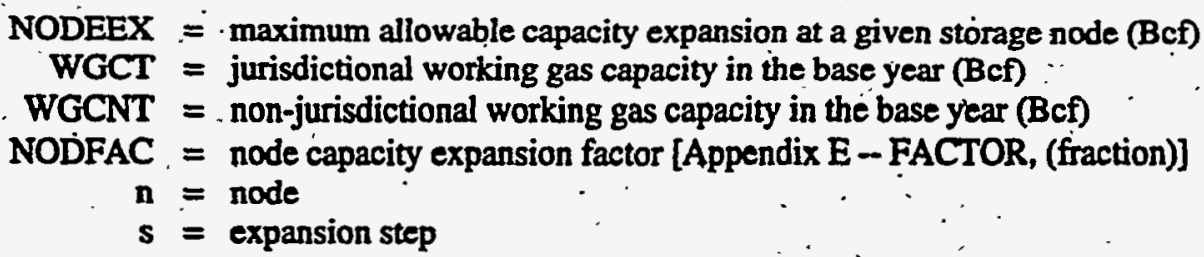

For pipeline capacity expansion, the peak day reservations are set equal to the daily capacity (the capacity provided by the Capacity Expansion Module divided by 365 days per year). The annual flow through the pipeline is calculated as the capacity multiplied by a utilization factor provided by the Capacity Expansion Module or assumed exogenously. For storage capacity expansion, the amount of gas withdrawn is set equal to the working gas capacity.

After the generic pipeline company transportation and storage volumes and cost-of-service are determined, the generic company is treated within the PTM as an additional arc-specific pipeline company and/or regional node-specific storage facility. Cost-of-service for the aggregate of all prior years' capacity expansion projects is projected to the forecast year according to the subsequent year's forecasting procedure discussed below. Company-level cost-of-service for the new incremental capacity in the forecast year are determined according to the base-year initialization procedure discussed above and added to the projected cost-of-service of the aggregate prior years' capacity.

\section{Forecasting Cost-of-Service ${ }^{\text {II }}$}

The primary purpose in forecasting cost-of-service is to capture major changes in the composition of the revenue requirements and major changes in cost trends through the forecast period. These changes may be caused by new construction or maintenance and life extension of nearly depreciated plants, as well as by changes in the cost and availability of capital.

The projection of the cost-of-service is approached from the viewpoint of a long-run marginal cost analysis for gas pipeline systems. This differs from the determination of cost-of-service for the purpose of a rate case. Costs that are viewed as fixed for the purposes of a rate case actually vary in the long-run with one or more external measures of size or activity levels in the industry. For example, capital investments for replacement and refurbishment of existing facilities are a long-run marginal cost of the pipeline system. Once in place, however, the capital investments are viewed as fixed costs for the purposes of rate cases. The same is true of operations and maintenance expenses which, except for short-run variable costs such as fuel, are most commoniy classified as fixed costs in rate cases. For example, customer expenses logically vary over time based on the number of customers served and the cost of serving each customer. The unit cost of serving each customer, itself, depends on factor cost changes (e.g., wage rates), the extent or complexity of service provided to each customer, and the efficiency of the technology level employed in providing the service.

The long-run marginal cost approach generally projects total costs as the product of unit cost for the activity multiplied by the incidence. of the activity. Unit costs are projected from factor cost changes combined with time trends describing changes in level of service, complexity, or technology. The level of activity is projected in terms of variables extemal to the PTM (e.g., annual throughput, etc.) which are both logically and empirically related to the incurrence of costs.

Implementation of the long-run marginal cost approach invoives forecasting relationships developed throügh empirical studies of historical change in pipeline/storage facility costs, accounting algorithms, exogenous assumptions, and inputs from other NEMS modules. These forecasting algorithms may be classified into three distinct projected pipeline cost . areas, as follows:

- The projection of existing and incremental rate base and capital costs

"All cost components in the forecast equations in this section are in nominal dollar, unless explicitly stated otherwise. 
- The projection of capital-related components of the revenue requirement.

- The projection of operations and maintenance expenses of the revenue requirements. $\therefore t$

The empirically derived forecasting algorithms discussed below are determined for each pipeline company.

\section{Projection of Rate Base and Cost of Capital}

The approach for projecting rate base and capital costs is summarized in Table 8-4. Long-run marginal capital costs of pipeline companies are reflected in changes in the rate base. Once projected, the rate base is translated into capitalrelated components of the revenue requirements based on projections of the cost of capital, capitalization, and algorithms for depreciation and tax effects.

Rate-Base Components. The projected rate base in year $t$ is computed as in the base year. That is, the rate base in year $t$ is the net plant in service in year $t$ plus working capital and transition expenses in year $t$.

$$
\mathrm{PRB}_{\mathrm{t}}=\mathrm{GPIS}_{\mathrm{t}}-\mathrm{ADDA}_{\mathrm{t}-1}+C W C_{t}+O W C_{t}
$$

where,

PRB = pipeline rate base before adjustmient in dollars

GPIS = original capital cost of plant in service (gross plant in service) in dollars

ADDA = accumulated depletion, depreciation, and amortization in dollars

CWC = cash working capital in dollars

OWC' $=$ other working capital in dollars.

. $t=$ forecast year

The variables of the rate-base equation are forecast by the following set of equations. First, gross plant in service in the forecast year is determined by the prior year's gross plant in service, new capacity expansion (as determined by the Capacity Expansion Module), current capital additions to existing plants for replacement and refurbishment, and cost associated with new facilities for complying with Order 636. Gross plant in service is forecast as follows:

$$
\text { GPIS }_{\mathrm{t}}=\begin{aligned}
& \mathrm{GPIS}_{\mathrm{t}-1}+\mathrm{BLAE}_{\mathrm{t}}+\text { PNEWFAC }_{\mathrm{t}} \\
& \text { GPIS }_{\mathrm{t}-1}+\text { NCAE }_{\mathrm{t}}
\end{aligned}
$$

where,

$$
\begin{aligned}
\text { GPIS } & =\text { original capital cost of plant in service (gross plant in service) in dollars } \\
\text { NCAE } & =\text { new capacity expansion expenditures allowed in rate base within the forecast year in dollars } \\
\text { BLAE } & =\text { capital expenditures associated with base year capacity (refurbishment/replacement } \\
& \text { expenditures) in dollars } \\
\text { PNEWFAC } & =\text { cost of new facilities required to comply with Order } 636 \text { (nominal dollars) }
\end{aligned}
$$

Capital expenditures associated with base year capacity (refurbishment on existing pipeline/storage) are obtained by using three available options (BLAESWT $=0 ; 1,2$ ). The first option (used in $A E O 98$ ) sets capital expenditures for pipeline refurbishment/replacement to zero. The second option sets refurbishment to be a proportion of the annual depreciation expense. The proportion is a function of the age of the plant. Option three allows the user to exogenously define total annual capital expenditures for refurbishment for the whole pipeline industry. The industry-wide expense is distributed to individual companies as a function of the gas plant in service. These options are defined as follows:

option 1 (BLAESWT=0):

$$
B L A E_{t}=0
$$

\footnotetext{
${ }^{82} \mathrm{New}$ facilities transition cost will be added to original capital cost of plant in service, on an individual pipeline basis. See Appendix E(A191YRS, ANUM191, AGSRCOSTS, SHARE_GSR_F, GSRYRS, NEWCOST_PER) for default assumptions on costs . and depreciation schedules.
} 
Table 8-4. Approach to Projection of Rate Base and Capital Costs

\begin{tabular}{|c|c|}
\hline Projection Component & -Approach \\
\hline $\begin{array}{l}\text { 1. Rate Base } \\
\text { a. Gross plant in service } \\
\text { I. Capacity expansion costs for generic } \\
\text { il. Replacement/refurbishment costs for } \\
\text { existing pipeline/storage } \\
\text { b. Accumulated Depreciation, Depletion \& } \\
\text { c. Cash and other working capital } \\
\text { d. Transition expenses } \\
\text { e. Accumulated deferred income taxes } \\
\text { f. Depreciation, depletion, and amortization }\end{array}$ & $\begin{array}{l}\text { Provided by the Capacity Expansion Module } \\
\text { Accounting algorithm or user defined options } \\
\text { Existing Pipelines: empirically estimated } \\
\text { Generic Pipelines: accounting algorithm } \\
\text { Empirically estimated } \\
\text { Accounting algorithm with exogenous } \\
\text { specification for recovery/absorption } \\
\text { Existing Pipelines: empirically estimated } \\
\text { Generic Pipelines: accounting algorithm } \\
\text { : } \\
\text { Existing Pipelines: empirically estimated } \\
\text { Generic Pipelines: accounting algorithm }\end{array}$ \\
\hline $\begin{array}{l}\text { 2. Cost of Capital } \\
\text { a. Long-term debt rate } \\
\text { b. Preferred equity rate } \\
\text { c. Common equity return }\end{array}$ & $\begin{array}{l}\text { Base year average rate, adjusted using } \\
\text { projected bond yields } \\
\text { Base year rate (fixed) } \\
\text { Incorporate changes in dividend/bond yields }\end{array}$ \\
\hline 3. Capital Structure & onstant at base year values \\
\hline
\end{tabular}


option 2 (BLAESWT=1):

$\mathrm{BLAE}_{\mathrm{t}}=\mathrm{DDA} \dot{A}_{\mathrm{t}} * \mathrm{ADDA}_{\mathrm{t}} / \mathrm{GPIS}_{\mathrm{t}-1}$

where,

BLAE = capital expenditures associated with base year capacity (refurbishment/ replacement expenditures) in dollars

DDA = depreciation, depletion and amortization costs in dollars

- $\mathrm{ADDA}=$ accumulated depreciation, depletion, and amortization in dollars

GPIS = original capital cost of plant in service (gross plant in service) in dollars

- $\quad t=$ forecast year

option 3 (BLAESWT=2):

BLAE $\left._{t}={\text { BLAETOT } . *\left(\text { GPIS }_{t-1} \text { ! INDUSTRYGPIS }\right.}_{t-1}\right)$

where,

BLAE = capital expenditures associated with base year capacity. (refurbishment/ replacement expenditures) in dollars

BLAETOT = user-defined total capital expenditure for refurbishment/replacement for the pipeline industry in dollars

- GPIS = original capital cost of plant in service (gross plant in service) in dollars

-INDUSTRYGPIS = total capital cost of plant in service (gross plant in service) for pipeline industry in dollars

$\mathbf{t}=$ forecast year

Accumulated depreciation, depletion, and amortization is given by:

$$
\mathrm{ADDA}_{\mathrm{t}}=\mathrm{ADDA}_{\mathrm{t}-1}+\mathrm{DDA}_{\mathrm{t}}
$$

where,
ADDA = accumulated depreciation, depletion, and amortization in dollars
DDA = depreciation, depletion, and amortization costs in dollars

A regression equation is used to define the annual depreciation, depletion, and amortization for existing pipelines, while an accounting algorithm is used for generic pipelines. For existing pipelines, this expense is forecast as follows:

$$
\begin{aligned}
\operatorname{DDA}_{t}= & (1-\rho) * \beta_{0}+\beta_{1} * \operatorname{NETPLT}_{t}+\beta_{2} * \text { DEPSHR }_{t} \\
& +\rho * \mathrm{DDA}_{t-1}-\rho *\left(\beta_{1} * \mathrm{NETPLT}_{t-1}+\beta_{2} * \mathrm{DEPSHR}_{t-1}\right)
\end{aligned}
$$

where,

$\mathrm{DDA}={ }^{\cdot}$ depreciation, depletion, and amortization costs in dollars

$\beta_{0}, \beta_{1}, \beta_{2}=$ coefficients estimated based on an empirical study (Appendix F, Table F4)

- $\rho=$ estimated auto-correlation coefficients (Appendix F, Table F4) .

NETPLT $=$ net capital cost of plant in service (dollars) :

DEPSHR = ratio of accumulated depreciation, depletion, and amortization expenses to gross plant in service (a proxy for pipeline age)

A certain portion of the cost of new facilities required to comply with Order 636 can also be depreciated during the recovery period. Thus during this period, the depreciation, depletion, and amortization costs for existing pipeline are calculated as follows: .

$$
\mathrm{DDA}_{\mathrm{t}}=\mathrm{DDA}_{\mathrm{t}}+\text { PNEWFAC/NEWCOST_PER }
$$

where,

DDA = depreciation, depletion, and amortization costs in nominal dollars

PNEWFAC $=$ cost of new facilities required to comply with Order 636 (nominal dollars)

NEWCOST_PER = period allowing recovery of new facility costs (Appendix E) 
The net plant in service and the proxy for pipeline age are defined'as follows:

$$
\begin{aligned}
& \text { NETPLT }_{t}=\text { GPIS }_{t-1}-\text { ADDA }_{t-1} \\
& \text { DEPSHR }_{t}=\text { ADDA }_{t-1} / \text { GPIS }_{t-1}
\end{aligned}
$$

where,

GPIS = original capital cost of plant in service (gross plant in service) in dollars

ADDA = accumulated depreciation, depletion, and amortization in dollars

The accounting algorithm used to define the annual depreciation, depletion, and amortization for generic pipelines assumes straight line depreciation over a 30 year lifé, as follows:

$$
\mathrm{DDA}_{\mathrm{t}}=\sum_{s=1991}^{t} \cdot\left(\mathrm{NCAE}_{\mathrm{s}} ! 30\right)
$$

where,

$$
\begin{aligned}
\mathrm{DDA}_{2} & =\text { depreciation, depletion, and amortization costs in dollars } \\
\mathrm{NCAE} & =\text { new capacity expansion expenditures occurring in year s (in dollars) } \\
s & =\text { the year new expansion occurred } \\
30 & =30 \text { years of plant life } \\
t & =\text { forecast year }
\end{aligned}
$$

Cash working capital is set equal to zero, because historically it has been at or near zero. Thus,

$$
C W C_{t}=0
$$

where,

$$
\text { CWC }=\text { cash working capital in dollars }
$$

Other working capital consists of material and supplies, gas held in storage, and other components that vary by company. Other working capital is calculated as a function of gross plant in service, as follows:

where,

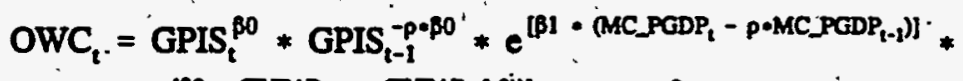

$$
\begin{aligned}
& e^{[\beta 2 \cdot(\text { TYEAR - p*(TYEAR-1.00)] }} * O \text { OWC }_{l-1}^{p} * \text { CONST } .
\end{aligned}
$$

OWC $=$ other working capital in dollars

GPIS = original capital cost of plant in service (gross plant in service) in dollars .

$\beta O=$ estimated coefficient on gross plant in service

$\rho=$ :estimated auto correlation coefficient

$\beta 1$ = estimated coefficient on price level

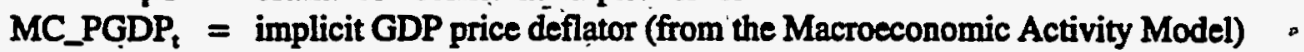

$\beta 2=$ estimated coefficient on time trend

TYEAR = year in Julian units (i.e., 1995)

CONST = estimated constant term

$t=$ forecast year

[Note: See Table F4 in Appendix F for derivation of coefficients and regression statistics]

The rate base is adjusted for accumulated deferred income taxes and other expenses as follows:

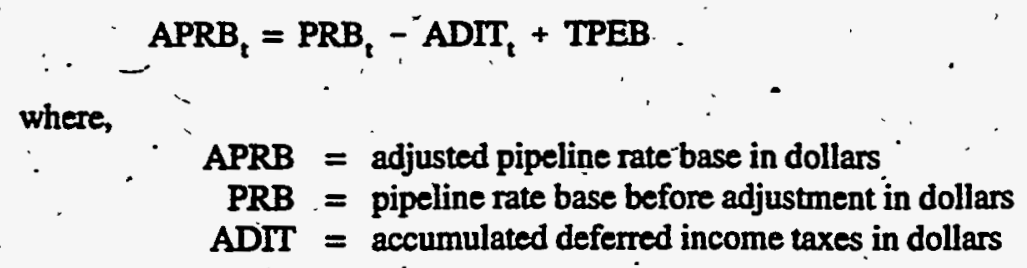




$$
\begin{aligned}
\text { TPEB } & =\text { transition expense balance in dollars } \\
\mathbf{t} & =\text { forecast year }
\end{aligned}
$$

Accumulated deferred income taxes depend on income tax regulations in effect, differences in tax and book depreciation, and the time vintage of past construction. The relationship established for the existing pipelines is different from the . generic pipelines. The accumulated deferred income taxes for existing pipeline/storage is derived as follows: ·

$$
\mathrm{ADIT}_{t}=\beta_{0}+\beta_{1} * \mathrm{ADTT}_{t-1}+\beta_{2} * \text { NETPLT }_{\mathrm{t}}
$$

where,

$\beta_{0}, \beta_{1}, \beta_{2}=$ coefficients estimated based on empirical study (Appendix F, Table F4)

ADIT $=$ accumulated deferred income taxes in dollars

NETPLT = difference between original capital cost of plant in service and accumulated depreciation in previous period (net plant in service) in dollars

$\mathbf{t}=$ forecast year

Accumulated deferred income taxes for generic companies is calculated using an accounting algorithm: It is assumed that for rate making purposes, straight line depreciation (SLD) is used. However, for tax purposes, modified accelerated cost recovery system (MACRS) with a $151 / 2$ year schedule is used. ADIT is derived from the difference between two depreciation schedules and the tax rate. Selecting the formula used to calculate ADIT depends on the difference between two depreciation schedules and the book value of the asset (calculated using the MACRS depreciation schedule). The formulae are as follows:

$$
\text { ADIT }_{t-1}+\left(D_{E P R M A C R S},- \text { DEPRSL }_{\mathrm{t}}\right) * \text { FRATE }_{\text {. }}
$$

$$
\begin{aligned}
& \text { if DEPRMACRS }>\text { DEPRSL } \\
& \text { if DEPRMACRS }<\text { DEPRSL } \\
& \text { and BOOKVL >0 }
\end{aligned}
$$$$
\operatorname{ADIT}_{t}=\operatorname{ADTT}_{t-1}
$$$$
\text { ADIT }_{\mathrm{t}-1}-\text { DEPRSL }_{\mathrm{t}} * \mathrm{FRATE}
$$

$$
\text { if } B O O K V L=0
$$

where,

$$
\begin{aligned}
\text { ADIT } & =\text { accumulated deferred income taxes in dollars } \\
\text { DEPRMACRS } & =\text { annual depreciation expense using MACRS } \\
\text { DEPRSL } & =\text { annual depreciation expense using } 30 \text { year straight line schedule } \\
\cdot \text { FRATE } & =\text { federal tax rate (Appendix F, Table F4) } \\
\text { BOOKVL } & =\text { book value of plant, which is calculated using straight line depreciation schedule } \\
t & =\text { forecast year. }
\end{aligned}
$$

and,

$$
\begin{aligned}
& \text { DEPRMACRS }_{t}=\sum_{s=1991}^{t} \operatorname{NCAE}_{s} * \text { MACRS_RATE }_{t-s+1} \\
& \text { DEPRSL }_{t}=\sum_{s=1991}^{t} \operatorname{NCAE}_{s} / 30
\end{aligned}
$$

where,

$$
\begin{aligned}
\text { NCAE } & =\text { new capacity expansion expenditures occurring in year s (in dollars) } \\
\text { MACRS_RATE } & =\text { rate of depreciation by MACRS schedule (Appendix F, Table F4) } \\
s & =\text { the year new expansion occurred } \\
t & =\text { forecast year }
\end{aligned}
$$

Cost of Capital. The capital-related components of the revenue requirement depend upon the size of the rate base and the cost of capital to the pipeline company. In turn, the company cost of capital depends upon the rates of return on debt and equity and the amounts of debt and equity in the overall capitalization.

Company cost of capital consists of long-term debt, preferred stock, and common equity. The rate of return variables for debt and equity will be related to forecast macroeconomic variables. For existing pipeline, it is assumed that the long: 
term debt rate will vary as a function of the difference in the long-term debt rate and the yield on AA utility bonds . - (provided by the Macroeconomic Activity Model) in the base year, as.follows:

$$
\begin{aligned}
\text { LTDR }_{i, t} & =\text { MC_RMPUAANS }, 100.0+\text { DLTDR }_{i, b} \\
& =\text { MC_RMPUAANS }, 100.0+\left(\text { LTDR }_{i, b}-\text { MC_RMPUAANS }_{b} / 100.0\right)
\end{aligned}
$$

where,

$\mathrm{LTDR}_{\mathrm{H}}=$ long-term debt rate [Appendix E-PLTDR, (fraction)]

MC_RMPUAANS,$\quad=A A$ utility bond index rate provided by the Macroeconomic Activity Model (percentage)

DLTDR $_{L b}=$ difference in the long term debt rate and the yield on AA utility bond for pipeline company $i$ in base year

$i=$ pipeline company $i$

$\mathbf{b}=$ base year

t $=$ forecast year

The rate of return on common equity for existing pipelines is considered to be a function of the long-term debt rate and the difference between the long-term debt rate and the rate of retum on common equity in the base year. That is,

$$
\begin{aligned}
\text { CMER }_{\mathrm{i}, \mathrm{t}} & =\dot{\mathrm{LTDR}_{\mathrm{i}, \mathrm{s}}}+\operatorname{DCMER}_{\mathrm{ib}} \\
& =\operatorname{LTDR}_{\mathrm{it},}+\left(\mathrm{CMER}_{\mathrm{i}, \mathrm{b}}-\operatorname{LTDR}_{\mathrm{i}, \mathrm{b}}\right)
\end{aligned}
$$

where,

$\mathrm{CMER}_{4 s}=$ common equity rate of return [Appendix E - PCMER, (fraction)]

$L_{T D R_{L s}^{-}}^{-}=$long-term debt rate [Appendix E-PLTDR, (fraction)]

DCMER $_{\mathrm{Lb}}$ = the difference between rate of return on common equity and rate of return on long-term debt in base year

$\mathrm{i}=$ pipeline company $\mathrm{i}$

b $=$ base year

$t=$ forecast year

The rate of return on preferred stock for existing pipelines is also tied to the AA bond rate through the long term debt rate, as following:

$$
\text { PFER }_{i, t}=L_{T D R_{i, t}}+\text { DPFER }_{i, b}
$$

where,

$$
\begin{aligned}
\text { PFER }_{4,} & =\text { rate of retum for preferred stock [Appendix E-PPFER, (fraction)] } \\
\text { LTDR }_{\text {i, }} & =\text { long-term debt rate [Appendix E - PLTDR, (fraction)] } \\
\text { DPFER }_{i b} & =\text { the difference between rate of return on preferred stock and rate of return on long-term debt } \\
\mathbf{i} & =\text { pipeline company } i \\
\mathbf{b} & =\text { base year } \\
t & =\text { forecast year }
\end{aligned}
$$

For generic pipelines, the rate of return on long term debt (LTDR) is defined as an industry average rate of return weighted by gross plant in service (GPIS) in the base year. In the forecast years, it is equal to the sum of the AA utility bond rate and a deviation constant calculated in the base year. The derivation is shown below:

- The DPFER variable is assigned as $0.5 \%$ and kept constant for each pipeline throughout the entire forecast. This value represents analyst's judgement because attempts to derive it from historical data produced unrealistic results. 


$$
\begin{aligned}
& \operatorname{LTDR}_{t}=\sum_{\cdot i}\left(\operatorname{LTDR}_{i, t} * \frac{\text { GPIS }_{i, b}}{\sum_{j} \text { GPIS }_{j, b}}\right) \\
& =\sum_{i}\left(\text { MC_RMPUAANS }_{i} / 100.0+\operatorname{DLTDR}_{\mathrm{i}, \mathrm{b}}\right) * \frac{\text { GPIS }_{\mathrm{i}, \mathrm{b}}}{\sum_{j} \mathrm{GPIS}_{\mathrm{j}, \mathrm{b}}} \\
& =\text { MC_RMPUAANS } / 100.0+\sum_{i}\left(D_{-1 T R_{i, b}}\right) * \frac{\text { GPIS }_{L b}}{\sum_{j} G_{i} S_{j, b}} \\
& =\text { MC_RMPUAANS } / 100.0+\text { GLTDR0 }
\end{aligned}
$$

where,

$$
\begin{aligned}
& \mathrm{LTDR}_{4} \text { = industry average long-term debt rate for generic pipeline (fraction) } \\
& \text { LTDR }_{\mathrm{H},} \text { = long-term debt rate for existing pipeline company i [Appendix E -- PLTDR, (fraction)] } \\
& \text { MC_RMPUAANS, = AA utility bond index rate provided by the Macroeconomic Activity Model (percentage) } \\
& \text { DLTDR }_{\mathrm{L}, \mathrm{b}}=\text { the difference between the long term debt rate and the yield on AA utility bond for pipeline } \\
& \text { company } \mathrm{i} \\
& \text { GLTDRO = deviation constant is the derived average difference between the rate of long term debt and the } \\
& \text { yield on AA utility bond in the base year } \\
& \text { GPIS }_{\mu}=\text { original capital cost of plant in service (gross plant in service) in dollars } \\
& \dot{\mathbf{i}}=\text { = existing pipeline company } \mathrm{i} \\
& \text { b }=\text { base year } \\
& t=\text { forecast year }
\end{aligned}
$$

The rate of return on common equity (CMER) for generic pipelines is tied to the AA utility bond rate through the longterm debt rate (LTDR). CMER is equal to the sum of long term debt rate for generic pipeline and a deviation constant. The derivation is, shown below:

$$
\begin{aligned}
& \mathrm{CMER}_{\mathrm{t}}=\sum_{i}\left(\mathrm{CMER}_{\mathrm{i}, \mathrm{t}} * \frac{\mathrm{GPIS}_{\mathrm{i}, \mathrm{b}}}{\sum_{\mathbf{j}} \mathrm{GPIS}_{\mathrm{j}, \mathrm{b}}}\right) \\
& =\sum_{i}\left(\operatorname{LTDR}_{\mathrm{i}, t}+\operatorname{DCMER}_{\mathrm{i}, \mathrm{b}}\right) * \frac{\text { GPIS }_{\mathrm{i}, \mathrm{b}}}{\sum_{\mathbf{j}} \text { GPIS }_{\mathrm{j}, \mathrm{b}}} \text {. } \\
& =\sum_{i}\left(\operatorname{LTDR}_{\mathrm{i}, \mathrm{b}} * \frac{\mathrm{GPIS}_{\mathrm{i}, \mathrm{b}}}{\sum_{j} \mathrm{GPIS}_{\mathrm{j}, \mathrm{b}}}\right)+\sum_{i}\left(\mathrm{DCMER}_{\mathrm{i}, \mathrm{b}} * \frac{\mathrm{GPIS}_{\mathrm{i}, \mathrm{b}}}{\sum_{\mathbf{j}} \mathrm{GPIS}_{\mathrm{j}, \mathrm{b}}}\right) \\
& =\mathrm{LTDR}_{\boldsymbol{t}} \text { + GCMERO }
\end{aligned}
$$

where,

$$
\begin{aligned}
& \text { CMER }_{4}=\text { industry average common equity rate for generic pipeline (fraction) } \\
& \mathrm{CMER}_{2 \mathrm{~s}} \cdot=\text { rate of return on common equity for existing pipeline company } \mathrm{i} \text { [Appendix E - PCMER, } \\
& \text { - (fraction)]. } \\
& \mathrm{LTDR}_{t}=\text { industry average long-term debt rate for generic pipeline (fraction) } \\
& \text { LTDR }_{1, k}=\text { long-term debt rate for existing pipeline company i [Appendix E - PLTDR, (fraction)] } \\
& \text { DCMER }_{L, b}=\text { the difference between rate. of return on common equity and rate of return on long-term debt } \\
& \text { for pipeline company } i \text { in base year } \\
& \text { GCMERO = deviation constant is the derived average difference between the rate of return on common } \\
& \text { equity and the yield on AA utility bond in base year } \\
& \text { - } \text { GPIS }_{L \ell}=\text { original capital cost of plant in service (gross plant in service) in dollars } \\
& \mathrm{i}=\text { pipeline company } \mathrm{i} \\
& \text { b }=\text { base year } \\
& t=\text { forecast year }
\end{aligned}
$$

Similarly, the rate of retum on preferred stock (PFER) is equal to the sum of the long term debt rate for generic pipelines and a deviation constant. It can be derived as shown below: 


$$
\begin{aligned}
& \text { PFER }_{\mathrm{t}}=\sum_{\mathbf{i}-}\left(\text { PFER }_{\mathrm{i}, \mathrm{t}} * \frac{\mathrm{GPIS}_{\mathrm{i}, \mathrm{b}}}{\sum_{\mathbf{j}} \mathrm{GPIS}_{\mathrm{j}, \mathrm{b}}}\right) \\
& =\sum_{i}\left(\operatorname{LTDR}_{\mathrm{i}, \mathrm{t}}+\mathrm{DPFER}_{\mathrm{i}, \mathrm{b}}\right) \cdot \frac{\text { GPIS }_{\mathrm{ib}, \mathrm{b}}}{\sum_{j} \mathrm{GPIS}_{\mathrm{j}, \mathrm{b}}} \\
& =\operatorname{LIDR}_{\mathbf{t}}+\sum_{\mathbf{i}}\left(\text { DPFER }_{\mathrm{i}, \mathrm{b}} * \frac{\text { GPIS }_{\mathrm{i}, \mathrm{b}}}{\sum_{\mathbf{j}} \text { GPIS }_{\mathrm{j}, \mathrm{b}}}\right) \\
& =\mathrm{LTDR}_{\mathrm{t}}+\mathrm{GPFER}_{0}
\end{aligned}
$$

where,

$\mathrm{PFER}_{4}$ = average rate of preferred stock for generic pipelines (fraction)

$\mathrm{PFER}_{\mathrm{L} \text { s }}=$ rate of return for preferred stock for the existing pipeline company i [Appendix E - PPFER, (fraction)]

$L_{T D R_{1}}=$ industry average long-term debt rate for generic pipeline (fraction)

.LTDR $R_{42}=$ long-term debt rate fór existing pipeline company i [Appendix E - PLTDR, (fraction)]

DPFER $_{L, b}=$ the difference between rate of return on preferred stock and rate of return on long-term debt for company $i$

GPFERO = deviation constant is the derived average difference between the rate of return on preferred stock and the yield on AA utility bond in base year

GPIS $_{\text {is }}=$ original capital cost of plant in service (gross plant in service) in dollars

$\cdot \mathbf{i}=$ pipeline company $\mathbf{i}$

b $=$ base year

$t=$ forecast year

For existing companies, the values of common stock, preferred stock and long term debt are assumed to be constant in real dollars; therefore, in nominal dollars these are increased by the inflation rate for the forecast period:

$$
\begin{aligned}
\text { PFES }_{i, t} & =\text { PFES }_{i, t-1} * \text { GDPINEL }_{t} \\
\text { CMES }_{i, t} & =\text { CMES }_{i,-1} * \text { GDPINFL }_{t} \\
\text { LTD }_{i, t} & =\text { LTD }_{i, l-1} * \text { GDPINFL }_{t}
\end{aligned}
$$

where,

PFES $_{i s}=$ value of preferred stock in nominal dollars

$\mathrm{CMES}_{\mathrm{is}}=$ value of common equity in nominal dollars

$\mathrm{LTD}_{L}=$ long-term debt in nominal dollars

GDPINFL = implicit GDP price inflator relative to previous year (from the Macroeconomic Activity Model)

$\mathrm{i}$ = pipeline company $\mathrm{i}$

$t=$ forecast year

The capital structure for generic pipelines is assumed constant. The three components of capital structure (GPFESTR, GCMESTR, and GLTDSTR) are defined as the average 1990 capital structure of the pipeline directly represented in the PTM (Appendix E - PFES, CMES, LTD), and are used, along with the adjusted pipeline rate base, to determine the values of preferred stock, common stock, and long term debt:

$$
\begin{aligned}
\text { PFES }_{\mathrm{t}} & =\text { GPFESTR }_{\mathrm{t}} * \text { APRB }_{\mathrm{t}} \\
\text { CMES }_{\mathrm{t}} & =\text { GCMESTR }_{\mathrm{t}} * \text { APRB }_{\mathrm{t}} \\
\text { LTD }_{\mathrm{t}} & =\text { GLTDSTR }_{\mathrm{t}} * \text { APRB }_{\mathrm{t}}
\end{aligned}
$$

where,

PFES = value of preferred stock in nominal dollars

CMES = value of common equity in nominal dollars 
LTD $=$ ' long-term debt in nominal dollars

GPFESTR = average historical ratio of preferred stock to total capital used as capital structure for generic pipeline (constant over forecast period)

GCMESTR = average historical ratio of common stock to total capital used as capital structure for generic pipeline (constant over forecast period)

GLTDSTR . = average historical ratio of long.term debt to total capital used as capital structure for generic pipeline (constant over forecast period)

APRB = adjusted pipeline rate base (dollars)

$t=$ forecast year

Capital structure is the percent of total capitalization represented by each of the three capital components: long-term debt ' costs, preferred equity, and common equity. The proportions of total capitalization due to common stock, preferred stock, and long-term debt are considered fixed at the base-year values throughout the forecast. Assuming that the fractions of total capitalization remain the same over the forecast horizon, ${ }^{24}$ the weighted average cost of capital in the forecast.year is given by:

$$
\text { WAROR }_{t}=\left[\left(\text { PFER }_{t} * \text { PFES }_{t}\right)+\left(\text { CMER }_{t} * \text { CMES }_{t}\right)+\left(\operatorname{LTDR}_{t} * \text { LTDS }_{t}\right)\right] / \text { TOTCAP }_{t}
$$

where,

WAROR $=$ weighted-average before-tax rate of return on capital (fraction)

PFER = coupon rate for preferred stock (fraction)

PFES $=$ value of preferred stock (dollars)

CMER ' = common equity rate of return (fraction)

- CMES = value of common stock (dollars)

LTDR = long-term debt rate (fraction)

LTDS = value of long-term debt (dollars)

-TOTCAP = sum of the value of long-term debt, preferred stock, and common stock equity [Equation 109 (dollars)]

$t=$ forecast year

\section{Projection of Capital-Related Components of the Revenue Requirements}

The approach to the projection of capital-related components of the revenue requirements is summarized in Table 8-5. Given the rate-base and capitalization projections discussed above, the components of revenue requirements are relatively straightforward to project. The capital-related components of the revenue requirements include total return; Federal and State tax credits; Federal and State income taxes; other taxes; and depreciation, depletion, and amortization costs. These

- cost components are projected as follows:

The total return is computed from the projected weighted cost of capital and estimated rate base, as follows:

$$
\operatorname{TRRB}_{\mathrm{t}}=\mathrm{WAROR}_{\mathrm{t}} * \mathrm{APRB}_{\mathrm{t}}
$$

where,

TRRB = total return on rate base (before taxes) in dollars

WAROR = weighted-average before-tax rate of return on capital (fraction)

APRB = adjusted pipeline rate base in dollars

$\cdot t=$ forecast year

The return on rate base for existing companies is broken out into the three components as shown below.

4Changes in capital structure could be treated later as an enhancement to the PTM. This would involve consideration of, among other factors, sources and uses of funds, dividend payout policies, and regulatory caps on how much common equity is permitted in determining rates. It is not clear that this enhancement would offer large benefits to the forecast. 
Table 8-5. Approach to Projection of Revenue Requirements: Capital-Related Costs and Taxes

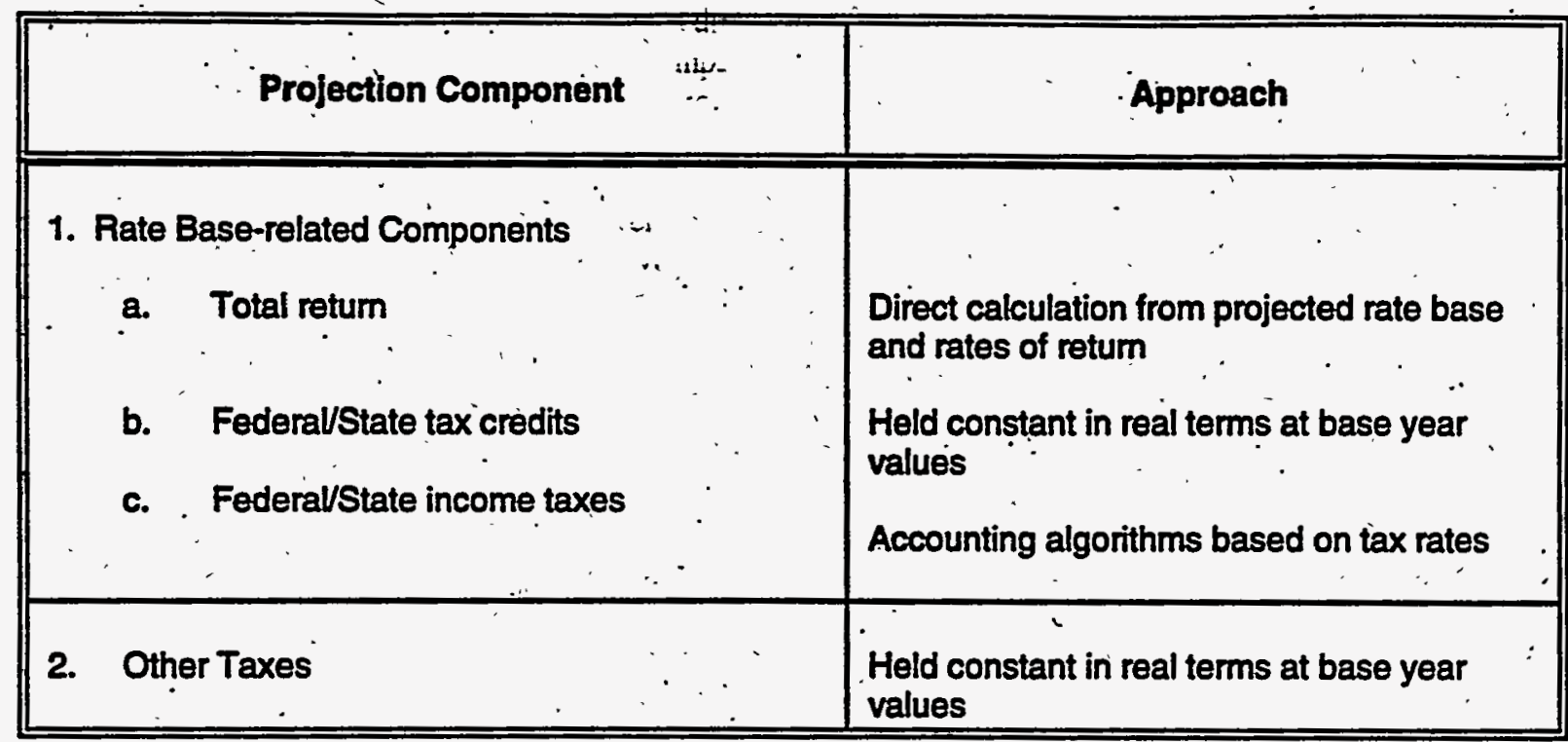

$$
\begin{aligned}
& \text { PFEN }_{\mathrm{t}}=\left(\text { PFES }_{\mathrm{f}} \text { TOTCAP }_{\mathrm{t}}\right) * \mathrm{PFER}_{\mathrm{t}} * \text { APRB }_{\mathrm{t}} \\
& \text {.CMEN, }=\left(\text { CMES }_{\mathrm{t}} \mathrm{TOTCAP}_{\mathrm{t}}\right) * \mathrm{CMER}_{\mathrm{t}} \text { * } \mathrm{APRB}_{\mathrm{s}} \text {. }
\end{aligned}
$$

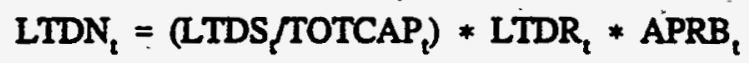

where,

$$
\begin{aligned}
\text { PFEN } & =\text { total return on preferred stock (dollars) } \\
\text { PFES } & =\text { value of preferred stock (dollars) } \\
\text { TOTCAP } & =\text { total capitalization (dollars) } \\
\text { PFER } & =\text { coupon rate for preferred stock (fraction) } \\
\text { APRB } & =\text { adjusted pipeline rate base (dollars) } \\
\text { CMEN } & =\text { total return on common stock equity (dollars) } \\
\text { CMES } & =\text { value of comimon stock equity (dollars) } \\
\text { CMER } & =\text { common equity rate of return (fraction) } \\
\text { LTDN } & =\text { total return on long-term debt (dollars) } \\
\text { LTDS } & =\text { value of long-term debt (dollars) } \\
\text { LTDR } & =\text { long-term debt rate (fraction) } \\
t & =\text { forecast year }
\end{aligned}
$$

For generic companies the capital structure is assumed to be constant over the forecast period. Therefore, the return on rate base for generic companies (new expansion portion of pipeline/storage) is defined using a simpler format:

$$
\begin{aligned}
& \text { PFEN }_{\mathrm{t}}=(\text { GPFESTR }) * \text { PFER }_{\mathrm{t}} * \text { APRB }_{\mathrm{t}} \\
& \text { CMEN }_{\mathrm{t}}=(\text { GCEMSTR }) * \text { CMER }_{\mathrm{t}} * \text { APRB }_{\mathrm{t}} \\
& \text { LTDN }_{\mathrm{T}}=(\text { GLTDSTR }) * \text { LTDR }_{\mathrm{t}} * \text { APRB }_{\mathrm{t}}
\end{aligned}
$$

where,

$$
\begin{aligned}
& \text { PFEN = total return on preferred stock (dollars) } \\
& \text { CMEN }=\text { total return on common stock equity (dollars) } \\
& \text { LTDN }=\text { total return on long-term debt (dollars) }
\end{aligned}
$$




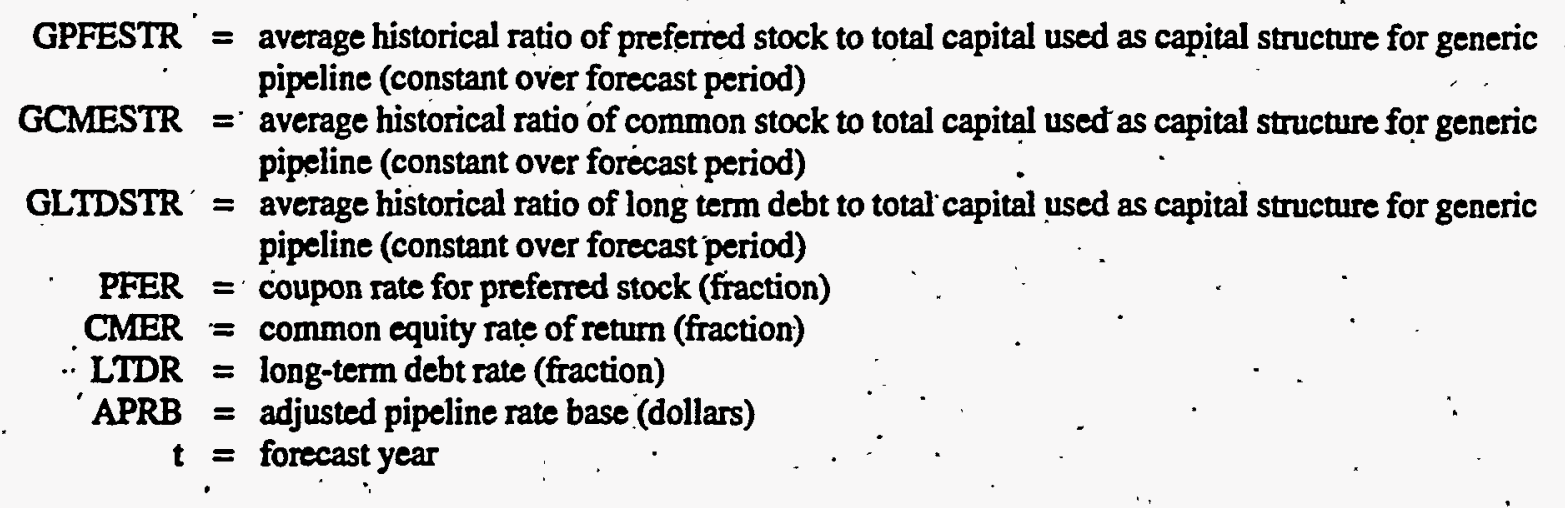

Total taxes consists of Federal income taxes, State income taxes, and other taxes at average rates, minus tax credits for Federal and State income taxes. Federal income taxes and State income taxes are calculated in the same manner as in the base year (Equations 113-117) using average tax rates. The equation for total taxes is as follows:

$$
\text { TOTAX }_{\imath}=\text { FSIT }_{\imath}+\text { OTTAX }_{\imath}-\text { FSITC }_{\imath}
$$

where,

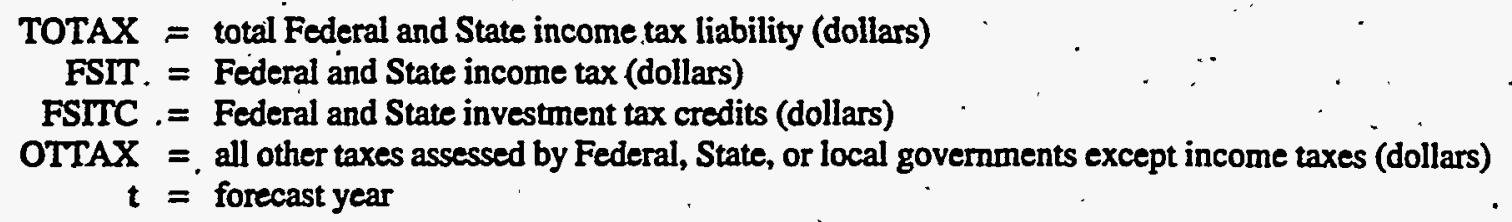

Federal income tax credits are assumed to remain constant in real terms at the base year level throughout the forecast. and therefore they are adjusted for inflation. Other taxes relate to a combination of ad valorem taxes (which grow with company revenue), property taxes (which grow in proportion to gross plant), and all other taxes (assumed constant in real terms). Other taxes are determined as a function of the previous year's level times the inflation rate.from the previous year.

$$
\text { OTTAX }_{\imath}=\text { OTTAX }_{t-1} *\left(M_{-} \text {PGDP }_{t} / \text { MC_PGDP }_{t-1}\right)
$$

where,

OTTAX = all other taxes assessed by Federal; State, or local governments except income taxes (dollars) MC_PGDP = implicit GDP price deflator (from the Mactoeconomic Activity Model)

$t=$ forecast year

\section{Projection of Normal Operating Expenses and Revenue Credits}

The remaining projected components of the revenue requirements are normal operating expenses and revenue credits. Normal operating expenses are further disaggregated into depreciation, depletion, and amortization expenses, total taxes (previously estimated above), administrative and general expense, customer expenses, and total operations and maintenance expenses. The approach to the projection of these line items is summarized in Table 8-6. The projected costs are based on long-run marginal cost relationships in the pipeline industry which relate cost incurrence to external measures of industry size or activity and which relate unit costs to measurable changes in factor costs, the level and nanure of the service, and technology. In some cases costs are assumed to be held constant because of limited resources available to develop data and develop the empirical estimates.

The total cost of service for a forecast year is as follows:

$$
\operatorname{TCOS}_{t}=\operatorname{TRRB}_{t}+\operatorname{TNOE}_{\mathrm{t}}-\mathrm{REVC}_{\mathrm{t}}
$$

where,

$$
\begin{aligned}
& \text { TCOS }=\text { total cost-of-service (dollars) } \\
& \text { TRRB }=\text { total return on rate base [before taxes (dollars)] } \\
& \text { TNOE }=\text { total normal operating expenses (dollars) }
\end{aligned}
$$


Table 8-6. Approach to Projection of Revenue Credits and Normal Operating Expenses

\begin{tabular}{|c|c|}
\hline Projection Component & Approach \\
\hline 1. Revenue Credits to Cost of Senvice & $\begin{array}{l}\text { Held constant at base-year value adjusted for } \\
\text { inflation }\end{array}$ \\
\hline 2. Depreciation, Depletion, and Amortization & Empirically estimated \\
\hline $\begin{array}{l}\text { 3. Administrative \& General } \\
\quad \text { salaries, pension benefits, regulatory } \\
\text { expenses, and other expenses. }\end{array}$ & $\begin{array}{c}\text { Empirically estimated } \\
\qquad: \cdots\end{array}$ \\
\hline 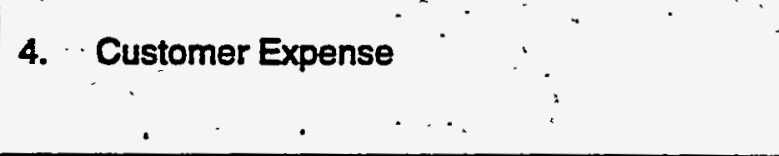 & $\begin{array}{l}\text { Held constant at base-year value adjusted for } \\
\text { inflation }\end{array}$ \\
\hline 5. Total Operating and Maintenance Expense & Empirically estimated \\
\hline
\end{tabular}

REVC = revenue credits to cost-of-service (dollars)

$t=$ forecast year

Revenue credits to cost-of-service is determined as a function of the previous year's level times the inflation rate from the previous year, as follows:

$$
\text { REVC }_{t}=\text { REVC }_{t-1} *\left(M_{-} \text {PGDP }_{t} / M_{-} \text {PGDP }_{t-1}\right)
$$

where,

$$
\begin{aligned}
\text { REVC } & =\text { revenue credits to cost-of-service.(dollars) } \\
\text { MC_PGDP } & =\text { implicit GDP price deflator (from the Macroeconomic Activity Model) } \\
\text { t } & =\text { forecast year }
\end{aligned}
$$

The revenue requirement consists of a just and reasonable return on the rate base plus normal operating expenses.

$$
\operatorname{TRR}_{t}=\operatorname{TRRB}_{\mathrm{t}}+\mathrm{TNOE}_{\mathrm{t}}
$$

where,

$$
\begin{aligned}
\text { TRR } & =\text { total revenue requirement (dollars) } \\
\text { TRRB } & =\text { total return on rate base [before taxes (dollars)] } \\
\text { TNOE } & =\text { total normal operating expenses (dollars) } \\
t & =\text { forecast year }
\end{aligned}
$$

The total normal operating expenses costs consist of the following components:

$$
\text { TNOE }_{t}=\mathrm{DDA}_{\mathrm{t}}+\mathrm{TOTAX}_{\mathrm{t}}+\mathrm{TAG}_{\mathrm{t}}+\mathrm{TCE}_{\mathrm{t}}+\mathrm{TOM}_{\mathrm{t}}
$$

where, 


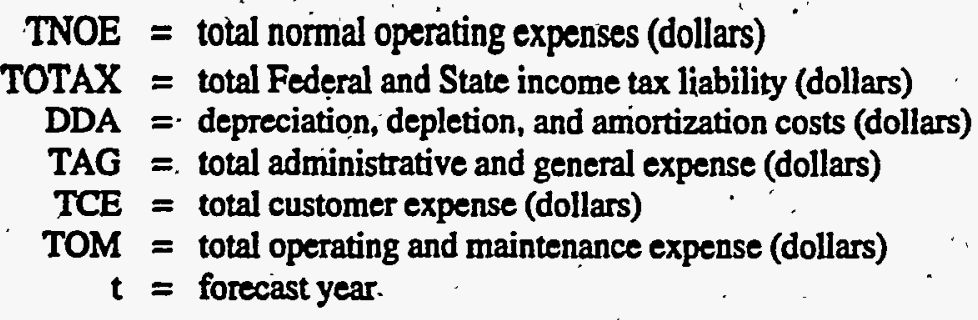

A regression equation is used to define the annual depreciation, depletion, and amortization for existing pipelines, while an accounting algorithm is used for generic pipelines. For existing pipelines, this expense is forecast as follows:

$$
\begin{aligned}
\operatorname{DDA}_{t}= & (1-\rho) * \beta_{0}+\beta_{1} * \mathrm{NETPLT}_{t}+\beta_{2} * \text { DEPSHR }_{t} \\
& +\rho * \mathrm{DDA}_{t-1}-\rho *\left(\beta_{1} * \mathrm{NETPLT}_{t-1}+\beta_{2} * \mathrm{DEPSHR}_{t-1}\right)
\end{aligned}
$$

where,

$$
\begin{aligned}
\text { DDA }= & \text { depreciation, depletion; and amortization costs in dollars } \\
\beta_{0,} \beta_{1}, \beta_{2}= & \text { coefficients estimated based on an empirical study (Appendix F, Table F4) } \\
\rho= & \text { estimated auto-correlation coefficients (Appendix F, Table F4) } \\
\text { NETPLT }= & \text { net capital cost of plant in service (dollars) } \\
\text { DEPSHR }= & \text { ratio of accumulated depreciation, depletion, and amortization expenses to gross plant in } \\
& \text { service (a proxy for pipeline age) }
\end{aligned}
$$

A certain portion of the cost of new facilities required to comply with Order 636 can also be depreciated during the recovery period. During this period, the depreciation, depletion, and amortization costs for existing pipeline are calculated as:

$$
\mathrm{DDA}_{\mathrm{t}}=\mathrm{DDA}_{\mathrm{t}}+\text { PNEWFAC/NEWCOST_PER }
$$

where,

DDA = depreciation, depletion, and amortization costs in nominal dollars

PNEWFAC = cost of new facilities required to comply with Order 636 (nominal dollars)

NEWCOST_PER = period allowing recovery of new facility costs (Appendix E)

The net plant in service and the proxy for pipeline age are defined as follows:

$$
\begin{aligned}
& \text { NETPLT }_{t}=\text { GPIS }_{t-1}-\text { ADDA }_{t-1} \\
& \text { DEPSHR }_{t}=\text { ADDA }_{t-1} / \text { GPIS }_{t-1}
\end{aligned}
$$

where,

GPIS = original capital cost of plant in service (gross plant in service) in dollars

ADDA = accumulated depreciation, depletion, and amortization in dollars

The accounting algorithm used to define the annual depreciation, depletion, and amortization for generic pipelines assumes straight line depreciation over a 30 year life, as follows:

$$
\therefore \quad \mathrm{DDA}_{\mathrm{t}}=\sum_{\mathbf{s}=1991}^{t}\left(\mathrm{NCAE}_{\mathrm{s}} / 30\right)
$$

where, .

$\mathrm{DDA}_{1}=$ depreciation, depletion, and amortization costs in dollars

$\mathrm{NCAE}_{s}=$ new capacity expansion expenditures occurring in year $s$ (in dollars)

$\mathbf{s}=$ the year new expansion occurred

$30=30$ years of plant life

$t=$ forecast year

For projection purposes, total customer expense is a function of last year's level times the inflation rate from the previous year. 


$$
\mathrm{TCE}_{\mathrm{t}}=\mathrm{TCE}_{\mathrm{t}-1} *\left(\mathrm{MC} \mathrm{PGDP}_{\mathrm{q}} / \mathrm{MC}_{-} \mathrm{PGDP}_{\mathrm{t}-1}\right)
$$

where,

$$
\begin{aligned}
\text { TCE } & =\text { total customer expense (dollars) } \\
\text { MC_PGDP } & =\text { implicit GDP price deflator (from the Macroeconomic Activity Model) } \\
t & =\text { forecast year }
\end{aligned}
$$

Total administrative and general costs (TAG) are determined using an estimated equation and an efficiency adjustment term. The efficiency adjustment.term is included to incorporate the observation that the efficiency of the natural gas pipeline system has been dramatically improved as a result of the increase in competition associated with open access. ${ }^{.5}$ The estimated equation used for the unadjusted TAG (Appendix F, Table F4) is determined as a function of gross plant in service, labor and rental cost indices, and some pipeline specific variables, as defined below:

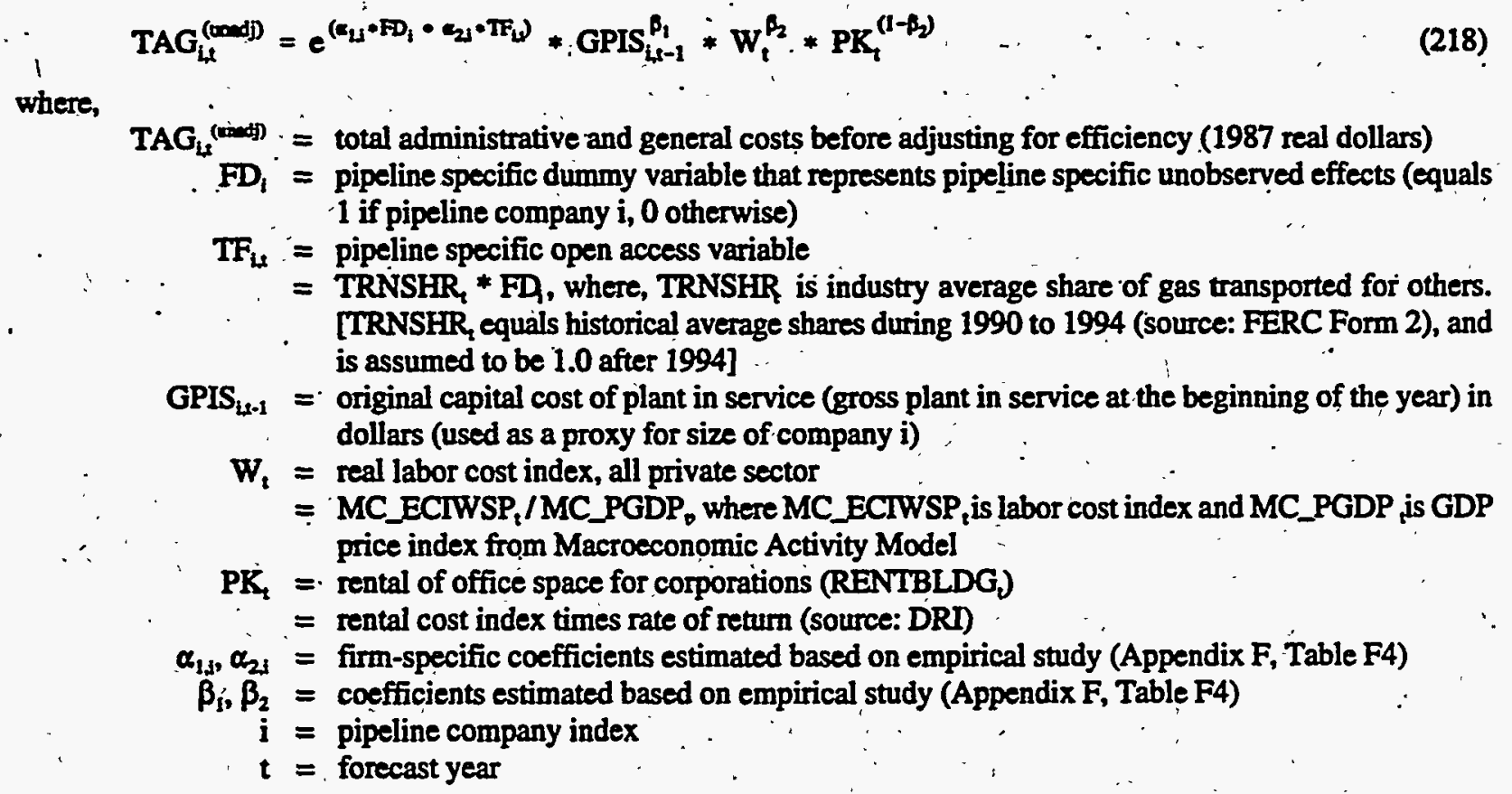

Next, the estimated TAG equation is used to determine total administrative and general costs which include the efficiency adjustment (TAG ${ }_{i s}$ (t) $)$. Similar methods are used for existing and generic pipelines to accomplish this. For both cases, the adjusted TAG equation is composed of two cost components: a discounted cost frontier and a discounted inefficiency measure. For generic pipelines, the inefficiency term is also multiplied by the GPIS (used as a proxy for size). The equations are presented below:

Existing pipeline:

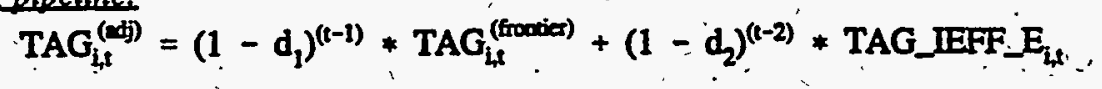

where,

$\mathrm{TAG}_{\mathrm{is}}{ }^{(\omega)}=$ total administrative and general costs with efficiency adjustment for existing pipeline $\mathrm{i}$ in year. $t$ (1987 real dollars)

$\mathrm{TAG}_{\mathrm{L} \text { (frosia) }}=$ cost frontier of total administrative and general costs for existing pipeline $\mathrm{i}$ in year $\mathrm{t}$ (1987 real dollars)

TAG_IEFF_E $E_{2,}=$ TAG inefficiency measurement for existing pipeline $\mathrm{i}$ in year $\mathrm{t}$ (see Endnote 2)

$d_{1}=$ discount rate of TAG cost frontier [Appendix E - TAG_DCLE_CF, (fraction)]

$d_{2}=$ discount rate of TAG inefficiency for existing pipeline [Appendix E - TAG_DCLE, (fraction)]

$\mathrm{i}=$ pipeline company index

$t=$ forecast ýear

. 2s"Efficiency in the Natural Gas Industry;" by Kevin Forbes, SAIC, January 31, 1995. 
Generic pipeline:

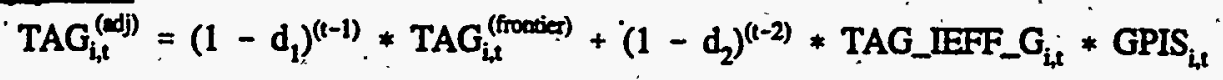

where,

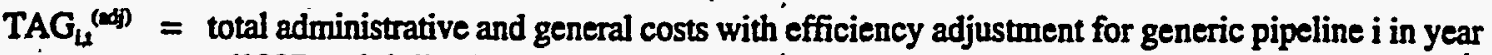

$$
\begin{aligned}
& t \text { (1987 real dollars) } \\
& \mathrm{TAG}_{\mathrm{it}}^{\text {(roorter })}=\text { cost frontier of total administrative and general costs for generic pipeline } i \text { in year } t(1987 \text { real } \\
& \text { dollars) } \\
& \text { TAG_IEFF_G } G_{i}=\text { TAG unit inefficiency factor (e.g., inefficiency per GPIS) for generic pipeline i (calculated in } \\
& \text { base year and kept constant in forecast years, see Endnote 2) } \\
& \text { GPIS }_{L-1}=\text { original capital cost of plant in service (gross plant in service at the beginning of the year) in } \\
& \text { dollars (used as a proxy for the size of company i) } \\
& d_{1}=\text { discount rate of TAG cost frontier [Appendix E - TAG_DCLE_CF, (fraction)] } \\
& d_{2}=\text { discount rate of TAG inefficiency for generic pipeline [Appendix E-TAG_DCLG, (fraction)] } \\
& \mathbf{i}=\text { pipeline company index } \\
& \mathbf{t}=\text { forecast year }
\end{aligned}
$$

The cost frontier for total administrative and general costs $\left(\right.$ TAG $_{i s}$ (tom) is defined the same for both existing and generic pipelines: the coefficients and dummy variables of the most efficient pipeline company are substituted into the estimated equation (TAG $\left.{ }_{L, ~}^{(\mathrm{smoj})}\right)$. This defines the least cost for a company with the same size. The inefficiency term, however, is defined differently, For existing pipeline, the inefficiency measurement (TAG_IEFF_E $E_{i}$ ) is defined as the difference between the unadjusted cost and the cost frontier (after discounting). Thus, the amount of inefficiency is calculated each year by subtracting the discounted cost frontier from the unadjusted costs. For generic pipelines, the inefficiency measurement term (TAG_IEFF_G $G_{b}$ ) is the product of a unit inefficiency factor times a discount rate. The unit inefficiency factor is defined as the inefficiency per GPIS (used as a proxy for the size of expansion). This factor is calculated as the difference between the unadjusted pipeline TAG costs and the frontier TAG costs using the historical arc average data in the base year. The discount rate is applied to model the potential efficiency improvement in new generic pipélines.

Finally, the total administrative and general costs are converted to nominal dollars to be consistent with the conivention used in this module.

$$
\mathrm{TAG}_{\mathrm{i}, \mathrm{t}}=\mathrm{TAG}_{\mathrm{i}, \mathrm{t}}^{(\mathrm{dd})} * \mathrm{MC} \mathrm{PGDP}_{\mathrm{t}}
$$

where,

$$
\begin{aligned}
& \mathrm{TAG}_{\mathrm{L}}=\text { total administrative and general costs with efficiency adjustment for generic pipeline } \mathrm{i} \text { in year } \\
& t \text { (nominal dollars) } \\
& \mathrm{TAG}_{\mathrm{L}}^{(\boldsymbol{( \omega )})}=\text { total administrative and general costs with efficiency adjustment for generic pipeline } \mathrm{i} \text { in year } \\
& \text { t (1987 real dollars) } \\
& \text { MC_PGDP = implicit GDP price deflator (from the Macroeconomic Activity Model) } \\
& t=\text { forecast year }
\end{aligned}
$$

As with the TAG calculations, the total operation and maintenance costs (TOM) are determined using an estimated equation and an efficiency adjustment term. The estimated equation used for the unadjusted TOM (Appendix F, Table F4) is determined as a function of gross plant in service, labor and rental cost indices, and some pipeline specific variables, as defined below:

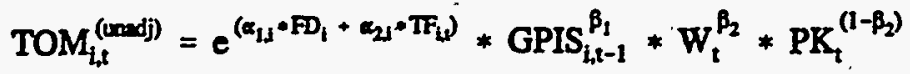

where,

$\mathrm{TOM}_{4 \mathrm{~s}}$ (imed) $=$ total operation and maintenance costs before adjusting for efficiency (1987 real dollars).

$\mathrm{FD}_{i}=$ pipeline specific dummy variable that represents pipeline specific unobserved effects (equals 1 if pipeline company $i, 0$ otherwise) 


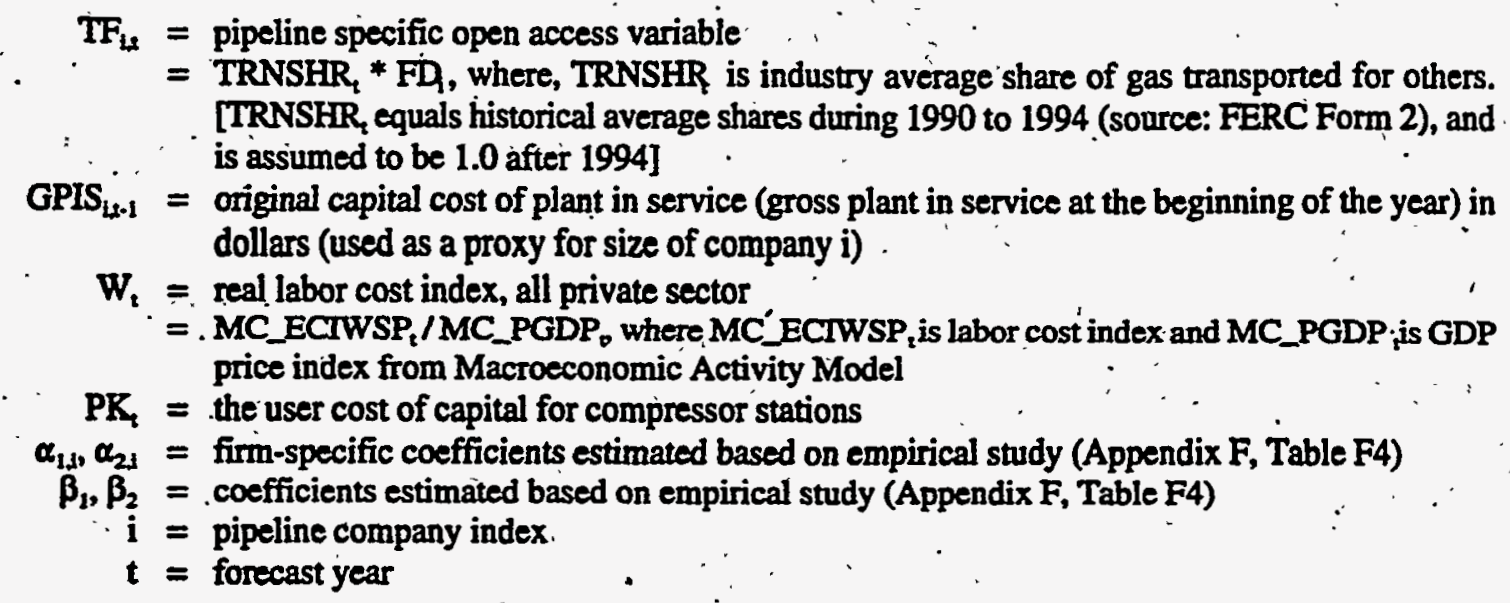

In the above equation, the user cost of capital for compressor stations is defined as the rental price of capital,represented as:

$$
\mathrm{PK}_{\mathrm{t}}=\left(\text { REALAA + PIPE_DEPR }-\frac{\text { PIPE }_{\mathrm{t}}-\mathrm{PIPE}_{\mathrm{t-1}}}{\text { PIPE }_{\mathrm{t}-1} \cdot}\right) * \mathrm{PIPE}_{\mathrm{t}}
$$

where,

$$
\because \mathrm{PK}_{\mathrm{t}} \cdot=\text { the user cost of capital for compressor stations }
$$

PIPE_DEPR $=$ assumed depreciation rate on compressor station equipment $(=0.10$ annually, from PTARIFF $)$

$\because$ PIPE $=$ Producer price index for compressor station equipment [initial values of PIPE are 1.133 (index of 1990) and 1.184 (index of 1991) $]^{26}$

REALAA = the real rate of AA utility bonds

Next, the estimated TOM equation is used to determine total operation and maintenance costs which include the efficiency adjustment ( $\left(\mathrm{TOM}_{4 *}^{(\star j)}\right)$. Similar methods are used for existing and generic pipelines to accomplish this. For both cases, the adjusted TOM equation is composed of two cost components: a discounted cost frontier and a discounted inefficiency measure. For generic pipelines, the inefficiency term is also multiplied by the GPIS (used as a proxy for size). The equations are presented below:

Existing pipeline:

$$
\operatorname{TOM}_{i, t}^{(x-1)}=\left(1-d_{1}\right)^{(t-1)} * T^{2} M_{i, t}^{(f r o x i c t)}+\left(i-d_{2}\right)^{(t-2)} * \text { TOM_IEFF_E }
$$

where,

$$
\begin{aligned}
& \operatorname{TOM}_{1 x}^{(\alpha+1)}=\text { total operation and maintenance costs with efficiency adjustment for existing pipeline } \mathrm{i} \text { in year } \\
& \mathrm{TOM}_{\mathrm{it}}^{\text {(t) }} \text { = cost frontier of total operation and maintenance costs for existing pipeline } \mathrm{i} \text { in year } t \text { (1987 real } \\
& \text { dollars) }
\end{aligned}
$$

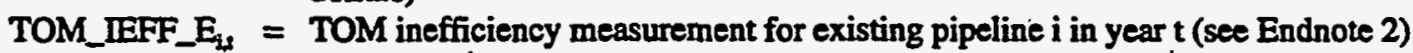

$$
\begin{aligned}
& d_{1}=\text { discount rate of TOM cost frontier [Appendix E-TOM_DCLE_CF, (fraction)] } \\
& d_{2}=\text { discount rate of TOM inefficiency for existing pipeline [Appendix E - TOM_DCLE, } \\
& \text { (fraction)] } \\
& \mathrm{i}=\text { pipeline company index } \\
& t=\text { forecast year }
\end{aligned}
$$

Generic pipeline:

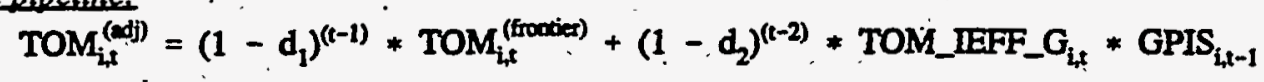

where,

\footnotetext{
${ }^{25}$ Source of historical data: Bureau of Labor Statistics $(1987=1.00)$. 


$$
\begin{aligned}
& \left.\mathrm{TOM}_{\mathrm{L}}{ }^{(\alpha)}\right)=\text { total operation and maintenance costs with efficiency adjustment for generic pipeline } i \mathrm{in} \text { year } \\
& t \text { (1987 real dollar) } \\
& . \mathrm{TOM}_{\mathrm{L}}{ }^{(\text {tronter) }}=\text { cost frontier of total operation and maintenance costs for generic pipeline } i \text { in year } t \text { (1987 real } \\
& \text { dollars) -. } \\
& \text { TOM_IEFF_G } G_{i}=\text { TOM unit inefficiency factor (e.g., inefficiency per GPIS) for generic pipeline i (calculated in } \\
& \text { base year and kept constant in forecast years; see Endnote 2) } \\
& \text { GPIS }_{L \cdot 1}=\text { original capital cost of plant in service (gross plant in service at the beginning of the year) in } \\
& \text { dollars (used as a proxy for size of company i) } \\
& d_{1} \text { = TOM_DCLE_CF: discount rate of TOM cost frontier [Appendix E - TOM_DCLE_CF, } \\
& \text { (fraction)] .. . } \\
& d_{2}=\text { discount rate of TOM inefficiency for generic pipeline [Appendix E - TOM_DCLG, } \\
& \text { (fraction)] } \\
& \text { i = pipeline company index } \\
& t=\text { forecast year }
\end{aligned}
$$

The cost frontier for total operating and maintenance costs (TOM ${ }_{\mathrm{is}}^{(\text {trosices) }}$ ) is defined the same for both existing and generic pipelines: the coefficients and dummy variables of the most efficient pipeline company are substituted into the estimated equation ( $\mathrm{TOM}_{23}{ }^{(u a d j)}$ ). This defines the least cost for a company with the same size. The inefficiency term, however, is defined differently. For existing.pipeline, the inefficiency measurement (TOM_IEFF_E difference between the unadjusted cost and the cost frontier (after discounting). Thus, the amount of inefficiency is calculated each year by subtracting the discounted cost frontier from the unadjusted costs. For generic pipelines, the inefficiency measurement term (TOM_IEFF_G $\mathrm{G}_{i}$ ) is the product of a unit inefficiency factor times a discount rate. The . unit inefficiency factor is defined as the inefficiency per GPIS (used as a proxy for the size of expansion). This factor is calculated as the difference between the unadjusted pipeline TAG costs and the frontier TAG costs using the historical arc average data in the base year. The discount rate is applied to model the potential efficiency improvement in new generic pipelines.

Finally, the total operation and maintenance costs are converted to nominal dollar to be consistent with the convention in this module.

$$
\operatorname{TOM}_{i, t}=\operatorname{TOM}_{i, t}^{(\mathrm{ded})} * \mathrm{MC}_{\mathbf{S}} \mathrm{PGDP}_{\mathrm{t}}
$$

where,

$$
\begin{aligned}
& \text { TOM }_{\mathrm{L}, \mathrm{s}}=\text { total operation and maintenance costs with efficiency adjustment for generic pipeline } i \text {.in year } \\
& t \text { (nominal dollars) } \\
& \mathrm{TOM}_{\mathrm{i},}{ }^{\left({ }^{(d j)}\right)}=\text { total operation and maintenance costs with efficiency adjustment for generic pipeline } \mathrm{i} \text { in year } \\
& \text { t (1987 real dollar) } \\
& \text {.MC_PGDP = implicit GDP price deflator (from the Macroeconomic Activity Model) } \\
& t=\text { forecast year }
\end{aligned}
$$

\section{Computation of Rates for Forecast Years}

Rates for the forecast years are computed using the procedures for the base-year initialization phase discussed above. These procedures include the following steps: (1) classify line items of the cost of service as fixed and variable costs, (2) allocate fixed and variable costs to rate component (reservation and usage fee, volumetric charge) based on the rate design, (3) aggregate costs to the network arc/network node, (4) for transportation services allocate costs to type of service (firm and interruptible), and (5) compute arc-specific (node-specific) rates. Estimation of pipeline costs for forecast years was presented in the previous section. Adjustment of the billing determinants in each year of the forecast is discussed below.

The method used to forecast billing factors is consistent with (1) the assumptions used in the scenario definition, (2) the capacity factor/load factor assumptions, and (3) the incremental new capacity derived from the capacity expansion algorithm. Base-year peak-day billing factors will not change throughout the forecast period for capacity in place in the - base year. Rather, changes in billing factors from capacity additions will be captured through arc-specific generic pipeline companies. Forecast pipeline and storage capacity requirements are determined by the Capacity Expansion 
Module. Incremental annual pipeline capacity and storage requirements and capital cost requirements by arc provided by the Cápacity Expansion Module are assigned to arc-specific generic pipeline companies and storage facilities. Arcspecific adjustments to billing factors are modeled through the addition to base-year volumes of incremental annual and - peak service volumes for each generic pipeline company. Annual volume billing factors will change based on throughput solved for in the Annual Flow Module in the previous year with an adjustment to include an estimate of throughput on incremental expansion in the current year assuming a load factor provided by the Capacity Expansion Module.

Billing factors are determined, at the arc-level; by peak-day design delivery requirements, annual firm transportation volumes, annual interruptible transportation volumes, and the arc distances between regional nodes. Since regional growth in pipeline capacity is aggregated to the arc-level, are distance between regional nodes remains constant throughout the forecast period. Consequently, changes in billing factors are effected solely through changes in peak-day design and annual natural gas flows through each network are during the forecast period. 


\section{Model Assumptions, Inputs, and Outputs}

This last chapter summarizes the model and data assumptions used by the Natural Gas Transmission and Distribution Model (NGTDM) solution methodology and also presents the data inputs to and the outputs from the NGTDM.

\section{Assumptions}

This section presents a brief summary of the assumptions used within the Natural Gas Transmission and Distribution Model (NGTDM). Generally, there are two types of data assumptions that affect the NGTDM solution values. The first type can be derived based on historical data (past events), and the second type is based on experience and/or events that are likely to occur (expert or analyst judgment). A discussion of the rationale behind assumed values based on analyst judgment is beyond the scope of this report. Information on the performance testing of a previous version of the NGTDM through variation in key inputs to the model is provided in a Volume II of this document (the Model Developer's Report, January 3, 1995), which discusses the model performance and results of sensitivity testing. ${ }^{87}$ All FORTRAN variables related to model input assumptions, both those derived from known sources and those derived through analyst judgment, are identified in this chapter, with background information and actual values referenced in Appendix E.

The assumptions summarized in this section are referred to in Chapters 3 through 8. They are used in NGTDM equations as starting values, coefficients, factors, shares, bounds, or user specified parameters. Six general categories of data assumptions have been defined: classification of market services, demand, transmission and distribution service pricing, pipeline tariffs and associated regulation, pipeline capacity and utilization, and supply. These assumptions, along with their variable names, are summarized below.

\section{Market Service Classification}

Nonelectric sector natural gas customers are classified as either core or noncore customers, with core customers transporting their gas under firm (or near firm) transportation agreements and noncore customers transporting their gas under interruptible or short-term capacity release transportation agreements. The residential, commercial, and transportation (vehicles using compressed natural gas) sectors are assumed to be core customers. The transportation sector is further subdivided into fleet and personal vehicle customers. Industrial end users fall into both categories, with industrial boilers and refineries assumed to be noncore and all other industrial users assumed to be core.

Electric generation customers of natural gas are classified as either (1) core, (2) noncore, priced competitive with distillate fuel oil, or (3) noncore, priced competitive with residual fuel oil. The classification is based on the type of electric generator boiler. The electric generator units defining each of the three customer classes modeled are as follows: (1) core - gas steam units or gas combined cycle units, (2) noncore priced competitive-with-distillate - dual-fired turbine units or gas turbine units; (3) noncore priced competitive-with-residual fuel - dual-fired steam plants (consuming both natural gas, and residual fuel oil).

\section{Demand}

The shares (NG_CENSHR) for disaggregating nonelectric Census Division demands to NGTDM regions are held constant throughout the forecast period and are based on average historical relationships.

The Alaskan natural gas consumption levels for residential, commercial, and industrial sectors (Equations 12, 13, 14) are primarily defined as a function of the exogenousily specified number of customers (Tables FI. F2). Alaskan gas

\footnotetext{
"Sensitivity testing was performed on the version of the model used to produce the AEO9S. This document has not been updated and will not be updated to reflect the AEO98 version of the NGTDM. -
} 
consumption is disaggregated into North and South Alaska in order to separately compute the natural gas production forecasts in these regions (Equations 15, 16). The value of gas consumption in South Alaska as a percent of total Alaskan gas consumption (AK_PCTSOUTH) is based on average historical data. Similarly, the Alaskan lease fuel, plant fuel, and pipeline fuel consimption levels are calculated as historically based percentages of total dry production in Alaska (AK_PCTPLT, AK_PCTPIP, AK_PCTLSE) W-The forecast for reporting discrepancy in Alaska (AK_DISCR) is set to the last historical value. To compute natural gas prices by end-use sector for Alaska, fixed markups derived from historical data (AK_RM, AK_CM, AK_EM) are added to the average Alaskan natural gas wellhead price over the North and South regions (Equation 17), with the exception of the industrial sector which is estimated as a function of the world oil price (equation 18). Historically based percentages and markups are held constant throughout the forecast period.

Lease and plant fuel consumption in each NGTDM region is computed as an historically derived percentage of dry gas production (PCTLSE_SUPL) in each NGTDM/OGSM region. These percentages are held constant throughout the forecast period.

Pipeline fuel use is derived using the efficiency factors associated with each arc in the NG'TDM network. Exogenousiy specified shares are used to allocate fuel use along an interregional are to its associated regions based on the relative pipeline mileage in a given region (NG_ARCSIZE). These shares are held constant throughout the forecast period.

In the Capacity Expansion Module, peak and off-peak consumption levels are calculated as exogenously specified percentages of expected annual consumption levels. These exogenous peak and off-peak shares (NON_POSHR_F. NON_POSHR_, UTH_POSHR_F, UTIL_POSHR_J, UTTL_POSHR_C, EXP_PSHR) by market type and sector are estimated based on historical monthly natural gas consumption and are held constant throughout the forecast period:

\section{Pricing of Distribution Services}

End-use prices for residential, commercial, industrial, transportation, and electric generation customers are derived by adding markups to the regional hub price of natural gas. Each regional end-use markup consists of an intraregional tariff (determined by the PTM), an intrastate tariff (INTRA_TARF, INTRA_TARI), a distribution tariff (endogenously defined), and a citygate benchmark factor [endogenously defined based on historical citygate prices (HCGPR_F, HCGPR_h)]. tariffs are defined differently for the core and noncore markets. The distributor tariff algorithm for the core market (with the exception of the transportation and electric generator sectors) uses parameters such as technical efficiency (TECHEFF), cost sharing percentages (DTM_BETA), bypass percentages (I_BYPASS), and debt/equity shares (WT_DEBT), all of which are exogenousiy defined. The algorithm also uses exogenously defined cost coefficients (TCF_COEFF) which represent the relative contribution of an annual change in demands and economic parameters to annual change in costs. The core electric generator distributor tariffs are historically based (HPGFELGR, HCGPR_F) and change based on the annual percentage change in consumption. The fleet vehicle (FV) component of the core transportation sector defines distributor tariffs using exogenously defined historical data (HPGFTRGR, HCGPR_F), a decline rate (TRN_DECL), and state and federal taxes (STAX, FTAX), while the personal vehicle (PV) component defines distributor tariffs as a márkup (RETAIL_COST. STAX, FTAX) over the core industrial sector distributor tariff. Noncore distributor tariffs are determined using historical estimates (HPGINGR, HPGIELGR, HPGCELGR, HCGPR_L), and exogenously defined decline rates (NONU_DTAR_DECL. UTIUR_DECL, UTIUD_DECL)

\section{Pipeline Tariffs and Regulation}

Firm transportation rates for interstate pipeline services (both between NGTDM regions and within a region) are calculated assuming that the costs of new pipeline capacity will be rolled into the existing rate base. However, the test for determining whether or not to build new capacity is done based on incremental rates. Core market transmission service rates are based on a cost-of-service/rate-of-return calculation, at PTMDPCTQ0 percent of the maximum effective pipeline capacity. To reflect recent regulatory changes related to alternative ratemaking and capacity release developments, these tariffs are discounted (based on an assumed price elasticity of TARCRV_ELAS) as pipeline

aCGPR_I is set at CGPR_MUI above the historical regional wellhead price.

"Currently set to zero. 
utilization rates decline. Noncore transmission services are competitively priced with the price floor equal to the-variable cost of delivering natural gas (generally compressor station fuel plus a few cents).

In the computation of natural gas pipeline transportation and storage rates, the Pipeline Tariff Module uses a set of data assumptions based on historical data or expert judgment. These include the following:

- Factors (ARF, ARV, AFR, AFU, AVR, AVU) to allocate each company's line item costs into the fixed and variable cost components of the reservation and usage fees (Equations 121 to 124, and Chapter 8 cross-reference in Appendix G)

- Capacity reservation shares (PS, currently assumed constant throughout the forecast) used to allocate costs to portions of the physical pipeline system:

Share of a pipeline company's storage capacity located in a region (TNS), used to allocate fixed and variable costs to network nodes (Equations 127, 128)

- Load factor, upper bound, and maximum allowable ànual escalation rate for tariffs (LFAC_F. LFACJ. IEXPCT, MAXESC, BASERADJ, LIMITFIRM, LMITINT, PTMDPCTFC) and FERC Order 636 transition cost parameters (SHARE_GSR_F, PNUM191, PGSRCOSTS, PNEWFAC, PSTRANDED) needed for the derivation of pipeline tariffs for firm and internuptible transportation services (Equations 144 and 153) and storage táriffs (Equation 167)

- Capacity expansion cost parameters (CCOST) and pipe míleage (MILES) used to derive total capital costs to expand pipeline capacity (Equation 170) and storage capacity (Equation 173), respectively.

- Input coefficients (TAG_JEFFADJ, TOM_JEFFADJ, TAG_DCLE_CF, TOM_DCLE_CF, TAG_DCLE, TAG_DCLG, TOM_DCLE, TOM_DCLG) for efficiency components in the TAG and TOM calculations.

All interstate pipeline companies are assumed to have completed the switch from modified fixed variable (MFV) to straight fixed variable (SFV) rate design by January 1994 to comply with Federal Energy Regulatory Cómmission Order 636 rate design changes. Approved transition costs are assumed to be consistent with FERC's revised cost estimate as - published by the General Accounting Office in "Natural Gas: Costs, Benefits, and Concerns Related to FERC Order 636, Final Report,". November 1993. It is assumed that the Gas Supply Realignment costs are recovered over a 5-year period beginning in 1994. Furthermore, it is assumed that 90 percent of these costs are assigned to firm transportation markets and 10 percent are assigned to interruptible markets as stipulated in Order 636. Purchase Gas Adjustment Account Balance (Account 191) costs are assumed to be collected over a 2-year period, also beginning in 1994. These costs will be paid only by core customers.

With full implementation of FERC Order 636 and the increasing array of unbundled services being offered by pipelines, it is assumed that segmentation of the natural gas market will continue and ultimately lead to prices reflecting the marginal costs of providing service to diverse groups of end users. The methodology employed in solving for the market equilibrium within the natural gas market assumes that marginal costs are the basis for determining market clearing prices throughout the forecast period. The NGTDM uses the market clearing prices in developing the supply and end-use prices paid by noncore customers. The weighted average cost of gas is used in deriving the cost of natural gas supplies delivered to core customers.

\section{Pipeline Capacity and Utilization}

The Annual Flow Module linear program formulation has been developed to minimize a supply and transportation cost objective function (Equation 23) subject to the following constraints: capacity utilization constraints (Equations 24-25), mass balance constraints (Equations 26-29), and bounds on model flow variables (Equations 31-35). The capacity utilization constraints for the firm market and total market along each interregional arc set the limits on the flows for the firm 'market and total market, respectively. These utilization levels represent the maximum fraction of the physical capacity on the pipeline that is expected to be used on an annual basis. A small portion (WTHR_XCAP) of this capacity is assumed to be reserved in the event of severe weather. The minimum bounds on flows along transshipment arcs in the 
firm and internuptible networks (Equations 31-35) are set as percentages (APCT_MINF, APCT_MINI) of flows in the previous forecast year. These minimum flows help to generate some continuity in flow patterns from year to year. The model methodology assumes that pipeline and storage capacities are available 2 years from the decision to add new capacity.

In the CEM, it is assumed that pipelines and local distribution companies build and subscribe to a portfolio of pipeline and storage capacity to serve a colder-than-normal winter consumption levels. This is represented by building 5 to 15 percent (WTHRFAC) more pipeline capacity than is necessary to support normal winter loads (with lower percentages on ares supplying areas with warmer winters).

The model represents net injections of natural gas into storage in the off-peak period and net withdrawals during the peak period. Annual net storage withdrawals equal zero in all forecast years (excluding historical years). The Capacity Expansion Module is constrained by an assumed maximum level of incremental storage capacity that can be built in each NGTDM region (FACTOR).

Several data assumptions ara embedded in the mathematical specification of the linear program in the Capacity Expansion Module. The constraints on the ares from each supply point during both the peak and off peak periods (SUP_PUTILZ, SUP_OUTIZ, SUP_PKSHR, EXP_PSHR) ensure that the production rates in a period do not exceed a plausible level. The formulation ensures that pipeline capacity is built primarily to satisfy firm peak demand. Exogenously specified seasonal maximum - pipeline utilization rates (ARC_PUTILZ, ARC_PFUTILZ, ARC_OUTILZ, CAN_UTIL_MAX, CAN_UTIL_PF_P) are used to capture the variation in load patterns within a period. For Canadian import arcs, exogenously . defined growth factors (CAN_UTZL_GRWI, CAN_UTIL_GRW2) allow the historically based utilization rates to change during the forecast years. Throughout the forecast years, firm and interruptible storage withdrawal levels are bounded above by the maximum storage leveis determined from assumed storage utilization rates (STR_UTTLZ, STR_FUTILZ), and below based on a declining percentage (APCT_MINF) of historical levels.

The Capacity Expansion Module provides the Annual Flow Module and Pipeline Tariff Module with a forecast of working gas storage capacity, physical pipeline capacity, and maximum annual pipeline capacity utilization rates. The total available pipeline capacity in a given forecast year is calculated as last year's value plus planned expansions (PNEW_CAP) and any additional expansion determined to be required within the model. Assumed maximum seasonal utilization rates (identified above) are used together with peak and off-peak flows within firm and interruptible markets to calculate the firm and total annual pipeline capacity utilization rates in the Capacity Expansion Module. The existing regional working gas capacity [including planned storage expansions (BGSCT, BGSCNT, WGCT, WGCNT, PNEW_STRX)] is added to the determined level of storage expansion to obtain the regional working gas storage capacity levels.

\section{Supply}

The supply curves for domestic dry gas production (Equation 11) incorporate assumed values of short-term price clasticity of supply (PARM_SUPCRV2, PARM_SUPCRV3) depending on the selected functional form. In addition, these supply . curves are limited by minimum and maximum levels, calculated as a factor (PARM_MAXPR, PARM_MINPR) times the reserves times the expected production-to-reserves ratio.

Imports from Mexico and Canada at each border crossing point are represented as follows: (1) Mexican imports are assumed constant and provided by the Oil and Gas Supply Model; (2) Canadian imports are largely determined from exogenously specified Canadian pipeline capacities (CANCAP) and exogenously defined maximum seasonal utilizations (CAN_UTILZ CAN_UTIL_MAX, CAN_UTIL_GRW1, CAN_UTILGRW2, CAN_UTIL_PF_P). Total gas imports from Canada (Equation 4) exclude the amount of gas that travels into the United States and then back into Canada (CANFLO_N).. Liquefied natural gas imports are provided by the Oil and Gas Supply Model.

Synthetic production of natural gas from coal (set exogenoussly) is also represented as a constant supply within the Annual Flow Module and the Capacity Expansion Module. However, synthetic gas production from liquid hydrocarbons in Illinois (Equation 2), which is defined within exogenously specified minimum and maximum production levels (SNGMIN), is represented as a function (Table F3) of the firm service market natural gas price in the East North Central Census Division. Synthetic gas production from liquid hydrocarbons in Hawaii is held constant throughout the forecast period at:an assumed average historical production level (SNGHI). Finally, other supplemental supplies (OSUP_TOT, OSUP_RSHR) are held constant throughout the forecast in the Annual Flow Module and the Capacity Expansion Module. 
A set of seasonal utilization parameters (SUP_PUTiLz, SUP_OUTILZ, SUP_PKSHR, EXP_PSHR) have been defined to split constant production levels into peak and off-peak categories, and to define seasonal splits for production from supply sources that are price responsive.

$\therefore s$

Discrepancies that exist between historical supply and disposition level data are modeled at historical levels (NATL_DISCR) in the NGTDM and kept constant throughout the forecast years. The discrepancy variable also includes an additional value to account for provisions of the Climate Change Action Plan to expand the Natural Gas Star program (Action 32). The programi is assumed to recover 35 billion cubic feet of natural gas per year by the year 2000 that otherwise might be lost to fugitive emissions. This is phased in by recovering an additional 7 billion cubic feet per year - from 1996, through 2000, and by recovering the full 35 billion cubic feet from 2000 through the end of the forecast period.

\section{Model Inputs}

The NGTDM is a comprehensive framework which simulates the natural gas transmission and distribution industry in the United States as regulated (by the Federal Energy Regulatory Commission) for the pipeline transportation services across States (at the interstate level) and (by State Public Utility Commissions) for the local distribution services within States (at the intrastate level). The natural gas pipeline network (including storage) ties the suppliers to the end-users of natural gas, and captures the interactions among these institutions that ultimately determine market clearing prices and quantities consumed of natural gas. The NGTDM inputs are grouped into six categories: supply inputs, pipeline financial and regulatory inputs, pipeline capacity and utilization inputs, storage inputs, end-use pricing inputs, and demand inputs. Short input data descriptions and identification of variable names that provide more detail (via Appendix E) on the sources and transformation of the input data are provided below.

\section{Supply Inputs}

- Supply curve parameters and historical/STEO data (WPRLAGON, WPRLAGOF, OGWPRNG, STOGWPRNG, OGPRDNG, PRNG_PADD, OGPRDNGON, OGPRDNGOF, WPRLAGON, WPRLAGOF, OSUP_TOT, OSUP_RSHR, PARM_SUPCRV2, PARM_SUPCRV3, PSHIFTON, PSHIFTOF, PSHIFT_SCALE, SNGAI, SNGA2)

- HistoricalSTEO production levels for supplemental natural gas supplies (OGPRSUP3, STOGPRSUP)

- Historical import levels and prices (CN_BRDPRC90, CN_NEWCAP90, CNWELPRC89, OGCNPPRD, OGCNQPRD, OGQNGIMP, OGPNGIMP, CANFLO_IN, CANFLOSSHR)

- Regional wellhead price benchmark variables (STAR_J, STAR_F, STAROF_L, STAROF_F)

- Alaskan lease, plant, and pipeline fuel parameters (AK_PCTPLT, AK_PCTPIP, AK_PCTLSE)

- Minimum and maximum production-to-reserves ratios (PARM_MAXPR, PARM_MINPR)

- Seasonal supply shares (SUP_PUTTLZ, SUP_OUTILZ,SUP_PKSHR, EXP_PSHR, CANFLO_PFSHR)

- Seasonal wellhead price differentials. (PKPRCFAC, OPPRCFAC)

- Maximum and minimum synthetic nátural gas production and historical data (CLSYNGWP, SNGMIN, SNGHI, SNG89 and Table F3)

\section{Pipeline Financial and Regulatory Inputs}

- Rate design specification (ARF, AFR, AVR, ASF, ARV, AFU, AVU, ASV)

- Pipeline rate base, cost, and volume parameters (DDA, OTTAX, TAG, TCE, SEOM, CSOML CSOMN, OTOM, CWC, OWC, ADT, GPIS, ADDA, PFES, CMES, LTD, REVC, PCMER, PPFER, PLTDR, DCMER, DLTDR, AFM_PTAR_, TRNSHR, RENTBLDG) 


\footnotetext{
- Revenue requirement forecasting equation parameters (Table F4)

Revenue crediting parameters

(RCREDIT_F, SCALE_F_MIN).

Order 636 transition cost parameters

(SHARE_GSR_F, PNUM 191, PGSRCOSTS, PNEWFAC, PSTRANDED)

Rate of return set for generic pipeline companies

(PPFER: PCMER, PLTDR, DCMER, DLTDR)

Federal and State income tax rates

(FRATE, SRATE)

- Parameters for interstate pipeline transportation rates

(LFAC_F, LFAC_I, IEXPCT, MAXESC, BASERADJ, LMTTFIRM, LIMITINT, PTMDPCTFC, PTMDPCTQ0, TARCRV_ELAS)
}

\section{Pipeline Capacity and Utilization Inputs}

- Seasonal transmission service utilization rates and minimum flows (APCT_MINF, APCT_MINI, ARC_PUTILZ, ARC_PFUTILZ, ARC_OUTILZ, BLARC_PFSHR, BIARC_PISHR, CAN_UTILZ, CAN_UUTL_HAX, CAN_UTTL_GRWI, CAN_UTIL_GRW2, CAN_UTIL_PF_P)

- Initial firm and total pipeline flows and utilization rates (AFLOW_F, AFLOWJ, AUTILZ_F, AUTTLZT)

- Existing pipeline capacity and planned capacity additions (PCAP_MAX, PNEW_CAP)

- Historical arid planned Canadian import pipeline capacities (CANCAP, CANEXP)

- Costs of new construction (CCOST, EXPFAC, CSTFAC, DELPR_CAP)

- Pipeline fuel usage parameters and historical/STEO data (NEFF_PIPE, UEFF_PIPE SEFF_PIPE, AEFF_PIPE, AEFF_PIPE_SCALE, MEXEFF, CANEFF, NG_ARCSIZE, QGPTR; STQGPTR)

- Factors related to planning for abnormal weather (WTHRFAC, WTHR_XCAP)

- Distance and capacity commitmenis by network arc - (MILES, CONDEM)

- Company volume shares by arc (PS)

\section{Storage Inputs}

- Existing storage capacity and planned additions (BGSCT, BGSCNT, BASET, WGCT, WGCNT, WORKT, PNEW_STRX)

- HistoricalSTEO net storage withdrawals and core/noncore designation (PKNETSTR, OPPNETSTR, PKSSTFR_F, OPPSTFR_F, NNETWITH)

- Seasonal utilization parameters (STR_UTILZ,STR_FUTILZ)

- Share of company storage capacity by region (TNS) -

- Costs of storage additions (CCOST, EXPFAC, CSTFAC, DELPR_STR)

- Maximum storage capacity potential by region (FACTOR)

\section{End-Use Pricing Inputs}

- Cost coefficients and other parameters used in core distributor tariff algorithm (TCF_COEFF, I_BYPASS, TECHEFF, DTM_BETA, MINMU_I, DTAR_REFYR)

- Distributor tariff decline rates used in noncore distributor tariff calculations

, (NONU_DTARI_DECL)

- Intrastate tariffs (INTRA_TARF, INTRA_TARI) 
State and Federal taxes, costs to disperise, and other compressed natural gas pricing parameters (STAX, FTAX, RETAIL_COST, TRN_DECL)

Historical citygate prices

(HCGPR_F, HCGPR」) . .

- Historical/STEO end-use prices

(HPGTELGR, HPGFELGR, HPGIELGR, HPGCELGR, HPGFRS, HPGFCM, HPGFTR, HPGFIN, HPGIRS, HPGICM, HPGIR, HPGIN,

HPGFRSGR, HPGFCMGR, HPGFINGR, HPGFTRGR, STPNGRS, STPNGCM, STPNGEL)

\section{Demand Inputs}

- Subregion gas consumption shares for Census Divisions 5, 8 and 9

(NG__CENSHR)

- Seasonal consumption shares

(NON_POSHR_F! NON_POSHR_I, UTIL_POSHR_F, UTIL_POSHR_, UTIL_POSHR_C)

- Historical export quantities and prices

(OGPNGEXP)

- Alaskan consumption and pricing parameters

(WOP89, WPR89, AK_RM, AK_CM, AK_EM, AK_PCTSOUTH, AK_C, AK_D, AK_E, AK_F, AK_G and Table FI)

- Lease and plant fuel consumption parameters and historical/STEO data

(PCTZSE.SUPL, LPTL_SCALE, QLPIN, STQLPIN)

- Short-term demand elasticities

(NONU_ELAS_F, NONU_ELAS_l)

- Discrepancies between historical regional supply and disposition data

(TOTDISCR, NATZ_DISCR, STEO_DISCR_SHR, AK_DISCR)

\section{Model Outpuits}

Once a set of solution values are determined within the NGTDM, those values required by other models of NEMS are passed accordingly. In addition, the NGTDM model results are presented in a series of internal and external reports, as outlined below.

\section{Outputs to NEMS Models}

The NGTDM passes its model solution values to different NEMS models as follows:

- Pipeline fuel consumption and lease and plant fuel consumption by Census Division (to NEMS PROPER)

- Natural gas wellhead prices by Oil and Gas Supply Model region (to NEMS REPORTS)

- Core and noncore natural gas prices by sector and Census Division (to NEMS PROPER)

- Dry natural gas production and supplemental gas supplies by Oil and Gas Supply Model region (NEMS REPORTS)

- Core and noncore (competitive with distillate and residual fuel oil) natural gas prices to electric generators

- by NGTDM/Electricity Market Model region (to Electricity Market Model)

- Dry natural gas production by Petroleum Administration for Defense Districts region (to Petroleum Market Model)

- Nonassociated dry.natural gas production by NGTDM/Oil and Gas Supply Model region (to Oil and Gas Supply Model)

- Canadian natural gas wellhead price and production (to Oil and Gas Supply Model)

- Natural gas imports and prices by border crossing (to Oil and Gas Supply Model)

\section{Internal Reports}

The NGTDM produces reports designed to assist in the detailed analysis of NGTDM model results. These reports include the following information: 
- Average natural gas wellhead price by NGTDM region

- Natural gas hub price at each tranśshipment node, by type of service .

- Natural gas distributor tariffs and markups by end-use sector, type of service, and NGTDM region

- Matrices of data describing interregional tranismission between NGTDM regions

- Flows of natural gas by type of service

- Maximum physical pipeline capacity

- Maximum annual pipeline capacity utilization

- Realized annual pipeline capacity utilization:

-. Peak period and off-peak period expected natural gas consumption levels by region and sector used in the Capacity Expansion Module

- Expected natural gas supply volumes as implied in the Capacity Expansion Module results; by Oil and Gas Supply Model region.

- Pipeline capacity expansion by arc

- Storage capacity expansion by region.

\section{External Reports}

In addition to the reports described above, the NGTDM produces external reports to support recurring publications. These reports contain the following information:

- Natural gas end-use prices and consumption levels by end-use sector, type of service (core and noncore), and Census Division (and for the United States)

- Natural gas weilhead prices and production levels by NGTDM region (and the average for the lower 48 United States)

- Natural gas end-use prices, margins, and revenues

- Natural gas import and expọit volumes and import prices

- Natural gas supply activity and prices by NGTDM region

$\because$ Pipeline fuel consumption by NGTDM region (and for the United States)

- Natural gas pipeline capacity (entering and exiting a region) by NGTDM region and by Census Division

- Natural gas pipeline capacity utilization (entering and exiting a region) by NGTDM region and Census Division

- Natural gas transmission and distribution revenues, activity levels, and unit costs

- Natural gas underground storage and pipeline capacity by NGTDM region

- Unaccounted for natural gas

90 Unaccounted for natural gas is a balancing item between the amount of natural gas consumed and the amount supplied. It includes reporting discrepancies, net storage withdrawals (in historical years), and differences due to convergence tolerance levels. 


\section{NGTDM Model Abstract}

Model Name:

Acronym:

Title:

Purpose: . The NGTDM is the component of the National Energy Modeling System (NEMS) that represents the mid-term natural gas market. The purpose of the NGTDM is to derive natural gas supply and end-use prices and flow patterns for movements of natural gas through the regional interstate network. The prices and flow patterns are derived by obtaining a market equilibrium across the three main components of the natural gas market: the supply component, the demand component, and the transmission and distribution network that links them.

Status: ACTTVE

Use: BASIC

Sponsor: - Office: Integrated Analysis and Forecasting

- Division: Energy Supply and Conversion

- Branch: Oil and Gas Analysis, EI-823

- Model Contact: Joe Benneche

- Telephone: (202) 586-6132

Documentation:

Energy Information Administration, Model Documentation of the Natural Gas Transmission and Distribution Model (NGTDM) of the National Energy Modeling System (NEMS), DOE/EIA-M062/1 (Washington, DC, December 1997).

Previous

Documentation:

Energy Information Administration, Model Documentation of the Natural Gas Transmission. and Distribution Model (NGTDM) of the National Energy Modeling System (NEMS), DOE/EIA-M062/1 (Washington, DC, December 1996).

Energy Information Administration; Model Documentation of the Natural Gas Transmission and Distribution Model (NGTDM) of the National Energy Modeling System (NEMS), DOE/EIA-M062/1 (Washington, DC, December 1995).

Energy Information Administration, Model Documentation, Natural Gas Transmission and Distribution Model (NGTDM).of the National Energy Modeling System, Volume II: Model Developer's Report, DOE/EIA-M062/2 (Washington, DC, January 1995).

Energy Information Administration, Model Documentation of the Natural Gas Transmission and Distribution Model (NGTDM) of the National Energy Modeling System (NEMS), DOE/EIA-MO62/1 (Washington, DC, February 1995). Energy Information Administration, Model Documentation of the Natural Gas'Transmission and Distribution Model (NGTDM) of the National Energy Modeling System (NEMS), DOE/EIA-M062/1 (Washington, DC, February 1994).

- Reviews Conducted: Paul R. Carpenter, PhD, Incentives Research, Inc. "Review of the Component Design Report Natural Gas Annual Flow Module (AFM) for the Natural Gas Transmission and Distribution Model (NGTDM) of the National Energy Modeling System.(NEMS)." Boston, MA, Aug 25, 1992. 
Paul R. Carpenter, PhD, Incentives Research, Inc. "Review of the Component Design Report Capacity Expansion Module (CEM) for the Natural Gas Transmission and Distribution Model (NGTDM) of the National Energy Modeling System (NEMS)." Boston, MA, Apr 30, 1993.

Paul R. Carpenter, PhD, Incentives Research, Inc. "Review of the Component Design Report Pipeline Tariff Module (PTM) for the Natural Gas Transmission and Distribution Model (NGTDM) of the National Energy Modeling System (NEMS)." Boston, MA, Apr 30, 1993.

Pail R. Carpenter, PhD, Incentives Research, Inc. "Review of the Component Design Report Distributor Tariff Module (DTM) for the Natural Gas Transmission and Distribution Model (NGTDM) of the National Energy Modeling System (NEMS)." Boston, MA, Apr 30, 1993.

Paul R. Carpenter, PhD, Incentives Research, Inc. "Final Review of the National Energy Modeling System (NEMS) Natural Gas Transmission and Distribution Model (NGTDM)." Bośton, MA, Jan 4, 1995.

Archive Tapes: - NEMS98-(Part of the National Energy Modeling System archive package as archived for the Aninual Energy Outlook 1998, DOE/EIA-0383(98)).

NEMS97-(Part of the National Energy Modeling System archive package as archived for the Annual Energy Outlook 1997, DOE/EIA-0383(97)).

NEMS96-(Part of the National Energy Modeling System archive package as archived for the Annual Energy Outlook 1996, DOE/EIA-0383(96)).

NEMS95-(Part of the National Energy Modeling System archive package as archived for the Annual Energy Outlook 1995, DOE/EIA-0383(95)).

NEMS94-(Part of the National Energy Modeling System archive package as archived for the Annual Energy Outlook 1994, DOE/EIA-0383(94)).

Energy System

Covered:

The NGTDM models the U.S. natural gas transmission and distribution network that links the suppliers (including importers) and consurmers of natural gas, and in so doing determines the regional market c̀learing natural gas end-use and supply (including border) prices.

Coverage: Geographic: Demand regions are the 12 NGTDM regions, which are based on the 9 Census Divisions with Census Division 5 split further into South Atlantic and Florida, Census Division 8 split further into Mountain and Arizona/New Mexico, and Census Division 9 split further into California and Pacific with Alaska and Hawaii handled separately.

Time Unit/Frequency: Annually through 2015 -

Product(s): Natural gas

Economic Sector(s): Residential, commercial, industrial, electric generators and transportation

Data Input Sources:

- National Oceanographic and Atmóspheric Administratiơn (NOAA)

(Non-DOE)

- Heating degree data

- The Potential for Natural Gas in the United States (National Petroleum Council, December, 1992)

- Pipeline capacity expansion cost estimates

- Federal Offshore Statistics, OCS Report, MMS/0068

- Offshore gas production and market values

- Canadian Energy Research Institute

- Canadian natural gas wellhead price and production 
- Alaska Department of Natural Resources

- State of Alaska historical and projected oil and gas consumption.

- Information Resources, Inc., "Octane Week" .

- Federal vehicle natural gas (VNG) taxes

- Data Resources Inc., U.S. Quarterly Model

- Yield on AA utility bonds

- Board of Governors of the Federal Reserve' System Statistical Release, "Selected . Interest Rates and Bond Prices" .

- Real average yield on 10 year U.S.S. govemment bonds

Data Input

Sources:

Forms and Publications:

(DOE)

- ElA-23, "Annual Survey of Domestic Oil and Gas Reserves"

- Annual estimate of gas reserves by type and State

- ElA-176, "Annual Report of Natural and Supplemental Gas Supply and Disposition"

- Annual natural gas sources of supply, consumption, and flows on the interstate pipeline network

-. EIA-860, "Annual Electric Generator Repoit"

- Electric generators plant type and code information, used in the classification of power plants as core or noncore customers. Data from this report are also used in the derivation of historical prices and markups for firm/interruptible service.

- EIA-767, "Steam-Electric Plant Operation and Design Report"

- Electric generators plant type and boiler information, by month, used in the classification of power plants as core or noncore customers. Data from this report are also used in the derivation of historical prices and markups for firm/interruptible service

- EIA-759, "Monthly Power Plant Report".

- Natural gas consumption by plant code and month, used in the classification of power plants as core or noncore customers. Data from this report are also used in the derivation of historical prices and markups for firm/interruptible service

- Rate case filings under Section 4 of the Natural Gas Policy Act, as submitted to FERC by each pipeline company

- Contract demand data and cost allocation by pipeline company

- Annual Energy Review, DOE/EIA-0384

- Gross domestic product and implicit price deflațor

- FERC Form 2, "Annual Report of Major Natural Gas Companies" .

- Financial statistics of major interstate natural gas pipelines

- Annual purchases/sales by pipeline (volume and price)

- FERC-567, "Annual Flow Diagram"

- Pipeline capacity and flow information

- Federal Energy Regulatory Commission (FERC)

- FERC Order 636 transition costs

- EIA-191, "Underground Gas Storage Report"

- Base gas and working gas storage capacity and monthly storage injection and withdrawal levels by region and pipeline company

- EIA-846, "Manufacturing Energy Consumption Survey"

- Base year average annual core industrial end-use prices

- Capacity and Service on the Interstate Natural Gas Pipeline System 1990, DOE/EIA-. 0556

- Pipeline capacity and capacity reservations by customer.

- Natural Gas Monthly, DOE/EIA-0130

- Base year historical quantity and price data

- Federal Energy Regulatory Commission, NGA Section 7(c) Filings, "Applications for Certification of Public Convenience and Necessity"

- planned pipeline capacity additions 
- Natural Gas Imports and Exports, Office of Fuels Programs, Office of Fossil Energy, Department of Energy

- Peak/offpeak parameters for natural gas imports and exports

- Altematives to Traditional Fuels, DOE/EOA-0585.

- - State taxes for natural gas consumed in vehicles.

- Natural Gas Issues and Trends 1994, DOE/EIA-0560(94), p. 117 - Long-term debt as a percent of invested capital

- Short-Term Energy Outlook, DOE/EIA-0131.

- National forecast targets for first two forecast years beyond history .

- . FERC Form 423, Cost and Quality of Fuels for Electric Utility Plants, DOEEIA. 0191.

- Natural gas prices to electric generators

Models and other:

$\because$ National Energy Modeling System (NEMS)

- Domestic supply, imports, and demand representations are provided as inputs to the NGTDM from other NEMS models

- Interstate Natural Gas Pipeline Data System (PIPENET)

- Inter-regional pipeline capacity

- Contract demand data.

General Output Descriptions:
- Average natural gas end-use prices levels by sector and region

- Average natural gas supply prices and production levels by region

- Pipeline fuel consumption by region

- Lease and plant fuel consumption by region

- Pipeline capacity additions and utilization levels by arc

- Storage capacity additions by region

Related Models: NEMS (part of)

Part of

Another Model: Yes, the National Energy Modeling System (NEMS).

Model Features: ,

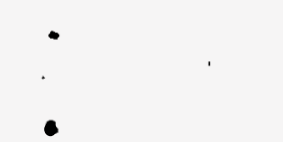

- Model Structure: Modular, four major components: the Annual Flow Module (AFM), the Capacity Expansion Module (CEM), the Pipeline Tariff Module (PTM), and the Distributor Tariff Module (DTM)

- AFM Integrating module of the NGTDM. Simulates the natural gas price determination process by bringing together all major economic and technological factors that influence regional natural gas trade in the United States .:

- CEM - Develops pipeline and storage facilities capacity and capacity expansion plans, and establishes effective maximum utilization rates for each pipeline route based on a seașonal analysis of supply and demand capability

- PTM Develops firm/intermuptible tariffs for transportation and storage services provided by interstate pipeline companies

- DTM Develops markups for distribution services provided by LDC's and intrastate pipeline companies.

- Modeling Technique:

- AFM Linear program

- CEM Linear program

- PTM Accounting algorithm

- DTM Empirical process 
- Special Features:

- Represents interregional flows of gas and pipeline capacity constraints

- Represents regional supplies.

- Represents different types of transmission service (firm and intermuptible)

- Determines the amount and the location of pipeline and storage facility capacity expansion on a regional basis

- Captures the economic tradeoffs between pipeline capacity additions and increases in regional storage capability

- Provides a peakJoff-peak, or seasonal analysis capability in the area of capacity expansion

- Distinguishes end-use customers by type (core and noncore).

Model Interfaces: NEMS

Computing

Environment:

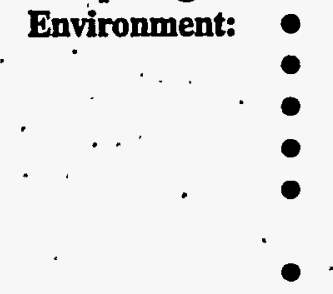

Status of

Evaluation Efforts:

Date of Last Update:
Hardware Used: RS/6000

Operating System: UNIX

Language/Software Used: FORTRAN

Memory Requirement: unknown

Storage Requirement: $444 \mathrm{~K}$ bytes for input data storage; $1162 \mathrm{~K}$ bytes for source code storage; and $9000 \mathrm{~K}$ bytes for compiled code storage

Estimated Run Time:

for CEM $2.7 \mathrm{CPU}$ seconds per forecast year

for AFM 1.0 CPU seconds per forecast year in 1st iteration :

$0.6 \mathrm{CPU}$ seconds per forecast year in subsequent iterations

Special Features: NGTDM uses a proprietary software package, Optimization and Modeling Library (OML) distributed by the Ketron Management Science Division of the Bionetics Corporation [Ketron, 1992]. This is a specially designed linear programming interface that is callable from FORTRAN.

Model developer's report entitled "Natural Gas Transmission and Distribution Model, Model Developer's Report for the National Energy Modeling System", dated November 14, 1994.

September 1997. 


\section{References}

American Gas Association, Introduction to the A.G.A-TERA Energy Modeling System (Arlington, VA, 1991).

Argonne National Laboratory, NES Environmental Assessment Model (NESEAM): ANL Technical Memorandum (1991b, forthcoming).

Barcella, Mary, "Natural Gas Distribution Cósts and Efficiency Implications for Regulation," as presented at 68th Annual WEA Conference, June 23, 1993.

Barcella, Mary, Chris Mamay, and G. Alan Comnes, "Wholesale and Retail Analysis for Estimating the Price Effect of Natural Gas Conservation," as presented at the Institute for Gas Technology conference on Energy Modeling in Atlanta, GA, April 3-5, 1995.

Beltramo, Mark, Alan S. Manne, and John P. Weyant, "A North American Gas Trade Model (GTM)," Energy Joumal, July 1986.

Blitzer, Charles, Final Report on Canadian-U.S. Natural Gas Trade (Cambridge, MA: MIT Center for Energy Policy Research, October 1985).

Carlton, Dennis W. and Perloff, Jeffrey M., Modern Industrial Organization (Scott, Foresman and Company, 1990).

Carpenter, Paul R., "Review of the Gas Analysis Modeling System (GAMS), Final Report of Findings and Recommendations" (Boston: Incentives Research, Inc., August 1991).

Decision Focus' Incorporate, Generalized Equilibrium Modeling: The Methodology of the SRI-GULF Energy Model (Palo Alto, CA, May 1977).

-Energy and Environmental Analysis, Guide to the Hydrocarbon Supply Model, 1990 Update (Arlington, VA, October 1990).

- Energy Information Administration,." Analytical Framework for a Natural Gas Transmission and Distribution Forecasting System," prepared by SAIC for the Analysis and Forecasting Branth within the Reserves and Natural Gas Division of the Office of Oil and Gas (Washington, DC, March 1991).

Energy Information Administration, 'Capacity and Service on the Interstate Natural Gas Pipeline System, 1990: Regional Profiles and Analyses, DOE/EIA-0556 (Washington, DC, June 1992).

Energy Information Administration, Coal Supply and Transportation Model (CSTM) Model Documentation, DOE/EIAM048 (Washington, DC, November 1991).

Energy Information Administration, Office of Integrated Analysis and Forecasting, "Component Design Report, Natural Gas Annual Flow Module for the Natural Gas Transmission and Distribution Model of the National Energy Modeling System". (Washington, DC, June 25, 1992).

Energy Information Administration, Documentation of the Gas Analysis Modeling System, DOE/EIA-M044(92) (Washington, DC, December 1991).

Energy Information Administration, Office of Integrated Analysis and Forecasting, "Component Design Report, Capacity Expansion Module for the Natural Gas Transmission and Distribution Model of the National Energy Modeling System" (Washington, DC, December 29, 1992).

Energy Införmation Administration, Office of Oil and Gas, "Effects of Interruptible Natural Gas Service: Winter 19891990," (Washington, DC, July 1991). 
Energy Information Administration, Office of Integrated Analysis and Forecasting, "Electricity Fuel Dispatch, Component Design Report,". Draft (Washington, DC, March 1992). •

Energy Information Administration, "An Evaluation of Problem Formulations and Mathematical Programming Software for the Gas Market Model of NEMS," Prepared by. SAIC for the Office of Integrated Analysis and Forecasting (Washington, DC, April 1992).

Energy Information Administration, Office of Integrated Analysis, and Forecasting, "Component Design Report, Natural Gas Annual Flow.Module for the Natural Gas Transmission and Distribution Model of the National Energy Modeling System" (Washington, DC, January 11, 1993).

Energy Information Administration, Office of Integrated Analysis and Forecasting, "Component Design Report, Pipeline - Tariff Module for the Natural Gas Transmission and Distribution Model of the National Energy Modeling System" (Washington, DC, December 29, 1992).

Energy Information Administration, Office of. Integrated Analysis and Forecasting, ."Electricity Fuel' Dispatch, Component Design Report, " Draft (Washington, DC, March 1992).

Energy Information Administration, Gasnet: Methodology Description, DOE/EIA-0103/10 (Washington, DC, August 1978).

Energy Information Administration, Growth in Unbundled Natural Gas Transportation Service: 1982-1987, DOE/EIA0525 (Washington, DC, May 1989).:

Energy Information Administration, Office of Integrated Analysis and Forecasting, "Electricity Fuel Dispatch, Component Design Report," Draft (Washington, DC, March 1992).

Energy Information Administration, Intermediate Future Forecasting. System, DOE/EIA-0430 (Washington, DC, October 1983).

Energy Information Administration, Inventory of Power Plants in the United States: 1990, DOE/ELA-0095(90) (Washington, DC, October 1991).

Energy Information Administration, Manufacturing Fuel-Switching Capability, DOE/EIA-0515(88) (Washington, DC, September 1991).

Energy Information Administration, Model Methodology and Data Description of the Production of Onshore Lower-48 Oil and Gas Model, DOE/EIA-M034(92) (Washington, DC, April 1992).

Energy Information Administration, Natural Gas 1992: Issues and Trends DOE/EIA-0560(92) (Washington, DC, March 1993).

Energy Information Administration, Natural Gas 1994: Issues and Trends DOE/EIA-0560(94) (Washington, DC, July 1994).

Energy Information Administration; Natural Gas 1995: Issues and Trends DOE/EIA-0560(95) (Washington, DC, November 1995).

Energy Information Administration, Office of Integrated Analysis and Forecasting, "Requirements for a National Energy Modeling System," (Working Paper) (Washington, DC, May 1992).

Energy Modeling Fonum, "North American Natural Gas Markets," EMF Report 9, Volume II (Palo Alto, CA: Stanford University, February 1989).

Forbes, Kevin, Science Applications International Corporation, "Efficiency in the Natural Gas Industry," Task 93-095 Deliverable under Contract No. DE-AC01-92-EI21944 for Natural Gas Analysis Branch of the Energy Information Administration, Jạnuary 31, 1995. 
Gartman, John A., Public Service Electric \& Gas Company, "Prepared Testimony Before the U.S. House of Representatives Subcommittee on Energy and Power" (Washington, DC, July 8, 1992).

Gas Research Institute, "Analysis of GRI North American Regional Gas Supply-Demand Model," North American Natural Gas Markets: Selected Technical Studies, EMF Report 9, Volume III (Palo Alto, CA, April 1989), pp. 191-194.

Gas Research Institute, North American Natural Gas Markets: Selected Technical Studies, "Analysis of GRI North American Regional Gas Supply-Demand Model," EMF Report 9, Volume III (Palo Alto, CA, April 1989), pp. 191-194.

Greene, William H., Econometric Analysis (New York: MacMillan, 1990).

Grenier, Edward J., Jr., "Restructuring añd the End User: Bumps in the New Road," Natural Gas, Vol. 8, No. 11., June 1992, pp. 5-7.

- Gujarati, Damodar, Basic Econometrics (MćGraw Hill).

Ketron Management Science, a Division of Bionetics Corporation, "MPSII Optimzation and Modeling Subroutine Library -- Drafț (Arlington, VA, November 1992).

Logistic Management Institute, The Integrating Model of the Project Independence Evaluation System, Volume II-Primer (Washington, DC, March 1979).

Neșbitt, Dale M., et. al., Decision Focus Incorporated, "Appendices for the GRì North American Regional Natural Gas Supply-Demand Model," prepared for Gerald Pine of Gas Research Institute (Los Altos, CA, February 1990).

U.S. Department of Energy, National Energy Strategy, First Edition 1991/1992 (Washington, DC, February 1991).

Wharton Econometric Forecasting Associattes, WEFA Natural Gas Service Long-Term Forecast (Bala Cynwyd, PA, Winter 1992). 


\section{NEMS Model Documentation Reports}

The National Energy Modeling System is documented in a series of 15 model documentation reports, most of which are updated on an annual basis. Copies of these reports are available by contacting the National Energy Information Center, 202/586-8800.

Energy Information Administration, National Energy Modeling System Integrating Module Documentation Report, DOE/EIA-M057.

Energy Information Administration, Model Documentation Report: Macroeconomic Activity Module of the National Energy Modeling System.

Energy Information Administration, Documentation of the D.R.I. Model of the U.S. Economy.

Energy Information Administration, National Energy Modeling System International Energy Model Documentation Report.

Energy Information Administration, World Oil Refining, Logistics, and Demand Model Documentation Report.

Energy Information Administration, Model Documentation Report: Residential Sector Demand Module of the National Energy Modeling System.

Energy Information Administration, Model Documentation Report: Commercial Sector Demand Module of the National Energy Modeling System.

Energy Information Administration, Model Documentation Report: Industrial Sector Demand Module of the National Energy Modeling System.

Energy Information Administration, Model Documentation Report: Transponation Sector Demand Module of the National Energy Modeling System.

Energy Information Administration, Documentation of the Electricity Market Module.

Energy Information Administration, Documentation of the Oil and Gas Supply Module.

Energy Information Administration, EIA Model Documentation: Petroleum Market Module of the National Energy. Modeling System.

Energy Information Administration, Model Documentation: Coal Market Module.

Energy Information Administration, Model Documentation Report: Renewable Fuels Module. 


\section{Alternative Modeling Approaches}

During the design phase of the NGTDM, a survey was conducted of models and modeling approaches being used throughout the industry to analyze and forecast natural gas transmission and distribution activities. These approaches, along with other general modeling approaches, were considered as possible candidates for the NGTDM design. For the AEO99 a project is underway to replace the Annual Flow Module and the Capacity Expansion Module with a single methodology that jointly performs the function of both. An approach that was up for consideration during the original design phases will be employed (based on the SRI-GULF allocation process). This appendix provides an overview of the methods and modeling techniques considered when the NGTDM was first developed. First, the modeling techniques employed in several different natural gas transmission and distribution models are reviewed. Second, modeling approaches used in models not specifically designed for natural gas transmission and distribution, but which could be applied to this area, are discussed. This Appendix concludes with a comparison of the modeling approaches presented.

\section{Other Natural Gas Transmission and Distribution Models}

The natural gas transmission and distribution industry is a segment of the complex natural gas production/delivery/demand system, and therefore. is usually modeled as part of a larger, overall modeling system. Because the market structure of the transmission and distribution industry is rapidly evolving; most representations developed in the past are no longer adequate. Several of the models reviewed have detailed supply and demand representations, with fairly simple mechanisms for linking the two. Others have-incorporated mechanisms for dealing with such issues as capacity expansion and the unbundling of transportation services, but none offers a comprehensive modeling treatment of the trarismission and distribution industry as a whole. Additionally, none of the models reviewed addresses the issue of the environmental impacts associated with the transmission and distribution of natural gas. It was ultimately decided that there were no models in existence that could be used either intact or as a base to begin with and modify for the development of the NGTDM. Although it would have been very difficult to develop a model that addresses all of the regulatory issues and complexities of the industry, the design of the NGTDM considered desirable features of all the modeling approaches reviewed, and the resultant model provides a more comprehensive analysis tool than any other models available. This section provides an overview of the other natural gas models that were considered.

\section{Gas Analysis Modeling System (GAMS)'}

EIA's previous model of the natural gas market is the Gas Analysis Modeling System (GAMS), a computer-based partial equilibrium model used to analyze the U.S. natural gas production/delivery/demand system. GAMS produces annual forecasts through 2010 of natural gas production, consumption, and prices. GAMS interacts with a separate supply component which represents the various available sources of natural gas supplies and separate demand components that represent natural gas consumption by end-use sector and Federal region. GAMS consists of a mechanism for representing the costs and losses associated with the transmission and distribution of natural gas and an iterative equilibration process that solves the entire system to determine the wellhead and end-use prices at which an overall supply/demand balance can be achieved. Although the model can be run in a stand-alone mode, it is primarily used as the natural gas module within the Intermediate Future Forecasting System (IFFS), ${ }^{92}$ a modeling system representing the. supply and demand response within all the primary U.S. energy markets. The GAMS demand representation is provided through IFFS by the Demand Modeling System (DEMS), for the non- electric generators demand sectors, and by the Electricity Market Model (EMM) for the electric generators sector. The representation of onshore Lower-48 natural gas production is provided through direct linkage with the Production of Onshore Lower-48 Oil and Gas Model

\footnotetext{
9'For complete documentation of GAMS, see Energy Information Administration, Documentation of the Gas Analysis Modeling System, DOE/EIA-M044(92) (Washington, DC, December 1991). .

${ }_{92}$ For more information on 'IFFS, see Energy Information Administration, Documentation of the lntegrating Module of the Intermediate Future Forecasting System, DOEIEIA-M023(91) (Washington, DC, May 1991).
} 
(PROLOG). ${ }^{93}$ Supply estimates for other sources of gas are either set exogenously or determined endogenously via additional supply submodules.

GAMS was developed in 1982 and 1983, when the complex system of price ceilings in effect under the Natural Gas Policy Act (NGPA) of 1978 covered both interstate and intrastate wellhead purchases of natural gas. The categorization of gas under the NGPA and the contractual nature of the natural gas market that existed at the time were primary factors in the early structure of the model. The laws and regulations concerning the natural gas market have changed rapidly in support of deregulation and increased competitiveness (for a detailed discussion on industry background, see Appendix C): The GAMS model has subsequently undergone a number of methodological changes, to represent the active spot market, the deregulation of wellhead gas prices, and the increase in competitive pressures throughout the industry.

In the original version of GAMS, a detailed pipeline network consisting of 17 pipeline systems was used to reconcile supply and demand in the market equilibration process. This network represented sales of gas from the wellhead, through pipelines, to distributors, and to end-users. Physical movement of gas through the system was not tracked, and pipeline capacities were not accounted for. Reserves were dedicated to the individual pipeline systems and drawn down, as produced, through an elaborate accounting mechanism that tracked gas by NGPA category and contract terms and conditions. The sales structure allowed for analysis of alternative wellhead contract pricing schemes and their effect on the natural gas market. In order to represent both the increased spot market activity and the growing competition within the marketplace, GAMS was subsequently modified to include a pool of spot or decontrolled gas available to all pipelines. Reserves were no longer treated as dedicated to individual pipelines. GAMS was also revised to reflect changes in producer contracts, with contracts treated as respondent to market conditions and new contracts excluding take-or-payst restrictions.

-As a result of increased competition and the unbundling of pipeline sales and transportation services, the cost-of-service representation of bundled rates originally used to represent tariffs within GAMS was no longer representative of the market. The tariff component in GAMS was replaced with a simple mechanism that calculates end-use prices by adding exogenously determined regional transmission and end-use distribution costs (which are fixed throughout the forecast) to the national average wellhead price. Competition was represented by allowing these costs to be discounted in the -industrial and electric generators sectors. As pricing distinctions responsive to market conditions between different levels of transmission and distribution service developed, the different levels of service were represented by expanding the level of electric generators sector detail. The electricity market module (EMM) provides demand curves to GAMS in the form of step functions defined by a set of price/quantity pairs. The steps on the curves simulate the effect of large-scale fuel switching and changes in the plant dispatching order by electric utilities. To model the price variation associated with different levels of service, these demand curves were redefined to represent three categories of electric generator plant types as follows: (1) core customers assumed to purchase firm service and pay the highest rates; (2) noncore customers assumed to purchase interruptible service and pay lower rates, and (3) customers with fuel switching capabilities sometimes offered discounted rates based on competing fuel prices. In contrast to the detailed electric generators demand representation, each regional demand curve provided to GAMS by DEMS for the non- electric generators sectors is defined simply by a unique reference price/quantity pair and an associated elasticity.

Transmission/distribution losses and pipeline fuel use are taken into account within GAMS during the supply/demand equilibration process by applying factors based on historical data to total throughput. The equilibrating process includes the following steps: (1) estimating a national wellhead price (the initial estimate is the previous year's solution price, and subsequent estimates are based on the previous iteration's price), (2) adding appropriate markups (representing transmission and distribution tariffs) to arrive at regional/sectoral end-use prices, (3) evaluating end-use consumption levels at these prices using the appropriate demand curves, (4) summing these consumption levels and adding losses to arrive at the amount which would be demanded at the wellhead given the estimated wellhead price, and (5) comparing this aggregate consumption (plus-losses) to the level (provided by PROLOG) that would be supplied given the estimated wellhead price. If the calculated copsumption is not within a specified tolerance of the corresponding supply level, a new wellhead price is estimated and the process is repeated until convergence is achieved.

\footnotetext{
${ }_{93}$ For more information on PROLOG, see Energy Information Administration, "Model Methodology and Data Description of the Production of Onshore Lower-48 Oil and Gas Model," DOE/EIA-M034(91) (Washington, DC, Apnil 1991).

-Take-or-pay contract restrictions required a pipeline to pay for the specified quantity of gas whether or not it could be resold.
} 


\section{Data Résources, Inc. (DRI)}

The DRI natural gas market analysis is done in conjunction with an overall analysis of the enitire U.S. energy sector. The principal models used are short-term natural gas spot price and demand models, a longer term U.S. and regional energy model (which has detailed sectoral demand submodels), and a U.S. oil and gas drilling/production model. Annual forecasts through 2010 are provided for 11 regions based'on Census regions and subdivisions of Census regions.

The DRI modeling system uses an iterative process (based on achieving a wellhead price/residual fuel oil price ratio that is deemed to reflect accurately free-market supply/demand influences) which determines average regional wellhead gas acquisition prices and then applies region- and sector-specific markups to arrive at end-use prices. Average natural gas prices are projected for U.S. domestic wellhead gas (based on spot, contract, and regulation-influenced gas prices) and for Canadian and LNG imports. These prices are then combined into regional "acquisition" prices, based on the varying volume weights of each gas source in the region. Region- and sector-specific markups are then applied to each region's average acquisition cost to arrive at each sector's end-use price for the region. The markups are intended to capture the transmission, distribution, and other delivery costs for each sector in each region. The markups are based on historical -EIA data. Thus interstate pipeline transmission rates are not separately and specifically estimated, but rather, are rolled in with local distribution and other charges into the overall retail markups. Growth in price markups is assumed to increase at the rate of inflation, as determined by the GNP deflator. Pipeline capacity constraints and capacity expansion issues are not addressed in the model.

\section{Wharton Econometric Forecasting Associates (WEFA) ${ }^{96}$}

WEFA models the transmission/distribution of natural gas by means of a supply/transportation model within its Natural Gas Modeling System. The North American natural gas market is defined as a collection of many markets (i6 hubs) which trade gas both intra-regionally (within hubs) and inter-regionally (between hubs). Markets may be defined geographically, by type of transaction (spot or contract), by quality of service (interruptible or firm), and by season (heating or nonheating). The model is implemented as a spreadsheet that determines the production and consumption in each market and the volume of gas transported between markets and between seasons (storage), using a heuristic algorithm to solve iteratively for a set of prices actoss regions, seasons, and time periods that achieves a market balance. Annual forecasts are provided through 2020 for natural gas production and wellhead prices in 13 domestic supply.basins, and for flows, capacity utilization, transportation costs, and required capacity expansion along the ares connecting the 16 hubs.

Three key assumptions are made as follows:

- Producers maximize profits and consumers minimize costs, subject to demand requirements and capacity constraints

- Pipeline transportation and storage rates are a function of regulation, and capacity expansion only takes place if it is economic (i.e., if the marginal cost of expansion is less than the marginal price that consumers are willing to pay for the additional gas)

- Prices are permitted to adjust freely to clear all markets simultaneously;

Initial estimates of regional, end-use gas requirements are determined from econometric models for the non- electric generators sectors and from regional load dispatch models for the electric generators sector. The demand is then assigned to the different supply regions based on initial market shares. Initial estimates of regional/sectoral prices are also used. Actual prices are then determined, and the relevant demands adjusted via price elasticities for subsequent iterations. Transportation tariffs are initialized assuming a load factor of 85 percent, but may be discounted if the actual utilization is less.

\footnotetext{
9s The most current documentation on DRI's model was written in 1984 and is out of date. A brief report entitled "Natural Gas Forecasting Methodology" provided by Margaret Rhodes of DRI was used for a more accurate description of their current methodology.

The WEFA model is used for internal forecasts only, and thus full documentation does not exist. Information on their current methodology was obtained from a brief methodology description in the WEFA Natural Gas Service Long-Term Forecast (Bala Cynwyd, PA, Winter 1992) and from telephone conversations with Morris Greenberg of WEFA.
} 
Consumption is disaggregated into heating and nonheating seasons, and further disaggregated by users with and without fuel switching capability. Consumers have the flexibility of selecting alternative supply sources. Gas can be transported from regions linked by the pipeline network or withdrawn from storage, both subject to available capacity. Any gas withdrawn from storage during a heating season is replaced during.the following nonheating season. Consumers adjust . supply sources to minimize costs, given the price of gas in the source region and the transportation (or storage) rate, including fuel and loss. Transportation rates are determined assuming competitive conditions, and rates on routes with excess capacity can be discounted down to variable costs. Alternatively, if pipeline capacity on a given route is constrained, rates may be adjusted upward in the solution process to the point where they exceed the regulated . - transportation ceiling rate in order to clear the market. In this case, if the marginal value of the expansion, as measured by current and future price differentials and utilization rates; exceeds its marginal cost, capacity is expanded. If such expansion does not occur, transportation-constrained sources will lose market share to unconstrained routes.

Throughout the solution process, prices are adjusted to reduce excesses of supply or demand in any or all regions/seasons/time periods. The process is repeated iteratively until market-clearing prices are determined. Convergence is achieved when the following conditions are met:

- Excess supply/demand is zero in each market

- The delivered cost of gas to each region is the same for every active route .

- Pipeline capacity utilization is less than or equal to 100 percent on every route

- The marginal value of transportation on each route is less than or equal to the marginal cost of expansion.

\section{American Gas Association (AGA)}

Natural gas modeling at the American Gas Association is done within the framework of the American Gas Association's Total Energy Resource Analysis model (A.G.A.-TERA). The TERA modeling system provides annual projections through 2010 of natural gas production, consumption, and prices; with projections for the residential, commercial, industrial, and electric generators end-use sectors provided for the nine Census Regions. The àpproach is a heuristic one that simulates the market and does not assume optimization of either policy or market behavior. The equilibration process involves the interaction of three components: (1) a set of drilling models, (2) a demand/marketplace model, and (3) a deliverability model. The drilling models and the demand/marketplace model provide inputs for the deliverability model, but there is not an automated feedback loop from the deliverability model to the drilling and demand/marketplace models. Analyst intervention is often necessary to equilibrate the market via adjustments in the trial wellhead prices.

The models treat the natural gas transmission and distribution segment of the industry very.simply. 'Flows are not explicitly represented, and capacity constraint/expansion issues are not treated. The prices of natural gas to consumers are calculated as linear functions of the wellhead price via ordinary least squares regression in order to reflect the combination of supply-related costs and transmission and delivery-related costs.

\section{Gas Research Institute (GRI) Energy Overview Model (EOM)}

In producing its yearly Baseline Energy Forecast, the Gas Research Institute (GRI) uses a model known as the Energy Overview Model (EOM). The transmission and distribution segment of the natural gas industry is represented by a separate model, the National Pipeline/Flowing Gas Model developed by Energy and Environmental Analysis, Incorporated (EEA). The EEA model is a simulation model that represents the U.S. pipeline system by means of 12 composite pipeline groups, which are aggregates of actual pipeline systems chosen to represent the major differences in gas supply areas serving the 10 Federal regions. The network has recently been expanded to include the entire North American gas market (including both Canada and Mexico). Each pipeline group has its ọwn inventory of gas reserves, access to one or more of 15 supply regions (as represented in the GRI Hydrocarbon Supply Model), and an individual

\footnotetext{
IIntroduction to the A.G.A-TERA Energy Modeling System, American Gas Association (Arlington, VA, 1991), provides a very general overview of the overall model; phone conversations with Leon Tucker of the A.G.A. provided specifics on the handling of transmission and distribution.

${ }^{9}$ Guide 10 the Hydrocarbon Supply Model, 1990 Update, Energy anid Environmental Analysis, Inc. (Arlington, VA, October 1990) and conversations with EEA and GRI staff.
} 
cost of service estimate for pipeline operations. The EEA model is integrated with the EOM, and thus flows are considered in the market equilibration process. Nonlinear optimization is used to minimize costs subject to supply and demand constraints.

The pipeline model simulates pipelines in their role as both merchants and transporters of gas. Transportation services are provided to distributors and end-users under a mix of rates based on the quality of service. Rates are based on costof-service with the flexibility for rate discounting caused by market pressures. An accounting system tracks both committed gas supplies under long-term contracts with pipelines and uncommitted supplies being marketed by producers and sold on the spot market. Associated with committed supplies are detailed contract terms and conditions.

The model represents the distribution of supply from the city gate to end-users by means of an aggregate local distribution company (LDC) in each demand region. Revenue requirement accounts are maintained for each $L D C$ to set distribution margins by end-use sector, with margins and burnertip gas prices differing by demand region. LDCs themselves offer end-users both sales service and transportation of gas purchased on the spot market.

Seasonal transmission charges for each pipeline group and distribution charges for the LDC in each Federal region are estimated by the model based on cost-of-service estimates. The charges are then allocated to the services provided by the distributor or pipeline. Market pressures and regulatory structures determine the extent to which those charges recover gas transmission and distribution costs. A cost-of-service algorithm estimates year-to-year changes in the overall nongas costs of pipeline operations so as to take into account the response of the costs to changes in system throughput, compression costs (which change with volume and cost of gas), rate base, and the cost of capital. After determining the cost of service for each pipeline group, the model allocates these costs between the sales and transportation services offered to customers based on the mix of each pipeline's merchant and transport services. After allocating costs, the model pipelines establish a structure of differential rates for the various classes of service. The transmission margin included in pipeline resale rates is assigned on a fully allocated basis, meaning that the costs allocated to this service will be fully recovered in providing the service. Pipelines also maintain separate firm and interruptible rates applicable to transportation. Competitive forces and market pressures may prevent pipelines from fully recovering costs for interruptible service. The model allows margins on transportation to distributors to be reduced below full cost.recovery to represent the potential discounting pressures on pipeline supplies caused by interpipeline competition. Costs not recovered due to discounting are reported.

The EEA model has recently been updated to include a detailed representation of capacity expansion in support of an ongoing National Petroleum Council (NPC) study. ${ }^{99}$ The model takes into account both planned expansion and other future expansion. An input data file describes planned projects for the next 5 years, including their construction costs. For projects beyond the 5-year time horizon, the same data file contains "generic" projects that can be undertaken if it is economic to do so. Data for these generic projects include cost estimates on a dollars per thousand cubic feet/mile (where mileage figure represents miles that the gas is actually moved). Cost data are determined by using a cost algorithm that reflects today's capacity addition costs. Three sets of cost algorithms are employed: one for the Lower 48 States, one for Canada, and one for frontier areas where expansion is costly. Regional differences in construction costs are not captured. Costs are determined for three types of possible expansion: compression only, looping and compression combined, and construction of new pipe. Potential future projects are set up throughout the system as though they were real ones. Thus the model sees what is analogous to a supply curve.for capacity additions at each node. The steps on the "supply" curve are analogous to the amount of each of the three types of expansion possible at that point in the system. The data allow for expansion everywhere in the system, with those areas deemed most likely to have more expansion activity provided higher bounds on the amount of expansion possible.

In solving for capacity expansion, the model begins each forecast year with an estimate of new capacity that would be needed to meet the demands for that year. Each potential new pipeline link has a supply source with an associated volume and price elasticity, and a demand at its destination. The model takes into account how much the supply price would be raised at the source due to the added volume, and how much the demand would be depressed as a result of the associated higher prices. Capacity to be added is controlled by the criteria that any added capacity must be able to operate at a minimum of an 80-percent load factor. New links compete against alternate supply sources and each pther - capacity will not be added if there is a cheaper alternative for meeting demand. New costs are compared against

\footnotetext{
The enhanced treatment of capacity expansion in the EEA Pipeline/Flowing Gas Model has not as yet been documented. The above information was provided through conversations with Robert Crawford of EEA.
} 
the cost of adding capacity. The cost of the added capacity must be less than the price differential on competing links, and the throughput high enough (at least 80 percent) in order for capacity to be added.

Storage is considered to be a supply source during the winter months and a demand source during the summer months. Storage expansion is not endogenously determined. Offline scenarios are run to determine how much storage capacity would increase, and storage is fixed within any given model run. The offline analysis to determine storage expansion is an iterative process in which estimates of expected increases in storage are made, the model is run and results analyzed, estimates are revised and the model rerun until analyst judgment indicates a satisfactory estimate of future storage expansion.

\section{Decision Focus, Inc. (DFI) North American Regional Gas Model (NARG) ${ }^{100,107}$}

Decision Focus, Inc. has developed a multiregion Samuelson spatial equilibrium model used by the Gas Research Institute (GRI) for sensitivity analyses. This model is referred to as the GRI North American Regional Natural Gas Supply-Demand Model.

The model represents approximately 150 distinct gas supply sources in the United States and Canada. Fifteen demand regions are represented, 3 in Canada and 12 in the United States (based on disaggregations of the census regions), with" distinctions within each demand region between core and noncore markets. ${ }^{102}$ In the United States, all of the residential and commercial and half of the industrial demand are assumed to be core, while the balance of the industrial and all of the electric generators demand are assumed to be noncore.

The model's representation of the North American pipeline system includes:

- A comprehensive pipeline network consisting of current and potential future pipeline links from supply regions to demand regions

- Tariffs and losses for each pipeline link.

The degree of pipeline detail is consistent with the degree of supply and demand detail elsewhere in the model. In particular, while the model could have been designed to enumerate and distinguish every individual pipeline in the United States, its developers instead sought commonalities among supply regions, pipelines, and demand regions that would allow aggregation. Rather than representing individual pipelines, the model instead represents pipeline corridors from its supply regions to its demand regions. These corridors are explicitly defined by the characterization of the model's supply and demand regions, and by the configuration of the U.S. and Canadian pipeline systems that exist today. Each of the existing pipeline corridors represented in the model begins in a given supply region, extends perhaps through intermediate supply and demand regions, and terminates in a demand region. The network of existing pipeline corridors interconnects all currently producing regions with all currently consuming regions.

The model also enumerates all prospective future pipelines that might be built in the next 50 years. These pipelines connect new producing regions (or subregions) with various demand regions, and connect Canada and Mexico to the United States. They are truly prospective in the sense that they will be built only if they become economic (i.e., only if supplies at the upstream end, marked up to account for the cost of the new pipelines, constitute the most competitive source at the downstream end). In the model, looping is considered as an option for all existing capacity, as well as for the existing links of the new corridors.

The linkage between Canada and the United States is potentially very important. The model therefore distinguishes the pipelines in Canada that directly or indirectly lead to the Lower 48 United States. The model also includes two

\footnotetext{
${ }^{100}$ Dale M. Nesbitt et. al., "Analysis of GRI North American Regional Gas Supply-Demand Model", in North American Natural Gas Markets: Selected Technical Studies, Energy Modeling Forum (EMF) Report 9, Volume III, pp. 185-234 (Stanford University, April 1989).

- ${ }^{101}$ Dale M. Nesbitt et. al (DF), "Appendices for the GRI North American Regional Natural Gas Supply-Demand Model," prepared for Geraid Pine (GRI), February 1990.

${ }^{102}$ The core service customer is guaranteed service (i.e., is assumed to purchase firm service) and generally pays the highest rate for natural gas. The noncore customers consume gas under a less certain and/or less continuous basis (i.e., an interruptible basis) and typically are offered a lower rate than the core customers:
} 
prospective Canadian export routes to the United States. Orie of these routes runs from North Alaska through Alberta and ultimately to the United States, and represents the upstream leg of the Alaska Natural Gas Transportation System. The other runs from Northern Canada (MacKenzie and Beaufort Sea), through Alberta, and ultimately to the United States, and represents the pipeline that will have to be built in order to exploit Canadian Arctic gas (the Polar project and prospective expansions).

The current version of the model contains corridor capacity estimates prepared by Benjamin Schlesinger and Associates (BSA, under contract to the California Energy Commission). BSA also provided appropriate corridor transmission costs, which represent the embedded cost of each pipeline and specifically account for discounting behavior on the part of pipeline owners. Pipeline capacities and cost structures for all Canadian pipelines are based on data from the National Energy Board of Canada.

Several generic types of pipeline capacity expansion are explicitly represented (for each pipeline link) within the model:

- Expansion of capacity of a given pipeline by such actions as looping or increasing pressure

- Expansion of capacity along a given corridor by adding a new pipeline

- Addition of an entirely new pipeline corridor.

For each pipeline link, the model assumes that the embedded cost of the capacity currently in place will affect the rates for quantities of gas transported that do not exceed the current known capacity. In order to transport more gas than the current capacity of the corridor, it is necessary to augment the capacity through looping or pressure increases. Such augmentation is possible (at a cost) and is usually bounded by an upper constraint (i.e., looping and pressure increases can each add only a limited quantity of additional capacity). In order to exceed the capacity of an existing, fully looped, maximum pressure pipeline link, it is necessary to add new pipeline capacity. At the incremental cost of securing appropriate rights of way and building such a pipeline, it is possible to expand the capacity of that corridor virtually without bound.

The model thus requires current transportation cost information, capacity expansion costs through augmentation, and new capacity addition costs. For the current version of the model, such data (for every existing and prospective future corridor) were provided by BSA under contract to the California Energy Commission.

\section{Stanford University North American Gas Trade Model. (GTM) ${ }^{103}$}

The North.American Gas Trade Model (GTM) developed at Stanford University in conjunction with the Stanford University International Energy Project is an interregional natural gas trade partial equilibrium model which computes, for 2 single time periods (1990 and 2000), market clearing prices and a possible pattern of trade flows between 11 supply and 14 demand regions in the United States, Mexico, and Canada. Demands within the United States are provided for each of four consuming sectors (residential, commercial, industrial, and electric generators). Key inputs to the model include:

- The regional distribution of gas supplies and demands at alternate price levels

- Transportation charges .

- Pipeline capacity constraints

- Canadian and Mexican export quantity limits.

In some regions, prices are free to move so as to equilibrate supplies and demands, while in others there may be disequilibria associated with controls over prices and/or quantities traded. The objective of the solution process is to maximize the sums of producers' and consumers' surpluses, or, alternatively, maximize the sum of consumers' benefits minus the costs of production and transportation. With the exception of the nonlinearity of the objective function, the GTM is a straightforward transportation model. The model is solved using MINOS, a nonlinear programming computer package.

\footnotetext{
${ }^{103}$ Mark A. Beltramo, Alan S. Manne, and John P. Weyant, "A North American Gas Trade Model (GTM)," Energy Joumal, July
} 1986, pp. 15-32. 
Economic policy and technical constraints are handled as upper or lower bounds on objective function variables. For example, pipeline capacity limits are represented as upper bounds on the transportation variables, and take-or-pay contract limits are represented as lower bounds. The user can specify limits on certain demands or export volumes, which allows the simulation of export and price controls. Taxes or subsidies on individual supplies or demands can be similarly represented by constraints on individual supply and demand variables. Each of these conditions is represented as an upper or lower bound on an individual variable.

The objective function contains linear cost coefficients related to the transportation variables. Supply and demand variables enter in a separable nonlinear form. A market equilibrium is computed by maximizing the objective function . subject to supply and demand constraints and upper and lower bounds on individual variables. If supply and demand are unconstrained, the shadow prices will be the marginal costs of production or the price consumers are willing to pay. This information can aid the analyst in making decisions (e.g., whether to expand production or increase capacity).

\section{Massachusetts Institute of Technology (MIT) Center for Energy Policy Research ${ }^{104}$}

The Center for Eniergy Policy Research Energy Laboratory at MIT has developed a North American natural gas trade model as part of a project on international gas issues. The primary purpose of the model is to estimate the costs and benefits to Canada and Canadian firms of aiternative gas production and export programs. While it is an interregional trade equilibrium model similar in concept to the Gas Trade Model (GTM) described above, it has been formulated as a linear, rather than a nonlinear, programming problem. The model solves for exports to the United States and investment and production in each Canadian supply area, reporting additional information including marginal costs of production, export prices, marginal export revenues, capital rental charges, resource depletion costs, etc. The model includes nine different pools of Canadian reserves and three gas markets within the United States: West Coast, Middle West, and North East.

Constraints involve supply/demand balances, production-reserve relationships, production-investment relationships, export delivery patterns, pipeline capacity constraints, and export revenues. Demand functions are represented by piecewise linear approximations. Pipeline capacity is input exogenously. Investment in capacity expansion, although incorporated in annual capital costs, is not, however, endogenously determined. Pipeline operating costs are handled as linear functions of export volumes based on operating cost coefficients.

The model can be solved using any one of three objective functions:

- Maximize net benefits to Canada as a whole

- Maximize the sum of net benefits to Canada and to U.S. importers of Canadian gas

- Simulate competitive profit maximizing behavior among Canadian producers, inclusive of royalties.

The second objective function seeks to determine the perfectly competitive solution, in effect maximizing net benefits to Canada (producers' surplus) and net benefits to the United States (consumers' surplus).

\section{Energy Information Administration Gasnet Moder105}

The Gasnet model is an optimization model, developed by ElA in the late 1970's to forecast short-term seasonal patterns of natural gas distribution given predetermined projections of both supply and demand for natural gas. Although no longer in use within EIA, the Gasnet model was reviewed in doing background research for development of the NGTDM as it explicitly represents a pipeline network, using a series of constrained optimization techniques to simulate the transmission pattern within the natural gas industry. Gasnet provides summary tables listing quarterly estimates of natural gas supply by State and consumption and excess demand by State for the residential, commercial, industrial, and electric generators sectors.

${ }^{104}$ Charles Blitzer, "A North American Natural Gas Model: Part I," Final Report on Canadian-U.S. Natural Gas Trade, (Cambridge, MA: MiT Center for Energy Policy Research October 1985).

${ }^{105}$ Energy Information Administration, Gasriet: Methodology Description (Washington, DC, August 1978) 
On the demand side, 48 States; the District of Columbia, Mexico, and 5 Canadian provinces are represented. On the supply side, there are 45 producing areas located in the 26 producing U.S. States and 4 Canadian provinces. Four of the producing States are divided into substate regions. Five major interstate pipeline activities are represented in the model: (1) selling gas to end-users, (2) receiving produced gas, (3) injecting or withdrawing gas from storage, (4) exchanging gas with other pipeline companies, and (5) transmitting their own gas volume to other States. Within the model, various nodes are interconnected by ares. Each node is associated with one or more of the five major activities described above.

The model connects the demand regions and supply areas to estimate the sectoral effects of natural gas shortages. The model represents each pipeline. by a system of interconnected nodes allowing the calculation of interstate flows along a pipeline system. A separate module, the Historical Apportionment Model (HAM), computes the distribution of the forecasted gas production through the network on the basis of the historical relative flows (i.e., the pattern determined from the base year data). The HAM model solution provides a base case for the final phase of the modeling process: the linear program. The linear program minimizes the deviations of gas from the desired storage goals, the sum of excess demands and supplies by consuming sector in each State, and the costs of operation for the transmission of gas throughout the entire network, subject to the following constraints:

- Mass balance at each node

- Regional gas production equation for each region

- Balance of supply and demand over all States and demand sectors.

\section{Solution Methods for Solving Network Flows}

In developing the methodology for the NGTDM, a number of modeling techniques were evaluated other than those employed in natural gas models. In particular, specific mathematical formulations and solution techniques, such as linear programming (LP), mixed integer programming (MIP), special ordered sets (SOS), and nonlinear programming were considered. ${ }^{106}$ In addition to the specific natural gas models discussed above, the following models were reviewed because they employ techniques that were considered for use in the NGTDM.

\section{Energy Information Administration Project Independence Evaluation System (PIES) $^{107}$}

The PIES model, developed in the mid-1970's, was EIA's first large scale energy forecasting model. The PIES framework consists of three major components: a demand model, a supply network, and an equilibrating mechanism.

The PIES supply network is composed of production, conversion, and transportation activities. They are linked by means of a distribution network that represents the movement of raw materials or products. The major economic assumption implicit in the PIES structure is that market equilibrium conditions govern the purchase prices and quantities of fuels so that the sum of consumers' and producers' surplus is maximized across all regions and all energy industry sectors, subject to the constrained market conditions introduced by government regulation.

The following assumptions are made: (1) subject to regulatory constraints, participants in the economy act in their own self-interest, (2) consumers are rational and maximize their benefits, and (3) producers maximize profits. A linear programming formulation is used, incorporating step-like approximations to the supply and demand curves.

\footnotetext{
${ }^{106}$ For further information on formulations, see "An Evaluation of Problem Formulations and Mathematical Programming Software for the Gas Market Model of NEMS," Science Applications International Corporation (McLean, VA, April 1992).

${ }^{10}$ The Integrating Model of the Project Independence Evaluation System, Volume I - Executive Summary, Logistics Management Institute (Washington, DC, April 1979).
} 


\section{Stanford Research Institute SRI-GULF Energy Model'108}

The Stanford Research Institute's SRI-Gulf Energy Model is a highly-detailed regional, dynamic model of the supply and demand for energy in the United States. It was developed in 1973 to analyze synthetic fuels strategy for the Gulf Oil Corporation and has subsequently been extended and widely used in other energy analyses. It employs a generalized equilibrium modeling methodology which represents a synthesis of several modeling techniques. The conceptual framework of generalized equilibrium modeling emphasizes: (1) the need to focus modeling efforts on decisions and (2) the coordinated decomposition of complex decision problems using iterative methods. A decision problem is first conceptualized, and then decomposed to define the basic decision and physical processes that must be included in the modeling process. The overall model is then implemented using the following three basic elements of generalized equilibrium modeling: (1) processes describing the fundamental submodels, (2) a network describing the interactions among the processes, and (3) an algorithm for determining the numerical values of the variables in the model.

In the SRI-GULF model, 17 end-use demands are modeled for each of the 9 U.S. Census Divisions through 2025. Approximately 2700 processes are represented, with processes that describe end-use demands for energy and primary resource supply linked by a network of other processes describing market behavior, conversion, and transportation. The algorithm used to solve the model finds the set of variables (primarily prices and quantities) that satisfy the physical and behavioral relations embodied in the processes and the linkages among the variables as defined by the network.

Although the model involves hundreds of distinct processes, each can be implemented as one of a few basic processes which consist of: (1) simple conversion processes, (2) allocation processes,' (3) primary resource processes; (4) end-use demand processes, (5) transportation processes, (6) complex conversion processes, and (7) secondary industry processes. The main process of interest in the SRI-Gulf model is the allocation process, which allocates the demand for a fuel among the competing sources of supply. The allocation process used in the model is a dynamic process that responds continuously to changes in price. The sharing method is represented in terms of simple market share curves and simple market penetration (behavioral lag) curves that reflect lags or time delays in responding to price changes. This is preferable to an allocation process that responds sharply to small differences in prices (as would be the case if demand were allocated entirely to the lowest price source), as the latter tends to overstate the market response to prices. .

\section{Conclusions}

This section consists of two subsections. The first compares the NGTDM with EIA's former modeling system, GAMS, as one of the main goals of the design of the NGTDM was to address the weaknesses of the GAMS in modeling the current natural gas industry and provide EIA with a more effective modeling tool. The second section compares the NGTDM with the other modeling approaches considered, detailing which aspects of each approach were included and why each particular model or approach was, or was not, adopted for the NGTDM.

\section{Comparison of Capabilities of GAMS to the NGTDM}

GAMS has a number of limitations that precluded its use within the NEMS. The NGTDM was designed to address these limitations. As indicated in the Model Quality Audit review of GAMS performed for the Office of Statistical Standards, ${ }^{109}$ one of the major limitations of GAMS was that it does not take into account significant regional differences in both supply availability and pricing. "When GAMS was first modified to explicitly treat deregulated gas, a simple structure was included to represent a single national pool of deregulated gas. This national representation of deregulated gas means that GAMS does not fully account for regional supply distinctions on the overall market. The NGTDM represents both supply availability and price levels for all supply sources by region.

\footnotetext{
${ }^{100}$ Generalized Equilibrium Modeling: The Methodology of the SRI-Gulf Energy Model, Decision Focus, Incorporated (Palo Alto, CA, May 1977).

${ }^{109}$ Carpenter, Paul R., "Review of the Gas Analysis Modeling System," Incentives Research Inc. (Boston, MA, August, 1991). (Also contained in Appendix B of the GAMS Model Quality Audit.)
} 
Another drawback to GAMS is that it does not include a representation of the physical flow of gas, and thus can not be used to analyze pipeline capacity issues. The assumption was made during the initial development of the model that sufficient capacity would exist to satisfy demand, and therefore neither capacity constraints nor future capacity expansion issues were considered. In reality, there are significant differences across regions in capacity utilization, with very heavy utilization occurring in certain sections of the country (specifically the West and Northeast): ${ }^{110}$ One of the key determinants of how pipelines will price services in the future will be how intensely their systems are utilized. To represent this, a treatment of both capacity constraints and capacity expansion (pipeline and storage) decisions is necessary. These issues are addressed by a separate Capacity Expansion Module within the NGTDM. Flows are accounted for in the Annual Flow Module (AFM) by incorporating an aggregate representation of the natural gas transmission and distribution network. This allows a more comprehensive analysis of the results of supply and demand shifts on capacities and flow patterns, as well as a more representative analysis of the pricing of natural gas transmission. and distribution services.

Also key to the pricing of natural gas transmission and distribution services is the representation of tariffs. While the GAMS representation of tariffs via markups based on fixed historical levels reflects both transmission and local distribution costs, the representation is simplistic and can not be easily adapted to reflect future market conditions. While pipelines and distributors formerly could be assumed to price strictly on the basis of their average cost of service, they are now offering a full range of services under competitive and market-based pricing arrangements. Although not totally deregulated, they have considerable pricing flexibility. The GAMS structure does not reflect this, and thus does not permit regulatory analysis of pricing issues. Tariffs in the NGTDM are endogenously determined along different segments of the physical pipeline system, with separate modules to model tariffs for pipeline and distributor services. The NGTDM also represents differences in pricing various classes of service more adequately than GAMS. GAMS applies the class-of-service pricing distinction only to the electric generators sector. Many industrial sector and large commercial sector users are also taking advantage of the lower prices associated with interruptible service, which is available to all customers. The NGTDM has the capability of distinguishing customers by type of service in all end-use sectors. Cost-based, average pricing is applied to core customers (firm service) within each sector and market-based, marginal pricing is applied to noncore customers (interruptible service).

There are two final areas not addressed in GAMS. The first is that of environmental impacts, which has become an area of considerable importance as a result of the Clean Air Act Amendments (CAAA) of 1990. The NGTDM tracks emissions of criteria pollutants associated with the transmission and distribution of natural gas. The second is that of energy related investment. Energy related investments in areas such as the capacity expansion of natural gas pipelines are quantified in the NGTDM.Key features of the natural gas models reviewed are summarized below in Table D-1. While some of the models, such as WEFA and GRI, do address most of the issues that were of concem in the development of the NGTDM, others, such as the DRI and AGA models, employ a very simplistic representation of the transmission and distribution segment of the industry. In the DRI'and AGA models, flows are not explicitly represented, end-use prices are determined via fixed markups, and capacity constraints and capacity expansion decisions are not represented. These models were thus not suitable to address the requirements of NEMS.

\section{Comparison of Capabilities of Other Models to the NGTDM}

The WEFA and GRI/EEA models address several of the issues which are represented in the NGTDM. Like the NGTDM, these models track flows, take into account capacity constraints and capacity expansion decisions, and have endogenous determination of tariffs. Both models also have structures not represented within the NGTDM, as well as some general drawbacks in comparison to the NGTDM. The WEFA model is implemented as a spreadsheet, and is therefore not directly compatible with the NEMS system. While tariffs are endogenously determined, the methodology is a simple one which does not allow the type of regulatory analysis required by NEMS. While the GRI/EEA model has a miore sophisticated determination of tariffs, all pricing is based on cost-of-service, and marginal pricing, which the NGTDM allows for, is the direction in which the industry is going. Capacity and capacity expansion issues are considered to be of great importance, and thus are treated in more detail in the NGTDM than in the GRI/EEA model.

\footnotetext{
${ }^{110}$ Carpenter, Paul R., "Review of the Gas Analysis Modeling System," Incentives Research Inc.
} 
- Table D-1. Natural Gás Models Reviewed

\begin{tabular}{|c|c|c|c|c|c|c|c|c|c|c|}
\hline Model Feature & DRI & WEFA & AGA & GRI & DFI & GTM & MIT & Gasnet & GAMS & NGTDM \\
\hline Flows represented & no & yes & no & yes & yes. & yes & yes & yes. & no & yes \\
\hline Endogenous tariffs & no & yes & no & yes & no & no & no & no & no & yes \\
\hline $\begin{array}{l}\text { Capacity } \\
\text { constraints }\end{array}$ & no & yes & no & yes & yes & yes & yes & no & no & yes \\
\hline $\begin{array}{l}\text { Capacity } \\
\text { expansion }\end{array}$ & no & yes & no & yes & yes & no & -yes & no & no & yes \\
\hline $\begin{array}{l}\text { Core/noncore } \\
\text { markets }\end{array}$ & no & yes & , no & yes & yes & no & no & no & no & yes \\
\hline Seasonal & no & yes & no & yes & no & no & no & yes & no " & no \\
\hline $\begin{array}{l}\text { Spot and contract } \\
\text { gas }\end{array}$ & yes & yes & no & yes & no & no & no & no & yes & no \\
\hline $\begin{array}{l}\text { Environmental } \\
\text { issues }\end{array}$ & no & no & ṇo. & no & no & no & no & no & no : & yes \\
\hline
\end{tabular}

Two features of the WEFA and GRI/EEA models not directly incorporated into the NGTDM are seasonal pricing and the distinction between wellhead spot and contract gas. A detailed treatment of contract pricing provisions for system supply is no longer necessary, since total deregulation of the wellhead market occurred in 1993. In addition, given the resulting competitive nature of the market at the wellhead, it is expected that the majority of new supply contracts will contain clauses tieing the contract price to the going price on the spot market, resulting in these prices moving in tandem over time. If the relative difference between the spot and contract gas price is determined to be significant, this distinction can be readily incorporated within the NGTDM. Seasonal pricing is an important issue for future consideration within NEMS, but is beyond the scope of the current design.

The basic structure of the GTM and MIT models is similar to the design of the NGTDM. Both are interregional trade equilibrium models which, like the NGTDM, are formulated as optimization problems that maximize the sum of producers' and consumers' surpluses subject to supply, demand, regulatory, and technological constraints. There are, however, a number of significant enhancements that are provided in the NGTDM. The GTM focuses on long-term market equilibria rather thàn on mid-term institutional and regulatory issues, which are important for NEMS to address. Like many of the other models, the GTM does not incorporate an endogenous determination of tariffs or capacity expansion decisions. While the structure of the MIT model is similar to that of the NGTDM, it is basically a Canadian model without the U.S. market detail required of NEMS.

Because of the number of supply regions and pipeline corridors, the representation of the transmission and distribution network incorporated in the DFI model is the most detailed of any of the models reviewed. Given that the solution time required to solve a system of this level of detail does not fall within the NEMS guidelines and that tariffs are determined based on exogenously determined values, the structure was not considered to be suitable for NEMS.

Since the Gasnet model was developed during a time period when the gas market was very different from the current market, it has a structure that could not be easily modified to address the issues relevant to NEMS. It does, however, 
provide a good example of the general technique of applying network optimization to natural gas transmission and distribution, which is the method that is used in the NGTDM to model the noncore transportation segment of the market.

Of the nonnatural gas models reviewed, PIES was most relevant to the design of the NGTDM. The PIES solution methodology, in fact, forms the basis for the linear programming approach used as the solution methodology in the NGTDM. The allocation process used in the SRI-GULF model was seriously considered to be used as the basis for an heiristic approach to modeling cost-of-service pricing in the core market within the NGTDM. This approach was subsequently abandoned due to added operational and convergence complexity that would be introduced by the use of separate modeling approaches for core and noncore markets. 
Appendix E

\section{Model Input Variable Mapped to Data Input Files}

This appendix provides a list of the FORTRAN variables, and their associated input files, that are assigned values through FORTRAN READ statements in the source code of the NGTDM. Information about all of these variables and their assigned values (including sources, derivations, units, and definitions) are provided in the indicated input files of the NGTDM. Electronic copies of these input files are available upon request from Joe Benneche (202) 586-6132. 


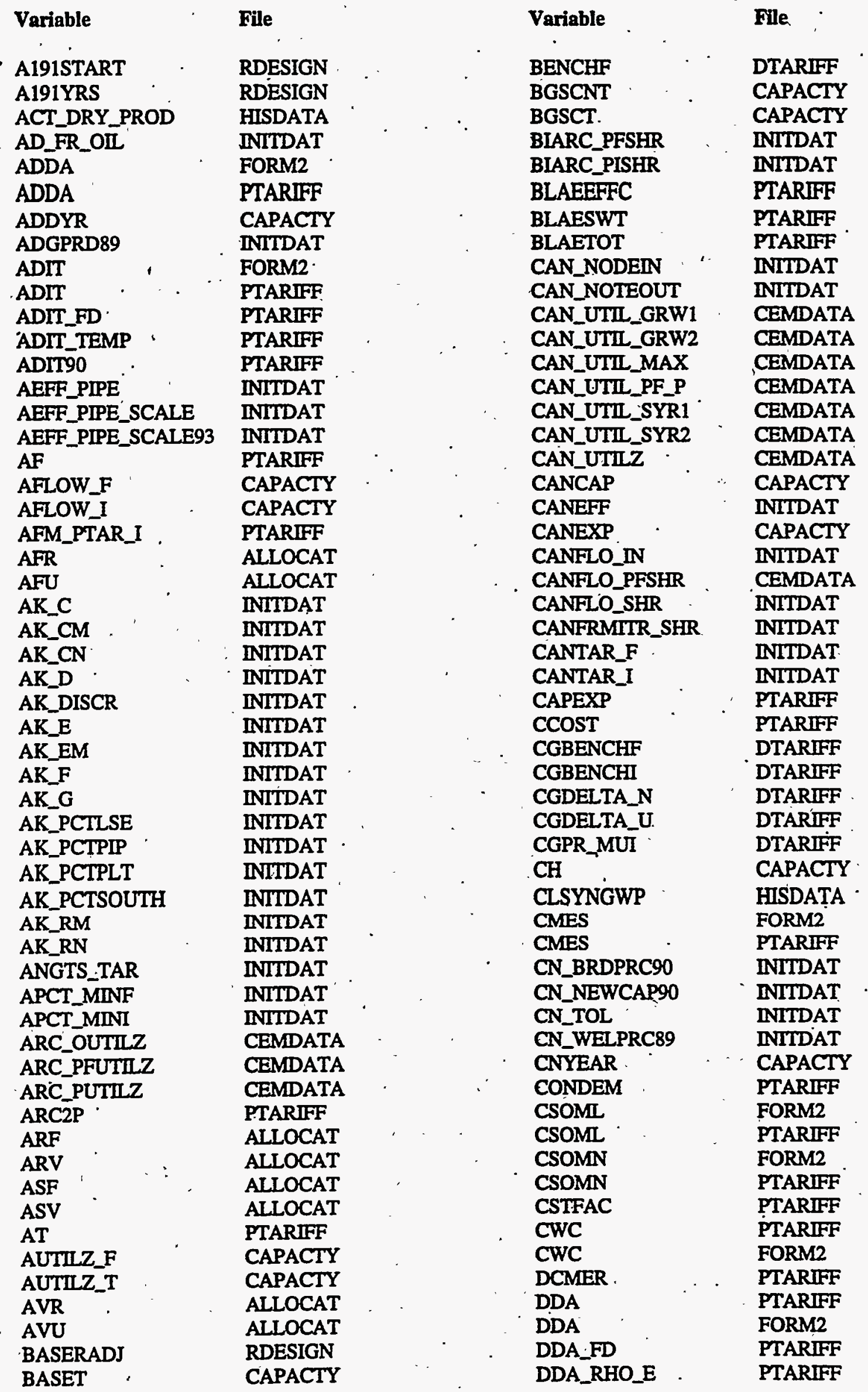




\begin{tabular}{|c|c|c|c|c|c|c|c|c|}
\hline Variable. & & File & & & & Variable & & File \\
\hline ODA_TEMP & & PTARIFF & - & & & .HPGITRGR & & HISDATA \\
\hline DEBTYR & & DTARIFF & $\because$ & & & HPGTELGR & & HISDATA \\
\hline EFPRICE & & INITDAT & & & & HPNGCM & & HISDATA \\
\hline ELFLG_CAP & & CEMDATA & & . & & HPNGEL & & HISDATA \\
\hline DELFLG_STR & & CEMDATA & & & & HPNGN & & HISDATA \\
\hline DELPR_CAP & & CEMDATA & & . & & HPNGRS & & HISDATA \\
\hline ELPR_STR & & CEMDATA & & & & HPNGTR & & HISDATA \\
\hline EPSHR9O & & PTARIFF & & & & HQAK_NONU_F & & HIS \\
\hline iR91 & & PTARIFF & $\cdot$ & & & HQAK_NONU_I & & HIS \\
\hline PR & & DAT & & & & WPRLAGOF & & HIS \\
\hline RC & & ATA & & & & RLAGON & & HISI \\
\hline DISTO & & RIFF & & . & & I_BYPASS & & IF \\
\hline LTDR & & PTARIFF & & i & & $\overline{\mathbf{B B R D}}$ & & \\
\hline OLYR & & PTARIFF & & & & ICEN & & HIS \\
\hline DTAR_REFYR & & IIFF & $\because$ & & & PCT & & RDESIGN \\
\hline IM_BETA & & DT & & & & IFLOOR & & DTARIFF \\
\hline F_STR & & INITDAT & & & & ING & & HISDATA \\
\hline MISRAT & & - INIT & & & & INGEM & & HISDATA \\
\hline EST_DRY_PROD & & ATA &. & & 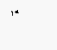 & INGOG & & HISDATA \\
\hline XP_PSHR & & CEMDATA & & & & INTRA_TARF & & DTARIFF \\
\hline IPFAC & & PTA & & & & INTRA_TARI & & IFF \\
\hline IAP & & AT & & & & & & TA \\
\hline OR & & IFF & & & & IPADD & & 18 \\
\hline $\mathbf{E}$ & & IGN & & & & IP & & IFF \\
\hline $\mathbf{F}$ & & IFF & & & & IP & & RIFF \\
\hline GDBGRPT & & AT & : & & & IPD2YR & & DTARIFF \\
\hline GPIS & & FO & 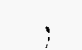 & & & TEX & & , P \\
\hline GPIS & & IFF & & & & ER & & $\mathbf{P}$ \\
\hline PIS89 & & FF & & & & PR & & $\mathbf{P}$ \\
\hline TART & & GN. & & . & & & & GN \\
\hline RS & & GN & & & & EII & & GN \\
\hline GBLU & & & & & & IFIRM & & $G N$ \\
\hline PUAANS & & IFF & & " & & TINT & & RDESIGNं \\
\hline HCGPR_F & & DTARIFF & & 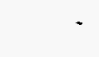 & & LPTL_SCALE & & INITDAT \\
\hline NONU_F & & TA & & & & LTD & & PTARIFF \\
\hline NONU_I & & TA & & & & LTD & & $\overline{12}$ \\
\hline ELGR & & TA & & & & 2S_RATE & & IFF \\
\hline $\mathrm{CM}$ & & ATA & $\therefore$ & & & MA & & SIGN \\
\hline CMGR & & ITA & & & & _MACRS_YR & & PTARIFF \\
\hline TPGFELGR & & & & . & & MAXCHNG & & DTARIFF \\
\hline IPGFIN & & TA & & : & & MAXESC & & RDESIGN \\
\hline FINGR & . & TA & & & & MAXPROF & & INITDAT \\
\hline RS & & & & & & PRON & & INITDAT \\
\hline PGFRSGR & & & & & & MEXEFF & & DAT \\
\hline HPGFTR & & TA & & & & RMITR_SHI & & $\mathrm{AT}$ \\
\hline HPGFTRGR & & & & & & ME & & AT \\
\hline HPGICM & & HIS & & & & MEXTAR_I & & DAT \\
\hline PGICMGR & & & & 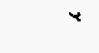 & & MIIE_FD & & PTARIFF \\
\hline PGIELGR & & & & & & - MI & & PTARIFF \\
\hline & & & & & & MINMU_I & & DTARIFF \\
\hline & & & & & & MNUMBX & & HISDAT \\
\hline & & & & & & MNUMOR & & HISDAT \\
\hline PGIRSGR & & ATA & & & & MNUMPR & & HISDAT \\
\hline IPGITR & & HISDATA & & & & MPIN_CRG & & HISD. \\
\hline
\end{tabular}




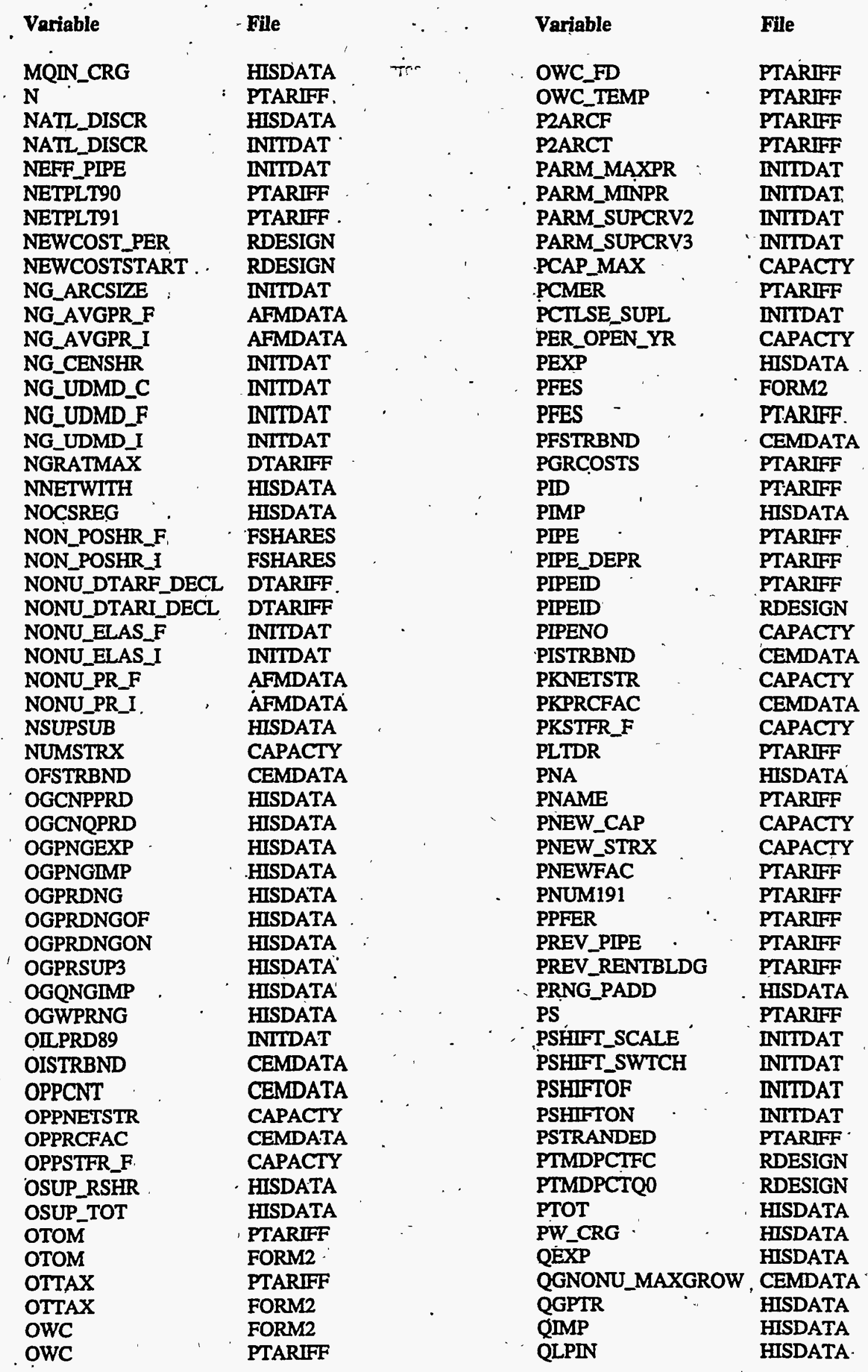




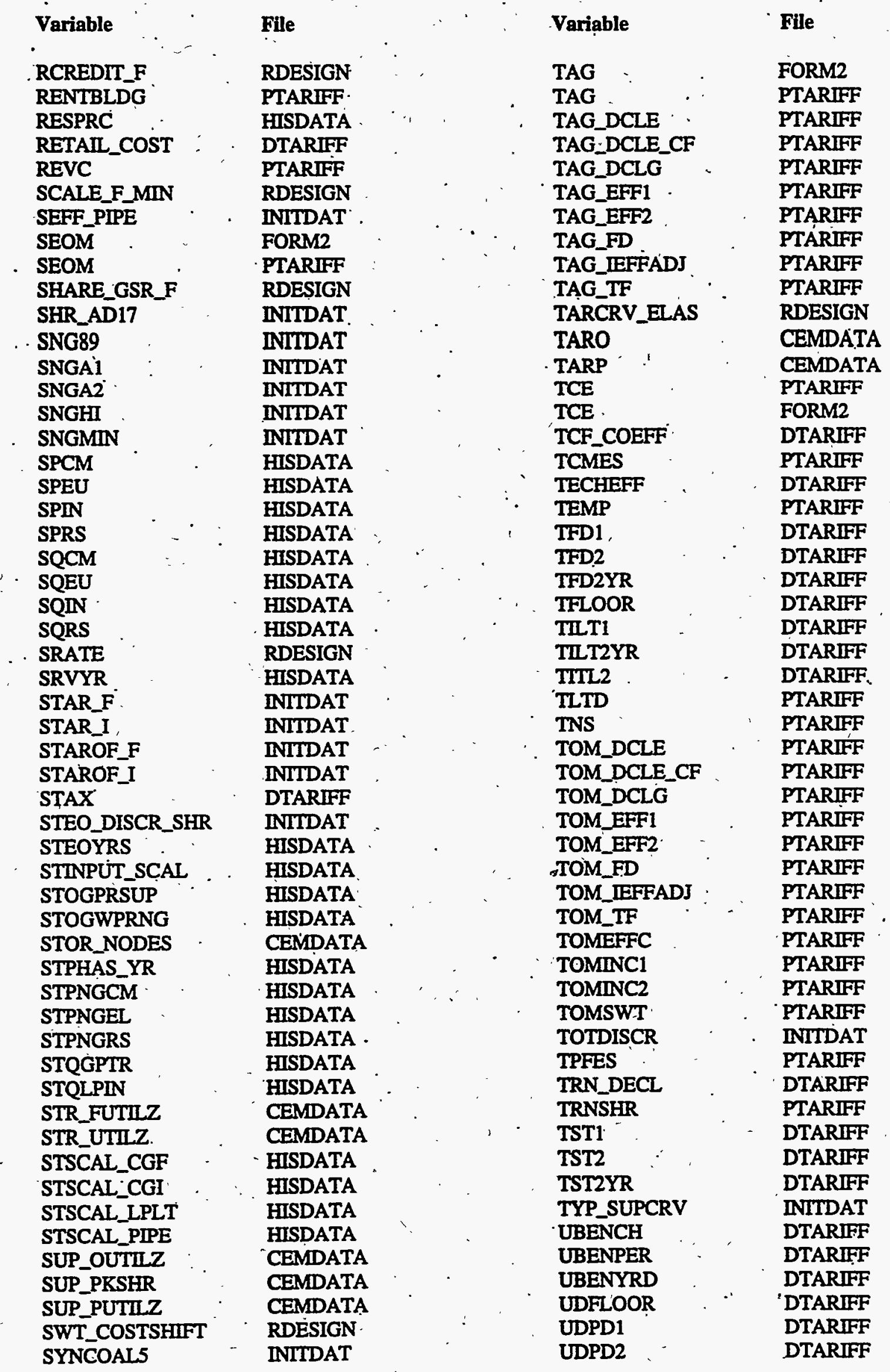




\begin{tabular}{|c|c|c|c|c|c|c|}
\hline Variable & File & & & Variable & & File \\
\hline UDPD2YR & DTARIFF & & & UTILT2Y. & & DTARIFF \\
\hline UEFF_PIPE & INITDAT & & 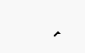 & w_C & & DTARIFF \\
\hline URFLOOR & DTARIFF & & & W_DIST & & DTARIFF \\
\hline URPD1 & DTARIFF & & & W_LPG & & DTARIFF \\
\hline URPD2 & DTARIFF & & & W_RESID & & DTARIFF \\
\hline URPD2YR & DTARIFF & & 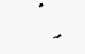 & WGCNT & & CAPACTY \\
\hline UTIL_DTARF_DECL & DTARIFF & & & WGCT & & CAPACTY \\
\hline UTILELAS_F & NITDAT &. & & WOP89 & & NNTDAT \\
\hline UTIL_ELAS_I & INITDAT & & & WORKT & & CAPACTY \\
\hline UTIL_POSHR_C & FSHARES & & & WPR89 & & INITDAT \\
\hline UTIL_POSHR_F & FSHARES & & . & WPRLAGOF & & INITDAT \\
\hline UTIL_POSHR_I & FSHARES & & & WPRLAGON & & INITDAT \\
\hline UTIL_PR_F & AFMDATA & $=$ & & WT_DEBT & & DTARIFF - \\
\hline UTIL_PR_I & AFMDATA & & & WTHR_XCAP & & AFMDATA \\
\hline $\begin{array}{l}\text { UTILT1 } \\
\text { UTILT2. }\end{array}$ & $\begin{array}{l}\text { DTARIFF } \\
\text { DTARIFF }\end{array}$ & & & $\begin{array}{l}\text { WTHRFAC } \\
\text { YR_KERNRIVI }\end{array}$ & ER_IN & $\begin{array}{l}\text { AFMDATA } \\
\text { PTARIFF }\end{array}$ \\
\hline
\end{tabular}




\section{Derived Data}

Table F1

Data: Parameter estimates for the Alaskan natural gas consumption equations for the residential, commercial, and industrial sectors. Parameter estimates for the Alaskan average natural gas wellhead and industrial price equations.

Author: Tianchi Wang, SAIC, July 1995.

Source: . Natural Gas Annual 1986, 1988, 1991, DOE/EIA-0131:

Annual Energy Review 1991 (Table 69, Appendix C).

Derivation: The method of Ordinary Least Squares (OLS) was used to estimate the parameters of the Alaskan natural gas consumption equation for each sector (except for electric generation), the industrial sector natural gas price equation, and the average wellhead price equation. These equations are defined as follows:

Residential Natural Gas Consumption

In $\mathrm{YR}_{t}=\mathrm{AK} \_\mathrm{C}(1)+\mathrm{AK} C \mathrm{C}(2) * \ln \mathrm{RN}_{\mathrm{t}}$ $\mathrm{N}=24$, R-Squared $=0.959$, Durbin-Watson $=2.5$

$\begin{array}{lcc}\text { Variables: } & \text { AK_C(1) } & \text { AK_C(2) } \\ \text { Estimated Value: } & .5 .871 & 0.852 \\ \text { t-statistic: } & (29) & (17)\end{array}$

Commercial Natural Gas Consumption

In $\mathrm{YC}_{\mathrm{l}}=\alpha_{\mathrm{c}}+\mathrm{B}_{\mathrm{c}}{ }^{*} \ln \mathrm{CN}_{\mathrm{t}}$

$\mathrm{N}=24, \mathrm{R}-\mathrm{Squared}=0.579$,

tho $=0.579(t-3.2)$, Durbin-Watson $=1.5$

Variables: $\quad \alpha_{c} \quad B_{c}$

Estimated Value: $\quad 9.0492 \quad 0.3708$

t-statistic $\quad(50) \quad(4.1)^{\circ}$

After incorporating the first-order autocorrelation, the forecast function becomes:

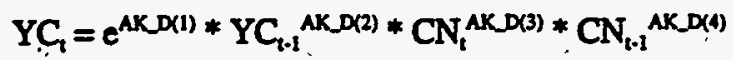

Variables: $\quad$ AK_D(1) ， AK_D(2) AK_D(3) AK_D(4)

Estimated Value: $\quad 3.8097 \quad 0.5790 \quad \cdot 0.3708 \quad-0.2147$,

Industrial Natural Gas Consumption

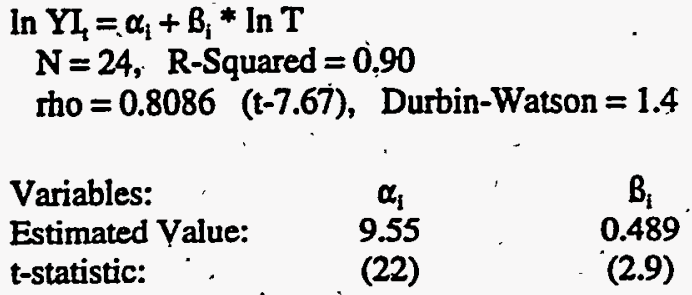

After incorporating the first-order autocorrelation, the forecast function becomes: 


$$
Y I_{8}=e^{A K E(1) * Y I_{-1}}{ }^{A K E E(2)} * T^{A K E(3)} *(T-1)^{A K E(4)}
$$

$\begin{array}{lcccc}\text { Variables: } & \text { AK_E(1) } & \text { AK_E(2) } & \text { AK_E(3) } & \text { AK_E(4) } \\ \text { Estimated Value: } & 1.8280 & 0.8086 & 0.4890 & -0.3954\end{array}$

Average Natural Gas Wellhead Price

$$
\begin{aligned}
& W P_{t}=\left(A K_{-} F(1) * W P_{t-1}\right)+\left(A K_{-} F(2) * T C_{l}\right) \\
& N=24, \quad R-S q u a r e d=0.72, \text { Durbin-Watson }=1.85
\end{aligned}
$$

$\begin{array}{lcc}\text { Variables: } & \text { AK_F(1) } & \text { AR_F(2) } \\ \text { Estimated Value: } & 0.6964 & 0.002346 \\ \text { t-statistic: } & (5.2) & (2.4)\end{array}$

Industrial Natural Gas Price

(Note: esimated with 2 less years of data than the equations above)

\begin{tabular}{|c|c|}
\hline & $\begin{array}{c}A K G G(1) \\
1.0191 \\
(9.997)\end{array}$ \\
\hline
\end{tabular}

$\mathrm{IP}_{\mathrm{t}}=\mathrm{AK} \_\mathrm{G}(1)+A \mathrm{~K}_{-} \mathrm{G}(2) * \mathrm{OP}_{\mathrm{t}}$ Durbin-Watson $=2.149$, R-Squared $=0.288, \mathrm{~N}=12$

where,

$$
\begin{aligned}
\text { In } & =\text { natural logarithm operator } \\
t & =\text { year index } \\
N & =\text { number of observations }
\end{aligned}
$$

$\mathbf{R N}_{\mathrm{t}}=$ residential consumers (thousands) at current year. (AK_RN), See Table F2

$\mathrm{CN}_{\mathrm{t}}=$ commercial consumers (thousands) at current year. (AK_CN), See Table F2

$\mathrm{OP}_{\mathrm{t}}=$ total landed costs of crude oil imports (1987\$/barrel) in current year. (WOPCUR)

$\mathrm{YR}_{\mathbf{t}}=$ residential Alaskan natural gas consumption (MMcf) (QALK_NONU_F(1))

$\mathrm{YC}_{\mathrm{t}}=$ commercial Alaskan natural gas consumption (MMct) (QALK_NONU_F(2))

$\mathrm{YI}_{\mathrm{i}}=$ industrial Alaskan natural gas consumption (MMcf) (QALK_NONU_F(3))

$T=$ time trend variable having value $1,2,3, \ldots, 23$ starting from 1969 to 1991. In 2015, the $T$ variable will take on the value of 47. (CNTYR+21)

$\mathrm{TC}_{\mathrm{t}}=$ Total Alaskan natural gas consumption (MMcf) (AK_CONS_S + AK_CONS_N)

WP $=$ average wellhead price (1987\$/Mcf) in current year. (WPRCUR)

$\mathrm{WP}_{\mathrm{t}-\mathrm{t}}=$ average wellhead price $(1987 \$ / \mathrm{Mcf}$ ) lagged one year. (WPRLAG)

$\mathrm{IP}_{\mathrm{i}}=$ industrial gas price (1987\$/Mcf):(PALK_NONU_F(3))

Notes: Variables displayed in parentheses are used in the source code.

Variables: AK_C AK_D AK_E . AK_F AK_G
Parameters for Alaskan residential natural gas consumption (Appendix E). Parameters for Alaskan commercial natural gas consumption (Appendix E). Parameters for Alaskan industrial natural gas consumption (Appendix E). Parameters for average Alaskan natural gas wellhead price (Appendix E). Parameters for Alaskan industrial natural gas price (Appendix E). 
Data used in estimating.parameters in Tables F1 and F2

\begin{tabular}{rrrrrrrrrrr} 
YEAR & YR & YC & YI & YE & PD & RN & CN & OP & WP & IP \\
\hline 1969 & 4573 & 11018 & 13653 & 6618 & 50.864 & 14.000 & 4.000 & 8.38 & 0.7508 & 1.08108 \\
1970 & 6211 & 12519 & 14744 & 8198 & 111.576 & 15.000 & 4.000 & 8.41 & 0.7123 & 1.22507 \\
1971 & 6893 & 14256 & 10628 & 10260 & 121.618 & 18.000 & 3.000 & 8.54 & 0.6469 & 1.72507 \\
1972 & 8394 & 16011 & 12328 & 13085 & 125.596 & 21.000 & 3.000 & 8.30 & 0.3866 & 1.75258 \\
1973 & 5024 & 12277 & 14985 & 15400 & 130.007 & 23.000 & 3.000 & 9.88 & 0.3632 & 1.74334 \\
1974 & 4163 & 13106 & 13976 & 17117 & .128 .935 & 22.000 & 4.000 & 27.88 & 0.3786 & 1.67038 \\
1975 & 10393 & 14415 & 22388 & 19619 & 160.270 & 25.000 & 4.000 & 28.31 & 0.6098 & 1.64634 \\
1976 & 10917 & 14191 & 26687 & 22204 & 166.072 & 28.000 & 4.000 & 25.77 & 0.7457 & 1.66348 \\
1977 & 11282 & 14564 & 49302 & 23534 & 187.889 & 30.000 & 5.000 & 25.99 & 0.7156 & 1.80680 \\
1978 & 12166 & 15208 & 77138 & 24431 & 203.08833 .000 & 5.000 & 24.16 & 0.8624 & 1.59204 \\
1979 & 7313 & 15862 & 92733 & 28295 & 220.754 & 36.000 & 6.000 & 33.08 & 0.7939 & 1.60305 \\
1980 & 7917 & 16513 & 69773 & 28763 & 230.588 & 37.000 & 6.000 & 47.27 & 1.0181 & 0.52999 \\
1981 & 7904 & 16650 & 53083 & 29071 & 242.564 & 40.000 & 6.000 & 49.96 & 0.7858 & 0.45627 \\
1982 & 10554 & 24232 & 77621 & 30988 & 264.364 & 48.000 & 7.000 & 40.04 & 0.7518 & 0.69212 \\
1983 & 10434 & 24693 & 74641 & 31348 & 276.691 & 55.000 & 8.000 & 33.60 & 0.8372 & 0.76835 \\
1984 & 11833 & 24654 & 72465 & 31582 & 286.280 & 63.000 & 10.000 & 31.74 & 0.8022 & 0.72527 \\
1985 & 13256 & 20344 & 75676 & 34194 & 314.64365 .000 & 10.000 & 28.59 & 0.7839 & 0.75212 \\
1986 & 12091 & 20874 & 60439 & 34409 & 300.635 & 66.000 & 11.000 & 14.45 & 0.5160 & 0.83591 \\
1987 & 12256 & 20224 & 67467 & 30530 & 340.24768 .000 & 11.000 & 18.13 & 0.9400 & 0.74000 \\
1988 & 12529 & 20842 & 67805 & 30841 & 355.398 & 68.612 & 11.649 & 14.01 & 1.2223 & 1.02984 \\
1989 & 13589 & 21738 & 59341 & 32746 & 373.797 & 69.540 & 11.806 & 16.66 & 1.2546 & 0.99631 \\
1990 & 14165 & 21622 & 76849 & 34366 & 381.431 & 70.808 & 11.921 & 19.21 & 1.2223 & 1.07174 \\
1991 & 13562 & 20897 & 75637 & 31330 & 409.381 & 72.565 & 12.071 & 15.89 & 1.2650 & 1.00855 \\
1992 & 14350 & 21299 & 80938 & 28953 & 411.593 & 74.268 & 12.204 & 15.03 & 1.1640 & \\
1993 & 13858 & 20003 & 75795 & 28025 & 398.093 & 75.842 & 12.359 & 13.00 & 1.1430 &
\end{tabular}




\section{Table F2}

Data: Exogenous forecast of the number of residential and commercial customers in Alaska

Author: Tianchi Wang, SAIC, July 5, 1995.

Source: Natural Gas Annual (1985-1993), DOE/EIA-0131.

Derivation: The number of residential consumers represents the number of residential households. In the last 25 years this number has been steadily increasing, mirroring the population growth in Alaska. Since the current year population is highly dependent on the previous year population, the number of residential consumers was estimated based on its.lag value, as follows:

$$
\begin{aligned}
\log \left(\mathbf{R N}_{\ell}\right) & =0.276+0.9437 * \log \left(\mathrm{RN}_{\mathrm{t} \cdot \mathrm{l}}\right) \\
\mathbf{t} & =(3.7)(46) \\
\mathbf{R}^{2} & =0.99 \\
\mathrm{DW} & =1.504 \text { (rto is not statistically significant) }
\end{aligned}
$$

This translates into the following forecast equation:

$$
\mathrm{RN}_{\mathrm{t}}=1.3178 * \mathrm{RN}_{\mathrm{t}-1}{ }^{0.9437}
$$

The number of commercial consumers, based on billing units, showed a strong relationship to the number of residential households and the number of commercial consumers in the last year, as follows:

$$
\begin{aligned}
\mathrm{CN}_{\mathrm{t}}= & 0.1625 * \mathrm{RN}_{\mathrm{t}} \\
\mathrm{t} & =(31) \\
\mathrm{R}^{2} & =0.97 \\
\mathrm{DW} & =1.715 \\
\mathrm{to} & =0.627 \quad(\mathrm{t}=3.3)
\end{aligned}
$$

After incorporating the first-order autocorrelation, the forecast function becomes:

$$
\mathrm{CN}_{\mathrm{t}}=0.627 * \mathrm{CN}_{\mathrm{t}-1}+0.16248 * \mathrm{RN}_{\mathrm{t}}-0.10187 * \mathrm{RN}_{\mathrm{t}-\mathrm{i}}
$$

Notes: Documented in memo dated July 5, 1995 under SAIC Task 118.

Units: Thousands of customers.

Variables: AK_RN . Number of residential natural gas customers (thousands) in Alaska (Appendix E)

AK_CN Number of commercial natural gas customers (thousands) in Alaska (Appendix E) 


\section{Table F3}

Data: Parameter estimates of the regression equation for the projection of ilinois synthetic natural gas production from liquid hydrocarbons.

Author: Chetha Phang, EI-823, September 1993.

Source: Natural Gas Annual 1985, DOE/EIA-0131, Table 11.

Natural Gas Annual 1986, 1987, DOE/EIA-0131, Table 12.

Natural Gas Annual 1988, 1989, 1990, Table 15.

Annual Energy Review 1991 (Tables 71, 81, Appendix C).

Data created using PIPEJCL.SNGLQDS.PRDPROJ.D0420931.

Derivation: The method of Ordinary Least Squares (OLS) was used to estimate the parameters of the Illinois synthetic gas production from liquid hydrocarbons equation, which is assumed to be a log-linear function of East North Central regional gas price. This production function is expressed as follows:

$\ln \mathrm{SNG}_{\mathrm{t}}=\mathrm{al}+\left(\mathrm{a}_{2}^{*} \ln \mathrm{ENCGPR}_{\mathrm{l}}\right)$

where,

In = natural logarithm

$\mathrm{SNG}_{\mathrm{g}}=$ synthetic natural gas production from liquid hydrocarbons in Illinois in year $\mathrm{t}(\mathrm{Bcf})$

ENCGPR $_{1}=$ East North Central regional gas price (1987\$/Mcf) in year $t$.

al, $a 2=$ parameters to be estimated

The OLS regression results based on the given data (1981-1991) showed an evidence of positive serial correlation in the data with Durbin-Watson $d=1.125$. Using the Generalized Difference Equations [Gujarati] to correct for the positive serial correlation between the disturbance terms, the second stage regression results were obtained as follows:

$$
\begin{aligned}
\ln \mathrm{SNG}_{\mathrm{t}} & =-0.5161+2.81803 * \ln \text { ENCGPR }_{\mathrm{t}} \\
\text { t-statistic } & =(0.98)(6.46) \\
\text { Durbin-Watson } & =1.599, \quad \text { R-Squared }=0.8224, \mathrm{~N}=11
\end{aligned}
$$

The above production equation can be written as:

$$
\begin{aligned}
& \text { SNG }_{t}=\text { SNGA1 *ENCGPR } \\
& \text { SNG }_{t}=0.5968 * E_{1}^{\text {SNGA2 }} \text { or, }
\end{aligned}
$$

where, $S_{N G}$ and ENCGPR, are defined in the source code as VAL and VALUE, respectively.

Units: Not applicable (no units).

Variables: SNGA1 Intercept coefficient for the Illinois synthetic gas production function (Appendix E). SNGA2 Slope coefficient for the Illinois synthetic gas production function (Appendix E). 


\section{Table F4}

Data: Coefficients for PTM forecasting equations. Total working capital; total administrative and general expense; accumulated deferred income taxes; depreciation, depletion, and amortization experises; and total operations and maintenance expense.

$\therefore$ Author: Science Applications International Corporation

Source: · Form FERC-2: Data collected for.1980 - 1991.

Derivation: - Estimations are done. by using accounting algorithm or forecast software. Forecasts are based on a series of Fortran-based econometric equations which have been estimated using the Time Series Package (TSP) software. Equations are estimated for each pipeline company or generic pipeline: total working capital; total operations and maintenance expense; total administrative and general expense; depreciation, depletion, and amortization expenses; and accumulated income taxes. These equations are defined as follows:

\section{(I) Total Working Capital}

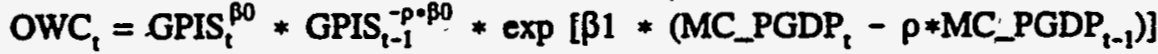

$$
\begin{aligned}
& * \exp [\beta 2 *(\text { TYEAR }-\rho *(T Y E A R-1.0))] * \text { OWC }_{\mathrm{l}-1}^{p} * \text { OWC_CONST }
\end{aligned}
$$

where,

(a) existing pipeline

$$
\begin{array}{ll}
\beta 0, \beta 1, \beta 2 & =(1.92244,1.99710,-0.170208) \\
\rho & =0.602771 \\
\text { OWC_CONST } & =(1-\rho) * \operatorname{EXP}(C+F D j) \\
\text { FD } j & \quad \begin{array}{l}
= \\
\text { firm dummy variable which is equal to } 1, \text { if } j=i \text {, or equal to } 0, \\
\end{array}
\end{array}
$$

$\begin{array}{ll}\text { t-statistic } & =\text { See Table F4.1 } \\ \text { DW. } & =1.65411 \\ \text { R-Squared } & =0.985791\end{array}$

(b) generic pipeline .

$$
\begin{aligned}
& \beta 0, \beta 1, \beta 2 \quad=(1.76412,1.94711,-0.159168) \\
& \begin{array}{ll}
\rho & =0 . \\
\text { OWC_CoNST } & =294.161 .
\end{array} \\
& \text { t-statistic } \quad=3.12307,26.9230,1.70727,-3.31806 \\
& \text { DW } \quad=1.93182 \\
& \text { R-Squared : } \quad \mathbf{=} \mathbf{0 . 9 5 2 2 4 1}
\end{aligned}
$$

(2) Total Administrative and General Expense

The following equation is used to calculate the TAG before adjustments for efficiency are made:

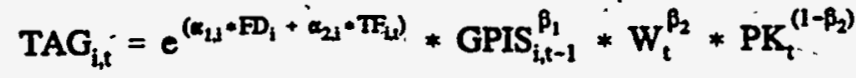

input variables, 


$$
\begin{aligned}
& \mathrm{FD}_{1} \quad \text { = pipeline specific dummy variable: equal to } 1 \text {, if pipeline company } \\
& \text { TF }_{i s} \quad \text { = pipeline specific open access variable: TRNSHR * FD (values } \\
& \text { for TRNSHR, listed in Table F4.2a) } \\
& \text { GPIS }_{\text {is-1 }} \cdots \quad \text { = original capital cost of plant in service (gross plant in service) } \\
& \mathrm{W}_{\mathrm{t}} \quad \text { = real labor cost index, all private sector [=.MC_ECTWSP / } \\
& \text { MC_PGDP] } \\
& \text { PK } \quad \text { = rental of office space for corporations (RENTBLDG): equal to } \\
& \text { rental cost index times rate of return (values listed in Table F4.2a) } \\
& \text { i } \\
& =\text { pipeline }
\end{aligned}
$$

resulting coefficients,

$$
\begin{array}{ll}
\alpha_{1,1} & =\text { FDj coefficients (values listed in Table F4.2b) } \\
\alpha_{21} & =\text { TFj coefficients (values listed in Table F4.2b) } \\
\cdot \beta_{1} & =\text { coefficient of In(GPIS) (TAG_EFF1 value in Table F4.2b) } \\
\beta_{2} & =\text { coefficient of labor cost (TAG_EFF2 value in Table F4.2b) }
\end{array}
$$

All Statistics are applied to transformed data with first order-autocorrelation correction in Log-linear regression function:

$\begin{array}{ll}\text { t-statistic } & =\text { See Table F4.2b } \\ \text { DW } & =1.94 \\ \text { Adjusted R-Squared } & =0.9998\end{array}$

The most efficient company is Trailblazer Pipeline ( $\mathrm{ID}=6410$ ), whose value of TAG represents the cost frontier in the industry.

\section{(3) Accumulated Deferred Income Tax}

(a) existing pipeline

$$
\begin{aligned}
& \operatorname{ADIT}_{4, t}=\beta_{0}+\beta_{1} * \operatorname{ADIT}_{t-1}+\beta_{2} * \text { NETPLT }_{t} \\
& \text { where, } \\
& \begin{array}{ll}
\beta 0, \beta 1, \beta 2 & =\text { (FDj }+ \text { POST86, 0.72988, 0.064099) } \\
\text { FDj } & =\text { firm dummy variable which is equal to } 1, \text { if } j=i \text {, or equal to } 0, \\
& \text { otherwise. (value of FDj see Table F4.3) }
\end{array} \\
& \text { POST86 } \quad=0.129514 \mathrm{E}+7 \\
& \text { i } \quad=\text { pipeline } \\
& \text { t-statistic } \quad=\text { See Table F4.3 } \\
& \text { DW } \quad=1.85921 \\
& \text { R-Squared : } \quad=0.956792
\end{aligned}
$$

Accumulated deferred income taxes for generic companies is calculated using an accounting algorithm. Straight Line Depreciation (SDL) is used for rate making purposes, while Modified Accelerated Cost Recovery System (MACRS) with a 151/2 year schedule is used for tax.purposes. The amount of depreciation using the MACRS and SDL schedules are derived as follows: 


$$
\begin{aligned}
& \text { DEPRMACRS }_{\mathrm{t} . .}=\sum_{s=2}^{s=t} \operatorname{NCAE}_{\mathrm{s}} * \text { MACRS_RATE }_{t-s+1} \\
& \text { DEPRSL }_{\mathrm{t},}^{s=t} \operatorname{NCAE}_{s} / 30
\end{aligned}
$$

where,

$$
\begin{aligned}
\text { MACRS_RATE } & =(5.00,9.50,8.55,7.70,6.93,6.23,5.90,5.90,5.91,5.90,5.91, \\
\text { FRATE } & =3.90,5.91,5.90,5.91,2.95)
\end{aligned}
$$

(4) Total Depreciation, Depletion, and Amortization

(a) existing pipeline

$$
\begin{aligned}
& \mathrm{DDA}_{\mathrm{it}, \mathrm{t}}=(1-\rho) * \beta_{0}+\beta_{1} * \mathrm{NETPLT}_{\mathrm{t}}+\beta_{2} * \mathrm{DEPSHR}_{\mathrm{t}} \\
& +\rho * \text { DDA }_{t-1}-\rho *\left(\beta_{1} * \text { NETPLT }_{t-1}+\beta_{2} * \text { DEPSHR }_{t-1}\right) \\
& \text { where, } \\
& \beta 0, \beta 1, \beta 2 \\
& =\left(F D_{j}, \beta 1, \beta 2\right) \\
& \text { FDj } \\
& =(F D j, 0.037362,-0.315983 E 7) \\
& P \quad=0.151232 \\
& \text { i } \quad \text { = pipeline } \\
& \text { t-statistic } \quad=\text { See Table F4.3 } \\
& \text { DW } \quad=1.77499 \\
& \text { R-Squared } \quad=0.9634^{\circ}
\end{aligned}
$$

(b) generic pipeline

A regression equation is not used for the generic pipeline; instead, an accounting algorithm ' is used (presented in Chapter 8).

\section{(5) Total Operations and Maintenance Expense}

The following equation is used to calculate the TOM before adjustments for efficiency are made:

$$
\operatorname{TOM}_{i, t}=e^{\left(\alpha_{L 1} \cdot F D_{i}+\alpha_{2 i} \cdot T F_{L}\right)} * \operatorname{GPIS}_{i, t-1}^{\beta_{1}} * W_{t}^{\beta_{2}} * \mathrm{PK}_{1}^{\left(1-\beta_{2}\right)}
$$

and,

$$
\mathrm{PK}_{\mathrm{t}}=\left(\text { REALAA + PIPE_DEPR }-\frac{\text { PIPE }_{t}-\text { PIPE }_{t-1}}{\text { PIPE }_{t-1}}\right) * \text { PIPE }_{t}
$$

input variables,

$$
\begin{aligned}
& \mathrm{FD}_{1} \quad \text { = pipeline specific dummy variable: equal to } 1 \text {, if pipeline company } \\
& \text { i, } 0 \text { otherwise (values listed in Table F4.2b) } \\
& \mathrm{TF}_{4} \cdot \quad \text { = pipeline specific open access variable: } \operatorname{TRNSHR}^{*} \text { FQ (values } \\
& \text { for TRNSHR, listed in Table F4.2a) } \\
& \text { GPIS }_{l-1} \text {. : = original capital cost of plant in service (gross plant in service) }
\end{aligned}
$$




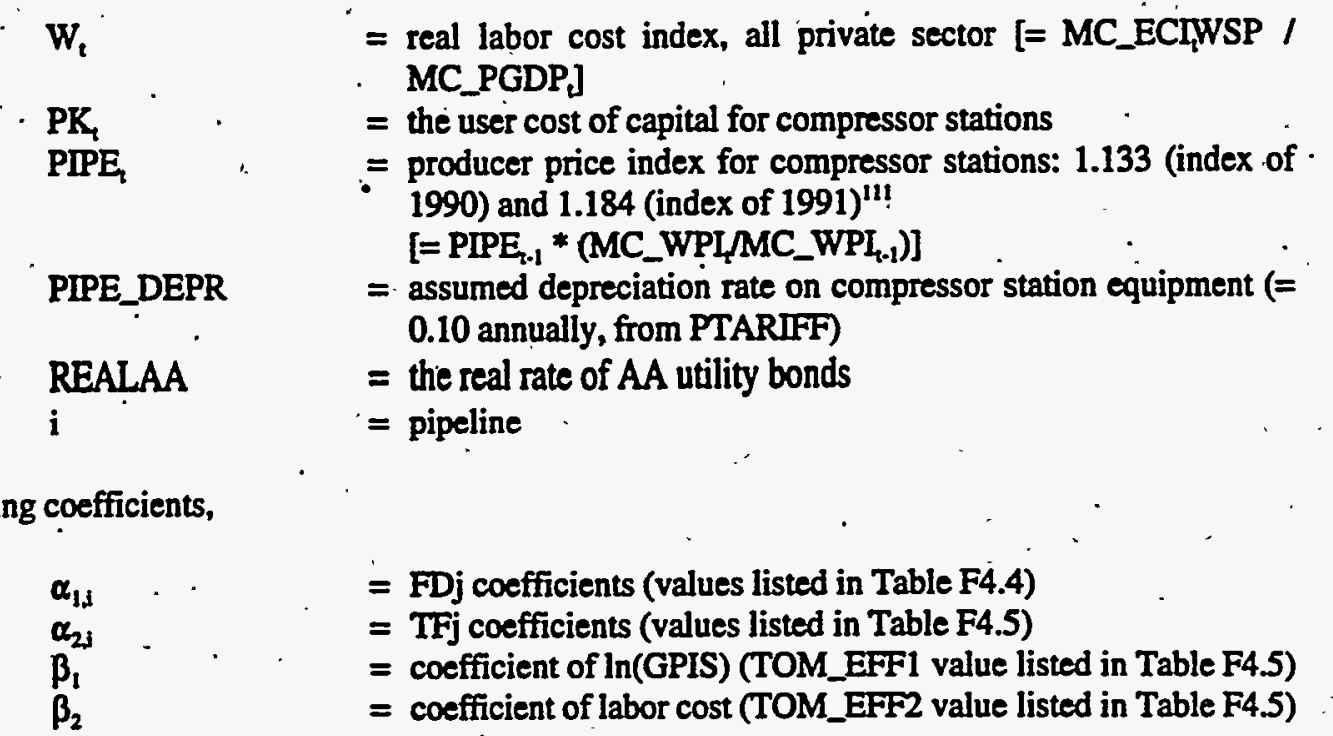

All Statistics are applied to transformed data with first order-autocorrelation correction in Log-linear regression function:

$$
\begin{array}{ll}
\text { t-statistic } & =\text { See Table F4.5 } \\
\text { DW } & =1.81 \\
\text { Adjusted R-Squared } & =0.99996
\end{array}
$$

The most efficient company is Trailblazer Pipeline ( $\mathrm{DD}=6410)$, whose value of TOM represents the . cost frontier in the industry.

Variables:

ADIT = accumulated deferred income taxes in dollars

DDA = depreciation, depletion, and amortization costs in dollars

DEPSHR = percentage of depreciation, derived from dividing accumulated depreciation by gross plant in service in previous period

FD = firm dummy variable which is equal to 1 if $j=i, 0$ otherwise ( $i=$ pipeline)

FRATE = federal tax rate

GPIS = original capital cost of plant in service (gross plant in service) in dollars

MACRS_RATE $=$ rate of depreciation by MACRS schedule

MC_ECTWSPNS = price index of labor (from Macroeconomic Activity Model)

MC_PGDP = implicit GDP price deflator for year $\mathrm{t}$ (from the Macroeconomic Activity Model)

MC_WPI = wholesale cost index provided by Macroeconomic Activity Model

NETPLT $=$ difference between original capital cost of plant in service and accumulated depreciation in previous period (net plant in service) in dollars

OWC $=$ other working capital in dollars

OWC_CONST = estimated constant term .

PIPE = producer price index for compressor station equipment ..

PIPE_DEPR = assumed depreciation rate on compressor station equipment

REALAA = the real rate of AA utility bonds

TAG $=$ total administrative and general costs in real dollars

- $\cdot \mathrm{TF}=$ pipeline specific open access variable $\left(\operatorname{TRNSHR}_{\mathbf{i}} * \mathrm{FD}_{\mathfrak{i}}\right)$

TOM = total operating and maintenance expense in real dollars

TRNSHR = industry average share of gas transported for others

TYEAR = year in Julian units (i.e., 1995)

$\mathrm{W}_{1}=$ real labor cost index, all private sector

\footnotetext{
"IISource of historical data: Bureau of Labor Statistics, 1987=1.00.
} 


$$
\begin{aligned}
\text { Notes: } & \text { None. } \\
\text { Units: } & \\
\text { ADIT } & =\text { rominal dollar } \\
\text { DDA } & =\text { nominal dollar } \\
\text { DEPSHR } & =\text { fraction } \\
\text { FRATE } & =\text { fraction } \\
\text { GPIS } & =\text { nominal dollar: } \\
\text { MACRS_RATE } & =\text { fraction } \\
\text { MC_ECIWSPNS } & =\text { index } \\
\text { MC_PGDP } & =\text { index } \\
\text { MC_WPI } & =\text { index } \\
\text { NETPLT } & =\text { nominal dollar } \\
\text { OWC } & =\text { nominal dollar } \\
\text { PIPE } & =\text { index } \\
\text { PIPE_DEPR } & =\text { fraction } \\
\text { REALAA } & =\text { rate } \\
\text { TAG } & =1987 \text { real dollar (ultimately, converted to nominal dollar) } \\
\text { TOM } & =1987 \text { real dollar (ultimately, converted to nominal dollar) } \\
\text { TRNSHR } & =\text { fraction } \\
\text { TYEAR } & =\text { Julian units (i.e., 1995) } \\
\text { W } & =\text { index }
\end{aligned}
$$

Reference: (1) "Documentation of the Pipeline Tariff Model. Econometric Equation" by Science Applications International Corporation, April 30, 1993.

(2) "Final Report, Documentation of Simplified PTM Algorithm," by Science Applications International Corporation, May 22, 1995. 
Table F4.1. Summary Statistics for the Total Working Capital Equation with Dummy Variables

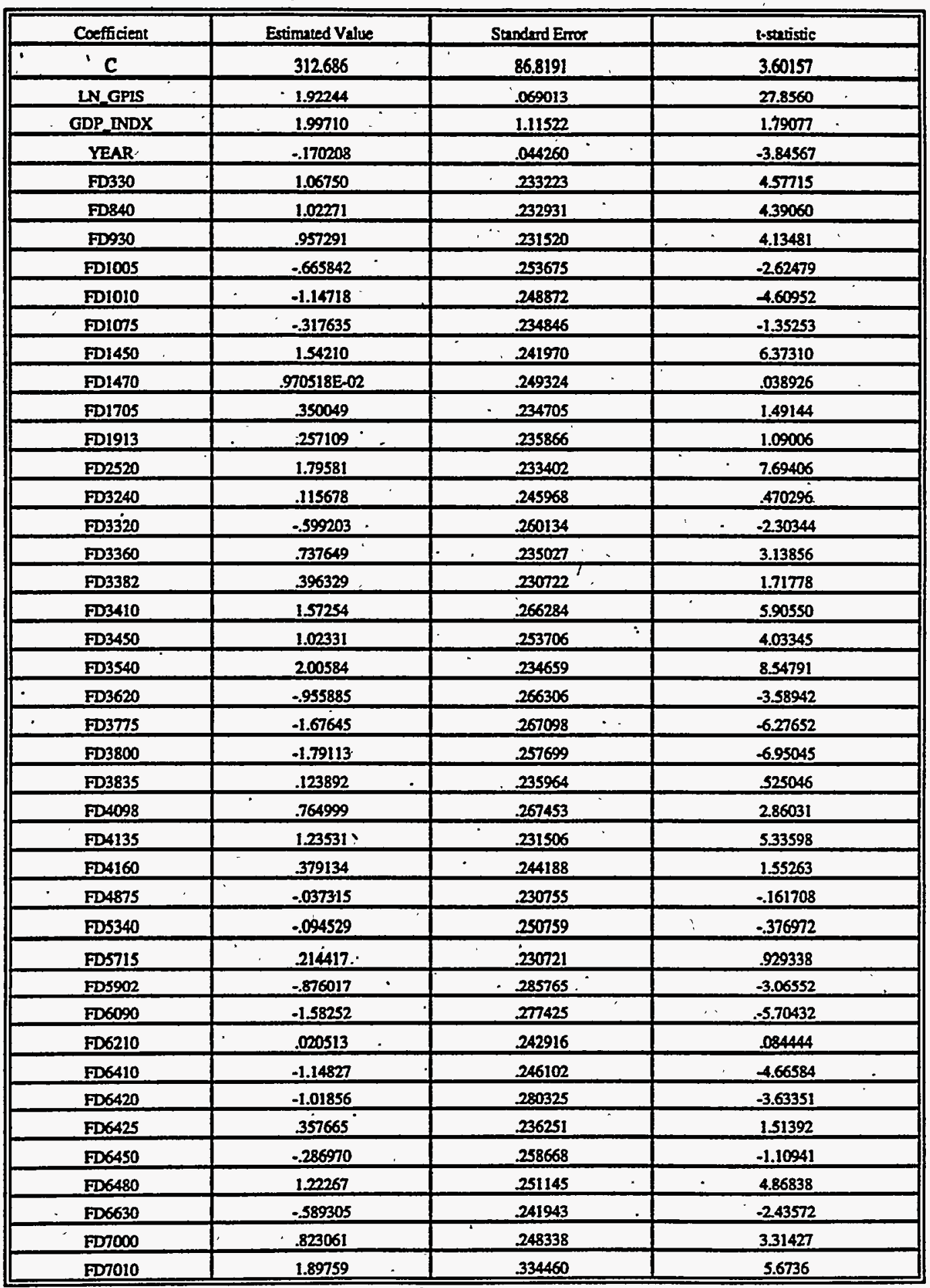


Table F4.2a. Some Input Data for Calculating Total Administrative and General Expense Equation

\begin{tabular}{|c|c|c|}
\hline Year & TRNSHR(12) & RENTBLDG ("') \\
\hline 1989 & 0.7550 & 0.1520 \\
\hline 1990 & 0.8029 & 0.1600 \\
\hline 1991 & 0.8367 & 0.1560 \\
\hline 1992 & 0.8780 & 0.1500 \\
\hline 1993 & 0.9200 & 0.1520 \\
\hline 1994 & 0.9600 & 0.1630 \\
\hline 1995 & 1.0000 & 0.1720 \\
\hline 1996 & 1.0000 & 0.1780 \\
\hline 1997 & 1.0000 & 0.1860 \\
\hline 1998 & 1.0000 & 0.1960 \\
\hline 1999 & 1.0000 & $0.2040^{\circ}$ \\
\hline 2000 & 1.0000 & 0.2100 \\
\hline 20001 & 1.0000 & 0.2170 \\
\hline 2002 & 1.0000 & 0.2250 \\
\hline 2003 & $1.0000^{\circ}$ & $0.2330^{\circ}$ \\
\hline 2004 & 1.0000 & 0.2400 \\
\hline 2005 & 1.0000 & 0.2480 \\
\hline 2006 & 1.0000 & 0.2570 \\
\hline 2007 & 1.0000 & 0.2670 \\
\hline 2008 & 1.0000 & 0.2760 \\
\hline 2009 & 1.0000 & 0.2850 \\
\hline 2010 & 1.0000 & 0.2940 \\
\hline 2011 & 1.0000 & 0.3030 \\
\hline 2012 & 1.0000 & 0.3130 \\
\hline 2013 & 1.0000 & 0.3230 \\
\hline 2014 & 1.0000 & 0.3340 \\
\hline 2015 & 1.0000 & $0.3460^{\circ}$ \\
\hline
\end{tabular}

112 Source: FERC Form 2 for 1990-1994, and assumed to be 1.0 after 1994.

${ }^{113}$ Source: DRI. 
Table F4.2b. Total Administrative and General Expense Equation with Dummy Variables

\begin{tabular}{|c|c|c|c|}
\hline Varisble & $\begin{array}{l}\text { Extimated } \\
\text { Value }\end{array}$ & $\begin{array}{l}\text { Sunderd } \\
\text { Error }\end{array}$ & i-statistic \\
\hline TAG EFFI & .546521 & .082891 & 6.59328 \\
\hline TAG_EFF2 & .746612 & .116822 & 6.39105 \\
\hline FDSO & 6.30018 & 1.71136 & 3.68138 \\
\hline FDं330 & 6.30285 & 1.75090 & 3.59978 \\
\hline FD840 & 6.58232 & 1.76219 & 3.73530 \\
\hline FD930 & $6.28602^{\circ}$ & 1.74518 & 3.60193 \\
\hline FD1005 & 6.80030 & 1.85334 & 3.66921 \\
\hline FDioso & 5.85094 & 1.84181 & 3.17673 \\
\hline FDi075 & 6.48892 & 1.76860 & 3.65897 \\
\hline FD1450 & 5.99875 & 1.61533 & 3.71362 \\
\hline FDI470 & 6.88913 & 1.82922 & 3.76615 \\
\hline FD1705 & 6.68265 & 1.77822 & 3.75804 \\
\hline FD1913 & 5.90418 & 1.78470 & 3.30822 \\
\hline FD20so & 4.96999 & 1.75473 & 283234 \\
\hline FD2520 & 6.56525 & 1.68432 & 3.89787 \\
\hline FD3240 & 6.81193 & 1.77880 & 3.82950 \\
\hline FD $332^{\circ}$ & 6.89382 & 1.85650 & 3.71335 \\
\hline FD3360 & 6.26835 & 1.68926 & 3.71070 \\
\hline FD 3382 & 5.95047 & $\begin{array}{r}\mathbf{1} 73896 \\
\end{array}$ & 3.42186 \\
\hline FD3410 & 4.91967 & 1.70103 & 2.89217 \\
\hline$F D 3450$ & 5.89680 & 1.59192 & 3.70419 \\
\hline FD3540. & 6.42158 & 1.66719 & 3.85173 \\
\hline FD3620 & 7.26868 & -1.89742 & 3.83081 \\
\hline FD3775 & 5.33731 & 1.86108 & 2.86785 \\
\hline FD 3800 & 6.87890 & 1.85380 & 3.71070 \\
\hline FD3835 & 6.55702 & 1.78981 & 3.66353 \\
\hline FD4098 & 3.56057 & 1.61480 & 2.20496 \\
\hline FD4135 & 6.00837 & 1.76093 & 3.41204 \\
\hline FD4160 & 6.72039 & 1.82418 & 3.68406 \\
\hline FD4875 & 6.13802 & $1.72427^{\circ}$ & 3.55978 \\
\hline FD 5340 & 6.84856 & 1.84478 & 3.71240 \\
\hline FDS715 & 4.73351 & 1.72216 & 2.74859 \\
\hline FD5902 & 7.01634 & 1.92765 & 3.63984 \\
\hline FD 6090 & 6.80537 & 1.90209 & 3.57784 \\
\hline FDS210 & 6.73741 & 1.81721 & 3.70755 \\
\hline FDSA10 & 4.11828 & 1.73453 & 2.37430 \\
\hline FD6420 & 7.09078 & 1.91477 & 3.70319 \\
\hline FD6425 & 6.36290 & 1.80033 & 3.53430 \\
\hline FD6450 & 6.05841 & 1.82361 & 3.32221 \\
\hline FD6480 & 3.91832 & 1.62231 & 241526 \\
\hline FD6630 & 7.08404 & 1.81856 & 3.89540 \\
\hline
\end{tabular}

\begin{tabular}{|c|c|c|c|}
\hline Variable & $\begin{array}{l}\text { Extimated } \\
\text { Value }\end{array}$ & $\begin{array}{l}\text { Stunderd } \\
\text { Extor }\end{array}$ & testatistic \\
\hline FD7000 & 4.15445 & 1.69712 & 244794 \\
\hline TF50 & .011031 & .100409 & .109860 \\
\hline TF330 & .368245 & .147138 & 250272 \\
\hline TFE40 & .028614 & .088847 & .322062 \\
\hline TF 930 & $.148615^{\circ}$ & .090249 & 1.64671 \\
\hline IFI005 & .148340 & .090299 & 1.64276 \\
\hline IF1010 & .065324 & .113296 & .576584 \\
\hline TFio7s & -.148067 & .080122 & -1.84803 \\
\hline IFI 450 & .084154 & .112457 & -.748322 \\
\hline IF1470 & .395586 & .114509 & 3.45464 \\
\hline TFl70S & .257853 & .126443 & -2.03929 \\
\hline TF1913 & -.285061 & .098021 & -2.90817 \\
\hline TF2050 & -.337730 & .102031 & -3.31009 \\
\hline TF2520 & -.258312 & .186565 . & -1.38457 \\
\hline TF3240 & -1.69449 & .692507 & .244690 \\
\hline TF3320 & .068891 & $.100 \mathrm{s07}$ & .685436 \\
\hline TF 3360 & $-.517070^{\circ}$ & .130362 & -3.96641 \\
\hline TF3382 & .057025 & 270856 & .210538 \\
\hline TF3410 & 1.43559. & 380451 & 3.77338 \\
\hline TF3450 & .279521 & .774890 & 360724 \\
\hline IF 3540 & -.140247 & .067834 & -2.06751 \\
\hline IF 3620 & .388410 & 379806 & 1.02265 \\
\hline TF3775 & .171861 & .111265 & -1.54460 \\
\hline IF3800 & .250739 & 209853 & 1.19483 \\
\hline TF3835 & .229598 & .117012 & -1.96218 \\
\hline TF4098 & $-.763932 E-02$ & .182092 & .041953 \\
\hline IF 4135 & 360972 & .113808 & 3.17176 \\
\hline IF 4160 & .268591 & .135490 & -1.98237 \\
\hline IF 4875 & -.745106 & .197142 & -3.77954 \\
\hline TF 5340 & .274110 & .101554 & -2.69915 \\
\hline IF5715 & 306619 & .082403 & 3.72096 \\
\hline IF 5902 & -.047441 & .093069 & .509738 \\
\hline TF6090 & 253314 & .124946 & 2.02739 \\
\hline TF6210 & $.424396 \mathrm{E}-02$ & .087744 & .048367 \\
\hline TF6410 & -.655675 & .185596 & -3.53280 \\
\hline IF6420 & -.177991 & .056635 & -3.14278 \\
\hline TF6425 & .310575 & 213246 & 1.45641 \\
\hline TF6450 & -.057026 & 206198 & .276561 \\
\hline IF 6480 & .707801 & .309742 & 2.28513 \\
\hline TF6630 & -.134852 & 2110205 & -1.22365 \\
\hline TF7000 & -.235443 & .097350 & -2.41851 \\
\hline
\end{tabular}


Table F4.3. Summary Statistics for Accumulated Deferred Income Tax Equation with Dummy Variables

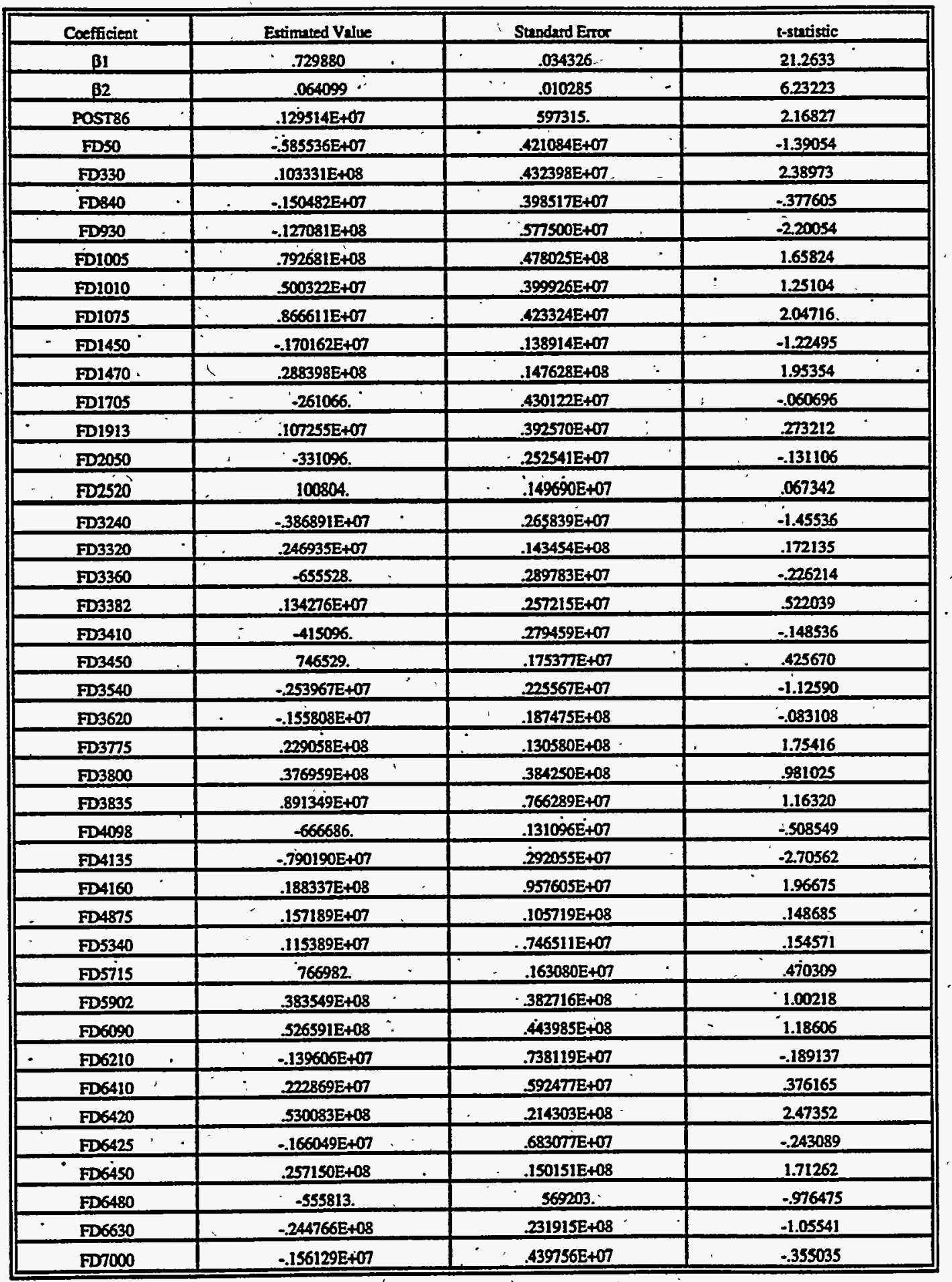


Table F4.4. Summary Statistics for Depreciation, Depletion, and Amortization Equation with Dummy Variables

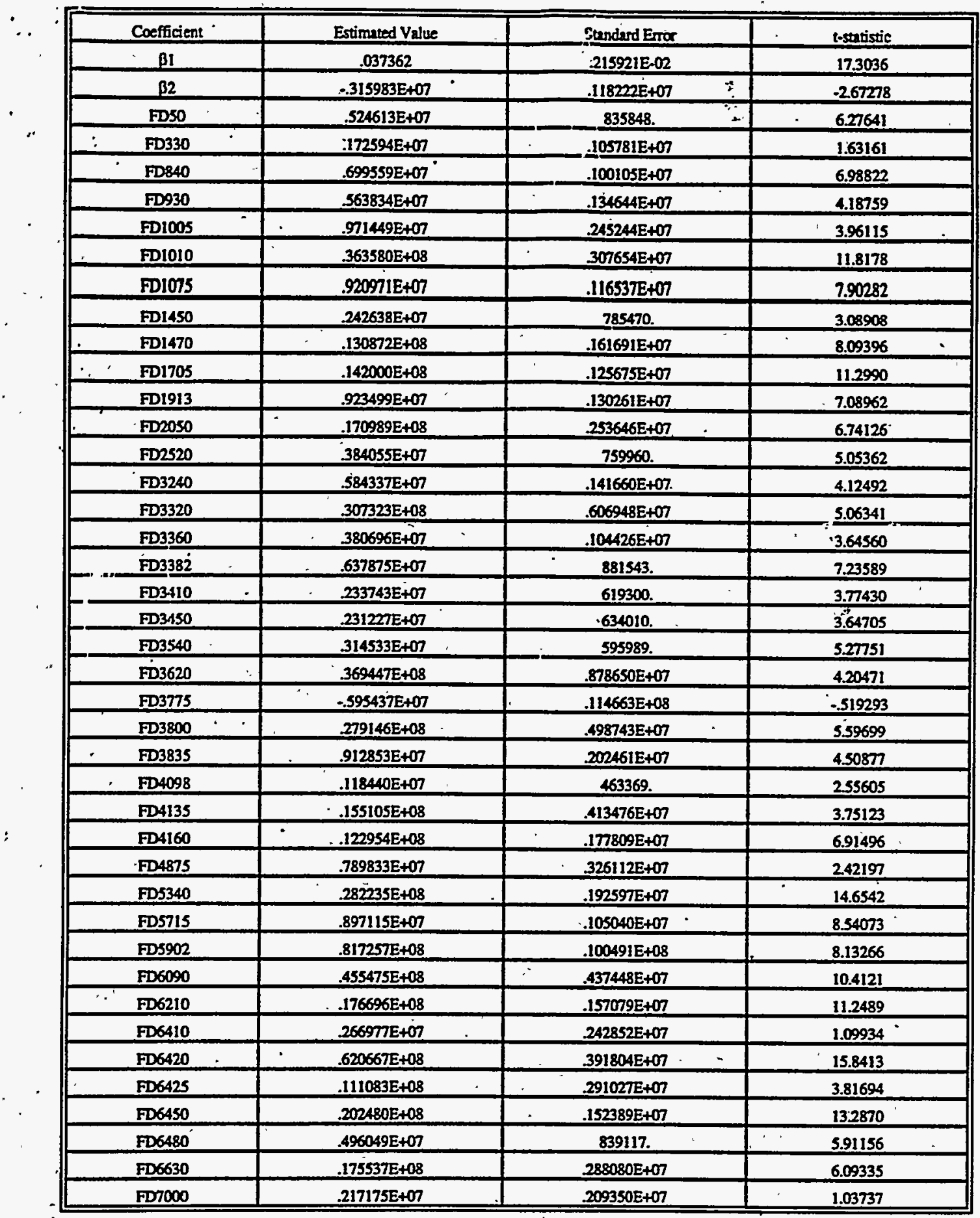


Table F4.5. Summary Statistics for Total Operations and Maintenance Expense Equation with Dummy Variables

\begin{tabular}{|c|c|c|c|}
\hline Coefficient & $\begin{array}{l}\text { Extimuted } \\
\text { Vahee }\end{array}$ & $\begin{array}{l}\text { Stunderd } \\
\text { Encor }\end{array}$ & t-xtatistic \\
\hline TOM_EFF 1 & .471373 & .068874 . & 6.84353 \\
\hline TOM EFF2 - & .889413 & .053922 & 16.4945 \\
\hline FDSO & 6.96331 & 1.30001 & 5.35634 \\
\hline FD330 & 7.57578 & 1.33699 & 5.66628 \\
\hline FD840 & 7.73947 & 1.34233 & 5.76570 \\
\hline FD930 & 7.41393 & 1.33069 & 5.57148 \\
\hline FDioos & 8.36626 & 1.41871 & 5.89707 \\
\hline FD1010 & 7.66465 & 1.40895 & 5.43996 \\
\hline FD1075 & 8.03127 & 1.34883 & 5.95426 \\
\hline FD1450 & 7.11237 & 1.22266 & 5.81714 \\
\hline FD1470 & 8.38273 & 1.39905 & 5.99171 \\
\hline FD1705 ${ }^{\circ}$ & 7.67533 & 1.35517 & 5.66374 \\
\hline FD1913 & 8.27210 & 1.36329 & 6.05775 \\
\hline FD20050 & 7.99393 . & 1.33608 & 5.98311 \\
\hline FD2520 & 7.34498 & 1.27522 & 5.75977 \\
\hline FD 3240 & 6.84323 & 1.33042 & 5.14365 \\
\hline FD3320 & 8.28663 & 1.42266 & 5.82476 \\
\hline FD3360 & 7.35924 & 1.28387 & 5.73208 \\
\hline FD3382 & 6.90328 & 1.31986 & 5.23031 \\
\hline ED3410 & 7.37303 & 1.25586 & 5.87088 \\
\hline FD3450 & 6.91595 . & 1.22364 & 5.65195 \\
\hline FD3540 & 7.45088 & 1.26369 & 5.89613 \\
\hline FD3620 & 8.26597 & 1.44693 & 5.71275 \\
\hline FD3775 & 5.47017 & 1.42607 & 3.83584 \\
\hline FD3800 & 8.55488 & 1.41678 & 6.03824 \\
\hline FD3835 & 7.10535 & $1.36952^{\circ}$ & 5.18822 \\
\hline FD4098 & 4.97742 & 1.21899 & 4.08325 \\
\hline FD4135 & 6.66477 & 1.34207 & 4.96602 \\
\hline FD4160 & 8.67776 & 1.39450 & 6.22286 \\
\hline FD4875 & 6.97743 & 1.31890 & 5.29034 \\
\hline FD 5340 & 7.99649 & 1.41132 & 5.66598 \\
\hline FDS715 & 6.99626 & 1.30970 & 5.34188 \\
\hline FDS902 & 8.13507 & 1.48410 & 5.48150 \\
\hline FD6090 & 8.61460 & 1.46708 & 5.87194 \\
\hline FD6210 & 8.15784 & 1.38849 & 5.87533 \\
\hline FD6410 & 5.19687 & 1.31866 & 3.94101 \\
\hline FD6420 & 8.31096 & 1.47041 & 5.65214 \\
\hline FD6425 :- & -8.16514 & 1.38047 & 5.91476 \\
\hline FD6450 & 7.85647 & 1.39139 & 5.64649 \\
\hline FD6480 & 5.75349 & 1.21779 & $4.72453 t$ \\
\hline FD6630 & .8 .14303 & $1.39281^{\circ}$ & 5.84646 \\
\hline
\end{tabular}

\begin{tabular}{|c|c|c|c|}
\hline Coefficient & $\begin{array}{l}\text { Estimumed } \\
\text { Vahe }\end{array}$ & $\begin{array}{l}\text { Sundard } \\
\text { Error }\end{array}$ & t-stutistic \\
\hline FD7000 & 5.28159 & 1.29356 & 4.08298 \\
\hline TFSO & .020084 & .0688888 & .291553 \\
\hline TF330 & -.134264 & 2005530 & -.650097 \\
\hline TFE40 & -.134700 & .039999 & -3.36756 \\
\hline TF930 & .415624. & .148109 & 2.80619 \\
\hline TFicos & .017809 & .057366 & .310443 \\
\hline TF1010 & .061322 & .072269 & .848519 \\
\hline TE1075 & -.261762 & .098872 & -264748 \\
\hline -TF1450 & .084376 & .167036 & .505136 \\
\hline TF1470. & .366504 & .103084 & 3.55539 \\
\hline TF1705 & .052810 & .047528 & 1.11113 \\
\hline TF1913 & -1.18168 & .140446 & -8.41381 \\
\hline TE2050 & -.322587 & .055622 & -5.79967 \\
\hline TF2520 & .250722 & .063448 & -3.95163 \\
\hline TF3240 & .073692 & 315465 & -.233597 \\
\hline TF3320 & -.173362 & .124727 & -1.38993 \\
\hline TF3360 & -.381712 & .162348 & -2.35119 \\
\hline TF3382 & $.065795^{-}$ & -.140738 & .467497 \\
\hline TF3410 & -.386684 & .093987 & -4.11423 \\
\hline TF3450 & .449951 & .740135 & .607931 \\
\hline IF3540 & -.085064 & .075943 & -1.12011 \\
\hline TF3620 & -.166116 & .131860 & -1.25979 \\
\hline TF3775 &. .102120 & .090072 & -1.13376 \\
\hline TF3800 & -.242226 & .085042 & -2.84832 \\
\hline TF3835 & .565609 & .194963 & 2.90111 \\
\hline TF 4098 & -.348827 & .116545 & -2.99307 \\
\hline . Tr4135 & .460569 & .105199 & 4.37809 \\
\hline TF 4160 & -.495938 & .105004 & -4.72306 \\
\hline IF 4875 & -.588361 & .291423 & -2.01892 \\
\hline IF 5340 & -.144959 & .051680 & -2.80494 \\
\hline TF5715 & .298722 & .085840 & -3.47999 \\
\hline TF5902 & .238422 & .179567 & 1.32776 \\
\hline IF 6090 & .249150 & .271168 & .918804 \\
\hline IF6210 & -.089265 & .052300 & -1.70679 \\
\hline TF6410 &. .962534 & .103827 & -9.27059 \\
\hline TF6420 & .198308 & .057589 & -3.44353 \\
\hline TF6425 & -.457778 & $.275375^{\circ}$ & -1.66238 \\
\hline TF6450 & -.147791 & .070887 & -2.08489 \\
\hline IF6480 & -.134680 & .060004 & -2.24452 \\
\hline TF6630 & $\because 415677$ & .177621 & -2.34025 \\
\hline TF7000 & .629484 & .191316 & -3.29029 \\
\hline
\end{tabular}




\section{Table F5}

Data: Parameter estimates for the average cost of capital component in the total cost equation of the Distributor Tariff Module.

Author: Chetha Phang, EI-823, September 1996.

Sources: National Income and Product Accounts, Bureau of Economic Analysis, Dept of Commerce (MC_PGDP).

Moody's Investor's Service, Inc. (MC_RMPUAANS)

Board of Governors of the Federal Reserve System Statistical Release G.13, "Selected Interest Rates and Bond Prices" (RMGFCM@10NS)

U.S. Department of Labor, Bureau of Labor Statistics (WPISOP3500)

Mary L. Barcella, Ph.D., Consulting Economist, 2944 Davenport St., N.W., Washington, D.C. 20008

(AVG_COSTCAP)

Note: MC_REALRMGBLUS = RMGFCM@10S -

$$
\left.100 *(\text { (WPISOP3500(1)/WPISOP3500(13) })^{(1 / 3)}-1\right)
$$

Derivation: Parameters were estimated for the LDC cost of capital equation, as a function of the previously used proxy for the LDC cost of capital and a time trend, using the method of Ordinary Lease Squares (OLS). The exponent used on the time variable is an assumed value, resulting in a decreasing nonlinear time trend $\left(\mathrm{T}^{0.7}\right)$. Due to a lack of data it was not possible to obtain a 20-year average for the yield on $\mathrm{AA}$ utility bonds. Therefore from 1978 through 1993 the value of AVG_RMPUAANS was based on the average over the available years of data only (e.g., for 1978 a five year average was used). .The LDC cost of capital is defined as follows:

AVGCOSTCAP $=7.44691+(1.22689 *$ AVG_COSTCAP_OLD $)+\left(72.60079 * \mathrm{~T}^{-0.7}\right)$

$$
\text { t-statistic }=\quad(0.876) \quad(0.933)
$$

$\mathrm{N}=12, \mathrm{R}$-Squared $=0.849$, Durbin-Watson $=1.40$

[The coefficient on the time trend (72.60079) was mistyped in the code as (71.60079).]

Variables: AVG_COSTCAP Average LDC cost of capital as used in estimated equation for total cost of capital (1994\$/\$100 of capital)

AVG_COSTCAP_OLD Previously used proxy for average LDC cost of capital, as defined using MC_RMPUAANS, NG_REALRMGBLUS, MC_PGDP, and WT_DEBT as described in Chapter 6.

T Time trend, where $T=1$ for 1980

MC_RMPUAANS Yield on AA utility bonds (percent per, annum, not seasonally adjusted)

NG_REALRMGBLUS Real average yield on 10-year U.S. Government Bonds, Constant maturity , (percent)

MC_PGDP . Implicit price deflator for gross domestic product.

- RMGFCM@10NS Yield on 10-year U.S. Treasury notes, Constant Maturity (percent per annum, not seasonaily adjusted, average of daily figures, bond yield equivalent basis)

WPISOP3500 - Producer price index, finished goods, excluding food and energy (Index base: $1982=1.00$, seasonally adjusted)

WT_DEBT weighting for debt/equity contribution to cost of capital 
Data used in estimating parameters in Table F5

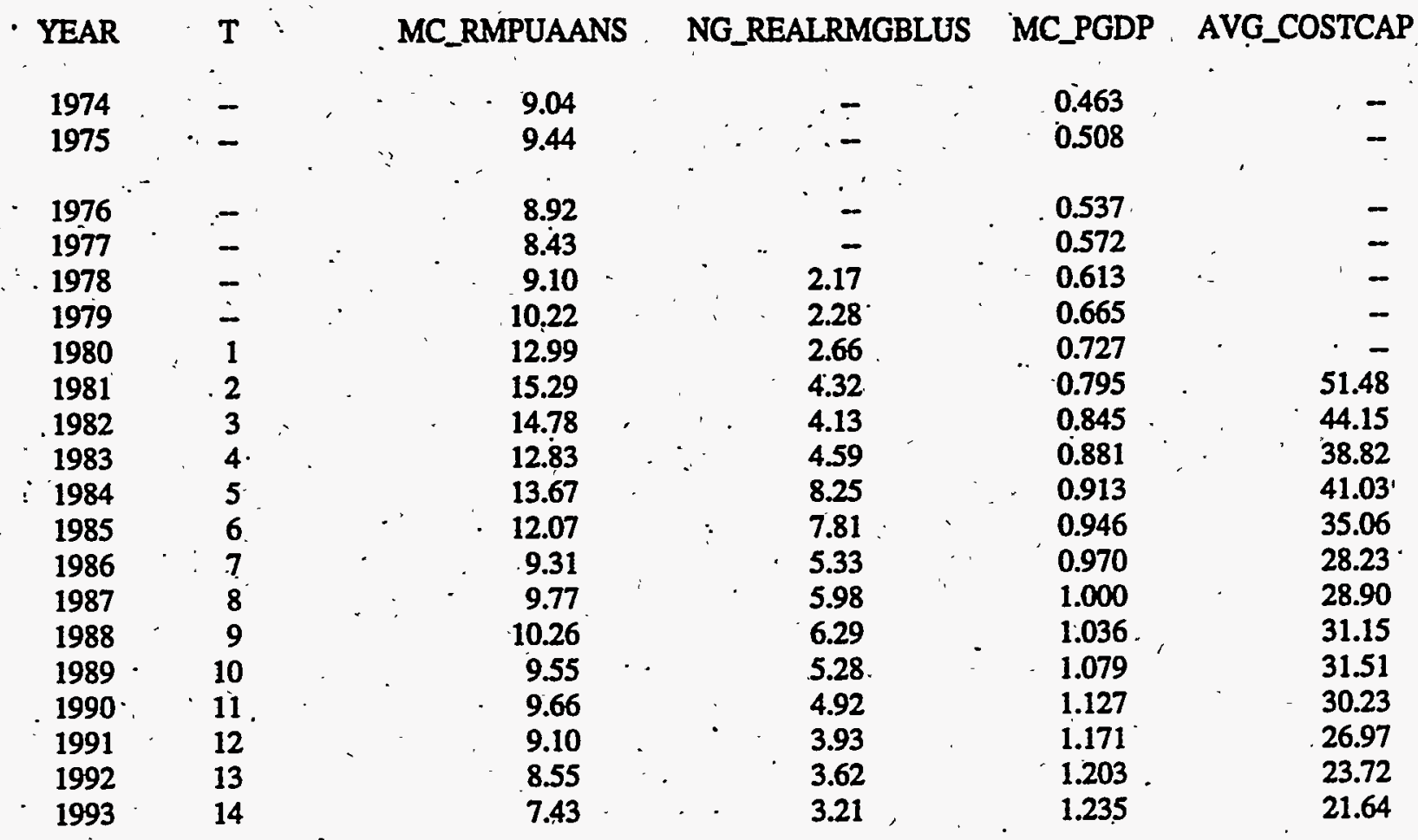




\section{Table F6}

Data: Historical electric generator natural gas prices by type of service, NGTDM/EMM region

\section{Subroutine: NGTDM_HISTUPR .}

Derivation: Natural gas prices by NGTDM/EMM region in the historical years for electric generators (HPGFELGR, HPGIELGR,-HPGCELGR) are read from NGTDM input files for the three types of services represented in the model: core, noncore and competitive-with-distillate, and noncore and competitive-with-residual. Assumptions are used to generate the competitive-with-distillate prices. Given the corresponding consumption levels assigned in the Electricity Market Module (EMM), and passed to the NGTDM during a model nin (QGFELGR, QGELGR, QGCELGR), the input file values for HPGFELGR, HPGIELGR; and HPGCELGR are scaled to insure that the resulting quantityweighted average prices for electric generators at the Census Division (TAVGPR) match published historical values (HPNGEL).

Variables: HPGFELGR Historical natural gas prices for core electric generators by NGTDM/EMM region (Appendix E, 1987\$/Mcf)

HPGIELGR Historical natural gas prices for noncore, competitive-with-distillate, electric generators by NGTDM/EMM region (Appendix E, 1987\$/Mcf)

HPGCELGR Historical natural gas prices for noncore, competitive-with-residual; electric generators by NGTDM/EMM region (Appendix E, 1987\$/Mcf)

QGFELGR Historical natural gas consumption by core electric generators by NGTDM/EMM region (Output from EMM, MMBtu)

QGIELGR Historical natural gas consumption by noncore, competitive-with-distillate, electric generators by NGTDM/EMM region (Output from EMM, MMBtu)

QGCELGR Historical natural gas consumption by noncore, competitive-with-residual, electric generators by NGTDM/EMM region (Output from EMM, MMBtu)

HPNGEL Historical natural gas price to electric generators by Census Division (Appendix E, 1987\$/Mcf) 


\section{Table F7}

Data: Historical industrial sector natural gas prices by type of service, NGTDM region.

\section{Subroutine: NGTDM_HISTIPR}

Derivation: .- The historical industrial natural gas prices published in the Natural Gas Annual only reflect gas purchased through local distribution companies. In order to approximate the average price to all industrial customers by service type and NGTDM region (HPGFINGR, HPGINGR), data available at the Census Region from 1988,-1991, and 1994 Manufacturing Energy Consumption Surveys (MECS) were used. The procedure outlined below is used in the NGTDM to fill in the intermediate years and expand the regional detail. Through a special request the Census Bureau generated the MECS data used in the NGTDM by service type (core versus noncore) based on an assumption of which industrial classifications are more likely to consume most of their purchased natural gas in boilers.

Notes:

supply price $=$ average of wellhead and import prices

markup = end-use price minus supply price

type $=$ core or noncore

1) Calculate markups based on MECS data by Census Region, by type, in MECS years.

2) Linear -interpolate to get intervening years data for MECS based markups and industrial consumption by Census Region and type.

3) For years beyond the last MECS year, set MECS based markups to the value from the last MECS year and set MECS industrial consumption by applying growth rates (equal to observed growth in NEMS consumption levels) to the consumption in the last MECS year. by Census region and type.

4) Set end-use industrial MECS based prices for all historical years equal to the supply price plus markup, by Census Region and type.

5) Scale the prices in step \#4 by a factor that will insure that the resulting prices, when averaged (across types in each Census Region) based on NEMS consumption level weights will equal the prices from step \#4 averaged based on MECS consumption level weights.

6) Calculate markups equal to the supply price minus the prices calculated in step 5 by Census Region and type.

7) Add these markups to the average supply price in each NGTDM region, within the associated Census Region, to derive industrial natural gas prices by NGTDM region and type.

8) Scale the prices in step \#7 by a factor that will insure that the resulting prices, when averaged (across types and across NGTDM regions in each Census Region) based on NEMS consumption level weights will equal the prices from step \#4 averaged based on MECS consumption level weights, to arrive at HPGFINGR and HPGIINGR.

9) Using NEMS consumption levels and HPGFINGR and HPGINGR, calculate the quantity-weighted average industrial natural gas prices in each-Census Division (HPGFIN, HPGIN).

Variables: MPIN_CRG Industrial core and noncore natural gas price from MECS by Census Region, in MECS survey years (Appendix E, \$1987/Mct)

MQIN_CRG Industrial core and noncore natural gas consumption from MECS by Census Region, in MECS survey years (Appendix E, Bcf)

PW_CRG : Average natural gas wellhead price by Census Region, in MECS survey years (Appendix E, \$1987/Mcf)

HPGFINGR Resulting industrial core natural gas price by NGTDM region (1987\$Mcf)

HPGINGR Resulting industrial noncore natural gas price by NGTDM region (1987\$/Mcf)

HPGFIN Resulting industrial core natural gas price by Census Division (1987\$/Mcf)

HPGIIN . Resulting industrial noncore natural gas price by Census Division (1987S/Mcf) 


\section{Variable Cross Reference Table}

The linear program (LP) formulation of the Annual Flow Module (AFM) is presented in matrix form in Figure G-1. The rows represent the objective function, variable bounds, and problem constraints, and the columns are the variables to be solved. Each row (constraint) and column (variable) have been given a unique name which also are defined in Figure G-1. The row and column names are used in the code to identify where changes are to be made in the working matrix during each model iteration or model year. Since the variables defined in the AFM LP equations are being referenced differently within 1) the mathematical equations presented in Chapter 5,2) the LP matrix (referenced above), and 3) the code, a cross reference table (Table $G-1$ ) has beeri generated for these variables. .

Similarly, Figure G-2 presents the LP matrix representation of the Capacity Expansion Module (CEM) formulation, as well as definitions of the abbreviations and names used. Again, the columns represent the variables, and the rows represent the objective function, variable bounds, and problem constraints corresponding to the model equations defined in Chapter 7. Table G-2 presents a cross reference of the names used within 1) the mathematical equations presented in Chapter 7, 2) the LP matrix (referenced above), and 3) the code to reference the variables in the model equations.

Note that in both figures, two coefficients are defined for a single variable in the mass balance constraints. This is a shortcut means of representing the coefficient associated with the same flow variable that is needed within two mass balance constraints. For example, when the are represents flow into a node, the coefficient is the arc efficiency variable; however, when the arc represents flow going out of a node, the flow should not be reduced by efficiency, thus the coefficient is one.

The Pipeline Tariff Module (PTM) is represented by economic and regression equations (see Chapter 8 for details). Table G-3 presents cross references of model equation variables defined in this document and in the code for the PTM. 
Figure G-1. LP Matrix Definition for the Annual Flow Module (AFM)

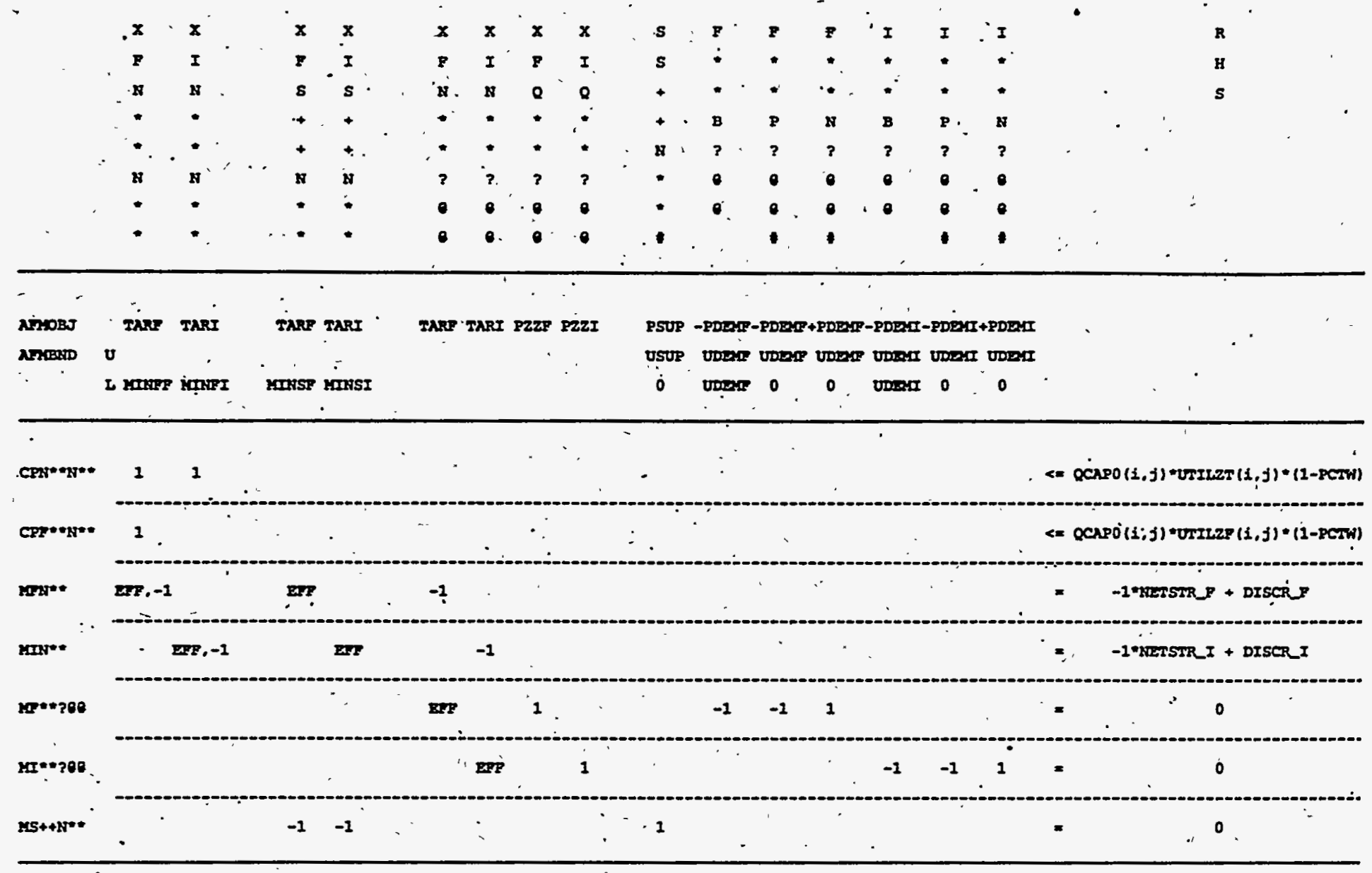

Legend: $*=$ nodes $(01-23),++*$ ogSy region $(01-06), Z=$ sector code $(R, C, I, T, U)$,

00-= CFisus (01-09) or NRRC region (01-13), = stop number on curve (1-9) 
Figure G-1. LP Matrix Definition for the Annual Fiow Module (AFM) (Continued)

Columns

\begin{tabular}{|c|c|c|}
\hline $\begin{array}{l}X F N * N * * \\
X I N * N * *\end{array}$ & $\begin{array}{l}= \\
=\end{array}$ & $\begin{array}{l}\text { Firm flow from node to node } \\
\text { Internuptible flow from node to node }\end{array}$ \\
\hline $\begin{array}{l}\text { XFS }++N_{* *}^{*} \\
X I S++N_{*}^{* *}\end{array}$ & $\begin{array}{l}= \\
=\end{array}$ & $\begin{array}{l}\text { Firm flow from supply to node } \\
\text { Interruptible flow from supply to node }\end{array}$ \\
\hline $\begin{array}{l}X F N^{* *} ? \text { ? @ @ } \\
X I N * * ? @ @ \\
X F Q * ? ? @ @ \\
X I Q * * ? @ @\end{array}$ & $\begin{aligned} \cdot & = \\
\cdot & = \\
& = \\
& =\end{aligned}$ & $\begin{array}{l}\text { Firm flow to end-use sector } \\
\text { Interruptible flow to end-use sector } \\
\text { Firm flow from backstop supply to end-use sector } \\
\text { Interruptible flow from backstop to end-use sector }\end{array}$ \\
\hline $\begin{array}{l}S S++N * * \# \\
F * * B ? @ @ \\
F * * P ? @ @ \# \\
F * * N ? \text { ? @ @ } \\
I * * B ? @ @ \\
I * * P ? @ @ \# \\
I * * N ? @ @ \#\end{array}$ & $\begin{array}{l}= \\
= \\
= \\
= \\
= \\
=\end{array}$ & $\begin{array}{l}\text { Steps on regional supply curve } \\
\text { Base step on core demand curve } \\
\text { Positive steps on core demand curve } \\
\text { Negative steps on core demand curve } \\
\text { Base step on noncore demand curve } \\
\text { Positive steps on noncore demand curve } \\
\text { Negative steps on noncore demand curve }\end{array}$ \\
\hline & & le of constraint equations \\
\hline
\end{tabular}

Rows

AFMOB J

AFM B N D

$C P N * * N * *$

$C P F * * N * *$

MFN**

$M I N * *$

$M F * *$ ?@@

$M I * * ? @ @$

$\mathrm{MS}++\mathrm{N}^{* *}$
= AFM Objective Function

$=\mathrm{AFM}$ Variable Bounds

$=$ Pipeline capacity limit--Total flow

= Pipeline capacity limit-Firm flow

$=$ Regional mass balance--Firm network

$=$ Regional mass balance--Interruptible network

= End-use mass balance--Firm network

= End-use mass balance--Interruptible network

$=$ Supply subregion mass balance

Legend: ** = nodes (01-21), ++ = OGSM region (01-06), ? = sector code $(\mathrm{R}, \mathrm{C}, \mathrm{I}, \mathrm{T}, \mathrm{U})$,

$@ @=$ CENSUS (01-09) or NERC region.(01-13), \# = step number on curve (1-9) 
Figure G-1. LP Matrix Definition for the Annual Flow Module (AFM) (Continued)

Coefficients, Right Hand Sides (RHS); and Bounds

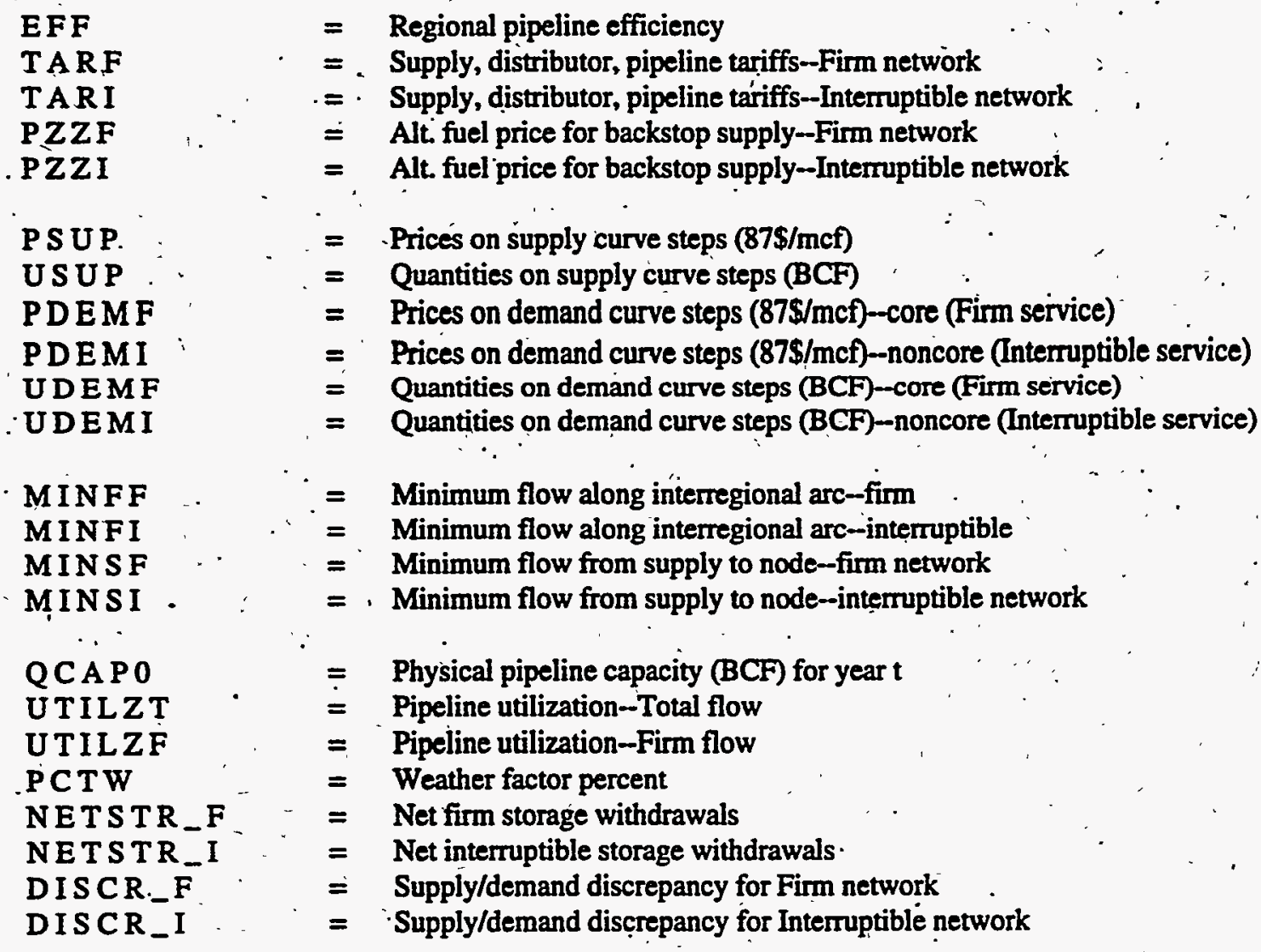




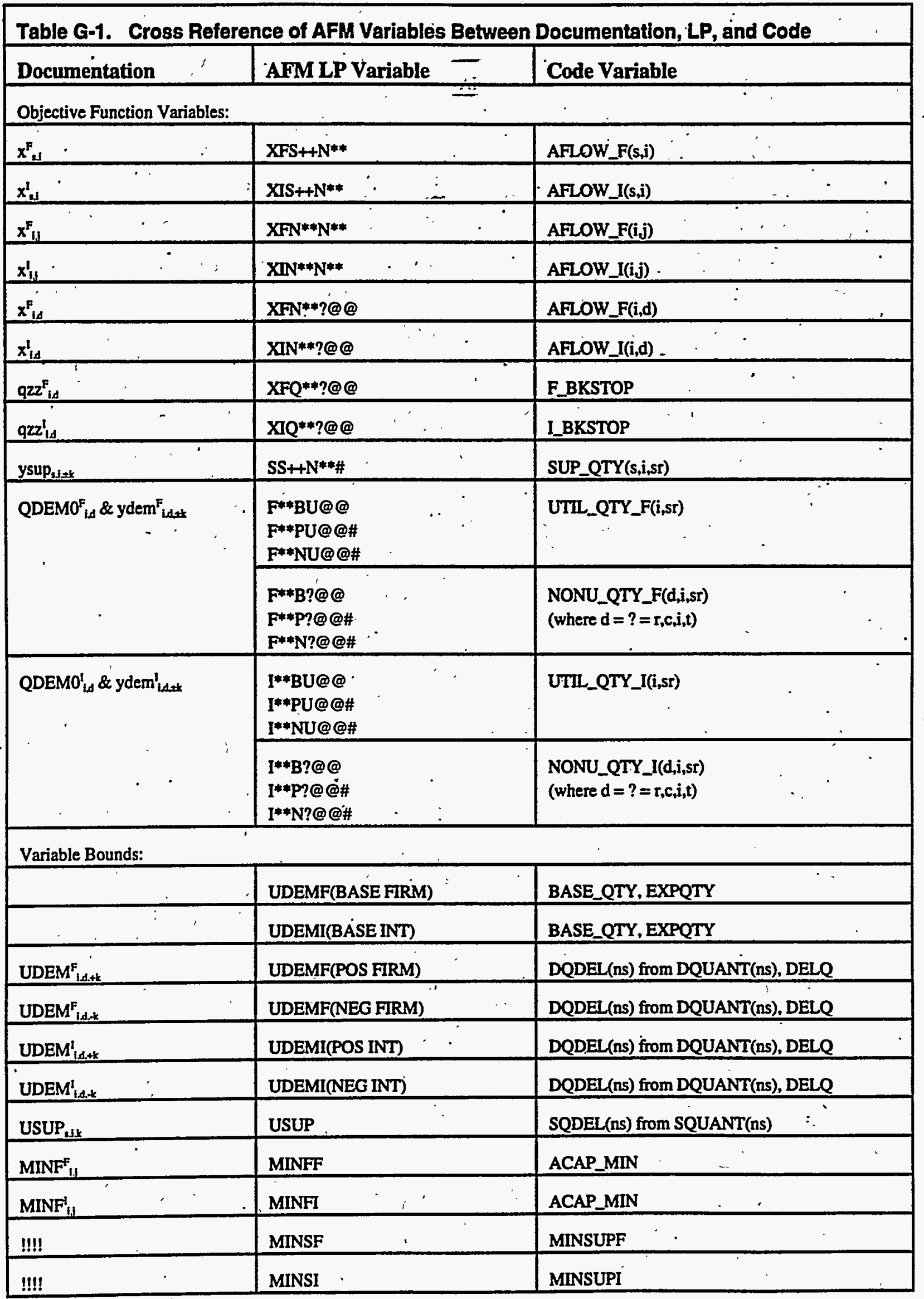




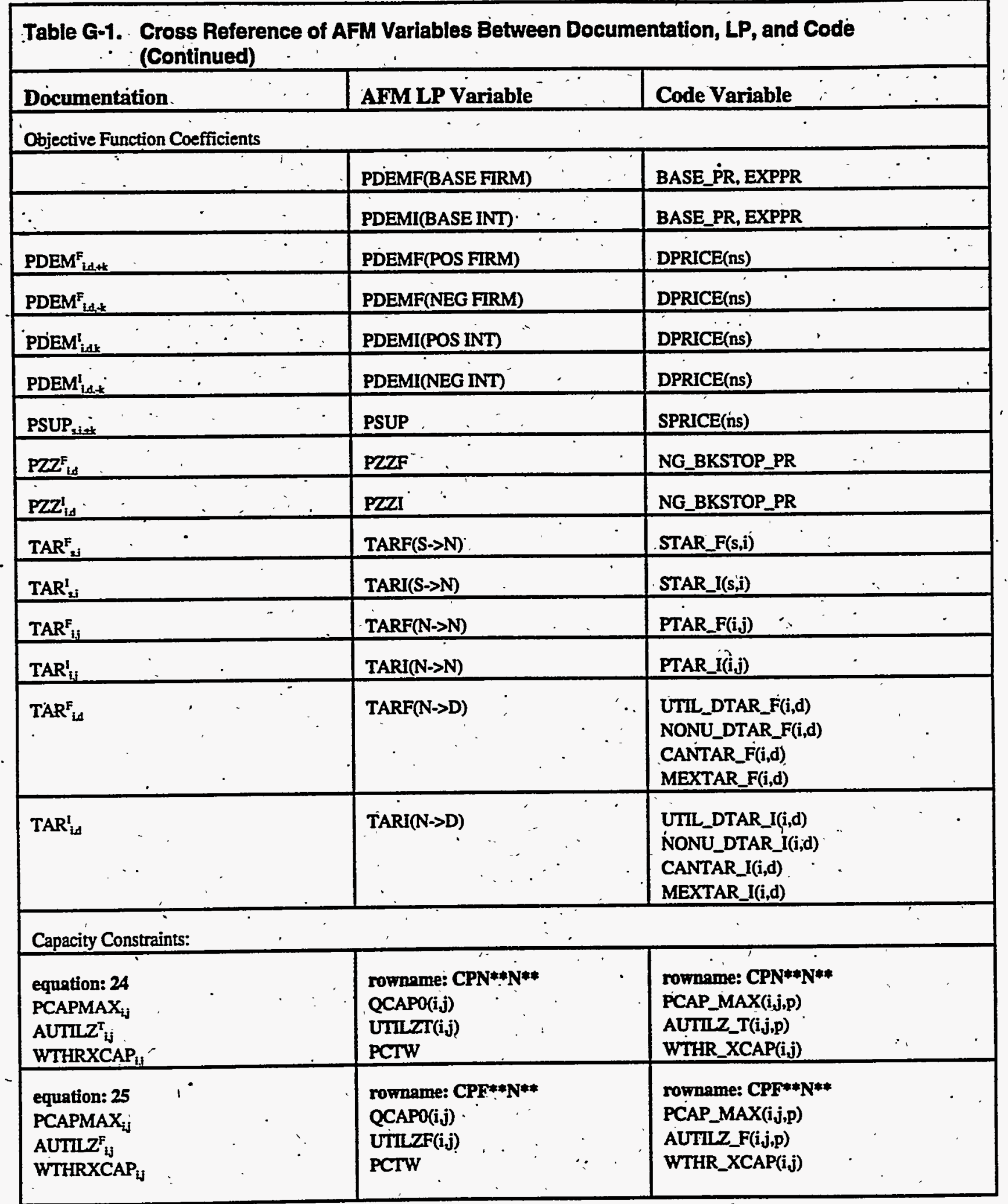




\begin{tabular}{|c|c|c|}
\hline Documentation & AFM LP Variable & Code Variable \\
\hline \multicolumn{3}{|c|}{ Mass Balance Constraints at Transshipment Nodes: } \\
\hline $\begin{array}{l}\text { equation: } 26 \\
\text { QSTR }_{s T} \\
\text { DISCR }_{m}^{F}\end{array}$ & $\begin{array}{l}\text { rowname: MFN** } \\
\text { NETSTR_F } \\
\text { DISCR_F . }\end{array}$ & $\begin{array}{l}\text { rowname: MFI** } \\
\text { NETSTR_F(i,p) } \\
\text { DISCR_F(i) }\end{array}$ \\
\hline $\begin{array}{l}\text { equation: } \mathbf{2 7} \\
\text { QSTR }_{5 \mathrm{TT}}^{1} \\
\operatorname{DISCR}_{\mathrm{m}}^{1}\end{array}$ & $\begin{array}{l}\text { rowname: } M N^{* *} \\
\text { NETSTR_I } \\
\text { DISCR_I }\end{array}$ & $\begin{array}{l}\text { rowname: MinN** } \\
\text { NETSTR_I(i,p)! } \\
\text { DISCR_I(i) }\end{array}$ \\
\hline $\begin{array}{l}\text { Coefficients: } \\
\mathrm{EFF}_{\mathrm{im}} \\
\mathrm{EFF}_{\mathrm{im}}\end{array}$ & $\begin{array}{l}E F F(N->N) \\
E F F(S->N) \\
\end{array}$ & $\begin{array}{l}\text { AEFF_PIPE(i,m) } \\
\text { SEFF_PIPE(s,sr) } \\
\end{array}$ \\
\hline \multicolumn{3}{|c|}{ Mass Balance Constraints at Demand Points: } \\
\hline $\begin{array}{l}\text { equation: } 28 \\
\text { QDEMO } \\
\end{array}$ & $\begin{array}{l}\text { rowname: MF**??@@ } \\
\text { F**B?@@ }\end{array}$ & $\begin{array}{l}\text { rowname: MF**?@@ } \\
\text { UTIL_QTY_F,NONU_QTY_F }\end{array}$ \\
\hline $\begin{array}{l}\text { equation: } 29 \\
\text { QDEMO }\end{array}$ & $\begin{array}{l}\text { rowname: MI**?@@ } \\
\text { I**B?@@ }\end{array}$ & $\begin{array}{l}\text { rowname: MI**?@@ } \\
\text { UTIL_QTY_I, NONU_QTY_I }\end{array}$ \\
\hline $\begin{array}{l}\text { coemclents: } \\
\text { EFF }_{\text {LS }}\end{array}$ & 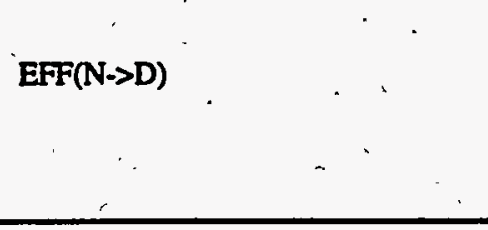 & $\begin{array}{l}\text { UEFF_PIPE(i,d) } \\
\text { NEFF_PIPE(i,d) } \\
\text { CANEFF(i) } \\
\text { MEXEFF(i) }\end{array}$ \\
\hline \multicolumn{3}{|c|}{ Mass Balance Constraint at Supply Points: } \\
\hline equation: 30 & rotrname: $M S++N^{* *}$ & rowname: $\mathrm{MS}++\mathrm{N}^{* *}$ \\
\hline
\end{tabular}


Figure G-2. LP Matrix Definition for the Capacity Expansion Module (CEM)

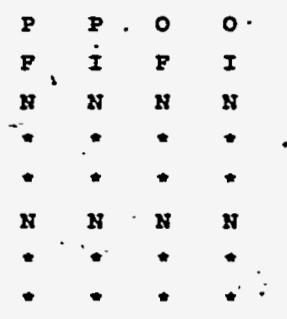

\begin{tabular}{|c|c|c|}
\hline $\mathbf{P}$ & $\mathbf{P}$ & 0 \\
\hline$E$ & $I$ & $\mathbf{F}$ \\
\hline$s$ & $\mathbf{s}$ & $\mathbf{s}$ \\
\hline & + & + \\
\hline & + & tôt. \\
\hline $\mathrm{N}$ & N & $3_{3}$ \\
\hline
\end{tabular}

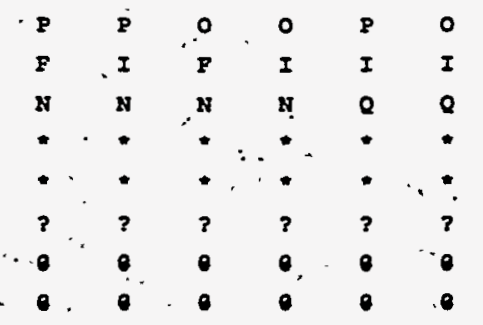

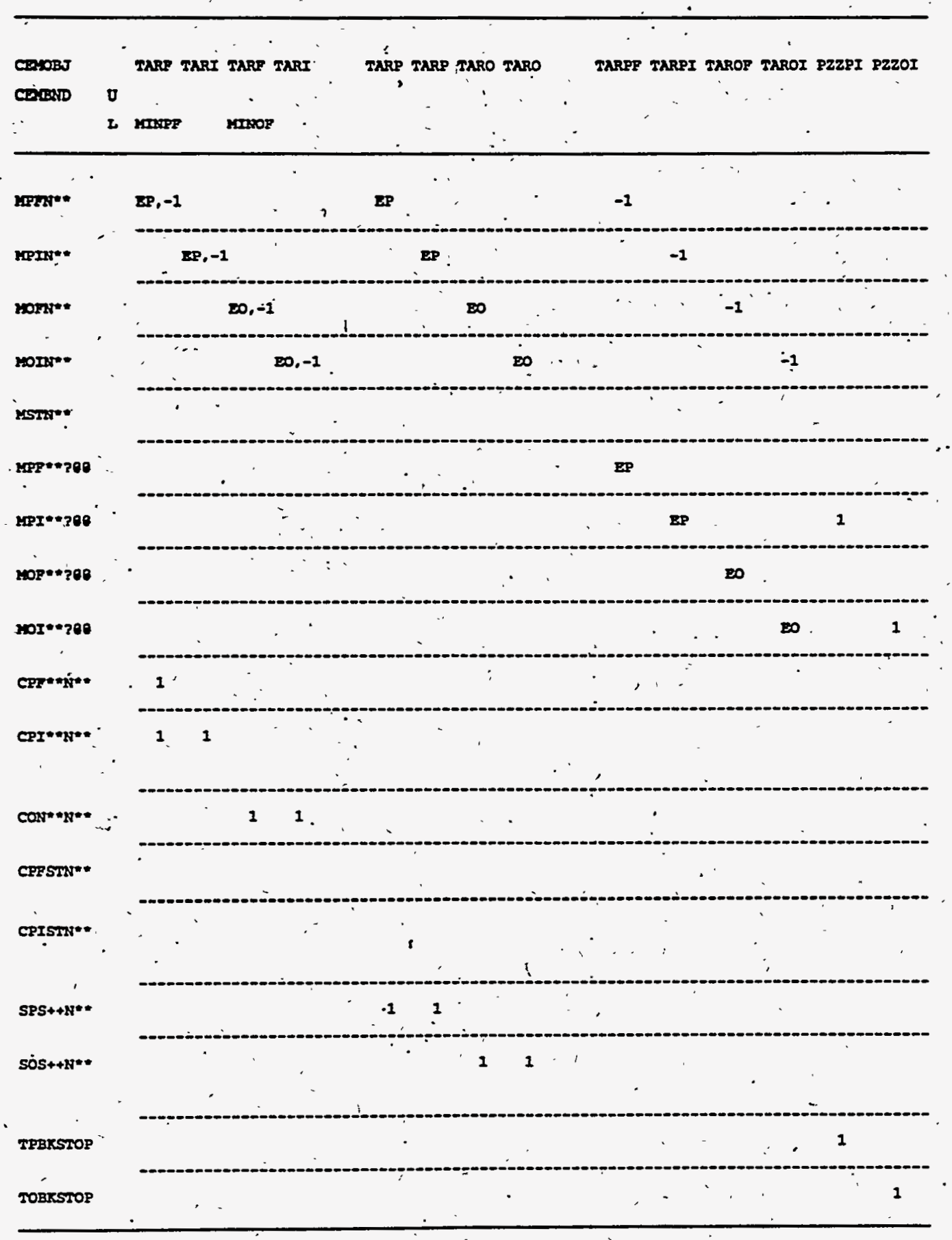

Iegend: $+*$ modes $(01-21),++=$ ocsy region $(01-06)$, $\}$ = sector code $(R, C, I, T, U)$ ee * Census $(01-09)$ or kERC region $(01-13)$. = atep number on curve $(0-9)$ 
Figure G-2. LP Matrix Definition for the Capacity Expansion Module (CEM) (Continued)

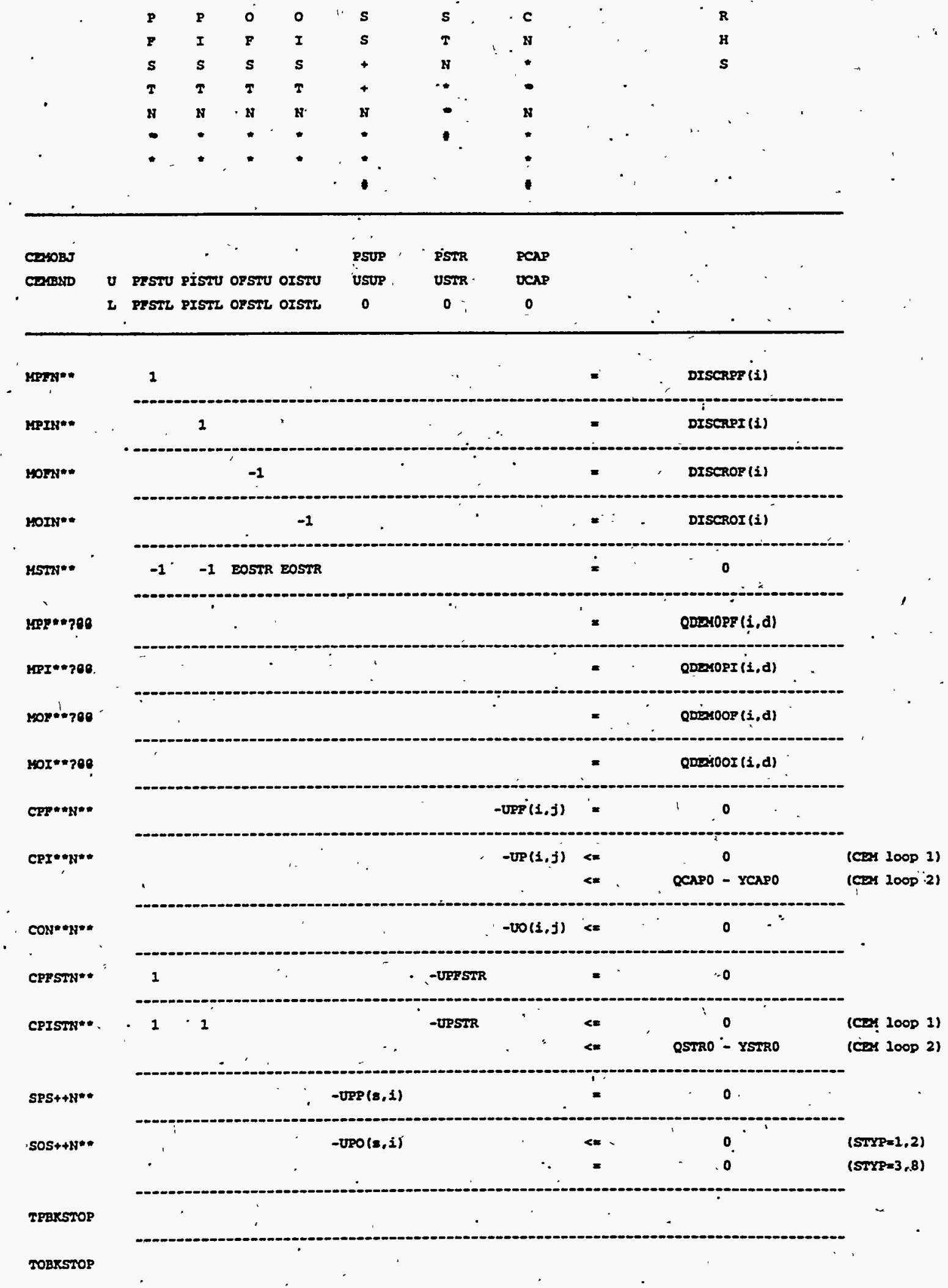

Logend: + a nodes $(01-21),++=$ OGSY region $(01-06), ?=$ iector code $(R, C, I, T, U)$, 00 - CENSUS (01-09) or sterc rogion (01-13), = step number on curve (0-9) 
Columns

\section{PFN**N** \\ $\operatorname{PIN} * * * * *$ \\ OFN**N** \\ OIN**N**}

PFS $++N^{* *}$

$\operatorname{PIS}++\mathbf{N} * *$

OFS $++N^{* *}$

OIS $++N^{* *}$

PFN**?.@@

OFN**?@@

OIN**??@@

PIQ**?@@

OIQ**?@@
PIN**?@@

$=$ Peak Firm flow from node to node

$=$ Peak Interiuptible flow from node to node

$=$ Off-Peak Firm flow from node to node :

= Off-Peak Interruptible flow from node to node

$=$ Peak Firm flow from supply to node

$=$ Peak Interruptible flow from supply to node

$=$ - Off-Peak Firm flow from supply to node

= Off-Peak Internuptible flow from supply to node

$=$ Peak Firm flow to end-use sector

$=$ Peak Interruptible flow to.end-use sector

$=$ Off-Peak Firm flow to end-use sector

$=$ Off-Peak Internuptible flow to end-use sector

$=$ Peak Interruptible flow from backstop supply to.end-use sector

$=\quad$ Off-Peak Interruptible flow from backstop supply to end-use sector .

$=$ Peak Firm flow from storage.

$=$ Peak Interruptible flow from storage

$=$ Off-Peak Firm flow from into storage

$=$ Off-Peak Interruptible flow from into storage

$=$ Steps on regional supply curve

$=$ Steps on storage.capacity expansion curve

$:=$ Steps on pipeline capacity expansion curve

R H S

$=$ Right hand side of constraint equations

Rows

\begin{tabular}{|c|c|c|}
\hline 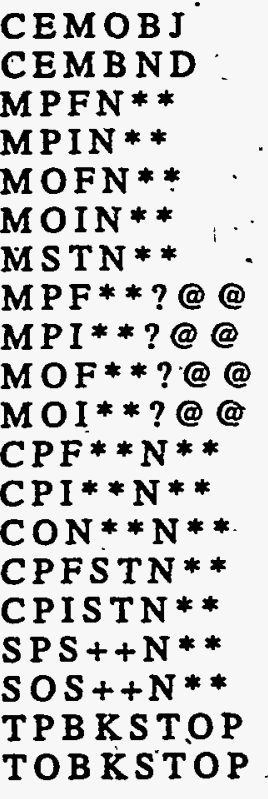 & $\begin{array}{l}= \\
=\end{array}$ & $\begin{array}{l}\text { CEM Objective Function } \\
\text { CEM Variable Bounds } \\
\text { Regional mass balance--Peak Firm network } \\
\text { Regional mass balance--Peak Intermptible network } \\
\text { Regional mass balance--Off-Peak Firm network } \\
\text { Regional mass balance--Off-Peak Intermptible network } \\
\text { Regional mass balance--Storage points } \\
\text { End-use mass balance--Peak Firm network } \\
\text { End-use mass balance--Peak Interuptible network } \\
\text { End-use mass balance--Off-Peak Firm network } \\
\text { End-use mass balance--Off-Peak Interruptible network } \\
\text { Pipeline capacity limit-Peak Firm flow } \\
\text { Pipeline capacity limit-Total Peak flow } \\
\text { Pipeline capacity limit--Total Off-Peak flow } \\
\text { Regional storage capacity limit-Peak Firm flow. } \\
\text { Regional storage capacity limit-Total Peak flow } \\
\text { Region supply limits for total Peak flows } \\
\text { Region supply limits for total Off-Peak flows } \\
\text { Backstop used--Total Peak } \\
\text { Backstop used--Total Off-Peak }\end{array}$ \\
\hline
\end{tabular}

Legend: $* *=$ nodes $01-21,++=$ OGSM region $01-06, ?=$ sector code, @ @ = CENSUS or NERC region, 01-13, \# = step number on curve 
Coefficients, Right Hand Side (RHS), and Bounds

TARF

- TARI

T A R P

TARO

T A R P F

TARPI

TAROF

TAROI

PZZPI

PZZOI

PSUP

US UP

PSTR

US TR

PCAP

UCAP

MINPF

MINOF

PFSTU.

PFSTL

PISTU

PISTL

OFSTU

OFSTL

OISTU

OISTL

\section{EP}

EO

EOSTR

\section{UPF}

UP

UO

UPFSTR

UPSTR

UP P

UPO

D I S C R P F

D IS CR P I

DISCROF

DISCROI

QDEMOPF

QDEMOPI

QDEMOOF

QDEMOOI

QS TRO

Y S TRO
$=$ Interregional pipeline tariffs--Firm networks

$=$ Interregional pipeline tariffs--Interruptible networks

$=$ Supply gathering charges--Peak networks

$=$ Supply gathering charges-Off-Peak networks

$=$ Distributor tariffs--Peak Firm network

$=$ Distributor tariffs--Peak Interriptible network

$=$ Distributor tariffs--Off-Peak Firm network

' = Distributor tariffs--Off-Peak Intrp. network

= Alt. fuel price for backstop supply--Peak Interruptible network

= Alt. fuel price for backstop supply-Off-Peak Interruptible network

$=\quad$ Prices on supply curve steps (87\$/mcf)

$=\quad$ Quantities on supply curve steps (BCF)

$=\quad$ Prices on storage capacity curve steps $(87 \$ / \mathrm{mcf})$

$=$ Quantities on storage capacity curve steps (BCF)

$=$ Prices on pipeline capacity curve steps (\$/mcf)

$=$ Quantities on pipeline capacity curve step (BCF)

$=$ Minimum interregional flow-Peak Firm

$=$ Minimum interregional flow--Off-Peak Firm

$=$ Maximum flow from storage.to Peak Firm network

$=$ Minimum flow from storage to Peak Firm network

$=$ Maximum flow from storage to Peak Interruptible network

$=$ Minimum flow from storage to Peak Interruptible network

$=$ Maximum flow from storage to Off-Peak Firm network

. = Minimum flow from storage to Off-Peak Firm network

=. Maximum flow from storage to Off-Peak Interruptible network

$=$ Minimum flow from storage to Off-Peak Interruptible network

$=$ Regional pipeline efficiency--Peak networks.

$=$ Regional pipeline efficiency-Off-Peak networks

$=$ Regional storage efficiency

$=\quad$ Utilization factor for Peak Firm flows (i.e., $: 33 * .95$ )

$=$ Utilization factor for total Peak flows (i.e., .33*.99)

$=\quad$ Utilization factor for total Off-Peak flows (i.e., .67*.80)

$=\quad$ Utilization factor for Peak Firm storage flows

$=$ Utilization factor for total Peak storage flows

$=$ Maximum \% supply available for Peak flows (i.e., .33 * .99)

$=$ Maximum \% supply available for Off-Peak flows (i.e., $.33 * .85$ )

$=$ Supply/demand discrepancy for Peak Firm network

$=$ Supply/demand discrepancy for Peak Interruptible network

$=$ Supply/demand discrepancy for Off-Peak Firm network

$=$ Supply/demand discrepancy for Off-Peak Interruptible network

$=$ Peak core (Firm service) demands (BCF) for year $t+n+h$ or $t+n$

$=$ Peak noncore (Interruptible service) demands (BCF) for year $t+n+h$ or $t+n$

$=$ Off-Peak core (Firm service) demands (BCF) for year $t+n+h$ or $t+n$

$=$ Off-Peak noncore (Interruptible service) demands (BCF) for year. $t+n+h$ or $t+n$.

$=$ Existing + Planned storage capacity (BCF) for year $t+n$

$=$ Utilized capacity (BCF) in alpha loop 1 
Table G-2. Cross Referénce of CEM Variables Between Documentation; LP, and Code

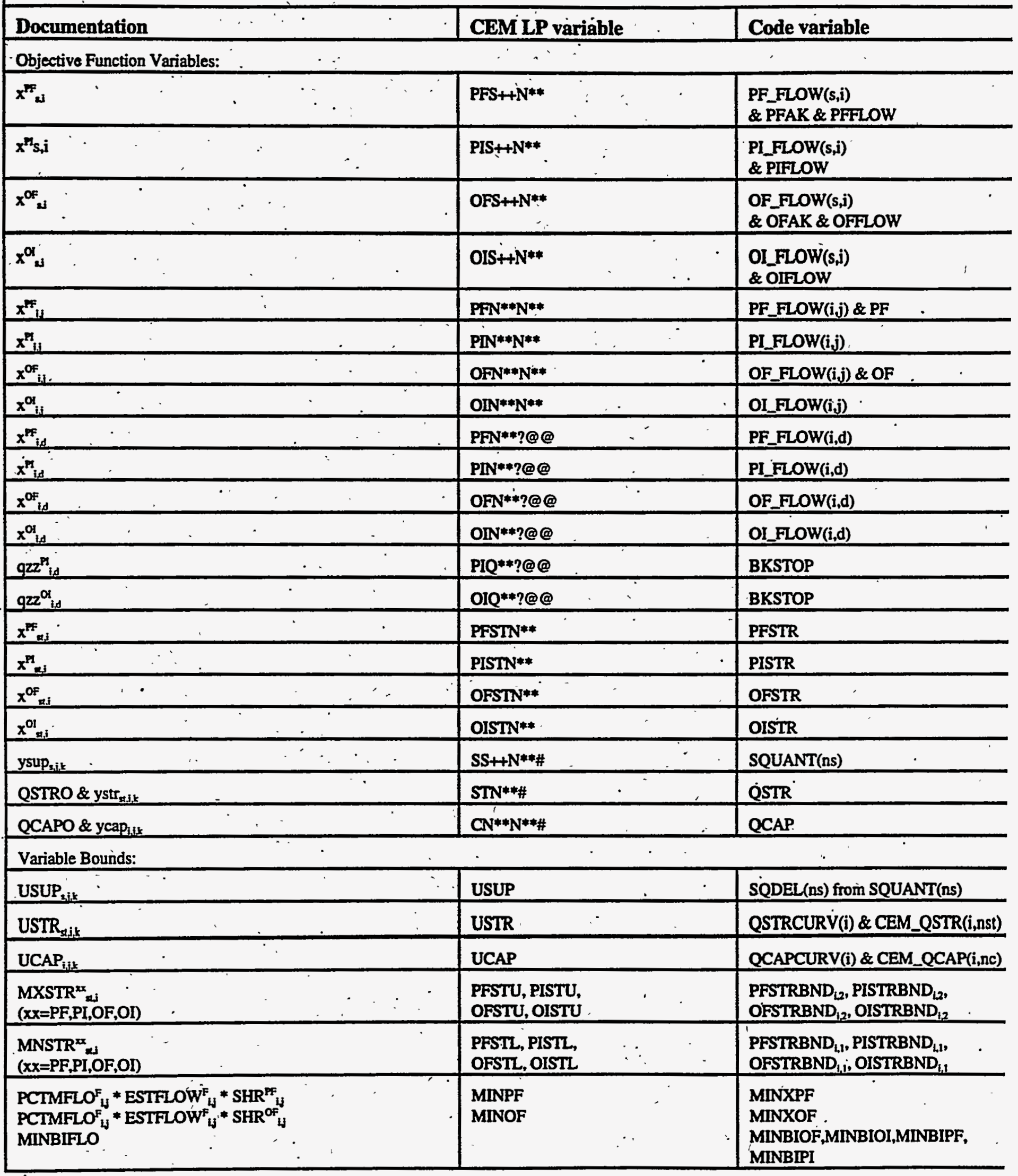




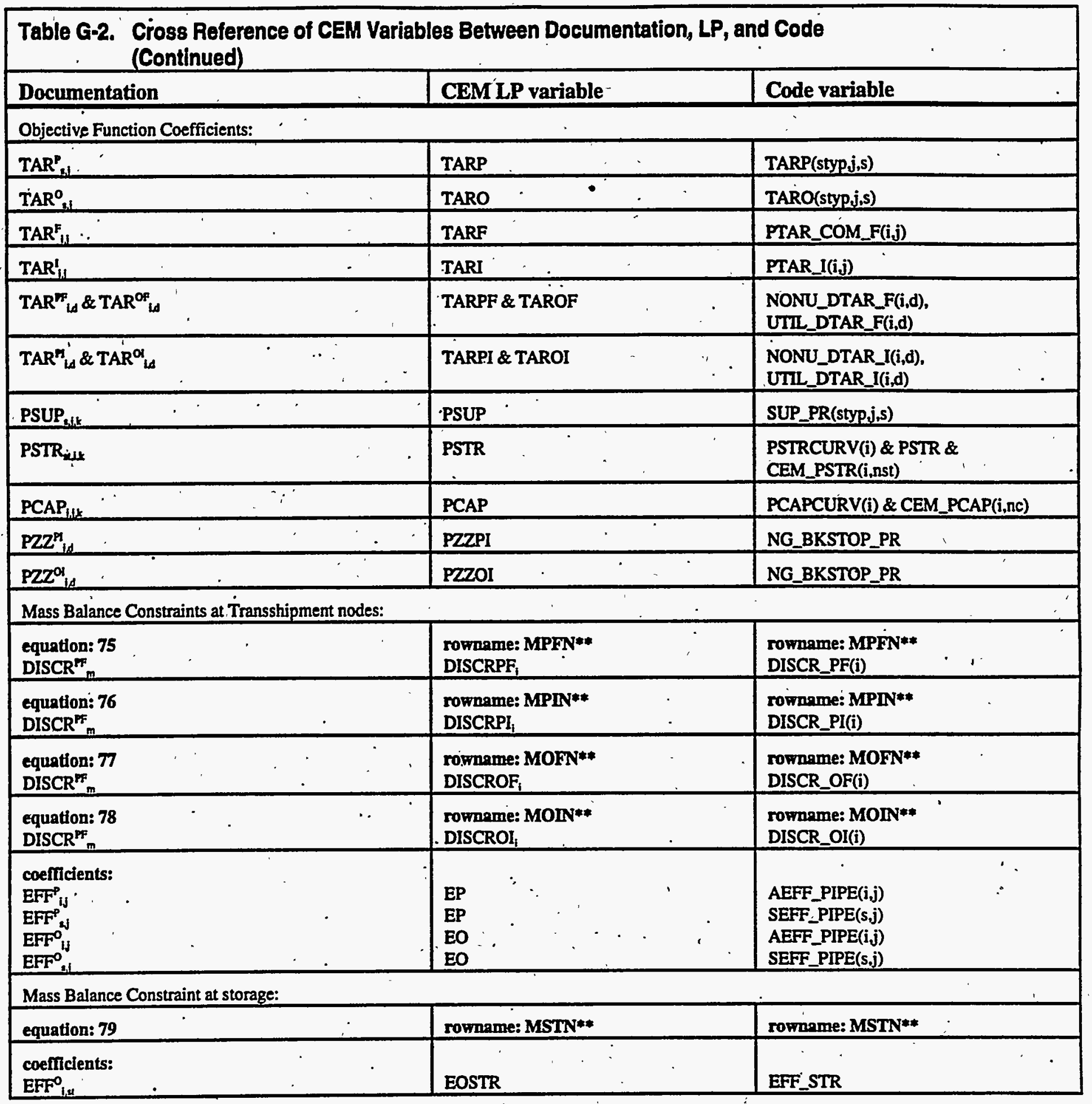




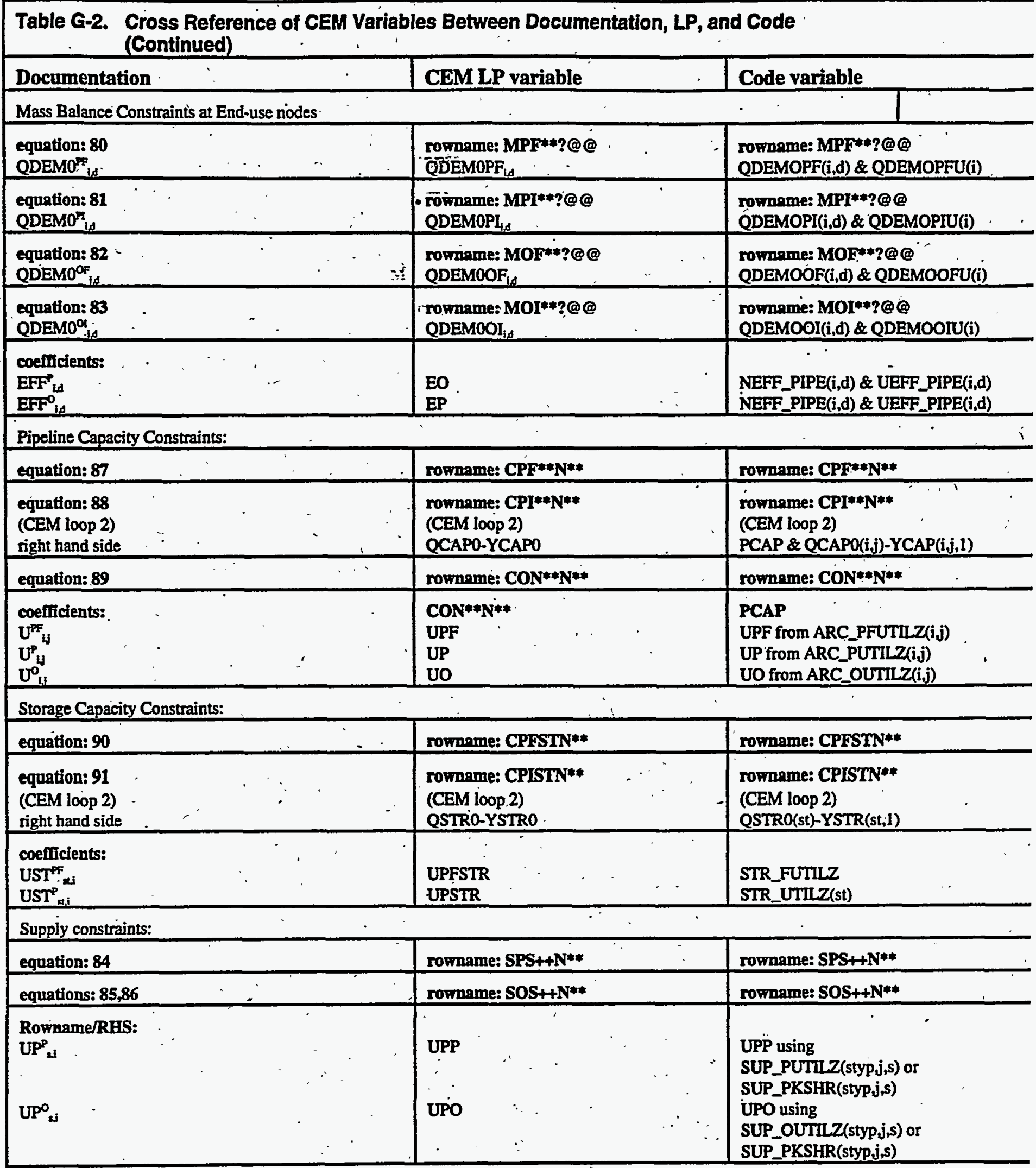




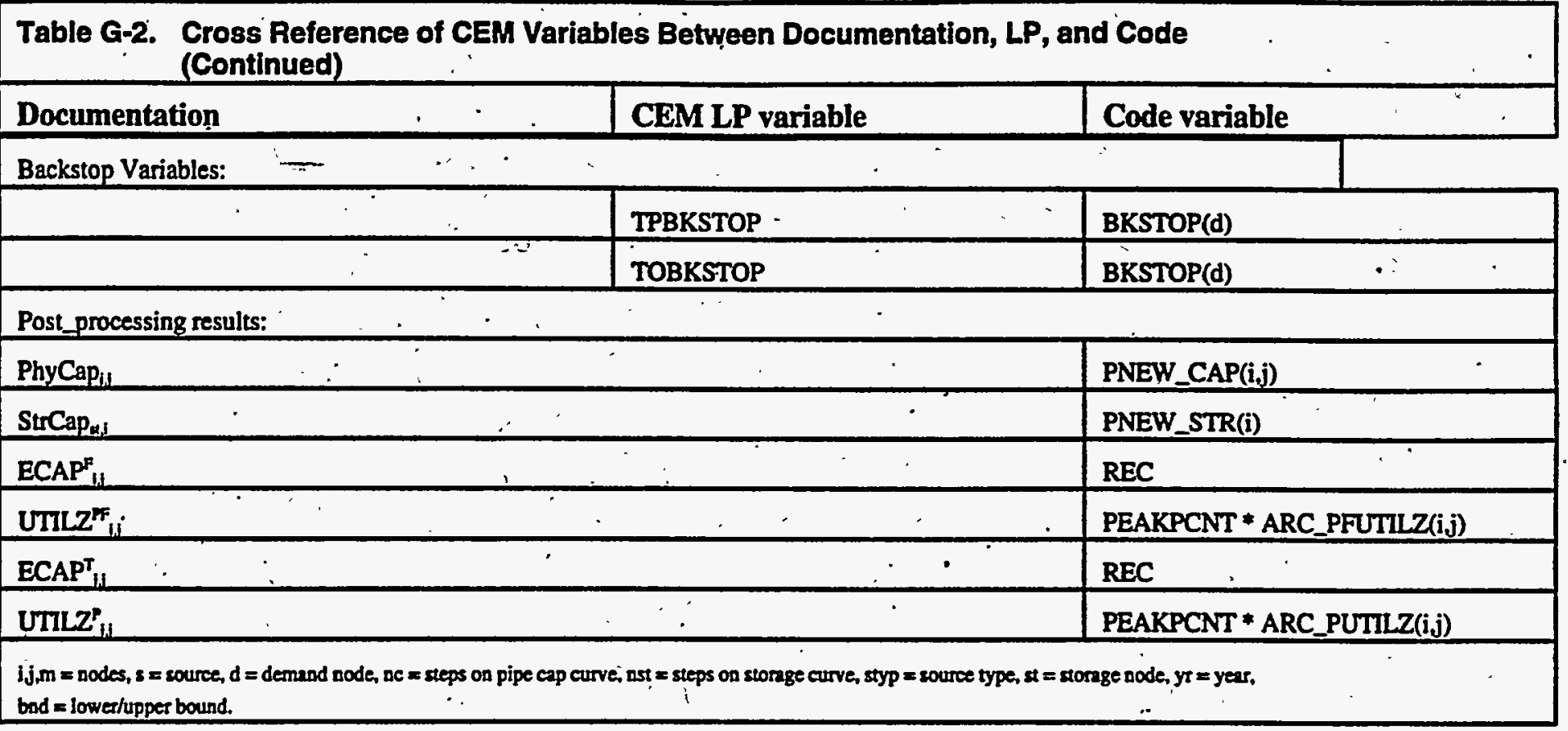




\begin{tabular}{|c|c|c|}
\hline Documentation & Code Variable & Equation \# \\
\hline \multicolumn{3}{|l|}{ 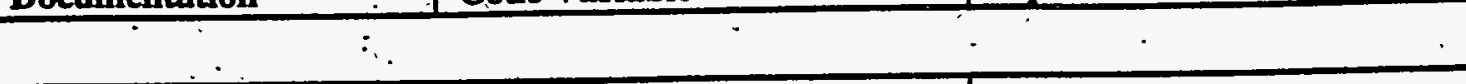 } \\
\hline$\underline{\mathbf{R}_{\mathbf{I}} \cdot \cdot \cdot}$ & RF. & $119,121,122$ \\
\hline $\mathbf{R}_{\mathbf{i , y}} \cdots$ & $\dot{.}$ & $120,123,124$ \\
\hline $\mathrm{ALL}_{1}$ & $A \dot{A R F}(\mathrm{rd}, \mathrm{i})$ & 119 \\
\hline ALL. & $\operatorname{ARV(rd,j)}$ & 120 \\
\hline $\mathbf{R}_{\mathbf{q}}$ & $\operatorname{cosT}(1, \mathbf{i})$ & 119,120 \\
\hline $\mathbf{R}_{\mathrm{ifr}}$ & RFR(i) & $\cdot$ \\
\hline $\mathbf{R}_{\mathrm{ifs}}$ & RFU(i) & $122 \quad: \quad$. \\
\hline $\mathbf{R}_{i, v s}$ & RVR(i) & 123 \\
\hline $\mathbf{R}_{\mathbf{p y n}}$ & RVU(i) & $124^{\circ}$ \\
\hline $\mathrm{ALL}_{x,}$ : & AFR(rd,i) & 121 \\
\hline$A L_{1,0}$ & AFU(nd,i) & 122 \\
\hline ALL, & AVR(id,i) & 123 \\
\hline$A L L$ & AVU(rd,i) & 124. \\
\hline $\mathbf{R}_{\mathbf{A}} \boldsymbol{D}^{-x}$ & Not used & 125 \\
\hline $\mathbf{R}_{\boldsymbol{A}}$ & RFR(18) & $125 \cdot$ \\
\hline$V_{A}^{b c} / V_{A}^{T}$ & PS(P,AF,AT) & 125 \\
\hline $\mathbf{R}_{1-2}$ & FĆR,VCR,FCU,VCU & 126 \\
\hline PMAX, & MAX(AF,AT) & 130 \\
\hline INDUSTRYGPIS $_{t, 1}$ & PLTOGPIS1 & 179 \\
\hline GPIS $_{1,1}$ & PGPIS & $176,178,179,183,186$ \\
\hline UTIL_RATE_I & UTILR_I & $154,155^{\prime}$ \\
\hline INC_REV, & not used & $157,160^{\circ}$ \\
\hline INC_COST & $\cdot \quad \cdot$ & 159,160 \\
\hline $\mathrm{CIS}_{2} / \mathrm{MC}$ PGDT, & REQR_INT & 157 \\
\hline PNEWFAC & NEWCOST & $182,214 \quad$ \\
\hline$\beta 0$ & OWC_BETAO & 186 \\
\hline : : : & OWC_BETA1 & 186 \\
\hline$\beta 2$ & OWC_BETA2 & 186 \\
\hline$\rho$ & OWC RHO & 186 \\
\hline
\end{tabular}




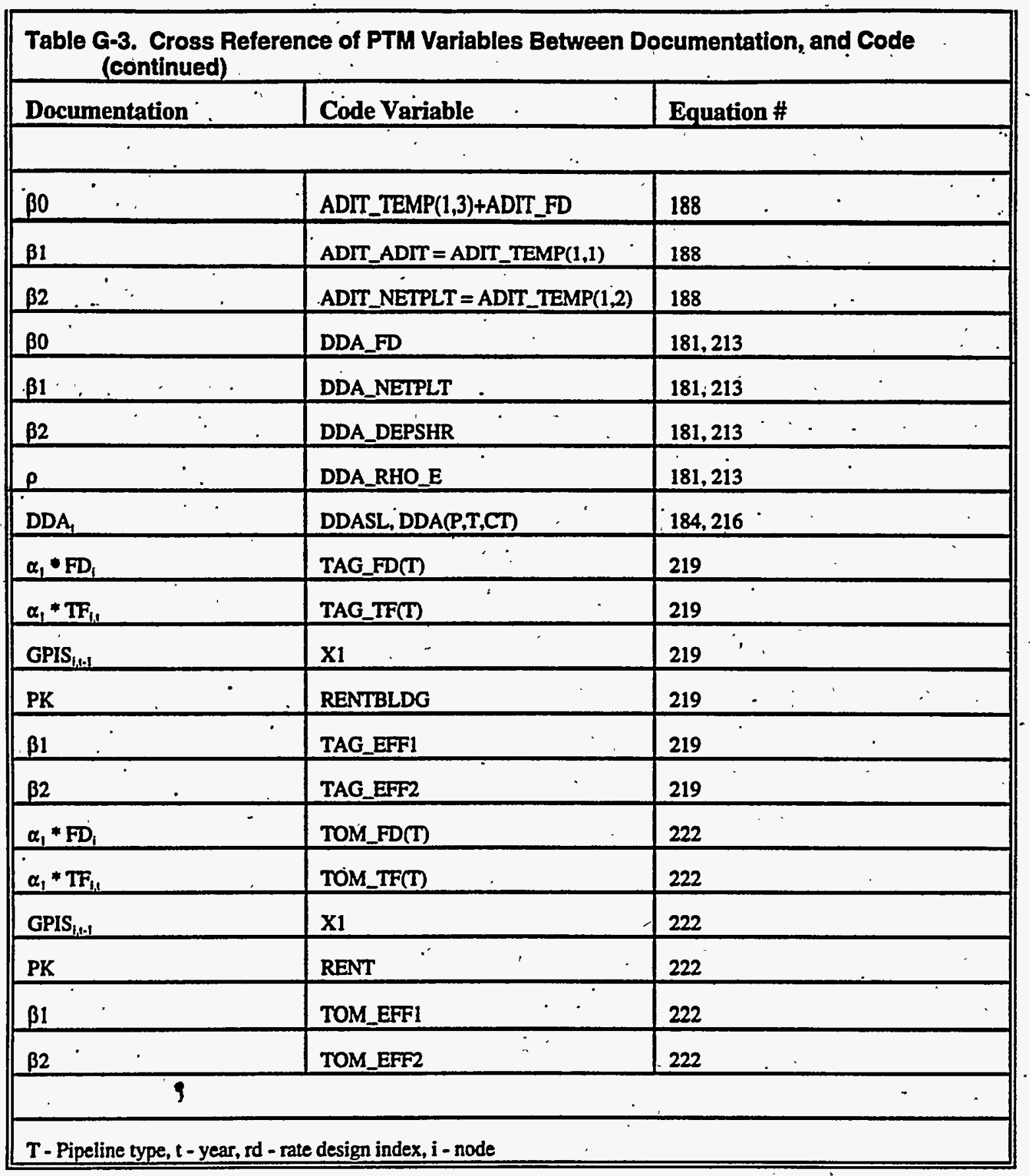




\section{Appendix H}

\section{Model Equations}

This appendix presents the mapping of the equation (by equation number) in the documentation with the subroutine in the NGTDM code where the equation is used or referenced. 


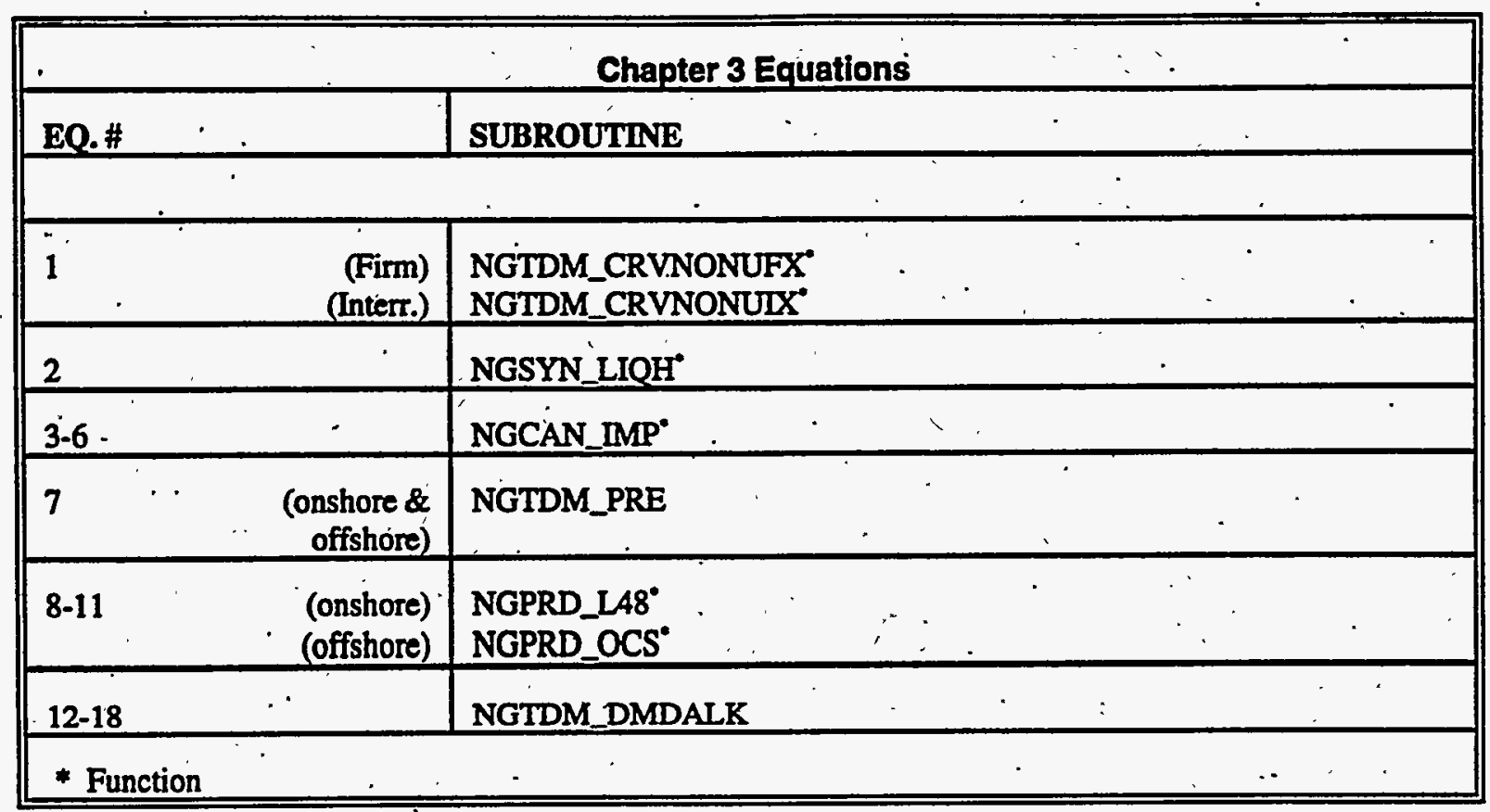

\begin{tabular}{|c|c|}
\hline \multicolumn{2}{|r|}{ Chapter 5 Equations } \\
\hline EQ.\# & SUBROUTINE \\
\hline & . \\
\hline $19-22$ & Not applicable \\
\hline 23 & $\begin{array}{l}\text { NGTDM_LPSI,NGTDM_LPEI,NGTDM_EFFLP, } \\
\text { NGTDM_TARPI,NGTDM_TARDI,NGTDM_SUPCI, } \\
\text { NGTDM_UTILCI,NGTDM_NONUCI,NGTDM_EXCI }\end{array}$ \\
\hline 24-27 & NGTDM_CAPI \\
\hline $28-29$ & NGTDM_UTLCI.NGTDM_NONUCI,NGTDM_EFFLP,NGTDM_LPEI \\
\hline 30 & NGTDM_SUPCI \\
\hline $31,34-35$ & NGTDM_CAPI \\
\hline $32-33$ & NGAFM_SUPMIN \\
\hline
\end{tabular}




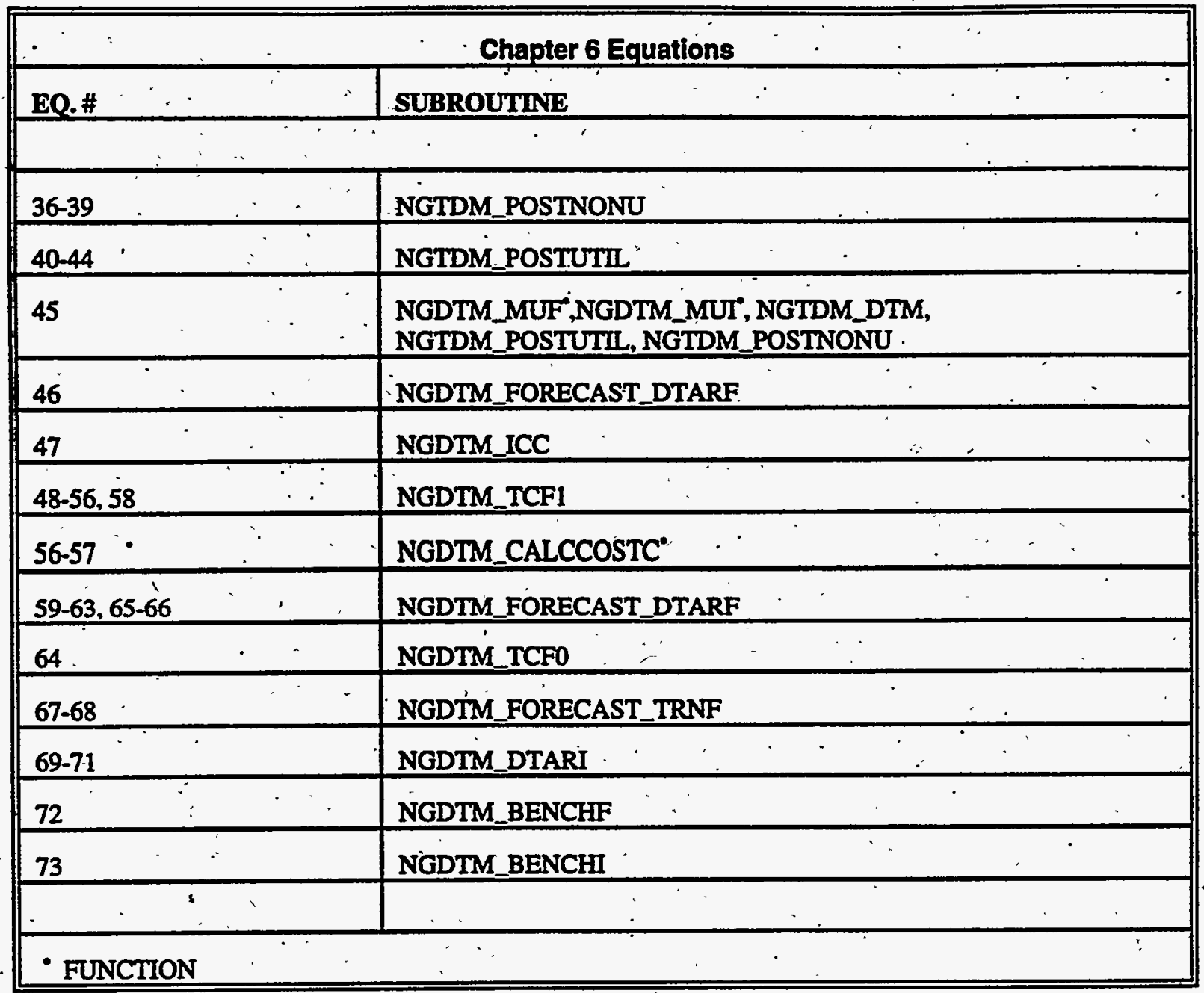




\begin{tabular}{|c|c|}
\hline , & $\therefore \quad$ Chapter 7 Equations \\
\hline EQ.\# & SUBROUTINE \\
\hline & $\because \because$ \\
\hline $7 \dot{4}$ & $\begin{array}{l}\text { CEMLPSNY, CEMLPNE, CEMCANIMP, CEMFLOWNN, CEMSUPCI, } \\
\text { CEMSCAP, CEMBACK, CEMPCAP, NGCEM_ADJSTR, } \\
\text { NGCEM_ADJCAP }\end{array}$ \\
\hline $75-78$ & CEMLPST,CEMLPNN,CEMLPSNB,CEMDISCR \\
\hline 79 & CEMLPST \\
\hline $80-83$ & CEMLPNE,CEMDMD \\
\hline 84 & CEMLPSUP,CEMCANSUP,CEMSUPCI \\
\hline 85 & CEMLPSUP,CEMSÜPCI \\
\hline 86 & CEMLPSUP,CEMCANSUP,CEMSUPCI \\
\hline 87 & CEMIPCAP,CEMCANIMP,CEMDMD,CEMPCAP \\
\hline 88 & RESET_RHS,CEMLPCAP,CEMCANIMP,CEMDMD,CEMPCAP \\
\hline 89 & CEMLPCAP,CEMCANMMP,CEMDMD,CEMPCAP \\
\hline $90-91$ & CEMLPST_UTII_CEMSCAP,RESET_RHS \\
\hline 92.93 & CEMCANIMP,CEMFLOWNN \\
\hline $94-95$ & RESETMATRIX \\
\hline $96-97$ & GETSOLUTION1 \\
\hline $98-99$ & NGCEM_AFMUTIIZ \\
\hline $100-101$ & GETSOLUTION2 \\
\hline
\end{tabular}




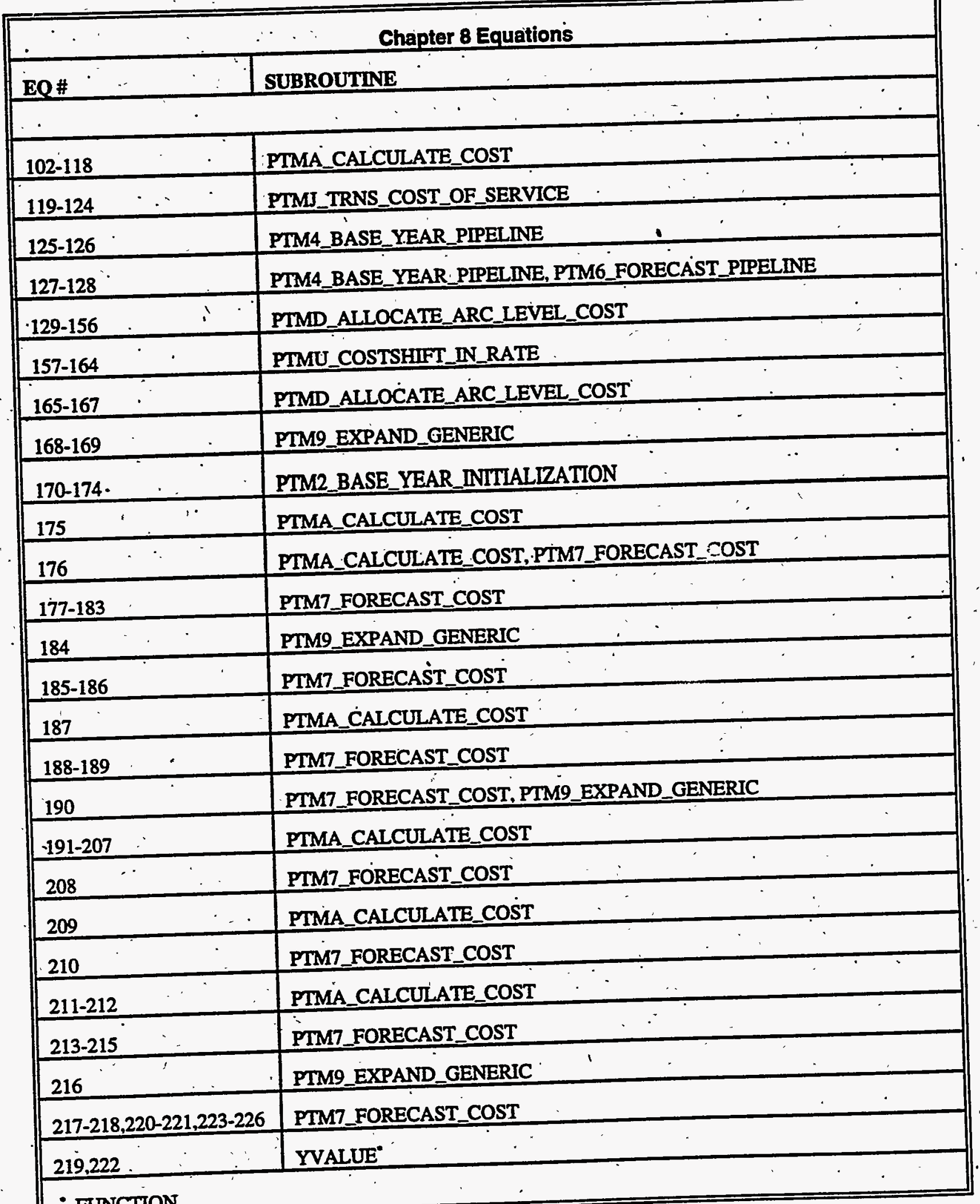

